\title{
Effects of Testing Variables on the Measured Compressive Strength of High-Strength (90 MPa) Concrete
}

Nicholas J. Carino

Structures Division

Building and Fire Research Laboratory

William F. Guthrie

Eric S. Lagergren

Statistical Engineering Division

Computing and Applied Mathematics Laboratory

QC

100

.056

N0.5405

1094

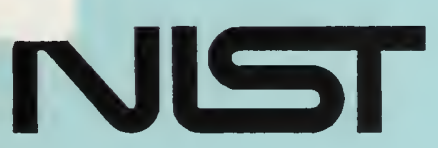

U.S. Department of Commerce

Technology Administration

National Institute of Standards and Tchnology

Gaithersburg, MD 20899

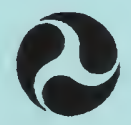

U.S.Department

of Transportation

Federal Highway

Administration

Prepared for:

U.S. Department of Transportation

Federal Highway Administration

Office of Advanced Research

Washington, DC 20590 



\section{Effects of Testing Variables on the Measured Compressive Strength of High-Strength (90 MPa) Concrete}

Nicholas J. Carino

Structures Division

Building and Fire Research Laboratory

William F. Guthrie

Eric S. Lagergren

Statistical Engineering Division

Computing and Applied Mathematics Laboratory

October 1994

Gaithersburg, Maryland 20899

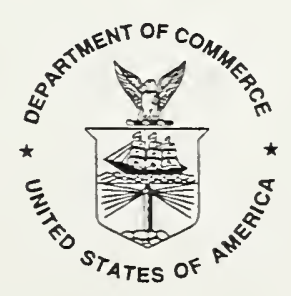

U.S. Department of Commerce

Ronald H. Brown, Secretary

Technology Administration

Mary L. Good, Under Secretary for Technology National Institute of Standards and Technology

Arati Prabhakar, Director
Prepared for:

U.S. Department of Transportation

Federico F. Peña, Secretary

Federal Highway Administration

Rodney E. Slater, Administrator

Associate Administrator for R \& D

John A. Clements, Associate Administrator 


\section{ABSTRACT}

A review is presented on the factors affecting the measured compressive strength of concrete specimens, with particular emphasis on the testing of high-strength concrete. A full factorial experiment was designed to examine the effects of cylinder size, end preparation, stress rate and type of testing machine on the measured compressive strength. Two concrete mixtures $(45 \mathrm{MPa}$ and 90 $\mathrm{MPa}$ ) were used to determine whether there were interactions between strength level and the other factors. In addition, a $65-\mathrm{MPa}$ mixture was required to allow testing four combinations of specimen size and testing machine. The cylinder sizes were $100 \times 200 \mathrm{~mm}$ and $150 \times 300 \mathrm{~mm}$. The ends of the cylinders were either capped with sulfur mortar or ground flat. The stress rate was either 0.14 $\mathrm{MPa} / \mathrm{s}$ or $0.34 \mathrm{MPa} / \mathrm{s}$, which are limits currently specified in ASTM C 39 (AASHTO T 22). One hydraulic testing machine was of the manually-operated type with a capacity of $1.33 \mathrm{MN}$. The other hydraulic testing machine was of the servo-controlled type with a capacity of $4.45 \mathrm{MN}$. The general linear model technique and analysis of variance were used to analyze the results. Statistical analyses showed that all the factors had statistically significant effects on the measured compressive strength. On average, the $100-\mathrm{mm}$ cylinders resulted in about $1.3 \%$ greater strength, the faster stress rate produced about $2.6 \%$ greater strength, the ground cylinders were $2.1 \%$ stronger than the capped cylinders, and the $1.33-\mathrm{MN}$ testing machine resulted in about $2.3 \%$ greater strength. There were significant interactions among the factors, so that the effects were greater (or smaller) than the average values depending on the particular factor settings. For example, the effect of end preparation depended on the strength level. For the 45-MPa concrete, there was no strength difference due to the method of end preparation, but for the $90-\mathrm{MPa}$ concrete, grinding resulted in as much as $6 \%$ greater strength in certain cases. Besides the main test series, supplementary tests were done to investigate the effects of a defective spherically-seated bearing block. The defective bearing block had a concave depression within the central $100 \mathrm{~mm}$. The maximum value of the depression was more than $0.2 \mathrm{~mm}$, compared with the value of $0.025 \mathrm{~mm}$ currently allowed by ASTM C 39 (AASHTO T 22). Comparative tests with 68-MPa concrete showed no difference in mean strength due to the defective bearing block. Analysis of dispersion showed that the $100-\mathrm{mm}$ cylinders had higher within-test variability, but the differences were not statistically significant. Recommendations for modifications to testing standards and future research are provided.

Keywords: Building technology; capping; high-strength concrete; compressive strength; cylinder size; design of experiments; standards; statistical analysis; stress rate; testing machine. 


\section{TABLE OF CONTENTS}

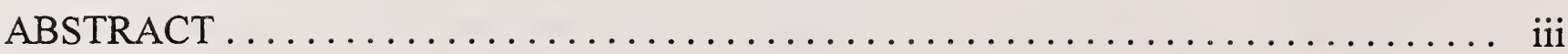

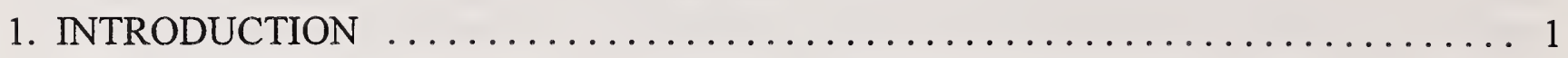

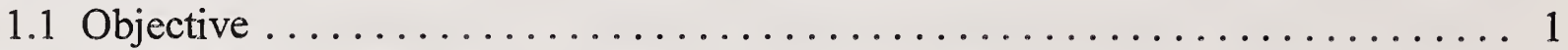

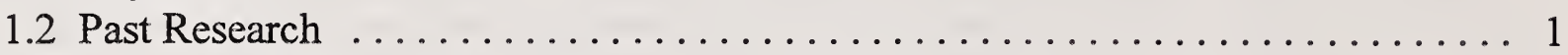

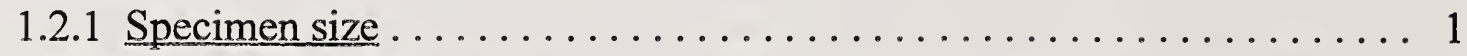

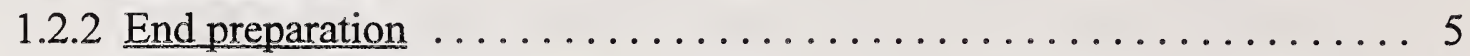

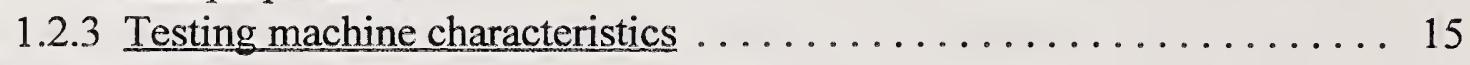

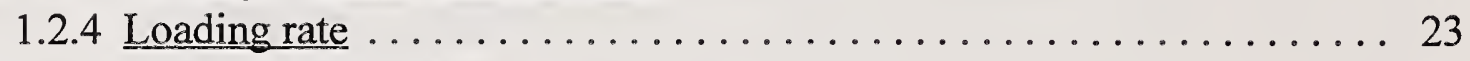

1.3 Review of ASTM Standards . . . . . . . . . . . . . . . . . . 25

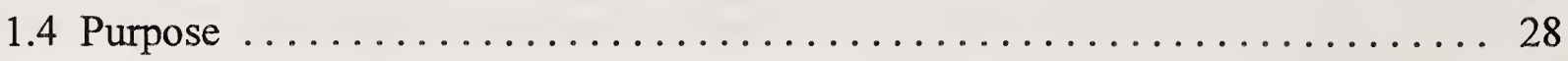

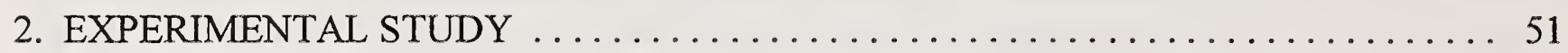

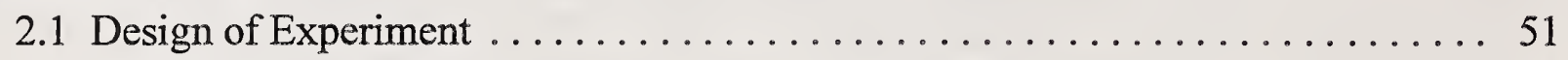

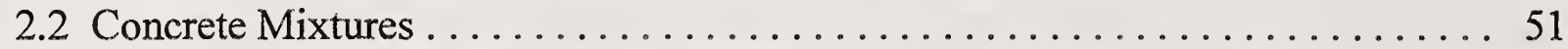

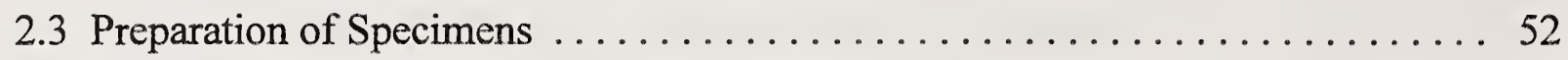

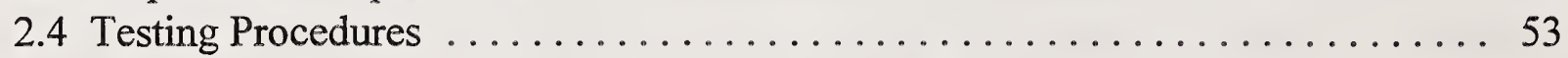

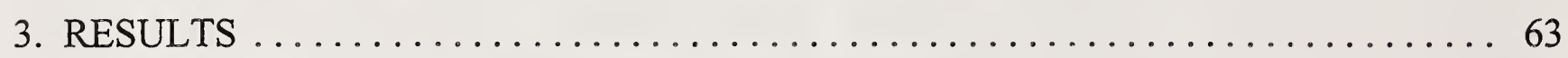

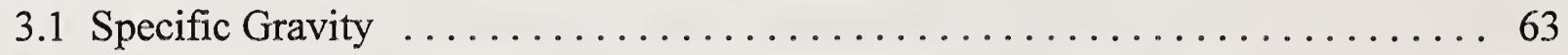

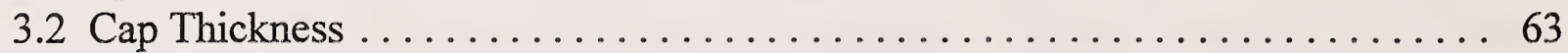

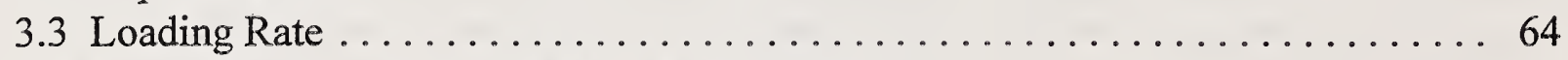

3.4 Wave Speed and Dynamic Modulus of Elasticity ................ 64

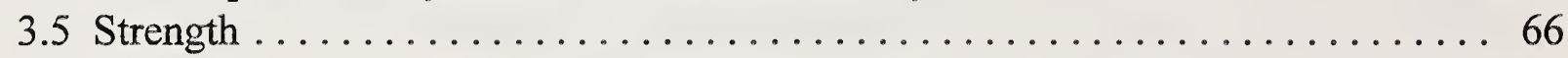

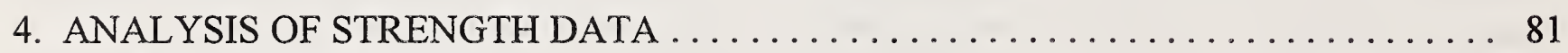

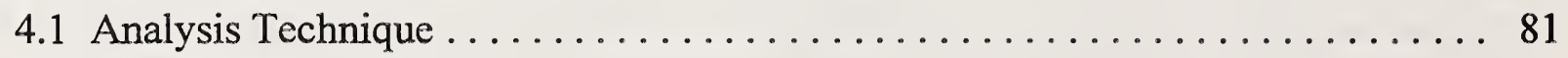

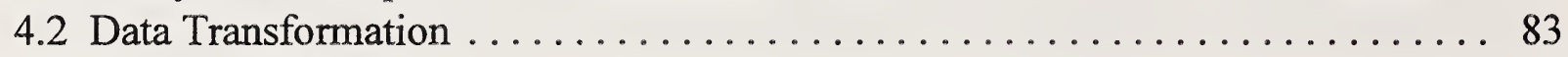

4.3 Effects on Means ................................. 84

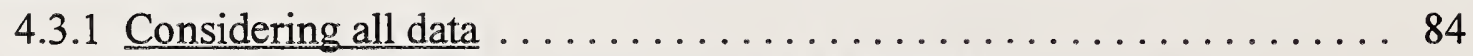

4.3.2 Sub-analyses of $100-\mathrm{mm}$ cylinders and 4.45-MN machine $\ldots \ldots \ldots .87$

4.3 .3 Summary of results $\ldots \ldots \ldots \ldots \ldots \ldots \ldots \ldots \ldots \ldots \ldots$

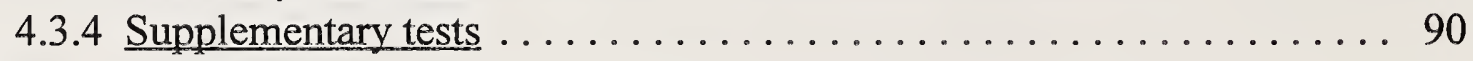

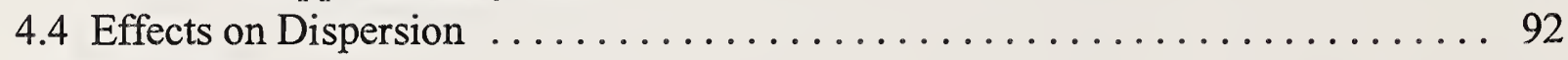

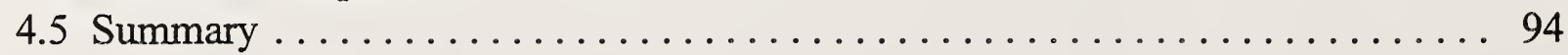

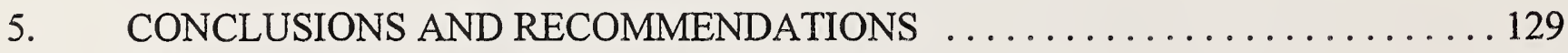

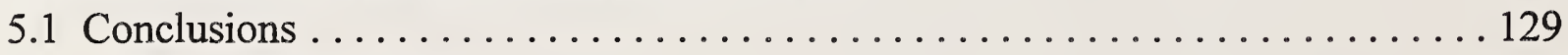

5.1 .1 Cylinder size .................................... 129

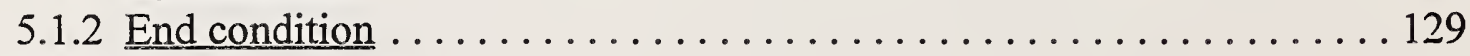

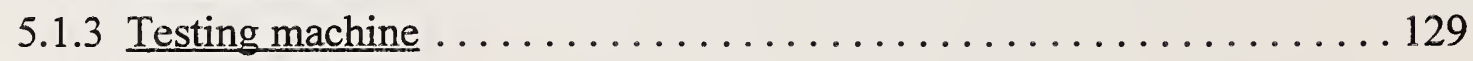

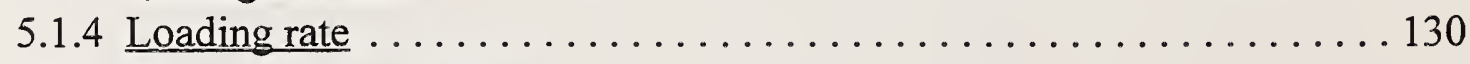

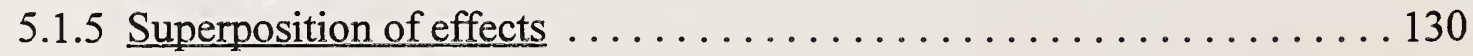




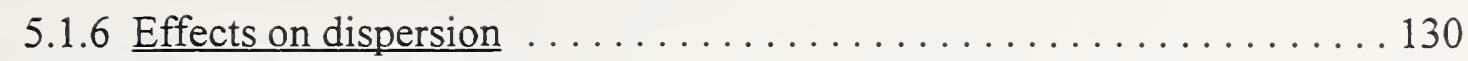

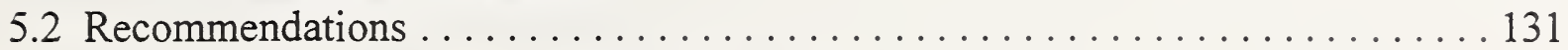

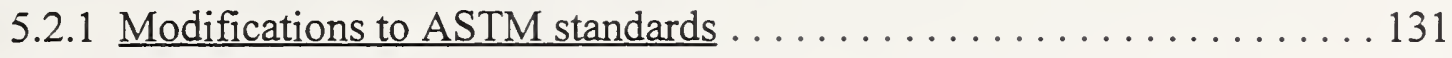

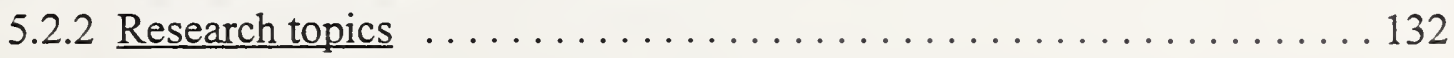

6. ACKNOWLEDGMENTS .................................. 135

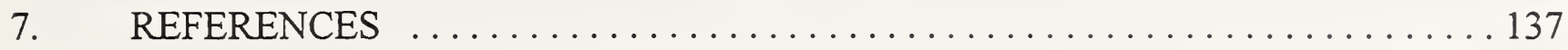





\section{INTRODUCTION}

\subsection{Objective}

In the United States, the compressive strength of the 150 by $300-\mathrm{mm}$ cylinder is the basis for acceptance of concrete. Although a seemingly simple procedure, results are only reliable when the specimens are prepared in a standard manner and tested using standard procedures on machines that satisfy certain criteria. Failure to follow the standards can lead to low or erratic measured strength that may be interpreted as a deficiency in the concrete (Richardson 1991). The standard practices and test methods for testing high-strength concrete are outgrowths of experiences gained from testing conventional concrete. With the increased use of high-strength concrete, problems have been reported in measuring strengths of test specimens (Hester 1980), and the adequacy of the current standards has been questioned (Carrasquillo and Carrasquillo 1988).

The objective of this study is to provide a critical examination of current standards for testing concrete and to provide the technical basis for their possible modification to improve the reliability of testing high-strength concrete. The study involved a review of the classical investigations that formed the basis of the current standards. In addition, experiments were designed to establish the significance of selected factors on the measured strength of molded, high-strength concrete specimens.

The remainder of this chapter reviews the previous research that forms the basis of the current standards and summarizes the main features of the current ASTM standards for measuring compressive strength of cylinders.

\subsection{Past Research}

\subsubsection{Specimen size}

In 1921, ASTM adopted a tentative standard test method (C 39-21T) for measuring compressive strength, which recommended the 152 by $305-\mathrm{mm}$ cylinder as the standard specimen. In $1925 \mathrm{H}$. F. Gonnerman of the Lewis Institute reported on a comprehensive study, conducted in cooperation with the Portland Cement Association, to gain information on the effects of specimen size and shape on the measured compressive strength (Gonnerman 1925). He investigated the following specimens:

- cylinders with a height-diameter ratio of two and with diameters ranging from 38 to $254 \mathrm{~mm}$

- cylinders $305 \mathrm{~mm}$ long with diameters ranging from 76 to $254 \mathrm{~mm}$

- cylinders with $152 \mathrm{~mm}$ diameters and height ranging from 76 to $610 \mathrm{~mm}$

- cubes $152 \mathrm{~mm}$ and $203 \mathrm{~mm}$ in size

- prisms, 152 by $305 \mathrm{~mm}$ and 203 by $406 \mathrm{~mm}$

The specimens were capped with neat cement paste, and the 28-day strengths of the concrete mixtures that were used ranged from about 10 to $30 \mathrm{MPa}$.

Some conclusions from Gonnerman's study are as follows: 
- The 152 by $305-\mathrm{mm}$ cylinder is a "satisfactory form" of specimen, but its use should be limited to concrete with maximum size of aggregate of $50 \mathrm{~mm}$ or less.

- Cylinders with dimensions of 102 by $203-\mathrm{mm}$ and 127 by $254-\mathrm{mm}$ are suitable for smaller aggregate sizes and the ratio of cylinder diameter to maximum size of aggregate should not be less than "about 3 ".

- For cylinders with height-diameter ratios of two, "lower strengths were generally obtained with the larger cylinders. The decrease in strength with size of cylinder was not important for diameters of $152 \mathrm{~mm}$ or less."

- In agreement with other investigators, the compressive strength increased with decreasing height-diameter ratio. For height-diameter ratios between 1.5 and 2.5 , the strength difference "was not important."

Gonnerman's observation that strength depends on the cylinder size has often been used as an argument against using 100 by $200-\mathrm{mm}$ cylinders as an alternative to the standard 150 by $300-\mathrm{mm}$ cylinders ${ }^{\mathrm{a}}$. As indicated above, however, the smaller cylinders were judged to be "suitable" provided the ratio of diameter to maximum size of aggregate was not less than three.

John Tucker, Jr. was one of the first to provide a theoretical explanation for the effect of specimen size on the average strength and the dispersion of strength (Tucker 1927, 1941, 1945). These explanations were based on the premise that a test specimen can be considered as being composed of smaller units that have an inherent strength distribution. The effect of specimen size was determined from statistical considerations of the strength of the units in the test specimen. Two failure theories were considered (Tucker 1941). In the weakest-link theory, the specimen is considered as a chain made of elements having a particular strength distribution and failure occurs when the stress is sufficient to cause one element to fail. In the strength-summation theory, it is assumed that strength of the specimen equals the sum of the strengths contributed by the individual elements. Thus the weakest-link theory can be considered as a series model whereas the strengthsummation theory is a parallel model. Tucker argued that on the basis of test data (Tucker 1927), the strength-summation theory is more applicable than the weakest-link theory in predicting the effects of specimen size on compressive strength (Tucker 1941). According to the strength summation theory, the compressive strength of cylinders having the same height-diameter ratio is independent of the cylinder diameter. The standard deviation of the strength, however, is inversely related to the diameter (Tucker 1945). Therefore, the ratio of the standard deviations for two different cylinder sizes equals the inverse of the ratio of their diameters. For example, the standard deviation for $100-\mathrm{mm}$ diameter cylinders would be expected to be 1.5 times the standard deviation of $150-\mathrm{mm}$ cylinders. If it is needed to measure the compressive strength of cylinders of different sizes with the same precision, the ratio of the number of cylinders should be the square of the inverse of the cylinder diameters. Thus to measure the mean strength with the same precision, one would have to use 2.25 times more $100-\mathrm{mm}$ diameter cylinders than $150-\mathrm{mm}$ cylinders.

In 1951, Walter H. Price of the Bureau of Reclamation reported on the factors influencing concrete strength (Price 1951). Among the various factors discussed was the effect of cylinder size.

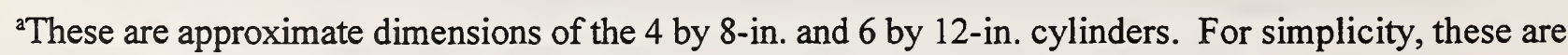
used instead of the exact metric equivalents when referring to these two cylinder sizes. 
Figure 1.1 shows the measured compressive strength, relative to the strength measured on $150-\mathrm{mm}$ diameter cylinders, as a function of cylinder diameter. All cylinders had a height-diameter ratio of two and the maximum size of aggregate was less than or equal to one-fourth the diameter. By using a smooth curve for interpolation, Fig. 1.1 shows that the strength of a $100-\mathrm{mm}$ diameter cylinder should be about $4 \%$ greater than the strength of a $150-\mathrm{mm}$ diameter cylinder. Price also reported that a comparison of the strength of $250-\mathrm{mm}$ diameter cores with the strength of $560-\mathrm{mm}$ diameter cores drilled from 5-year test blocks showed no difference. For molded cylinders, however, the 250-mm cylinders would be expected to be $9 \%$ stronger. Price surmised that age somehow reduced the strength differences expected due to specimen diameter.

Adam M. Neville reported on an empirical study to relate the strength measured on one concrete specimen to the strength measured on another specimen of a different shape or size (Neville 1966). He considered that the three most important variables affecting the strength of a test specimen were its volume, $V$, its maximum lateral dimension, $d$, and the ratio of height to lateral dimension, $h / d$. Using available data on strengths of cubes, cylinders and prisms, he developed an empirical relationship for the ratio of specimen strength to the strength of a $150-\mathrm{mm}$ cube. The $150-\mathrm{mm}$ cube was used as the reference because it is the standard test specimen in the United Kingdom. The empirical relationship had the following form:

$$
\frac{f}{f_{c, 150}}=a+\frac{b}{\alpha}
$$

where $f=$ compressive strength of test specimen,

$f_{c, 150}=$ compressive strength of $150-\mathrm{mm}$ cube,

$a, b=$ best-fit regression constants, and

$\alpha=$ geometric factor defined as follows

$$
\alpha=\frac{V}{150 h d}+\frac{h}{d}
$$

Based on the values of the $a$ and $b$ coefficients obtained by Neville, it can be shown that Eq. (1.1) predicts that the strength of a 100 by $200-\mathrm{mm}$ cylinder is $3 \%$ higher than the strength of a 150 by 300-mm cylinder.

Neville developed another empirical relationship that did not include $h / d$ as a factor. He argued that, for the available data, $h / d$ varied between one and three, and could be considered as a constant. The resulting best-fit empirical relationship was as follows:

$$
\frac{f}{f_{c, 150}}=\frac{150}{d} 0.8878\left(\frac{A}{A_{150}}\right)^{0.4525}
$$

where $A$ and $A_{I S 0}$ refer to the cross-sectional areas of the specimen and the $150-\mathrm{mm}$ cube, respectively. Based on Eq. (1.2), it can be shown that the strength of a 100 by $200-\mathrm{mm}$ cylinder would be predicted to be $4 \%$ greater than that of a 150 by $300-\mathrm{mm}$ cylinder. 
In 1976, V. M. Malhotra published the results of a study comparing the strengths of 100 by 200$\mathrm{mm}$ cylinders with those of 150 by $300-\mathrm{mm}$ cylinders (Malhotra 1976). Data were compiled from previous investigations done at the Canada Centre for Mineral and Energy Technology (CANMET). The range of strength was roughly from 10 to $40 \mathrm{MPa}$. It was concluded that the strengths of 100 by $200-\mathrm{mm}$ cylinders were generally higher than those of 150 by $300-\mathrm{mm}$ cylinders. There were indications, however, that the reverse may be true at low strength levels. It was also concluded that the differences in strength increased with strength level of concrete. Finally, Malhotra noted that the within-test variability of 100 by $200-\mathrm{mm}$ cylinders was larger than that of 150 by $300-\mathrm{mm}$ diameter cylinders. Therefore, more than twice the number of the smaller cylinders would have to be tested to measure the strength with the same precision.

Recent published and unpublished data, comparing the compressive strength of 100 by $200-\mathrm{mm}$ cylinders with the strength of 150 by $300-\mathrm{mm}$ cylinders, were analyzed by the authors. These data included normal strength and high strength concrete. The data sources are given in the References at the end of the report. Figure 1.2(a) shows the strength of the $100-\mathrm{mm}$ cylinders plotted as a function of the strength of the 150 -mm cylinders. There are 792 data pairs some of which are strengths of individual cylinders and others are the averages of replicate specimens. Figure 1.2(b) shows the strength ratios, for each pair of values plotted in Fig. 1.2(a), as a function of the 150-mm cylinder strength. There is considerable scatter of these strength ratios. A correlation analysis of strength ratio and compressive strength resulted in a correlation coefficient of 0.003 . Thus the strength ratio is not a linear function of compressive strength. Figure 1.2(b) does not show any nonlinear trends in the data, supporting the conclusion that the strength ratio is not a function of compressive strength. Figure 1.2(c) is a histogram of the strength ratio values, and it is seen that the histogram resembles a normal distribution. Figure 1.2(d) is a normal probability plot of the strength ratios. If these ratios were normally distributed, they should fall on a straight line in the normal probability plot. A best-fit line through the strength ratios shows that the distribution is very close to normal. The average value of the strength ratios is 1.038 with a standard error of 0.002 . Thus it can be concluded that the compressive strength measured using $100-\mathrm{mm}$ cylinders will, on average, be about $4 \%$ greater than that measured using $150-\mathrm{mm}$ cylinders. These findings agree with the earlier findings of Price (1951) and Neville (1966).

Some data plotted in Fig. 1.2(a) are averages of replicate specimens, and some are averages from different batches. So the data included information on the variability of the strength for the two cylinder sizes. Figure 1.3(a) is a plot of the coefficient of variation of strengths using $100-\mathrm{mm}$ cylinders versus the coefficient of variation using $150-\mathrm{mm}$ cylinders. The large variability associated with the data of Fortsie and Schnormeier (1981) is because they include batch-to-batch variability, whereas the other data include only within-batch variability. There is no clear systematic relationship between the coefficients of variation associated with the two cylinder sizes. For the data in Fig. 1.3(a), the median coefficient of variation for the $100-\mathrm{mm}$ cylinders is $3.2 \%$ and the median coefficient of variation for the $150-\mathrm{mm}$ cylinders is $2.7 \%$. The ratio is about 1.2 , which is lower than the value of 1.5 based on Tucker's strength summation theory. Figure 1.3(b) shows the coefficients of variation plotted as function of strength level. There is no apparent difference in the pattern of behavior for the two cylinder sizes. 


\subsubsection{End preparation}

One of the earliest comprehensive studies of the effects of end preparation on the measured cylinder strength was that by H. F. Gonnerman (Gonnerman 1924). At that time, the standard method for capping cylinders was by using neat cement paste. The cement paste was mixed and allowed to stand for two to six hours before being placed on the top of cylinders, which were also two to six hours old. The paste was covered with a machined cast-iron plate, which was pressed down until it rested on the cylinder mold. An objective of Gonnerman's study was to investigate an economical alternative to cement paste for preparing the ends of cylinders. Besides cement paste, other cementitious capping materials included gypsum and mixtures of portland cement and gypsum. Unbonded sheet materials (wall board, blotting paper, cork sheet, lead sheet, leather, cardboard, rubber and pine board) were also investigated as alternatives to capping. Besides capping materials, Gonnerman also investigated the effects of the following factors:

- location of the spherical bearing block (top or bottom of cylinder)

- deflection of table of testing machine

- eccentricity of cylinder axis

- defects (chipped edges) in caps

- irregularities in the ends of the cylinders

- inclination in the top surface or axis of cylinder

The concrete strengths ranged from 7 to $38 \mathrm{MPa}$ and tests were performed on 150 by $300-\mathrm{mm}$ cylinders.

The following summarizes the results of this extensive study:

(1) Influence of position of bearing block and deflection of table - A spherical bearing block is required for maximum measured strength. It did not matter, however, whether the spherical bearing block was placed at the top, the bottom, or both locations of the cylinder. An eccentricity of the bearing block up to $6 \mathrm{~mm}$ did not affect the measured strength (14 MPa concrete). The deflection of the table (as high as $0.8 \mathrm{~mm}$ ) did not affect the results.

(2) Capping materials - The cylinders were cast in steel molds with flat cast-iron bases, so that only the tops had to be capped. Caps of gypsum or a mixture of gypsum and portland cement resulted in strengths similar to those with neat portland cement caps. The unbonded sheet materials resulted in lower strengths, and it was observed that the decreases were greater for the higher concrete strengths. Sometimes, the use of sheet material resulted in lower strength compared with no capping on the top of the cylinder. The use of a $1.5-\mathrm{mm}$ thick rubber sheet resulted in the lowest strengths ( $41 \%$ to $87 \%$ of control).

(3) Chipped edges of caps - Caps with chips up to $13 \mathrm{~mm}$ from the edge of the cylinder did not affect the measured strength. For larger chips, strength reductions increased with the strength level of the concrete.

(4) Convex and concave ends - The bottoms of some cylinders were purposefully made convex or concave by using machined plates. The deviations from a plane surface varied from 0.08 to $1.3 \mathrm{~mm}$. The bottoms of the cylinders were not capped. In one series of tests, it was found that a convexity or concavity of $0.08 \mathrm{~mm}$ did not affect the measured strength (15 to $24 \mathrm{MPa}$ ). For deviations from a plane of $0.25 \mathrm{~mm}$ or greater, there were significant reductions in strength, and convex ends tended to result in lower strengths than concave ends. In another series, where the 
compressive strength level varied from 8 to $38 \mathrm{MPa}$, the strength reduction due to convex ends increased with increasing compressive strength.

(5) Inclined axis and inclined ends - For parallel ends, an inclination of the cylinder axis up to $6 \mathrm{~mm}$ over the height of $300 \mathrm{~mm}$ did not affect the measured strength (15 and $31 \mathrm{MPa}$ ). For cylinders with axes perpendicular to their bases, an inclination of the top surface of $6 \mathrm{~mm}$ over the $150-\mathrm{mm}$ diameter did not affect the measured strength.

(6) Dispersion of results - Contrary to expectations, the nonstandard conditions did not generally result in greater scatter of the measured strengths.

Gonnerman concluded his paper by noting that end preparation is the most important factor affecting the measured strength, and that great care should be exercised "to secure ends which are true planes."

A drawback of capping using portland cement paste is the need to cap sufficiently early so that the caps will have attained adequate strength when the cylinders are tested. As a result, alternative approaches were examined by many investigators. Purrington and McCormick reported on the use of a sand cushion to eliminate the need of bonded caps (Purrington and McCormick 1926). Fine sand was placed in a confining container having an inside diameter of $165-\mathrm{mm}$. The test cylinder was inverted so that the troweled top end rested in the sand. The other end of the cylinder did not require capping. In a comparative study using 14 and $21-\mathrm{MPa}$ concrete, it was reported that the strength of the cylinders tested with the sand cushion were similar to those capped with cement paste. In a subsequent study by McGuire, the strengths of cylinders capped on both ends were compared with the strength of cylinders capped on top and the bottom resting in a sand cushion (McGuire 1930). The effect of the inside diameter of the restraining ring was investigated by using three sizes: 160,170 and $215 \mathrm{~mm}$. Sand was placed to a depth of 20 to $25 \mathrm{~mm}$, and two strength levels of concrete were used (14 and $24 \mathrm{MPa}$ ). It was concluded that the $160-\mathrm{mm}$ restraining ring resulted in strengths similar to when caps were used on both ends, but the larger rings resulted in drastic strength reductions. It was also observed that for the $160-\mathrm{mm}$ ring, the agreement was better for the 24-MPa concrete. The sand cushion was not adopted as a routine method, but it has recently been reinvented as an alternative to grinding the ends of high-strength concrete cylinders (Boulay and de Larrard 1993).

Among other alternative materials to portland cement, Gonnerman found that gypsum (molding plaster) caps made as little as 15 minutes before testing gave adequate results for 31-MPa concrete (Gonnerman 1924). A problem with gypsum materials is that the caps cannot be kept moist after they are formed, otherwise they suffer a strength reduction. Thus other capping materials were investigated. In 1927, O. V. Adams, reported on the use of aluminous cement ${ }^{\mathrm{b}}$ for capping (Adams 1927). The use of aluminous cement was spurred by a need for a suitable capping material for cores that had to be moisture conditioned before testing. The caps were formed by placing a collar around the cores, the collars were filled with a mortar of aluminous cement and fine sand, and a glass plate was used to press out the excess mortar. The collars were removed at ages of 16 to $24 \mathrm{~h}$, and the

${ }^{\mathrm{b}}$ Aluminous cement is a hydraulic cement in which the cementitious compounds are predominantly calcium aluminates. One of its characteristics is a very high rate of strength development, and about $80 \%$ of its long-term strength can develop within $24 \mathrm{~h}$ (Neville 1973). 
cores were stored under water for $48 \mathrm{~h}$ before testing. For molded cylinders with "reasonably true" ends, the collars were not needed to form the caps.

In 1928, P. J. Freeman reported on the use of sulfur mortar for capping cylinders (Freeman 1928). Unlike the vertical capping method currently used with sulfur mortar (ASTM C 617) ${ }^{c}$, Freeman described a device for capping a cylinder in a horizontal position. The cylinder was placed in a fixture to hold it horizontal. Flexible bands were placed around the ends of the cylinders and around machined capping plates, thereby creating cavities between the ends of the cylinders and the plates. Molten sulfur mortar was poured into the cavities, and the bands were removed after the sulfur had hardened. Cap thickness could be controlled by adjusting the position of the capping plates. The mortar was composed of $50 \%$ sulfur, $31 \%$ alumina, and $9 \%$ of other unspecified materials (Freeman 1928). It was reported that the sulfur mortar attained a compressive strength of $55 \mathrm{MPa}$ when molded into 50 by $100-\mathrm{mm}$ cylinders. Freeman noted that for a thin, $150-\mathrm{mm}$ diameter specimen of mortar, the strength was "far above this." Although no comparative studies were reported by Freeman, the appearance of the broken specimens "has convinced those using the material that the results are better than can be obtained by any other system of capping with other materials" (Freeman 1930). By 1939, sulfur mortar was used to cap cylinders in many laboratories (Timms 1939).

In 1941, Troxell presented the results of a comparative study of the effects of capping materials and end conditions on the measured strength of 75 by $150-\mathrm{mm}$ molded cylinders. The capping materials included plaster of Paris, a high-strength gypsum product (Hydrostone), a sulfur-silica mixture, and 1.6-mm steel shot in a retaining head. Cylinders were produced with the following end conditions: (1) plane normal ends, (2) plane ends inclined about $5 \mathrm{~mm}$ in the $75-\mathrm{mm}$ diameter, (3) convex ends with a bulge of about $5 \mathrm{~mm}$, and (4) concave ends with a depression of about $5 \mathrm{~mm}$. The two ends of each cylinder had similar defects. Two nominal strength concretes were used: 20 and $55 \mathrm{MPa}$. Thus this is one of the first studies employing what can be considered as high-strength concrete. The bonded caps varied in thickness from about 1.5 to $6 \mathrm{~mm}$. Sulfur caps were formed using a vertical capping apparatus. The conclusions of the study were as follows:

- Cylinders capped with the high-strength gypsum or the sulfur mortar resulted in higher measured strengths and better uniformity compared with those capped with plaster of Paris or the steel shot. The high-strength gypsum was generally superior to the sulfur mortar.

- Shot caps resulted in low strengths, especially when testing specimens with concave ends.

- Cylinders capped with plaster of Paris resulted in low strengths especially for the cylinders with defective ends.

- Moist storage of cylinders capped with the sulfur mortar before testing did not adversely affect strength.

It was also found that, contrary to Gonnerman's results, the cylinders with the concave ends resulted generally in lower strengths than those with convex ends.

In the discussion of Troxell's paper, E. N. Vidal summarized the results of comparative studies by the Bureau of Reclamation on different capping materials. Reference strengths for those studies were based on the strengths of cylinders whose ends were ground flat to within $0.05 \mathrm{~mm}$ across the

'AASHTO designations of referenced ASTM standards are given in the reference list (Chapter 7). 
150-mm diameter. Capping materials included portland cement paste, sulfur mortar, aluminous cement paste, plaster of Paris, and a plaster-portland cement mixture. The cylinders capped with portland cement paste, aluminous cement paste, and sulfur mortar resulted in strengths equal to those of the ground cylinders (about $28 \mathrm{MPa}$ ). Vidal confirmed the unfavorable results obtained by Troxell with shot caps, and concluded that "the shot cap should be considered subject to question."

Other discussions of Troxell's paper addressed some fundamental aspects of testing concrete specimens in compression. W. M. Murray noted three stress conditions that are possible at the ends of the specimens: (1) a uniform uniaxial compressive stress, (2) compressive stress with restraining radial stresses induced by friction between the specimens and the loading blocks, and (3) compressive stresses and radial tensile stresses when capping materials are used that tend to flow laterally under load. The first condition is the one wanted, but is difficult to achieve in practice, and the third condition reduces the measured strength. Murray noted that Troxell obtained the best results with capping materials (sulfur and high-strength gypsum) that had high values of modulus of elasticity. Thus Murray concluded that the most desirable conditions result from using capping materials that are at least as strong as the concrete and have about the same modulus of elasticity and Poisson's ratio as the concrete.

A very interesting discussion of Troxell's paper was presented by A. J. Durelli, who used photoelasticity to study the two-dimensional stress distributions in thin, rectangular, plastic plates loaded in compression along opposite edges. These studies showed that stress concentrations exist at the loaded ends of the specimens even when they are perfectly flat. Different capping materials were found to alter the stress distribution. Soft capping materials, such as lead and rubber, which can flow outward when the specimen is loaded, produced outward radial stresses at the end of the specimen. Durelli showed that by using an appropriate capping material, the stress distribution at the ends of the specimen could be made nearly uniform.

The convenience of sulfur mortar as a capping material led to its widespread use. It was recognized, however, that not all sulfur mortars were equally suitable for capping cylinders, and investigations were carried out to gain a better understanding of this material. Collins reported on investigations done at the Lehigh Portland Cement Co. to investigate the properties of different sulfur mortar mixtures, and compare those with the properties of plain sulfur (Collins 1941). The raw materials included sulfur, fine sand (called banding sand), fly ash, and carbon black. It was shown that pure sulfur resulted in a compressive strength of only $16 \mathrm{MPa}$ and an elastic modulus that was only about $10 \%$ that of concrete. The combination of low strength and low stiffness makes pure sulfur an inappropriate capping material. One of the mixtures was composed of $60 \%$ sulfur, $30 \%$ sand and $10 \%$ fly ash (by mass). It resulted in a compressive strength (measured on 50 by 50 by $100-\mathrm{mm}$ prisms) of $52 \mathrm{MPa}$ and an elastic modulus of $12 \mathrm{GPa}$, which is about $50 \%$ of that of concrete. Collins also mentioned the problems of preparing large test specimens of sulfur mortar because of the shrinkage that accompanies solidification. Finally, it was shown that for the optimum mixture, capped cylinders could be tested one hour after capping without experiencing a strength reduction.

Another important comparative study of capping materials was reported in 1944 by T. B. Kennedy of the Corps of Engineers (Kennedy 1944). The study was prompted by an observation 
that specimens capped with a particular sulfur mortar resulted in higher strengths when the caps were 20 to 24 hours old compared with caps that were only five hours old. The main objective was to investigate the effects of the age of the caps on the measured strength. Four capping materials were used, two commercial sulfur-silica compounds and two gypsum products (identified by the manufacturer as "medium-strength" and "high-strength" materials). Nominal concrete strength varied from 20 to $50 \mathrm{MPa}$, test specimens were 150 by $300-\mathrm{mm}$ cylinders, and sulfur caps were formed with a horizontal capping device. Except for tests to study the effect of cap thickness, sulfur caps were about $6 \mathrm{~mm}$ thick and the gypsum caps were about $1.5 \mathrm{~mm}$ thick. In the comparison of the sulfur compounds, cylinders were made with flat ends and with tops having a 6-mm "step" over one-half of the end area. The following summarizes the main conclusions:

- The effect of age of cap type was very different for the two sulfur compounds. Cylinders capped with one compound had adequate strength within one hour after capping, while the strength of cylinders capped with the other compound continued to increase up to 40 hours.

- The stepped-end condition did not affect greatly the measured strength when sulfur caps were used (gypsum materials were not tested with stepped-ends).

- For compressive strengths up to $38 \mathrm{MPa}$, the sulfur compound that gained strength rapidly or the two gypsum materials resulted in equally adequate caps. While an age one hour was adequate for the sulfur caps, the gypsum caps should be allowed to harden for three hours.

- Caps of the materials used should be made as thin as possible.

In 1952, Masters and Loewer reported on a comparative study of four sulfur capping compounds to investigate the effects of age and cap thickness on the strength of 150-mm cylinders (Masters and Loewer 1952). Concrete strengths were about 20 and $40 \mathrm{MPa}$. For the lower strength concrete, cap ages from $1 / 2$ to 40 hours resulted in similar measured strengths, while for the higher strength concrete ages beyond two hours had negligible effect. For the higher strength concrete, cap thicknesses were intentionally varied from 3 to $13 \mathrm{~mm}$, and it was found that the $3-\mathrm{mm}$ caps produced the highest cylinder strengths.

The last of these historical studies of capping materials was reported in 1958 by G. Werner of the Bureau of Public Roads (Werner 1958). Capping materials included: aluminous cement paste, plaster of Paris, a mixture of portland cement and plaster of Paris, two high-strength gypsum plasters, pure sulfur, and two sulfur compounds. The report is based on three series of tests done over a span of eight years, which are described as follows:

1949 Series - A 48-MPa concrete was use to investigate the effects of capping materials and simulated defects in the top ends. The defects were made by indenting the top surface with finger tips to a depth varying from about 3 to $6 \mathrm{~mm}$.

1953 Series - A low-strength $(14 \mathrm{MPa})$ concrete and a high-strength ( $48 \mathrm{MPa})$ concrete were used to investigate different capping materials and the effects of simulated defects on both the top and bottom ends.

1956 Series - A 41-MPa concrete was used to investigate the effects of two techniques for forming sulfur caps: (1) with the cylinders aligned horizontally and (2) with the cylinders aligned vertically. For the horizontal method, the caps were from 6 to $8 \mathrm{~mm}$ thick, while for the vertical method they were from 1.5 to $3 \mathrm{~mm}$ thick. 
Werner measured the compressive strength and sonic modulus of elasticity of test specimens made of the capping materials. Some of that data have been included in Table 1.1. If it is assumed that the elastic modulus of concrete is about $30 \mathrm{GPa}$, it is seen that the aluminous cement paste had a stiffness close to that of concrete. The low strengths and stiffnesses of plaster of Paris, the plasterportland cement mixture, and the pure sulfur are evident. The significance of the properties of the capping materials is discussed later.

The principal conclusions reported by Werner include the following:

- Cylinders capped with aluminous cement had the highest strength in all cases except one.

- The use of different capping materials had greater effects on the strengths of cylinders made of high-strength concrete compared with cylinders of low-strength concrete.

- Cylinders of high-strength concrete with rough ends resulted in lower strengths than similarly capped cylinders with smooth ends. For the low-strength cylinders, the surface conditions had negligible effects on measured strength.

- The thickness of the sulfur caps resulting from the different capping methods affected the measured strength of the high-strength concrete cylinders. The thicker caps produced with the horizontal capping device resulted in about $5 \%$ lower strengths.

Based on the different effects of the capping materials for low-strength and high-strength concrete, Werner arrived at the following conclusion (Werner 1958):

"The results reported here show that the choice of capping material for concrete cylinders is of great importance when high-strength concrete is tested. In these tests, the highstrength concrete had a strength of $7000 \mathrm{psi}(48 \mathrm{MPa})$, but it is expected that specimens having strengths of 5000 psi (34 MPa) or more would show a similar behavior."

To gain additional insight into the relationship between capping material and measured strength, Werner's data were examined further by the authors. Figure 1.4(a) shows the average cylinder strength for the high-strength concrete cylinders with defective ends. The case shown is that for which the type of capping material greatly affected the measured cylinder strength. Figure 1.4(b) shows the modulus of elasticity and compressive strength of the different capping materials. These values are taken from Table 1.1, except that where strengths were measured with cubes the values were multiplied by 0.8 . This factor converts the cube strength to the approximate strength for a specimen with a length-width ratio of two. Also included in Fig. 1.4(b) are two points based on values presented by S. Helms in the discussion of Werner's paper. It is seen that there is a correlation between these two properties. Finally, Figs. 1.5(a) and 1.5(b) show the relationships between average cylinder strength and the strength and stiffness of the capping material. These figures show clearly that there are correlations between the mechanical properties of the capping material and the resulting cylinder strength. Because the strength and stiffness of the capping materials are correlated, it is not obvious whether it is the strength or the stiffness of the capping material that plays the fundamental role in affecting the measured cylinder strength.

In the discussion of Werner's paper, S. Helms presented a variety of data to show the suitability of high-strength gypsum cements and sulfur mortar as capping materials (Werner 1958). Cylinder strength values were between 14 and $40 \mathrm{MPa}$. An interesting part of Helm's discussion was a figure showing the compressive strength of 50-mm diameter specimens of sulfur mortar as a function of 
specimen height. As the height was reduced from $100 \mathrm{~mm}$ to $13 \mathrm{~mm}$, the compressive strength increased from about $50 \mathrm{MPa}$ to $140 \mathrm{MPa}$. Although not explained in the discussion, the increased strength in the thin specimens arises from the confinement stresses introduced as the interface between the steel bearing block and the sulfur. When the capping material is placed between a steel bearing block and concrete cylinder there is less restraint than when it is placed between two steel blocks. Therefore, the bearing capacity may not be as great as when tested between two steel blocks. In summary, while the compressive strength of a capping material as measured on standard specimens may be useful for comparative purposes, it is probably not indicative of the load bearing capacity when used as a thin cap.

Few developments were reported during the 1960s related to capping methods. In 1972, Saucier at the U.S. Army Engineer Waterways Experiment Station reported on a study to examine the effects of end preparation on the measured strength of 150 by $300-\mathrm{mm}$ cylinders (Saucier 1972). To improve the performance of low-strength, low-elastic modulus capping materials, steel rings were used to confine the capping material during the compression tests. The study was conducted in four phases, and involved different concrete strength levels, different capping materials, and different thicknesses of the constraining rings. In addition, the effect of a thin coating of oil on the caps was studied (cap cleanliness). The following summarizes the variables investigated in the four phases (I to IV) of the study.

\begin{tabular}{c|c|c|c|c|c}
\hline \multirow{2}{*}{$\begin{array}{c}\text { Concrete } \\
\text { Strength Level }\end{array}$} & End Condition & \multicolumn{4}{|c}{ Rings* } \\
\cline { 3 - 6 } & & None & $3 \mathrm{~mm}$ & $6 \mathrm{~mm}$ & $25 \mathrm{~mm}$ \\
\hline \multirow{2}{*}{$17 \mathrm{MPa}$} & Low-strength gypsum & I & I & & \\
& High-strength gypsum & I & I & & \\
& Cap cleanliness & I & I & & \\
\hline \multirow{2}{*}{$45 \mathrm{MPa}$} & Low-strength gypsum & I & I & & \\
& High-strength gypsum & I & I & & \\
& Cap cleanliness & I & I & & \\
\hline \multirow{2}{*}{$69 \mathrm{MPa}$} & Low-strength gypsum & III & III & III & III \\
& High-strength gypsum & II, III & II, III & II, III & III \\
& Sulfur compound & II, IV & II & II & IV \\
& Neat cement paste & II, IV & & & \\
\hline
\end{tabular}

* The inside diameter was $156 \mathrm{~mm}$, height was $13 \mathrm{~mm}$, and wall thicknesses varied as shown.

Phase I was designed to examine the effects of the constraining rings as a function of the type of capping material and concrete strength level. The cylinder $(150$ by $300 \mathrm{~mm})$ compressive strength of the low-strength gypsum was $14 \mathrm{MPa}$, while the strength of the high-strength gypsum was 36 $\mathrm{MPa}$. For the 17-MPa concrete cylinders, it was found that the type of capping material and the presence of the constraining rings did not affect the measured strength. For the 45-MPa concrete cylinders, the low-strength gypsum resulted in lower cylinder strength, and the presence of the constraining rings improved the cylinder strength. The strength improvement due to the rings was 
greater for cylinders with the low-strength gypsum caps. A thin layer of oil on the caps did not affect the cylinder strength for all conditions studied.

Phase II examined the effects of the constraining rings for high-strength concrete. The capping materials were the high-strength gypsum and a sulfur compound. The 50-mm cube strength of the sulfur compound was $48 \mathrm{MPa}$. It was found that neither the capping compound nor the presence of the rings affected the cylinder the strength. The cylinders capped with neat cement paste had lower strength, and this was attributed to lack of experience in making good quality paste caps.

The results of Phase II were unexpected, and Phase III was carried out to examine the effects of the constraining rings when the two types of gypsum caps were used with the high-strength concrete. Three ring thicknesses were used. It was found that the rings had no effect when the high-strength gypsum caps were used. For the low-strength gypsum, the rings improved the cylinder strength, but strengths were always lower than when high-strength gypsum was used. The low-strength gypsum also resulted in higher strength variability. Thus even the $25-\mathrm{mm}$ thick rings were unable to improve the performance of the low quality capping material.

Phase IV was conducted to examine the effect of a heavy constraining ring with the sulfur compound and to compare with a cement paste cap proportioned to a stiff consistency. The results showed that the ring had no effect, and the paste cap resulted in the same cylinder strength as the sulfur compound.

The premise of Saucier's study was that low quality capping materials resulted in lower cylinder strength with medium- and high-strength concretes because of lateral flow of the caps during testing. It was believed that if the flow were restrained by steel rings, the performance of the low quality capping material would be improved. The results showed that while the confining rings did improve the measured cylinder strength, the cylinders strengths were never as high as when good quality capping materials were used. This lead Saucier to conclude that "there should be no substitute for high-strength, high-modulus capping compound for high-strength concrete" (Saucier 1972). Saucier also concluded that, with thin caps, capping materials can give satisfactory results when testing concrete that is stronger than the strength of the capping materials measured on bulk tests specimens. For example, he suggested that sulfur compounds with cube strengths of $50 \mathrm{MPa}$ could be used with concrete as strong as $110 \mathrm{MPa}$.

In the 1970s, interest developed in using an unbonded capping system composed of neoprene rubber pads restrained by metal rings with slightly larger diameters than the cylinder. As is known, an unrestrained rubber pad is unsuitable as a capping material because it induces large tensile stresses as it is squeezed outward from between the cylinder and bearing block. By using a metal ring to prevent the rubber from expanding laterally, the tensile stresses are reduced, and the rubber functions effectively to distribute the compressive stresses over the end of the cylinder.

An early published study comparing the so-called pad-cap system with conventional capping methods was reported by C. Ozyildirim (Ozyildirim 1985). Over 400 pairs of 150 -mm cylinders were prepared under field conditions, one cylinder of each pair was tested using sulfur-mortar caps and the other using the unbonded caps. The concrete strength varied between 20 and $40 \mathrm{MPa}$. 
Based on a paired t-test, it was found that the sulfur-mortar capped cylinders resulted in a statistically higher strength. The average difference, however, was only $0.4 \mathrm{MPa}$. It was also found that there were no statistically significant differences in the variability of the measured strengths for the two capping methods. Therefore, it was concluded that the pad-cap system was a suitable alternative to sulfur-capping for the range of concrete strength used.

Carrasquillo and Carrasquillo (1988b) reported on a laboratory study of unbonded caps that involved concrete strength ranging from 17 to $114 \mathrm{MPa}$. Two pad-cap systems were used: one had polyurethane pads (system A) with aluminum restraining rings and the other had neoprene pads with steel rings (system B). In addition, there was an investigation of the effect of the height and inside diameter of the restraining rings. Cylinder strengths with the unbonded caps were compared with cylinders with sulfur-mortar caps. The sulfur mortar was a commercial "high-strength" capping compound but the cube strength was not reported. The polyurethane pads were reported to have a Shore A hardness of about 40 to 50 . Neoprene pads with a hardness of about 55 were used for cylinders strengths below $55 \mathrm{MPa}$, and pads with a hardness of about 70 were used for stronger cylinders. Figure 1.6(a) shows the average cylinder strengths obtained with the pad-cap systems as a function of the average strength measured with sulfur mortar caps. The number of replicates per data point was different. For the tests using the system-A caps, the number of replicates were mostly two or three. For tests with the system-B caps, however, 12 out of the 21 cases involved 10 replicates. Figure 1.6(b) shows the ratios of the average cylinder strengths (pad-caps to sulfur caps) as a function of the strength with sulfur caps. Tests involving system-B with 10 replicates are shown as squares. It is seen that some points have a large deviation from the ratio of 1.0. Usually these points were associated with few replicates (two or three) or there was a larger than expected variation in the individual strengths. For tests with system- $B$ and having 10 replicates, the ratios are well grouped about an average value of 0.99 . Therefore, this study showed that the pad-cap system resulted in strengths that are similar to those with sulfur caps. It was also reported that the pad-cap systems tended to reduce the variability of the measured strengths. The variations in the restraining ring dimensions were reported to have no effects on the strength results but they did affect the damage sustained by the pads.

Richardson reported on a statistically designed laboratory experiment to compare unbonded caps with sulfur-mortar caps (Richardson 1990). The differences in cylinder strengths obtained by the two capping methods were compared under 12 testing conditions, some of which were outside the requirements of current ASTM standards. The testing conditions, or variables, are listed in Table 1.2. Besides the 12 testing variables, a control condition, which satisfied ASTM requirements, was used as a basis of comparison. The experiment was designed as a randomized block experiment with two treatments (capping method and test variable) and concrete strength as a blocking variable. There were ten concrete batches, with a strength range from about 25 to $40 \mathrm{MPa}$. Statistical software was used to detect significant differences among mean strengths for the different variables. A comparison of the overall means of the strengths for the two capping methods showed no differences. In addition, the following comparisons were made:

- Mean strength for a given variable using sulfur caps versus the mean strength of the control specimens with sulfur caps.

- Mean strength for a given variable using pad caps versus the mean strength of the control specimens with pad caps. 
- Mean strength for a given variable using pad caps versus the mean strength of the control specimens with sulfur caps.

The comparisons that resulted in significant differences among means are shown in Table 1.2. These comparisons show that the use of the pad-caps reduced the number of variables that resulted in significant differences when strengths were compared with the sulfur-capped control specimens.

In 1990, Chojnaki and Read reported on a study to examine the effects of end preparation, specimen size, testing machine and testing speed on the measured compressive of high-strength concrete cylinders (Chojnaki and Read 1991). Six end preparation conditions were investigated, as follows:

- Capped with sulfur capping compound

- Ground

- Ground and capped with sulfur compound

- Cut with a diamond saw and capped with sulfur compound

- Ground and tested with pad-caps

- Pad-caps

Two nominal strength levels were studied: $70 \mathrm{MPa}$ and $90 \mathrm{MPa}$. For the 70-MPa concrete, the padcaps were made of neoprene with a Shore A hardness of 55, but for the 90-MPa concrete the hardness was 60. Two testing machines were used for comparison. Figures 1.7(a) and 1.7(b) show the results obtained with one testing machine for the 70-MPa and 90-MPa mixtures, respectively. Six replicate tests were conducted for each condition, but the authors have removed outliers in producing the plots. For the 70-MPa mixture, the cylinders with the pad-caps had the lowest mean strength, while the cylinders which had been cut and capped had the highest mean strength. The highest variability occurred in the cylinders that had been ground and capped. The mean strength of the pad-cap cylinders was $96 \%$ of the strength of the ground cylinders. For the $90-\mathrm{MPa}$ mixture, the cylinders that were ground and capped had the highest mean strength, the cylinders with padcaps had the lowest mean strength, and the variability appears to be similar for all conditions. The mean strength of the pad-cap cylinders was about $98 \%$ of the mean strength of the ground cylinders. For both strength levels, there appears to be no significant difference between the mean strengths of the sulfur-capped cylinders and the ground cylinders.

Pistelli and Willems analyzed strength results from field-prepared cylinders to examine the effects of cylinder size and end preparation methods on the mean strength and the variability of test results (Pistelli and Willems 1993). The compressive strength of the concrete varied from about 20 to $120 \mathrm{MPa}$. The strengths of $100-\mathrm{mm}$ and $150-\mathrm{mm}$ cylinders were compared using sulfur caps, padcaps, and grinding of the cylinder ends. The sulfur capping compound was reported to have a cube strength of about $46 \mathrm{MPa}$. The following pad materials were used:

- Neoprene with hardness of 60 for concrete strength up to $35 \mathrm{MPa}$,

- Neoprene with hardness of 70 for concrete strength between 35 and $83 \mathrm{MPa}$, and

- Polyurethane with hardness of 90 for concrete strength above $83 \mathrm{MPa}$.

A comparison of the strengths of the cylinders tested using the pad-caps with those tested using sulfur mortar caps is shown in Fig. 1.8(a). The ratio of the strengths is shown in Fig. 1.8(b). The cylinders tested with pad-caps generally resulted in higher strengths, especially for strengths above about $60 \mathrm{MPa}$. It was also found that the variability of the pad-cap cylinders was lower than that of 
the sulfur-capped cylinders (Pistelli and Willems 1993). Strengths of cylinders tested with pad-caps were also compared with strengths of cylinders whose ends were ground flat. Figure 1.9(a) shows the resulting strengths. Note that some cylinders with rough ends were cut before testing with the pad-caps. Figure 1.9(b) shows the ratios of the pad-cap strengths to the strengths of the ground cylinders. It appears that the strength level of the concrete does not affect this strength ratio. The cut cylinders, however, tended to have a higher strength ratio. Figure 1.9(c) shows a histogram of the strength ratios for the uncut cylinders, and it appears that these ratios are normally distributed. Figure 1.9(d) is a normal probability plot of the strength ratios, and it is seen that the results lie close to a straight line. The mean strength ratio is 0.97 with a standard error of 0.007 . Thus these data show that the pad-cap system resulted in slightly lower cylinder strengths than grinding. It was reported that the cylinders tested with pad-caps had lower variability than the ground cylinders (Pistelli and Willems 1993).

Two recent studies focused on the effects of end preparation on measured strength of high strength concrete specimens. In one study (Lessard, et al. 1993), five high-strength mixtures with strengths between 115 and $130 \mathrm{MPa}$ were used to compare the strength of ground cylinders with cylinders capped with a sulfur compound. The $50-\mathrm{mm}$ cube strength of the sulfur compound ranged from 55 to $62 \mathrm{MPa}$. The caps were from 1 to $2 \mathrm{~mm}$ thick. Nine to 12 replicate tests were done at an age of 91 days using 100 by $200-\mathrm{mm}$ cylinders. On average, the capped cylinders resulted in $1.5 \%$ lower strength, but the difference was not statistically significant. The dispersion, however, was affected by the end conditions: the ground cylinders had a coefficient of variation of $2.1 \%$ compared with $3.6 \%$ for the capped cylinders.

The other study compared the strength of $100-\mathrm{mm}$ cylinders tested with three end conditions: capped with a high-strength sulfur compound, with ground ends, and with unbonded pad-caps (French and Mokhtarzadeh 1993). Strengths over $100 \mathrm{MPa}$ were tested. It was reported that all three end conditions resulted in similar strengths. The cylinders with ground ends produced only $1 \%$ higher strength than those with sulfur caps. For strengths between 50 and $80 \mathrm{MPa}$, the cylinders with unbonded pad-caps were reported to have slightly higher strength than the ground cylinders. These tests were done on a 2.67-MN capacity, servo-controlled testing machine operated so that the top spherically-seating bearing block moved at a rate of $1.3 \mathrm{~mm} / \mathrm{m}$. For deformation controlled testing, cylinders usually crack gradually after the ultimate load has been reached. The specimens with unbonded pad-caps, however, were reported to have violent failures due to energy stored in the neoprene pads. The next section includes a discussion of how energy stored in the test system affects the post-ultimate behavior of the specimens.

\subsubsection{Testing machine characteristics}

Background -Background information on testing machines is presented before discussing research related to the effects of testing machine characteristics on measured compressive strength, some. Two types of testing machines are generally used to measure compressive strength of concrete specimens: (1) a screw-type and (2) a hydraulically-operated type. In a screw-type machine, the compressive load is applied by a moving crosshead. As shown in Fig. 1.10(a), rotation of motor-driven screws produces movement of the crosshead. The lower platen of a screw-type machine remains stationary. The rate of deformation of the specimen is controlled by the rotation 
speed of the screws and the stiffness of the machine. In a hydraulically-operated machine, the crosshead remains stationary and the specimen is loaded by a moving piston as shown in Fig. 1.10(b). Typically, an electric pump forces hydraulic fluid into the cylinder under increasing pressure, thereby increasing the load on the specimen.

A screw-type machine provides for a deformation-rate controlled test since the crosshead moves at a constant speed (neglecting the reduction that may occur with increasing load). In a hydraulically-operated machine, the rate of movement of the piston is controlled by the flow rate of fluid into the cylinder. In a high-quality, hydraulically-operated machine a flow control system is used to maintain a nearly constant flow rate of fluid into the cylinder. This causes the piston to move at a nearly constant rate (Turner and Barnard 1962, Hinde 1964).

For either type of machine, the force applied on the test specimen for a given amount of crosshead or piston movement is governed by the stiffnesses of the specimen and the machine. Figure $1.10(\mathrm{c})$ is a simplified spring model of the testing machine and the test specimen, which is useful for understanding the interactions between specimen and testing machine (L'Hermite 1954, Sigvaldason 1966a). A spring with stiffness $k_{m}$ represents the longitudinal stiffness of the machine. The value of $k_{m}$ accounts for the size and length of the machine columns, the stiffness of the crosshead, the stiffness of the bearing blocks, and the stiffness of the load measuring system (Sigvaldason 1966a). For a hydraulically-operated machine, the flexibility of the hydraulic piping system and the fluid height in the piston contribute to reducing the total machine stiffness (Vutukuri, et al. 1974, Turner and Barnard 1962). Thus the testing machine stiffness includes the effects of more than just the structural frame. The test specimen is represented by a spring having a stiffness $k_{s}$. For a concrete cylinder, the value of $k_{s}$ depends on the modulus of elasticity, the cross-sectional area, and the length. Since the modulus of elasticity decreases with increasing strain, as the concrete undergoes microcracking, the value of $k_{s}$ is not constant during a compression test. Besides longitudinal stiffness, a testing machine is also characterized by its lateral stiffness, which refers to the resistance to horizontal movement (or rotation) of the crosshead with respect to the table.

Figure 1.10(d) shows the deformations of the specimen and the testing machine for a given amount of crosshead or piston movement, $\delta_{\mathrm{t}}$. The specimen compresses by an amount $\delta_{\mathrm{s}}$ and the testing machine elongates by an amount $\delta_{\mathrm{m}}$. Compatibility of deformations requires that

$$
\delta_{t}=\delta_{s}+\delta_{m}
$$

Equilibrium requires that the compressive force acting on the specimen, $\mathrm{P}_{\mathrm{s}}$, be balanced by the tensile force, $\mathrm{P}_{\mathrm{m}}$, in the testing machine. Figures 1.11(a) and 1.11(b) are force-deformation curves to illustrate the differences due to different machine stiffnesses. In both cases, the specimen is subjected to the same load, and therefore undergoes the same deformation. Figure 1.11(a) shows the situation when a hard machine is used, that is, a machine with a high longitudinal stiffness, and Fig. 1.11(b) shows the situation when a soft machine is used. A larger total deformation, $\delta_{t}$, is required to load the specimen to the same load with a soft machine compared with a hard machine. The elongation of the machine stores elastic strain energy, which is equal to the area under the machine's load-deformation curve. It is seen that more energy is stored in a soft machine than in a hard machine. The area under the load-deformation curve of the specimen represents the work 
required to compress the specimen. The sum of the energy stored in the machine and the work done on the specimen represents the work that must be done by the loading system (motion of piston or crosshead) to load the specimen.

To gain additional insight into the significance of the machine stiffness, consider the situation where the specimen, shown as a spring in Fig. 1.10(c), is subjected to an incremental load, $\Delta \mathrm{P}$. From equilibrium, there has to be an equal incremental tensile load in the testing machine. Thus there is an incremental shortening, $\Delta \delta_{s}$, of the specimen and an incremental elongation, $\Delta \delta_{m}$, of the testing machine. These incremental deformations are equal to the incremental force divided by the corresponding stiffnesses. The sum of these incremental deformations is the incremental movement, $\Delta \delta_{\mathrm{t}}$, of the crosshead or piston required to produce $\Delta \mathrm{P}$ :

$$
\Delta \delta_{t}=\Delta \delta_{s}+\Delta \delta_{m}=\Delta P\left(\frac{1}{k_{s}}+\frac{1}{k_{m}}\right)
$$

Assume that these changes occur over a short interval $\Delta \mathrm{t}$. If Eq. 1.4 is divided by $\Delta t$ and the terms are rearranged, the following rate equation is obtained:

$$
\frac{\Delta \delta_{t}}{\Delta t}=\frac{\Delta P}{\Delta t}\left(\frac{k_{m}+k_{s}}{k_{m} k_{s}}\right)
$$

Letting the interval $\Delta t$ approach zero, leads to the following equation that relates the rate of increase in load on the specimen, $P^{\prime}$, to the rate of total applied deformation, $\delta_{\mathrm{t}}$ :

$$
P^{\prime}=\delta_{t}^{\prime}\left(\frac{k_{m} k_{s}}{k_{m}+k_{s}}\right)
$$

Equation 1.6 summarizes the effect of machine stiffness on the loading response during a compression test. It is assumed that the applied deformation rate, $8_{t}$, and the machine stiffness, $k_{m}$, are constant. The stiffness of the concrete specimen is constant before the onset of microcracking. As the amount of microcracking increases, the specimen stiffness decreases, and it equals zero when the ultimate load is reached. Beyond the ultimate load, the specimen stiffness has a negative value, which means that an incremental shortening of the specimen is accompanied by a reduction in force (strain softening). From Eq. (1.6), it is seen that when the specimen stiffness is negative, the rate of loading is also negative. Figures 1.11(c) and 1.11(d) show the deformations of the specimen and testing machine for a given load drop beyond the ultimate load. Because the load decreases, the elongation of the testing machine is reduced, and this reduction is greater for a soft machine (Fig. 1.11(c)) than for a hard machine (Fig. 1.11(d)). During the descending-load portion of the test, the shortening of the specimen is equal to the applied deformation (movement of crosshead or piston) plus the shortening of the testing machine. Examination of Eq. (1.6) shows that as the slope of the load-deformation curve of the specimen, that is, the value of $k_{s}$, approaches $-k_{m}$, the rate of load decrease approaches infinity. This represents instability and the specimen undergoes very rapid, and often explosive, collapse. Additional information on the interactions between testing machine and specimen stiffnesses is available (Hinde 1964, Hudson, et al. 1972). 
Another approach for understanding the interaction between testing machine and specimen is by considering work and stored energy (Hudson, et al. 1972, Salamon 1970). During the ascendingload portion of the test, the piston (or crosshead) does work to compress the specimen and elongate the testing machine. The work done on the machine is stored as elastic strain energy (analogous to stretching a rubber band). When the ultimate load of the specimen is reached, the load stops increasing and begins to decrease. As the load decreases, the testing machine loses some of its stretch and releases some of its stored energy. This released energy is added to the energy supplied by the motion of the piston (or crosshead) to compress the specimen. Figures 1.12(a), 1.12(b) and 1.12(c) illustrate the work required to compress the specimen by additional amounts $\Delta \delta_{s}$ at different points beyond the ultimate load. The energy released by the testing machine is also shown. In Fig. 1.12(b), the energy released by the machine is less than the work required to compress the specimen. This difference must be provided by additional movement of the piston (or crosshead). In going from Fig. 1.12(a) to Fig. 1.12(c), it is seen that the amount of released energy increases with each incremental shortening of the specimen. In Fig. 1.12(c), the slope of the specimen load-deformation curve equals $-k_{m}$. Therefore, for an incremental deformation, $\Delta \delta_{s}$, the released energy equals the work required to deform the specimen. This is the point of instability. Beyond this point, more energy is available than can be absorbed by the specimen, and the specimen literally explodes. To avoid such an explosive failure, it is necessary to have a hard testing machine such that $k_{m}$ always exceeds the absolute value of $k_{s}$ during the test. This matter will be discussed later in this section.

C. S. Whitney was one of the first to explain the effect of testing machine stiffness on the loaddeformation behavior of a concrete specimen (Whitney 1943). In a discussion of a research paper dealing with complete stress-strain curves ${ }^{\mathrm{d}}$ of concrete, Whitney noted that, although a high-strength cylinder fails suddenly, the load-deformation curve of the cylinder is not vertical because the specimen is straining while the load drops. He emphasized the distinction between the load-time behavior and the load-deformation behavior. Whitney also presented the following explanation of how the release of strain energy in the machine leads to specimen destruction:

"Shortly after the maximum load, the slope of the concrete curve becomes equal to that of the machine curve. The elastic recovery of the machine at that stage is rapid enough to maintain the load required to continue the straining of the cylinder without operating the machine. At this point the strain starts to increase automatically and rapid failure follows."

Whitney made calculations of the energies involved during a concrete test and arrived at the following observations:

"...the amount of energy lost in deforming the concrete plastically is roughly proportional to its strength while the elastic energy stored in the concrete and the machine increases much more rapidly than the strength. At maximum load, the machine potential energy is about three times that in the concrete. No definite data are available regarding the amount of energy required to produce failure after the maximum load is reached; but since the ultimate strains appear to be smaller for stronger concrete, the energy required for destruction probably does not increase as rapidly as the strength. This indicates again why

${ }^{\mathrm{d}}$ The idealized stress-strain curves that were presented had vertical slopes at some point beyond the ultimate strength, which imply that stresses drop to zero without further straining of the concrete. 
the strong cylinders appear to destroy themselves near maximum load while the weaker ones do not."

In summary, compression tests are typically conducted using a screw-type or a hydraulicallyoperated machine. A general understanding of the interaction between machine and specimen can be gained by considering a simple spring model and by using two basic principles: compatibility of deformations and equilibrium of forces. Analysis of the spring model shows that the stiffness of the machine plays an important role during the descending-load portion of the compression test. If the absolute value of the specimen stiffness exceeds the machine stiffness, the specimen undergoes sudden and explosive fracturing.

Research results - Systematic studies of the effects of testing machine characteristics on the measured compressive strength of concrete specimens were conducted in the 1950s and 1960s in the United Kingdom. These studies were motivated by two factors. First, a large-scale research program was initiated at Imperial College to gain an understanding of the failure of concrete under load. As part of this work, the effects of various factors on the measured strength of concrete specimens were investigated (Newman and Lachance 1964). Second, the Cement and Concrete Association and the Road Research Laboratory had found that testing laboratories were reporting different strengths when testing companion specimens cast from the same batch of concrete (Wright 1957; Cole 1964, 1967). The objective of these studies was the development of standards for compression testing machines (Newman and Spooner 1969).

In the United Kingdom, the standard compression test specimen is a cube. Therefore, before discussing the findings of various studies, the differences between testing cubes and cylinders are discussed. As is well known, the quality of concrete is expected to be better at the bottom of a cast specimen than at the top (Cole 1967, Newman and Spooner 1969). Much of this difference is due to the accumulation of bleed water in the upper portion of the specimen and better compaction of the bottom portion. As a result, the modulus of elasticity and strength varies with elevation (Newman and Sigvaldason 1965). Figure 1.13(a) shows a concrete cube and a cylinder after molding. The varying shades represent the variation in strength and elastic modulus. To avoid capping, cubes are tested on their sides, as shown in Fig. 1.13(b). As a result, the loading direction is perpendicular to the casting direction. When the cube is subjected to a uniform deformation, the stress distribution will not be uniform. The side of the cube with higher elastic modulus has a higher stress. For the cylinder, the uniform compressive deformation leads to a uniform stress, because there is no variation in elastic modulus through a cross section. The non-uniform distribution in the cube is equivalent to the superposition of an axial load plus a bending moment. If there is sufficient friction in the spherical seat, the moment can be resisted, and there is no rotation of the spherical head. The moment is, in turn, imparted to the testing machine, and high lateral stiffness becomes critical to maintain uniform deformation. In the cylinder test, there is no bending moment, there is no tendency for rotation of the spherical seat, and the lateral stiffness of the machine is not critical. ${ }^{e}$

'This assumes that the all components of the testing machine are aligned, the cylinder is properly centered, and the cylinder has uniform properties through its cross section. 
The results of these studies in the United Kingdom, and others from elsewhere, revealed the following as the most important testing machine characteristics (Newman and Spooner 1969):

- behavior of the spherical seating

- testing machine stiffness

- planeness of bearing blocks

- alignment of machine components and test specimen

Compression tests are typically carried out with the specimen resting on a fixed bearing block and the top of the specimen bearing against a spherically-seated block. The main purpose of the spherically-seated block is to adapt to any non-parallelism between the loaded surfaces of the specimen. One of the earliest studies on the subject of spherical bearings suggested that, to ensure a uniform stress distribution, the spherically-seated block should be free to rotate during the test (Schuyler 1913). Studies in the 1960s, however, proved conclusively that the spherically-seated block should not rotate during load application, that is, after any initial rotation it should behave as a fixed block (Newman and Sigvaldason 1965; Sigvaldason 1966b, 1966c; Cole 1967; Newman and Spooner 1969). Fixed behavior is preferred because of the following reason (Newman and Sigvaldason 1965): If the block rotates during the test, the specimen is subjected to a uniform stress. If the specimen, however, is not homogeneous through its cross section, the ultimate strength is reached when the weakest portion of the specimen is stressed to its capacity. Specimen failure is localized in the weaker portion of the specimen, and a horizontal tension crack often develops on the opposite side (Erntroy 1954, Newman and Sigvaldason 1965, Sigvaldason 1966b). If the block is fixed, the specimen is subjected to uniform deformation. Therefore, different parts of the cross section develop stresses in proportion to their elastic modulus (see Fig. 1.13(b)). This results in a uniform failure of the specimen, and the ultimate strength is greater than in the case of uniform stressing. To achieve fixed behavior, the frictional resistance of the spherical seating has to be sufficient to overcome any tendency toward rotation due to the eccentricity between the reaction force in the specimen and the center of the seating. This resistance can be ensured by using a light lubricant that allows the mating surfaces of the spherical seat to make contact after the initial alignment has taken place (Sigvaldason 1966c, Cole 1967, Newman and Spooner 1969). Light motor oils and petroleum jelly are appropriate lubricants, while high-pressure greases are inappropriate. It was found that cylinders are less sensitive to the details of spherical-seating behavior than cubes (Sigvaldason 1966b). This is primarily because cylinders have more uniform properties through their cross sections compared with cubes, as was previously explained with the aid of Fig. 1.13.

The effect of testing machine stiffness on the measured compressive strength is not understood with the same certainty as is the effect of the spherically-seated block. There are two kinds of stiffnesses that need to be considered: longitudinal and lateral. As was explained, the longitudinal stiffness of the testing machine plays an important role in the behavior after the ultimate load has been reached (Whitney 1943). It is generally acknowledged that a hard testing machine is desirable to avoid explosive failures, which can result in more rapid deterioration of machine components and loss of accuracy (Sigvaldason 1966a, 1966b). Sigvaldason (1966a) noted that the descending portion of the load deformation curve of concrete specimens was about one-fourth as steep as the ascending portion. On this basis, he suggested that the longitudinal stiffness of a cube testing machine should exceed about $1.8 \times 10^{9} \mathrm{~N} / \mathrm{m}$. Other studies, however, have shown that the slope of the descending 
portion of the load deformation curve is dependent on the strength level of the concrete (Barnard 1964, Wang et al. 1978). For high-strength concrete, the descending slope can be as steep or even steeper than the ascending slope (Shah et al. 1981). As a result, a stiffer machine than suggested by Sigvaldason would be needed to avoid explosive failure of high-strength concrete specimens. If the machine stiffness should be at least twice the initial stiffness of a 150 by $300 \mathrm{~mm}$ high-strength cylinder having an initial elastic modulus $45 \mathrm{GPa}$, the required machine stiffness would have to be about three times the value suggested by Sigvaldason.

As mentioned, the longitudinal stiffness of the machine is affected by other factors besides the stiffnesses of the columns and crosshead. Thus it is difficult to make an accurate estimate of machine stiffness based on the dimensions of the structural frame. One approach for measuring the longitudinal stiffness is to replace the test specimen with a hydraulic jack. The machine is brought to its testing position and the hydraulic valves are closed. The jack is used to load the machine, and the deformation between the bearing blocks is measured as function of the jacking load (Whitney 1953, Hinde 1964). By making measurements during loading and unloading of the jack, the stiffness characteristics of the machine are found. A disadvantage of this method is the need for a compact, high-capacity jack and its accompanying hardware. In addition, the maximum load that can be attained will be limited by the capacity of the jack.

The controversial issue regarding longitudinal stiffness is whether it affects the measured compressive strength. L'Hermite (1954) postulated that the high amount of stored energy in a soft machine would play a role in initiating failure at a lower load compared with a hard machine. No experimental evidence, however, was available to confirm this belief. Glucklich and Cohen (1967) used the principles of fracture mechanics to develop a theory to explain why a soft testing machine should result in lower measured strength. Tests of gypsum mortars, in which springs were used in series with test specimens to vary the machine stiffness, confirmed the theory (Glucklich and Cohen 1968). Bažant and Panula (1978) predicted that machine stiffness would affect the ultimate strength under the following conditions: (1) if the specimen has a non-uniform distribution of strength through the cross section; and (2) the strain at peak stress decreases with increasing strength level of the concrete. On the other hand, Wright (1957) found that measured cube strength was not affected by the introduction of flexible proving rings in series with the specimens. Sigvaldason (1966b) performed a comparative study using two machines whose longitudinal stiffnesses differed by a factor of 20 . No difference was observed in the measured strength for a $32-\mathrm{MPa}$ concrete. Mindess and Bentur (1984) reviewed research on the effects of longitudinal stiffness and performed tests of cement paste specimens using six different machines. It was concluded that longitudinal stiffness had little or no effect on compressive strength of paste specimens. Thus it appears that additional investigations are needed before a firm conclusion can be reached on the effect of longitudinal stiffness on strength.

Cole (1967) noted that longitudinal stiffness does not appear to affect strength, but he stated the following:

"However, the testing machine's lateral rigidity is usually related to the longitudinal rigidity and it is the lateral rigidity which will have a marked effect upon the mode of failure of a brittle test specimen." 
Sufficient lateral stiffness is critical to maintain uniform deformation of the specimen during testing (Newman and Spooner 1969). Sigvaldason (1966a) suggested a minimum lateral stiffness of $1.8 \mathrm{x}$ $10^{6} \mathrm{~N} / \mathrm{m}$. When testing cubes, the non-uniform stress distribution due to variations in elastic modulus through the cross section leads to an eccentric load in the specimen. If the testing machine has low lateral stiffness, the eccentric load causes excessive lateral deformations of the frame. This, in turn, causes a relative rotation between the bearing blocks, and the specimen is no longer subjected to uniform deformation. Lateral deformations can also be induced by improper alignment of the test specimen between the bearing blocks. The eccentric load resulting from specimen misalignment tends to produce lateral motion of the frame and non-uniform straining of the specimen. If the frame has high lateral stiffness, the specimen can still be uniformly compressed even if it is misaligned (L'Hermite 1954). This provides for a simple procedure to judge the relative lateral stiffness of a testing machine (Newman and Spooner 1969). Test specimens are placed in the machine with different amounts of misalignment, and the resulting compressive strengths are compared with those of properly aligned specimens. A machine with low lateral stiffness will show marked strength reductions with increasing misalignment (Cole 1964, Sigvaldason 1966b). Alternatively, a steel tube, which is instrumented with strain gages around its circumference, is placed between the bearing blocks and loaded to different levels. The test is repeated with the tube at different eccentricities with respect to the center of the bearing blocks. The differences in the strain gage readings are noted as a function of the amount of misalignment (Foote 1970). Large differences suggest non-uniform straining of the cylinder.

In summary, testing machine stiffness is an important factor in compressive strength testing. The effect of longitudinal stiffness on the post-peak response is understood, and hard machines are needed to avoid explosive failures. On the other hand, the effect of longitudinal stiffness on strength is not understood. There are conflicting opinions and data, so additional study is warranted. The effect of lateral stiffness on strength is understood. A laterally stiff machine assures uniform straining of the specimen in the presence of eccentric loading, due to either heterogeneity of the specimen or misalignment. The adequacy of the lateral stiffness can be evaluated by a proving device that measures the uniformity of straining as a function of degree of misalignment.

Plane bearing blocks are necessary to assure uniformity of the stress distributions from one test specimen to another. Before discussing allowable deviations in planeness, the distribution of contact stresses between a concrete cylinder and a steel block is reviewed. Contrary to intuition, when a perfectly flat concrete specimen is compressed between flat bearing blocks, the compressive stresses at the interfaces are not uniformly distributed (Newman and Lachance 1964, Ottosen 1984). A linear-elastic, finite element analysis was done by the authors to get an understanding of the stress distribution between a 150 by $300 \mathrm{~mm}$ concrete cylinder and solid steel blocks $(200 \mathrm{~mm}$ in diameter and $100 \mathrm{~mm}$ thick). It was assumed that there was no sliding between the concrete and steel blocks. The results are shown in Fig. 1.14, where the normal stress between concrete and steel is plotted as a function of the distance from the center of the cylinder. The stress is expressed in terms of the nominal stress computed from load and cross-sectional area. It is seen that the stresses at the perimeter of the cylinder are higher than the nominal stress. By interposing capping materials of lower stiffness than the concrete, the stress concentration along the perimeter can be reduced. As previously mentioned, materials that are too soft will be squeezed from between the cylinder and bearing blocks. This flow induces outward tensile stresses that reduce the measured strength. 
Several investigations have arrived at similar conclusions regarding the allowable deviations in the planeness of bearing blocks used to test cubes. Bernhardt (1964) reported on experiments in which brass shims of different thicknesses were used to produce non-planar bearing surfaces. Various patterns were investigated, some of which simulated convex bearing surfaces and others simulated concave surfaces. The objective was to investigate the suitability of a proposed limit of $0.05 \mathrm{~mm}$ as the maximum allowable deviation from planeness. It was found that significant reductions in strength occurred when $0.09 \mathrm{~mm}$ thick shims were used, and it was concluded that the $0.05 \mathrm{~mm}$ limit was appropriate. A study of Bernhardt's results shows that the convex defects tended to produce greater strength reductions than the concave defects. Entroy (1964) used bearing blocks with approximately conical surfaces having apex heights of 0.05 and $0.1 \mathrm{~mm}$. Convex and concave shapes were used. It was found that the convex block with an apex height of $0.1 \mathrm{~mm}$ resulted in $10 \%$ lower strengths compared with a flat platen. Thus it appears that both the amount and direction of the deviation from planeness have to be considered in predicting the effect on measured strength.

\subsubsection{Loading rate}

It is well known that the strength of concrete, like most materials, is dependent on the rate of loading. Therefore, standards for measuring compressive strength specify allowable loading rates to ensure comparable results among laboratories. These loading rates are specified in terms of either a stress rate or a strain rate. For example, ASTM Test Method C 39 allows a stress rate of 0.14 $\mathrm{MPa} / \mathrm{s}$ to $0.34 \mathrm{MPa} / \mathrm{s}$. If the elastic modulus is about $25 \mathrm{GPa}$, this stress range corresponds to strain rates of 6 to 14 microstrain/s. Research studies on the effect of loading rate on strength can be divided into two groups: those that involve rates representative of static compression tests and those that involve rates representative of impact conditions. The former studies are discussed here. References on studies of very high loading rates may be found in Bažant and Oh (1982) and in Kaplan (1980).

Abrams reported one of the first studies on the effect of loading rate on measured compressive strength of $150 \times 300-\mathrm{mm}$ concrete cylinders (Abrams 1917). Tests were conducted with a screwtype testing machine, and loading rate was varied by changing the crosshead speed. Abrams noted that the idle speed of the machine was two to four times faster than the deformation rate of test specimens due to deformations in the various components of the testing machine. Two testing procedures were used: (1) about $10 \%$ of the expected ultimate load was applied at a fast deformation rate (347 microstrain/s), and the remainder of the loading was done at rates between 8 and 208 microstrain/s; (2) cylinders were loaded at a fast rate ( $347 \mathrm{microstrain} / \mathrm{s})$ up to various percentages of the expected ultimate load, and the remainder of the loading was accomplished at a rate of 14 microstrain/s. Three concrete mixtures were used with nominal strengths of 6,12 and $20 \mathrm{MPa}$. Figure 1.15(a) shows the results from the first procedure. The strengths reported by Abrams have been normalized by dividing by the strength at the slowest loading rate $(8 \mathrm{microstrain} / \mathrm{s})$. The results showed that an increase in the deformation rate increased the measured strength, but the size of the increase depended on the concrete mixture. Stronger concretes were more sensitive to loading rate. The results from the second loading method are shown in Fig. 1.15(b). Surprisingly, the initial fast loading rate did not affect the ultimate strength, even when the fast rate extended to about $90 \%$ of the expected strength. Based on these results, Abrams recommended that, for testing economy, 
specimens should be loaded at a fast rate to about 50 to $75 \%$ of the expected strength and after that loaded at deformation rates between 14 and $28 \mathrm{microstrain} / \mathrm{s}^{\mathrm{f}}$.

In 1936, Jones and Richart reported on a study in which $150 \times 300-\mathrm{mm}$ cylinders were loaded at nine different rates so that ultimate loads were reached within one second to four hours (Jones and Richart 1936). Tests were done on a screw-type machine, and advanced (for that time) electronic instrumentation was used to record the load- and strain-histories. Three concrete mixtures were used with nominal strengths of 14,24 , and $35 \mathrm{MPa}$. Tests were performed at ages of 7 and 28 days. Although tests were done with a constant crosshead speed, the load rate increased gradually at the start of the tests as slack was taken out of the loading system. The nominal loading rate was computed from the straight-line portion of the load-time history, which extended from about 25 to $90 \%$ of the ultimate load. Stress rates from $1.7 \mathrm{kPa} / \mathrm{s}$ to $26 \mathrm{MPa} / \mathrm{s}$ were obtained. Although there was considerable scatter in the results, it was found that, on average, the strength was a linear function of the logarithm of the stress rate $\mathrm{g}$ :

$$
S=S_{1}\left(1+k \log _{10} R\right)
$$

where $S_{I}=$ strength at a stress rate of $1 \mathrm{psi} / \mathrm{s}(6.89 \mathrm{kPa} / \mathrm{s})$

$k=0.07$ for 7 -day tests and 0.08 for 28 -day tests, and

$R=$ stress rate in $\mathrm{psi} / \mathrm{s}$.

Thus a tenfold increase in the stress rate is expected to produce a strength increase of 7 to $8 \%$. Using this relationship, an increase in stress rate from $0.14 \mathrm{MPa} / \mathrm{s}$ to $0.34 \mathrm{MPa} / \mathrm{s}$ (the current limits in ASTM C 39) is expected to produce about a $3 \%$ increase in the measured strength.

Petkov studied the effect of loading rate on measured cube strength (Petkov 1964). Nine concrete mixtures were used, and the cube strengths varied from about 6 to $25 \mathrm{MPa}$. Cube sizes were 100,150 , and $200 \mathrm{~mm}$. A hydraulic testing machine was used, and stress rates were approximately $0.05,0.2$ and $0.5 \mathrm{MPa} / \mathrm{s}$. Three replicate tests were performed for each rate/size combination. Figure 1.16(a) shows the measured average strengths for each of the mixture as a function of stress rate. Because of the different strength levels and cube sizes, it is difficult to observe any trends that may be present. Petkov normalized the average strengths by expressing them as percentage differences compared with the strengths measured at the intermediate stress rate, i.e., $0.2 \mathrm{MPa} / \mathrm{s}$. Figure 1.16(b) shows these differences as a function of the loading rates. Regression analysis by the authors showed that the straight line shown in Fig. 1.16(b) is statistically significant, and the slope is about $6 \% /(\mathrm{MPa} / \mathrm{s})$. Based on the fitted line, an increase in loading rate from 0.14 $\mathrm{MPa} / \mathrm{s}$ to $0.34 \mathrm{MPa} / \mathrm{s}$ is expected to increase the strength by only $1.2 \%$. Note the considerable scatter of the data about the best-fit line.

The actual recommendations were 0.25 to $0.50 \mathrm{~mm} / \mathrm{m}$, but these have been changed to microstrain/s by dividing by $300 \mathrm{~mm}$, the approximate height of the cylinders.

${ }^{8}$ The equation is presented in inch-pound units to agree with the original reference. 
In a recent study, Chojnacki and Read investigated the effect of loading rate on the measured strength of high-strength concrete cylinders (Chojnacki and Read 1991). Two nominal strength levels were used: 70 and $90 \mathrm{MPa}$. Cylinders were 100 and $150 \mathrm{~mm}$ in diameter. Three loading procedures were used:

- at a rate of $0.15 \mathrm{MPa} / \mathrm{s}$ for the entire test (slow),

- at a rate of $0.35 \mathrm{MPa} / \mathrm{s}$ for the entire test (fast), and

- at a rate of $0.70 \mathrm{MPa} / \mathrm{s}$ for the first $50 \%$ of the test and at a rate of $0.25 \mathrm{MPa} / \mathrm{s}$ for the remainder of the test (medium).

Dotplots of the test results (with outliers removed by the authors) are shown in Figs. 1.17(a) and 1.17(b). Analysis of variance was used to detect if there were statistically significant differences among the average strengths due to the different loading methods. For the 70-MPa concrete and 100 -mm cylinders, the slow rate resulted in $2.8 \%$ lower strength than the other rates, which resulted in similar strength. For the 150-mm cylinders, the third loading method (labeled "med" in the figures) resulted in a large scatter. Therefore, no statistically significant differences were detected among the three means. A comparison of the means for the "fast" and "slow" tests, however, showed that the difference was statistically significant at a significance level less than 0.01 . The slow loading rate resulted in $2.2 \%$ lower strength than the fast rate. For the $90-\mathrm{MPa}$ concrete and $100-\mathrm{mm}$ cylinders, the differences among the three means were statistically significant. The slow rate resulted in 3\% lower strength than the fast rate, but there was no strength difference between the fast and medium rates. For the $90-\mathrm{MPa}, 150-\mathrm{mm}$ cylinders, there was also a large scatter in the strengths at the medium rate, and so differences among the three means were not statistically significant. The slow rate, however, produced a statistically significant lower strength than the fast rate; the difference was $3.5 \%$.

This review of research conducted over a period of more than 75 years shows consistent results. Variations in the loading rate as permitted in the current ASTM procedures are expected to produce small but measurable differences in compressive strength. Based on the results by Chojnacki and Read (Chojnacki and Read 1991), the differences could be as high as 3\% when testing high-strength concrete.

\subsection{Review of ASTM Standards}

The previous section aimed to provide the bases of current standards related to the measuring compressive strength of cylindrical concrete specimens. This section presents some key requirements in current ASTM standards dealing with compressive strength measurement. The objective is to provide a rationale for the experimental investigation described in the next chapter. This investigation aims to study the applicability of current standards to testing high-strength concrete.

The compressive strength of concrete cylinders is measured according to ASTM Test Method C 39 (ASTM 1993). The method is applicable to testing cylinders made in the field or in the laboratory, to testing cores, and to testing cast-in-place cylinders (ASTM C 873). Before reviewing the requirements in Test Method C 39, pertinent requirements found in supporting standards dealing with preparation of molded test specimens are reviewed. 
ASTM Practice C 31 (ASTM 1993) provides procedures for preparing test specimens in the field. Two types of specimens are considered: (1) those for quality control, which are subjected to standard curing; and (2) those to assess in-place strength development, which are exposed to the same ambient conditions as the structure. The first type is of primary interest in this study. The following are some requirements in ASTM C 31:

- "Unless required by the project specifications, cylinders smaller than 6 by $12 \mathrm{in}$. shall not be made in the field." (paragraph 5.1)

- $\quad$ "After molding, the specimens shall be stored in a temperature range between 60 to $80^{\circ} \mathrm{F}$ $\left(16\right.$ to $27^{\circ} \mathrm{C}$ ) and in a moist environment preventing any loss of moisture up to $48 \mathrm{~h}$ (Note 2).

Note 2. It may be necessary to create an environment during initial curing to provide satisfactory moisture and to control the temperature. The specimens may be immersed immediately in saturated limewater, and/or stored in tightly constructed wooden boxes, damp sand pits, temporary buildings at construction sites, under wet burlap, or in heavyweight closed plastic bags...."

The first of these requirements may prevent some laboratories from testing high-strength concrete with existing testing machines unless project specifications specifically stipulate the use of smaller test specimens. The second requirement was developed based on experiences with conventional concrete, and its applicability to high-strength concrete cylinders needs to be verified.

ASTM Practice C 192 (ASTM 1993) provides procedures for preparing test specimens in the laboratory. The standard permits cylinders with diameters as small as $50 \mathrm{~mm}$ if the diameter is at least three times the nominal maximum size of the coarse aggregate. Paragraph 4.1, however, states: "Where correlation or comparison with field-made cylinders (Practice C 31) is desired, the cylinders shall be 6 by 12 in (or 150 by $300 \mathrm{~mm}$ ). ${ }^{\prime i}$ The requirements for placing concrete into molds and for consolidation are specified in Tables 1 and 2 of the standard. Table 1 states that for vertically-cast cylinders up to $300 \mathrm{~mm}$ in height, concrete should be placed in three equal layers. Table 2 specifies using 25 strokes of the tamping rod per layer. The diameter of the tamping rod is specified as 16 $\mathrm{mm}$ for $150-\mathrm{mm}$ diameter cylinders and $10 \mathrm{~mm}$ for cylinders smaller than $150 \mathrm{~mm}$. Thus for a $150-$ $\mathrm{mm}$ diameter cylinder, the rodded area is $28 \%$ of the cylinder cross section, and for a $100-\mathrm{mm}$ diameter cylinder it is $25 \%$ of the cross section. There is a need to determine whether it is necessary to use three layers to cast $200-\mathrm{mm}$ tall cylinders and whether the current consolidation procedures result in comparable density for different specimen sizes. The current requirement is that specimens are to be removed from molds $24 \pm 8 \mathrm{~h}$ after casting. There are, however, circumstances under which concrete may not have gained sufficient strength within this time, because of the retarding effect of high dosages of high-range water reducing admixtures often used in high-strength mixtures.

ASTM Test Method C 39 has the following requirements for the ends of test specimens:

${ }^{\mathrm{h}}$ AASHTO T 23 permits use of $100-\mathrm{mm}$ diameter cylinders when the nominal maximum size of aggregate does not exceed $25 \mathrm{~mm}$.

${ }^{i}$ AASHTO T 126 requires that laboratory cylinders shall be the same size as field-made cylinders. 
"The ends of compression test specimens that are not plane within $0.002 \mathrm{in} .(0.050 \mathrm{~mm})$ shall be capped in accordance with Practice C 617 or they may be sawed or ground to meet that tolerance." ASTM Practice C 617 (ASTM 1993) covers the use of the following capping materials to satisfy this planeness requirement:

- neat cement paste,

- high-strength gypsum plaster, or

- sulfur mortar.

Neat cement paste is intended for capping the top surface of recently molded cylinders. Presumably, the specimens would be made in steel molds so that the bottom surfaces would meet the planeness requirements without capping. The high-strength gypsum plaster and the sulfur mortar are intended for capping hardened cylinders. Regarding the strength requirements of capping materials, the Scope of Practice C 617 says that: "A cap shall be at least as strong as the concrete." Paragraph 5.2.1 on high-strength gypsum includes the following: "Neat high-strength gypsum cement (without any fillers or extenders added subsequent to its manufacture) may be used if 2-in. (50-mm) cubes are found to develop a strength of at least $5000 \mathrm{psi}(34 \mathrm{MPa}$ ) when subject to the same environment for the same length of time as capped specimens." Regarding sulfur mortar, paragraph 5.2.2 states that: "Proprietary or laboratory-prepared sulfur may be used if allowed $2 \mathrm{~h}$ in which to harden. Sulfur mortar shall conform to the following requirements [sic]: Compressive strength (aged $2 \mathrm{~h}$ ): min, 5000 psi (34.5 MPa)." As written, ASTM Practice C 617 has some ambiguity regarding the required strength of capping materials. In recognition of this ambiguity, proposed changes (June 1993) to Practice $C 617$ include the elimination of the statements mentioned above. Also, a table is added which states that the minimum cube strength of the capping material should be $35 \mathrm{MPa}$ for concrete strength up to $35 \mathrm{MPa}$. For higher strength concrete, the cube strength of the capping material must be at least the concrete cylinder strength.

Besides strength requirements, ASTM Practice C 617 also specifies maximum cap thickness. The current standard says that: "Caps should be about $1 / 8 \mathrm{in}$. (3-mm) thick, and in no instance shall any part of a cap be more than $5 / 16 \mathrm{in}$. $(8 \mathrm{~mm}$ ) thick." The following requirements were proposed in the 1993 revision of the standard:

\begin{tabular}{c|c|c}
\hline $\begin{array}{c}\text { Cylinder Compressive Strength, } \\
\text { MPa }\end{array}$ & $\begin{array}{c}\text { Maximum Average } \\
\text { Thickness of Cap, mm }\end{array}$ & $\begin{array}{c}\text { Maximum Thickness of } \\
\text { Any Part of Cap, mm }\end{array}$ \\
\hline 3.5 to 50 & 6 & 8 \\
\hline$>50$ & 3 & 5 \\
\hline
\end{tabular}

Once a proper specimen has been prepared, ASTM Test Method C 39 provides the requirements for the testing machine and the procedure to measure compressive strength. The standard considers two types of testing machines: (1) a screw-type and (2) a hydraulically-operated type. The following procedures are specified for loading the specimen: "For testing machines of the screw type, the moving head shall travel at a rate of approximately $0.05 \mathrm{in} .(1.3 \mathrm{~mm}) / \mathrm{min}$ when the machine is running idle. For hydraulically operated machines, the load shall be applied at a rate of movement (platen to crosshead measurement) corresponding to a loading rate on the specimen within the range of 20 to $50 \mathrm{psi} / \mathrm{s}(0.14$ to $0.34 \mathrm{MPa} / \mathrm{s})$. The designated rate of movement shall be maintained 
at least during the latter half of the anticipated loading phase of the testing cycle." It is further stated as follows: "Make no adjustment in the rate of movement of the platen at any time while a specimen is yielding rapidly immediately before failure." While the loading rate for a hydraulicallyoperated testing machine is specified in terms of a stress rate, note that the standard says a rate of movement must be used that results in a stress rate within the specified range. This is not equivalent to a load-rate controlled test, in which the rate of load application is kept constant throughout the test. In fact, a load-rate controlled test is not allowed by ASTM Test Method C 39, because this would violate the requirement that the rate of movement must not be adjusted as the specimen approaches the ultimate load condition. As ultimate load is approached, the specimen stiffness decreases and it would be necessary to increase the rate of piston movement to maintain a constant stress rate. The standard does not directly address the use of modern closed loop, servo-controlled hydraulic testing machines, which can be operated so that the specimen is subjected to a constant rate of deformation.

The current version of ASTM Test Method C 39 has no requirements on the longitudinal and lateral stiffness of the testing machine. As pointed out in section 1.2.3, there is a feeling among some investigators that the cylinder strength is not affected significantly by longitudinal machine stiffness (ACI 363R-92). The longitudinal stiffness, however, affects the post-ultimate behavior. A flexible machine results in more explosive fractures of the specimen, which subjects machine components to more wear and can affect machine calibration. The lateral stiffness of the machine is important in order for the machine to compress the specimen uniformly despite specimen misalignment or heterogeneity through the specimen cross section.

Loads are transferred to the test cylinder by flat bearing blocks. ASTM Test Method C 39 requires that the upper bearing block have a spherical seat. Figure 1.18 shows the dimensional requirements for the spherically-seated block. As explained in section 1.2.3, the purpose of the spherical seating is to accommodate nonparallel ends of the specimen. The spherically-seated bearing block should rotate as it is brought into contact with the specimen, but it should behave as a fixed block as the load on the specimen is increased. The fixed behavior assures uniform compression of the specimen during the test.

\subsection{Purpose}

This review presented in this section has examined some key factors that affect the results of compression tests of concrete specimens. Vast amounts of data provide the bases for current testing standards. Questions have been raised about the ability of these standards to provide for reliable test results when applied to high-strength concrete. The review has shown that the measured strengths of high-strength concrete specimens are more sensitive to changes in testing conditions than the strengths of ordinary strength specimens. The purpose of the experimental program to be described in the next chapter is to examine the effects of variations of certain factors on the measured compressive strength of high-strength concrete cylinders. The ultimate goal is to recommend modifications to the existing standards to ensure their applicability to testing high-strength concrete. 
Table 1.1 Properties of Capping Materials (Werner 1958)

\begin{tabular}{|c|c|c|c|c|c|}
\hline Capping Material & $\begin{array}{l}\text { Specimen } \\
\text { Type* }\end{array}$ & $\begin{array}{l}\text { Test } \\
\text { Age, } \mathrm{h}\end{array}$ & $\begin{array}{l}\text { Compressive } \\
\text { Strength, } \\
\mathrm{MPa}\end{array}$ & $\begin{array}{c}\text { Flexural } \\
\text { Strength, } \\
\mathrm{MPa}\end{array}$ & $\begin{array}{c}\text { Sonic } \\
\text { Modulus of } \\
\text { Elasticity, } \\
\mathrm{GPa}\end{array}$ \\
\hline \multicolumn{6}{|c|}{ Series 1949} \\
\hline Aluminous cement & $\begin{array}{l}\mathrm{P} \\
\mathrm{B}\end{array}$ & $\begin{array}{l}24 \\
24 \\
\end{array}$ & 96.5 & 8.7 & 24.3 \\
\hline Plaster of Paris & $\begin{array}{c}\mathrm{Cu} \\
\mathrm{B} \\
\end{array}$ & $\begin{array}{l}3 \\
3 \\
\end{array}$ & 11.6 & 2.7 & 7.7 \\
\hline Gypsum plaster - A & $\begin{array}{c}\mathrm{Cu} \\
\mathrm{B}\end{array}$ & $\begin{array}{l}2 \\
2 \\
\end{array}$ & 31.0 & 6.5 & 17.2 \\
\hline Gypsum plaster - B & $\begin{array}{c}\mathrm{Cu} \\
\mathrm{B}\end{array}$ & $\begin{array}{l}2 \\
2\end{array}$ & 23.8 & 5.5 & 15.7 \\
\hline Sulfur compound - A & $\begin{array}{l}\mathrm{P} \\
\mathrm{B}\end{array}$ & $\begin{array}{c}2 \\
400 \\
\end{array}$ & 54.1 & 8.3 & 20.0 \\
\hline \multicolumn{6}{|c|}{ Series 1953} \\
\hline Aluminous cement & $\begin{array}{l}\mathrm{Cy} \\
\mathrm{B} \\
\end{array}$ & $\begin{array}{l}24 \\
24 \\
\end{array}$ & 61.5 & 10.3 & 30.2 \\
\hline Plaster of Paris & $\begin{array}{c}\mathrm{Cu} \\
\mathrm{B} \\
\end{array}$ & $\begin{array}{l}3 \\
3 \\
\end{array}$ & 8.2 & & 5.5 \\
\hline $\begin{array}{l}\text { Plaster of Paris + portland } \\
\text { cement ( } 50: 50 \text { by mass) }\end{array}$ & $\begin{array}{c}\mathrm{Cu} \\
\mathrm{B} \\
\end{array}$ & $\begin{array}{l}24 \\
24 \\
\end{array}$ & 9.8 & & 9.1 \\
\hline Gypsum plaster - A & $\begin{array}{l}\mathrm{P} \\
\mathrm{B} \\
\end{array}$ & $\begin{array}{l}24 \\
24 \\
\end{array}$ & 50.4 & 5.5 & 14.6 \\
\hline Gypsum plaster - B & $\begin{array}{l}\mathrm{P} \\
\mathrm{B}\end{array}$ & $\begin{array}{l}24 \\
24 \\
\end{array}$ & 47.9 & 5.4 & 14.6 \\
\hline Sulfur compound - A & $\begin{array}{l}\mathrm{Cy} \\
\mathrm{B}\end{array}$ & $\begin{array}{l}3 \\
3 \\
\end{array}$ & 49.1 & 8.1 & 24.0 \\
\hline Sulfur compound - B & $\begin{array}{l}\mathrm{Cy} \\
\mathrm{B}\end{array}$ & $\begin{array}{l}3 \\
3 \\
\end{array}$ & 43.3 & 8.9 & 15.9 \\
\hline Sulfur $100 \%$ & $\begin{array}{c}\mathrm{Cy} \\
\mathrm{B}\end{array}$ & $\begin{array}{l}3 \\
3\end{array}$ & 10.2 & 1.6 & 10.1 \\
\hline
\end{tabular}

'P $=50$ by 50 by $100-\mathrm{mm}$ prism

$\mathrm{B}=50$ by 50 by $300-\mathrm{mm}$ beam

$\mathrm{Cu}=50-\mathrm{mm}$ cube

$\mathrm{Cy}=75$ by $150-\mathrm{mm}$ cylinder 
Table 1.2 Summary of testing variables and results of test for significant differences in average cylinder strength (Richardson 1990)

\begin{tabular}{|c|c|c|c|}
\hline \multirow{2}{*}{ Variable } & \multicolumn{3}{|c|}{ Significant Differences $(\alpha=0.05)$} \\
\hline & $\begin{array}{c}\text { Sulfur caps - } \\
\text { Control (sulfur) }\end{array}$ & $\begin{array}{c}\text { Pad caps - } \\
\text { Control (pads) } \\
\end{array}$ & $\begin{array}{c}\text { Pad caps - } \\
\text { Control (sulfur) } \\
\end{array}$ \\
\hline \multicolumn{4}{|l|}{ Concave top end, $6 \mathrm{~mm}$} \\
\hline Convex top end, $6 \mathrm{~mm}$ & Yes & & \\
\hline \multicolumn{4}{|l|}{ Eccentric loading, $3 \mathrm{~mm}$} \\
\hline Eccentric loading, $6 \mathrm{~mm}$ & Yes & & \\
\hline Eccentric loading, $12 \mathrm{~mm}$ & Yes & & \\
\hline \multicolumn{4}{|l|}{ Fast loading rate, $0.34 \mathrm{MPa} / \mathrm{s}$} \\
\hline \multicolumn{4}{|l|}{$\begin{array}{l}\text { Rough top end, } 6 \mathrm{~mm} \text { deep } \\
\text { depressions in end }\end{array}$} \\
\hline \multicolumn{4}{|l|}{$\begin{array}{l}\text { Air gaps, } 6 \mathrm{~mm} \text { depressions in } \\
\text { top end filled with rigid foam }\end{array}$} \\
\hline \multicolumn{4}{|l|}{ Inclined axis, $0.5^{\circ}$} \\
\hline \multicolumn{4}{|l|}{ Inclined axis, $2^{\circ}$} \\
\hline Out-of-round specimen, $2 \%$ & Yes & & Yes \\
\hline Out-of-round specimen, $4 \%$ & Yes & Yes & Yes \\
\hline
\end{tabular}




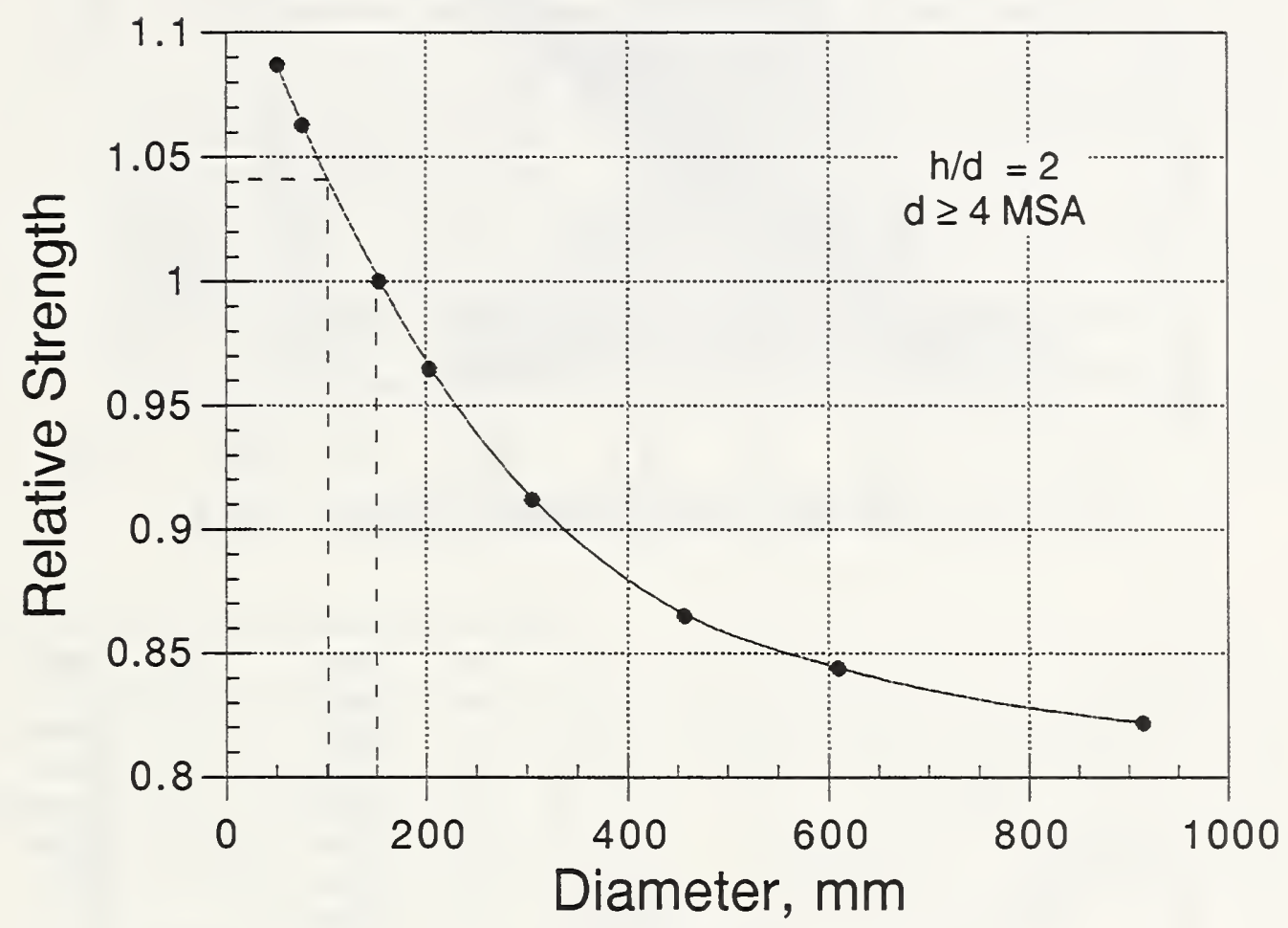

Figure 1.1 Relative compressive strength of cylinders of different diameters for $\mathrm{h} / \mathrm{d}=2$ (Price 1951) 

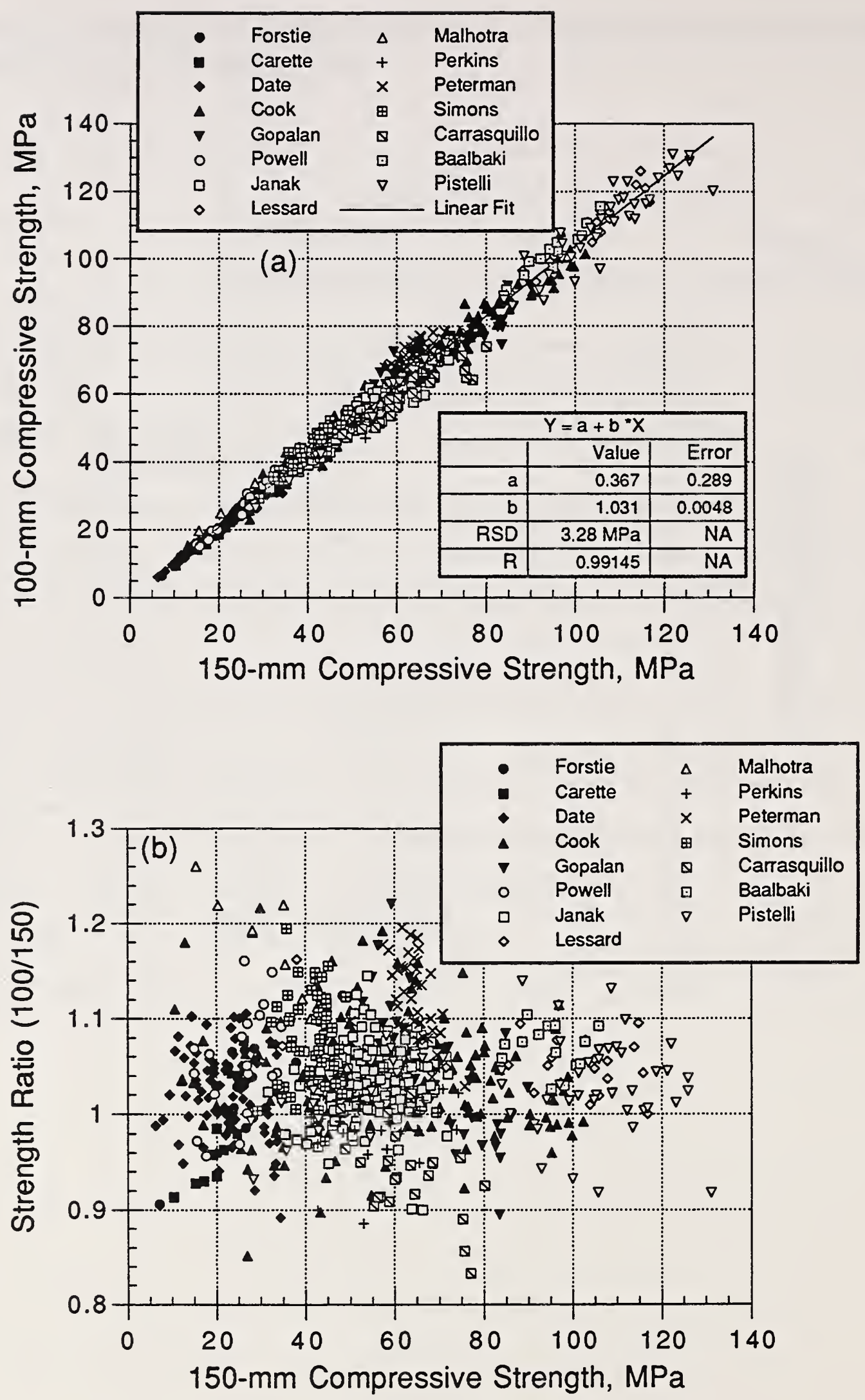

Figure 1.2 - (a) Comparison of compressive strength of 100- and 150-mm diameter cylinders; (b) strength ratio as a function of compressive strength 

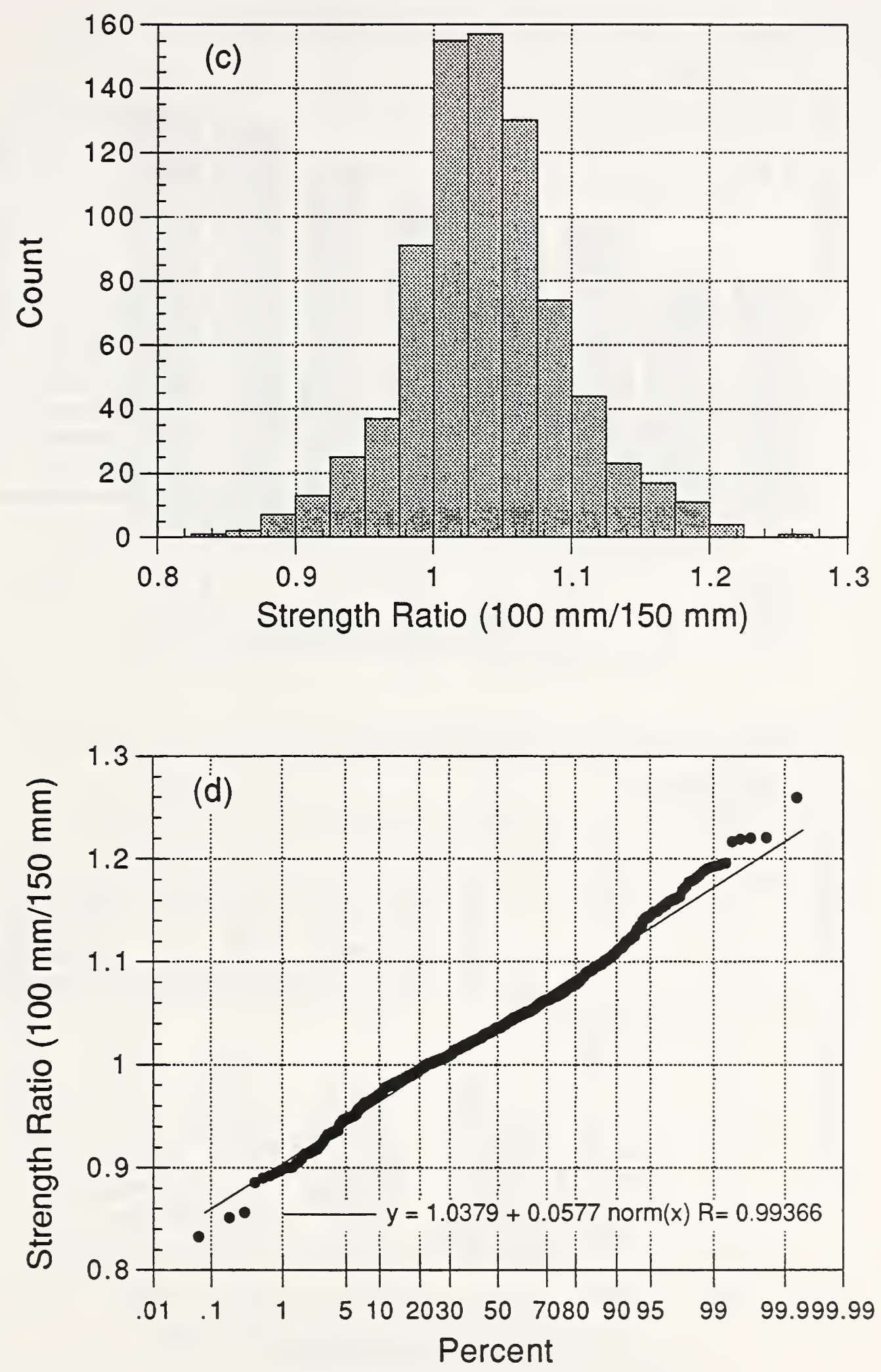

Figure 1.2 - (c) histogram of the strength ratios shown in Fig. 1.2(b); (d) normal probability plot of strength ratios 

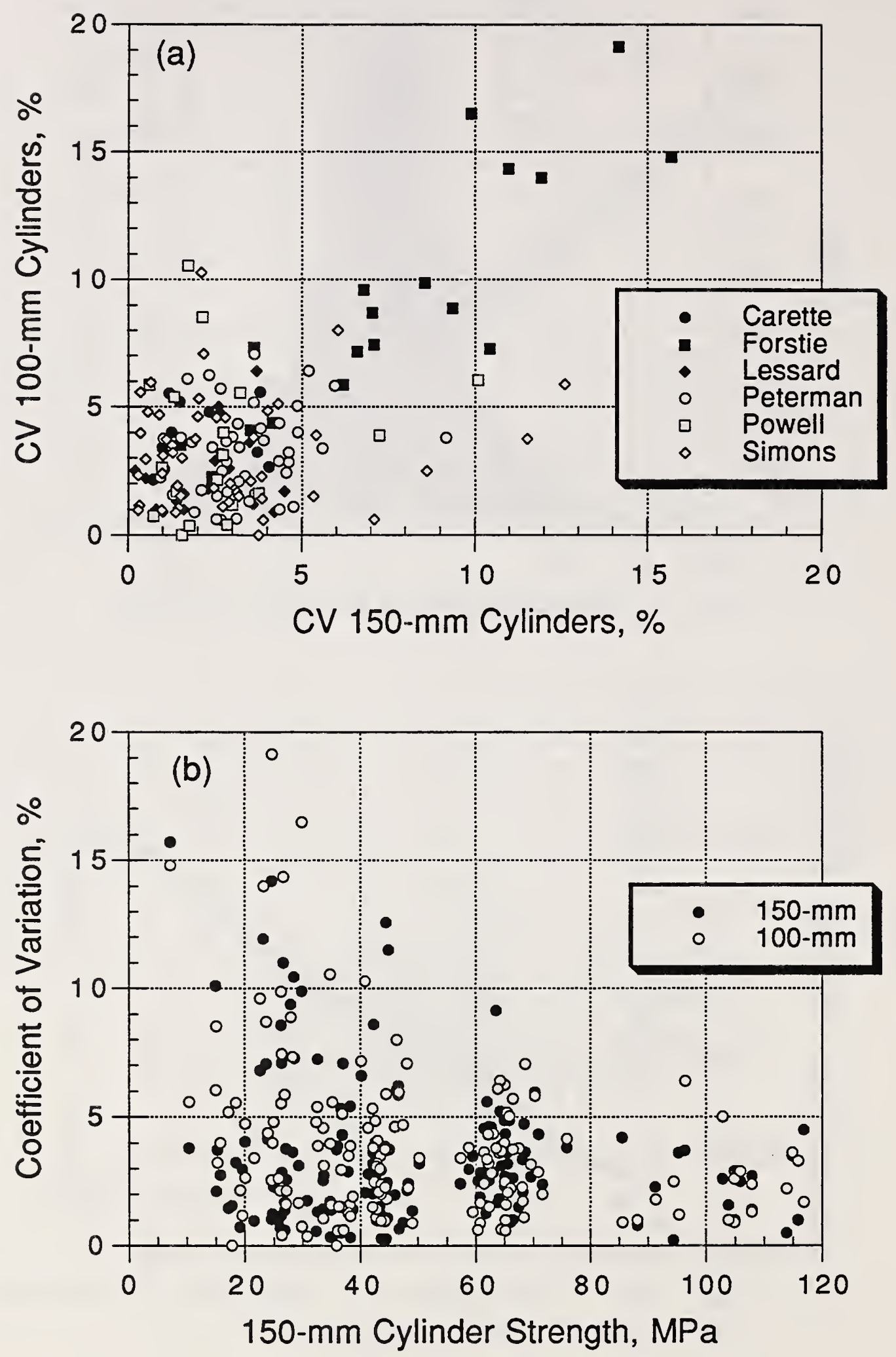

Figure 1.3 - (a) Comparison of coefficients of variation using $100-\mathrm{mm}$ and $150-\mathrm{mm}$ diameter cylinders; (b) coefficient of variation as a function of strength level 

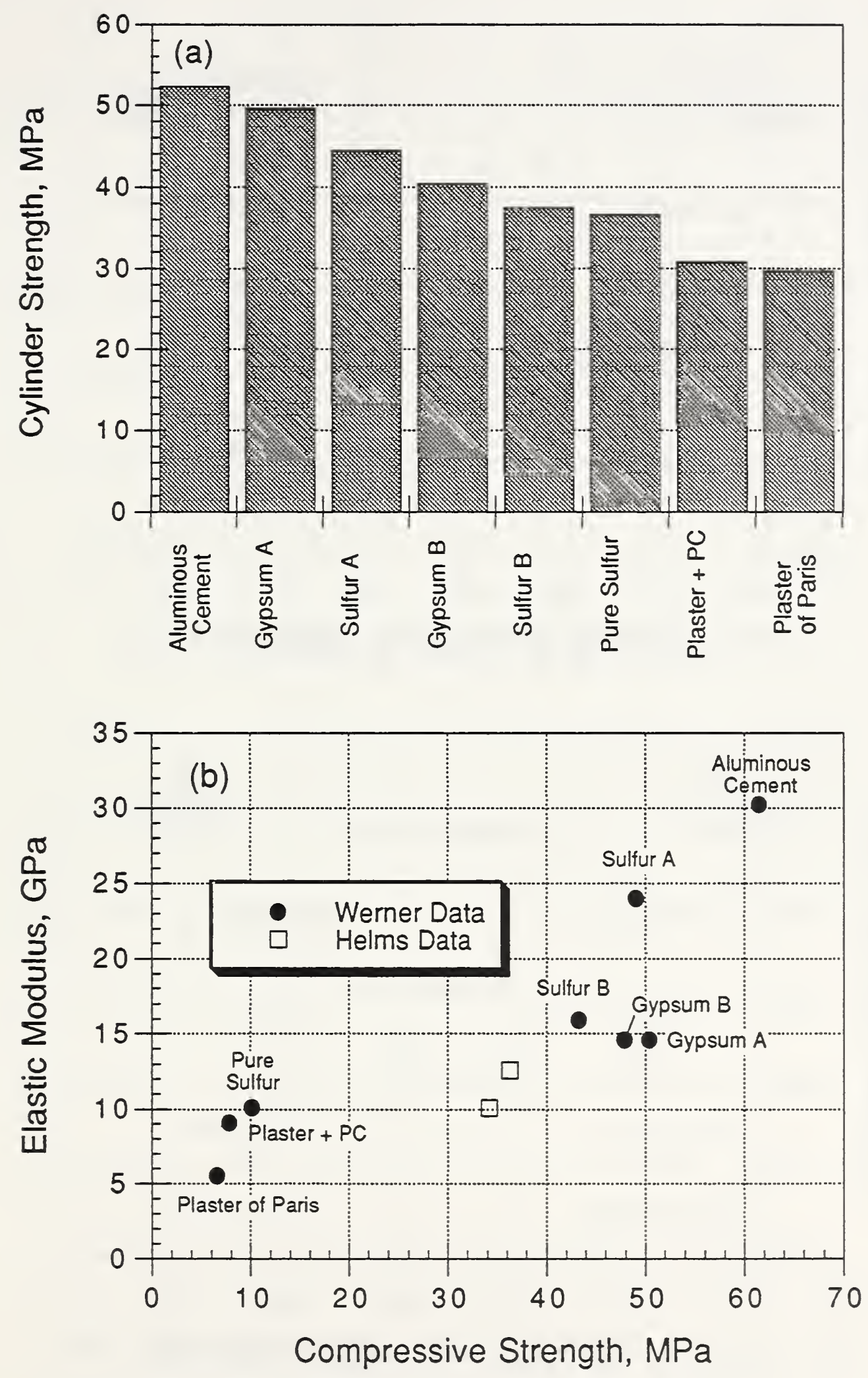

Figure 1.4 - (a) Average cylinder strength for different capping materials (Werner 1958); (b) modulus of elasticity and compressive strength of capping materials (Werner 1958) 

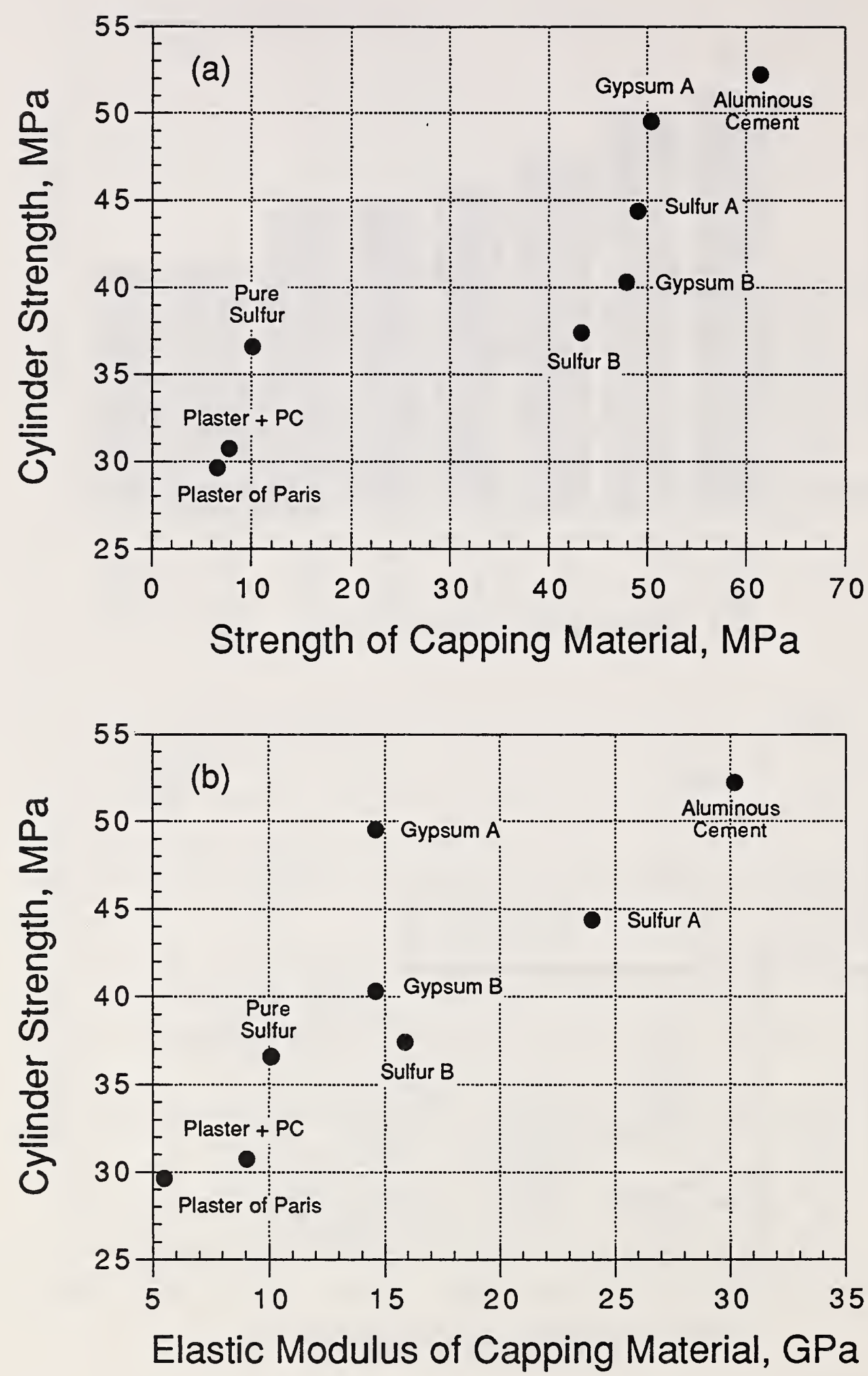

Figure 1.5 - (a) Cylinder strength as a function of strength of capping material; (b) cylinder strength as a function of elastic modulus of capping materials (data from Werner 1958) 

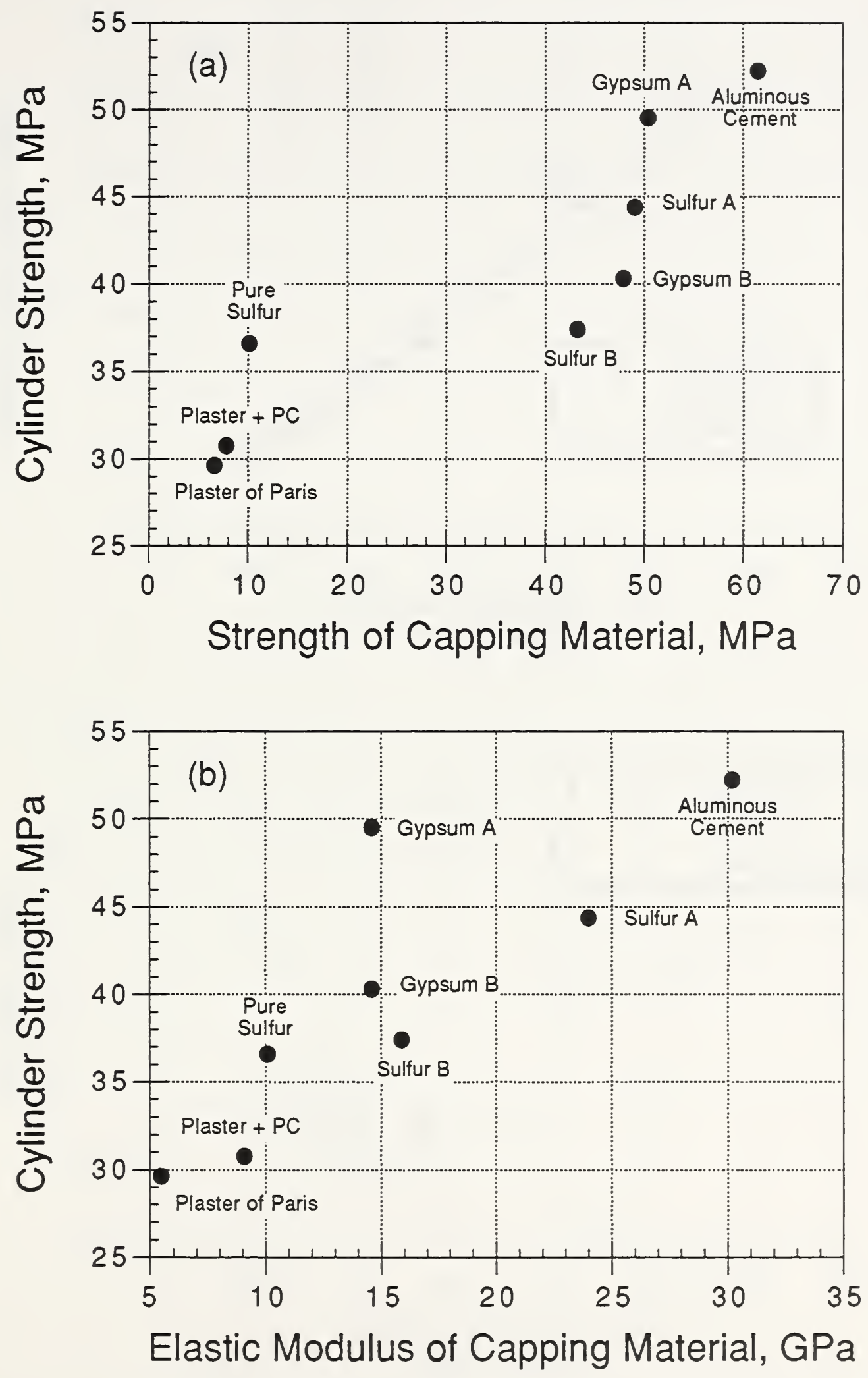




Figure 1.6 - (a) Comparison of compressive strength obtained with unbonded pad-caps and sulfur caps; (b) ratio of strengths as a function of strength level of concrete (data from Carrasquillo and Carrasquillo 1988b) 

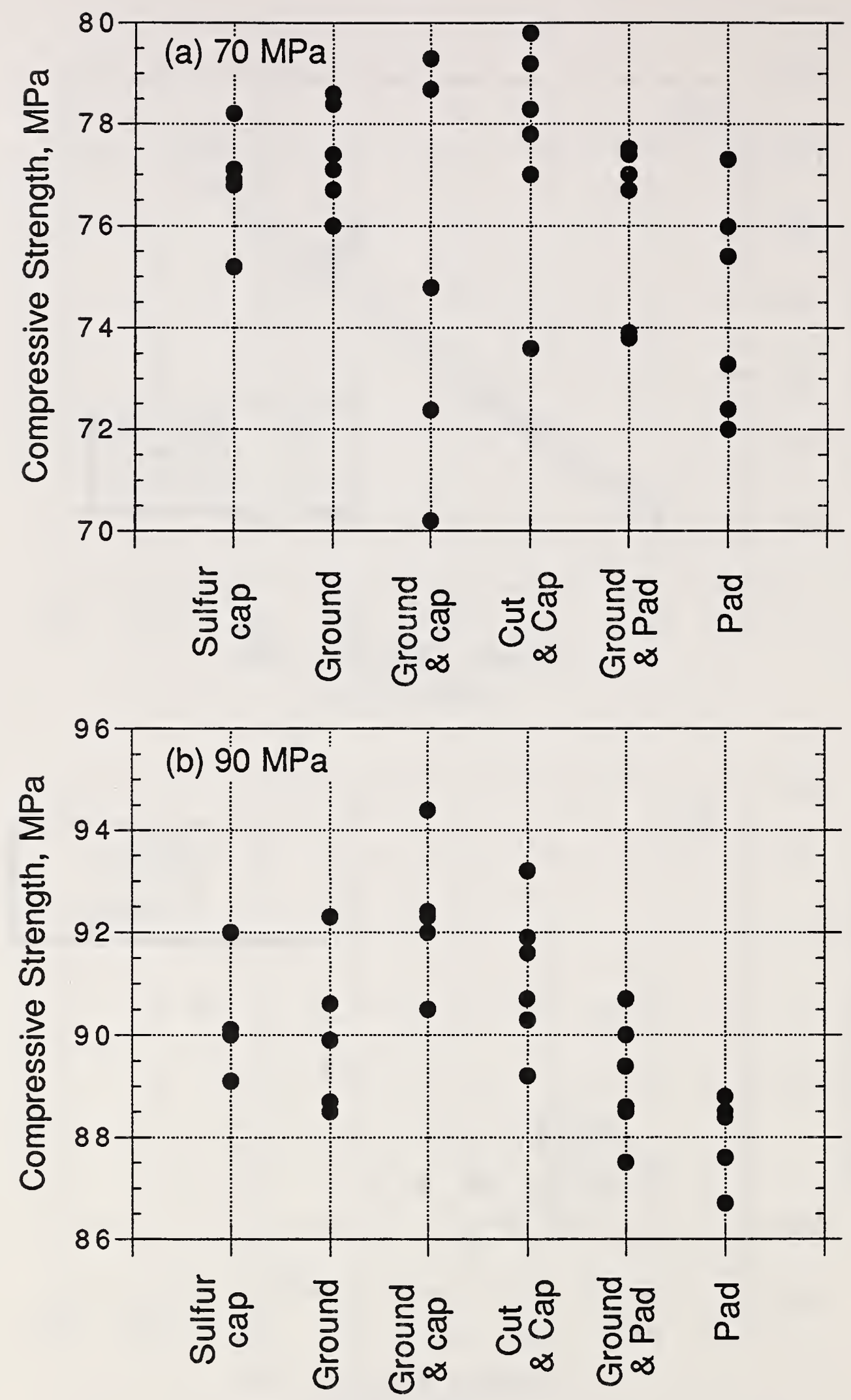

Figure 1.7 - Compressive strength of 150-mm diameter cylinders as a function of capping methods: (a) 70-MPa concrete and (b) 90-MPa concrete (data from Chojnaki and Read 1991) 

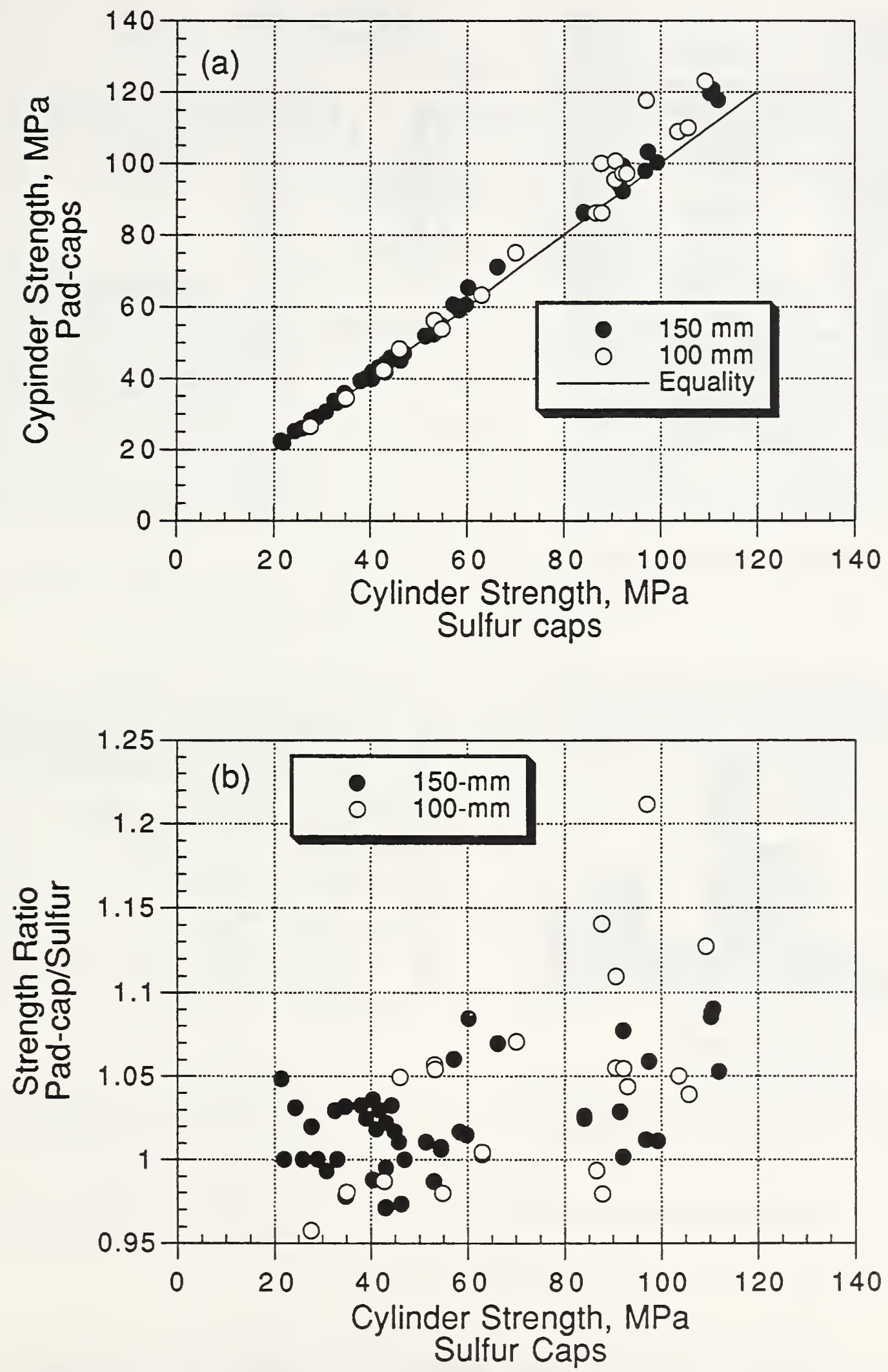

Figure 1.8 - (a) Comparison of compressive strength obtained with unbonded pad-caps and sulfur caps; (b) ratio of strengths as a function of strength level of concrete (data from Pistelli and Willems 1993) 

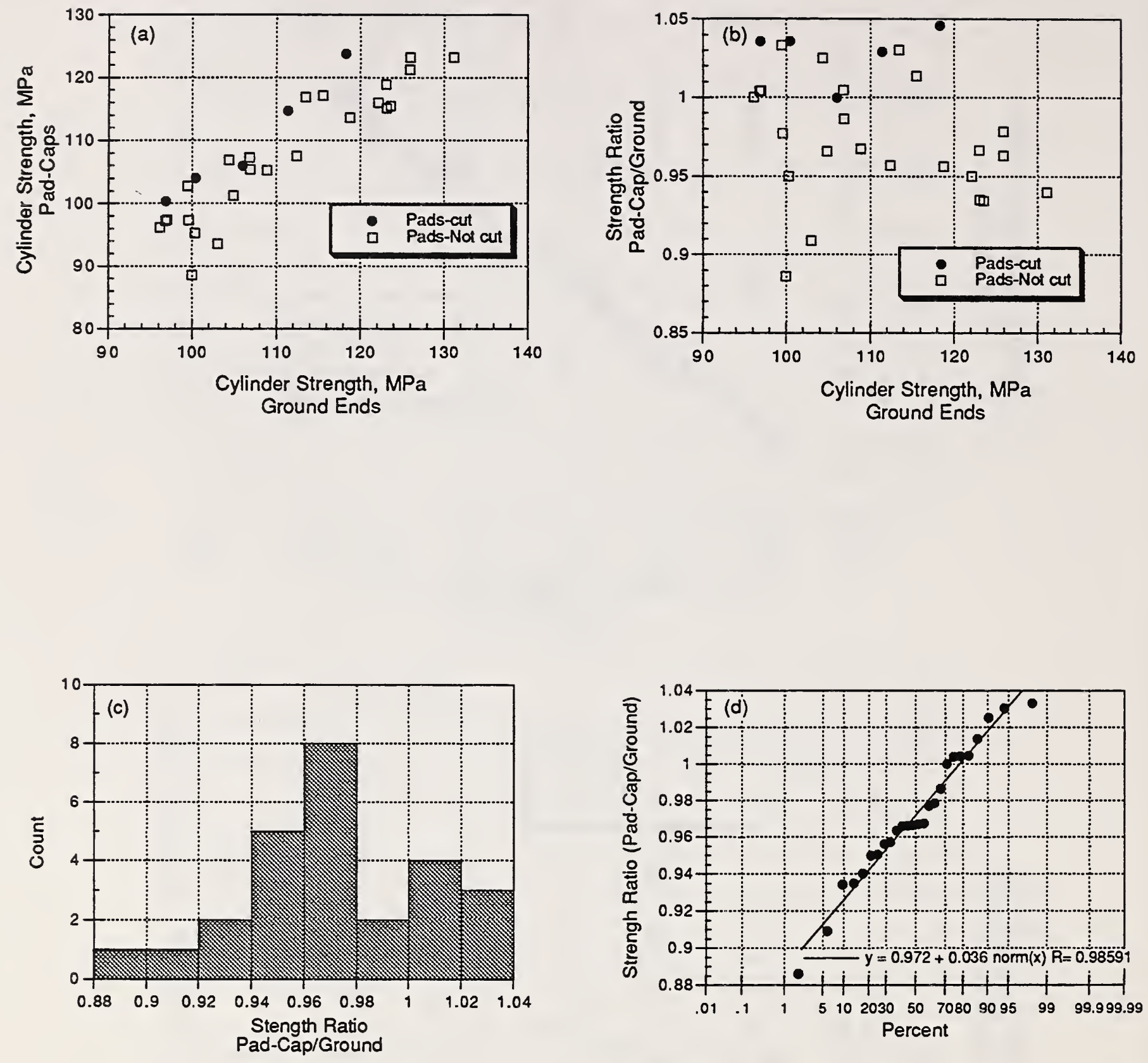

Figure 1.9 - (a) Strengths using pad-caps compared with strength using ground ends; (b) ratio of strengths using pad-caps to strength using ground ends as a function of strength level; (c) histogram of strength ratios; and (d) normal probability plot of strength ratios (data from Pistelli and Willems 1993) 


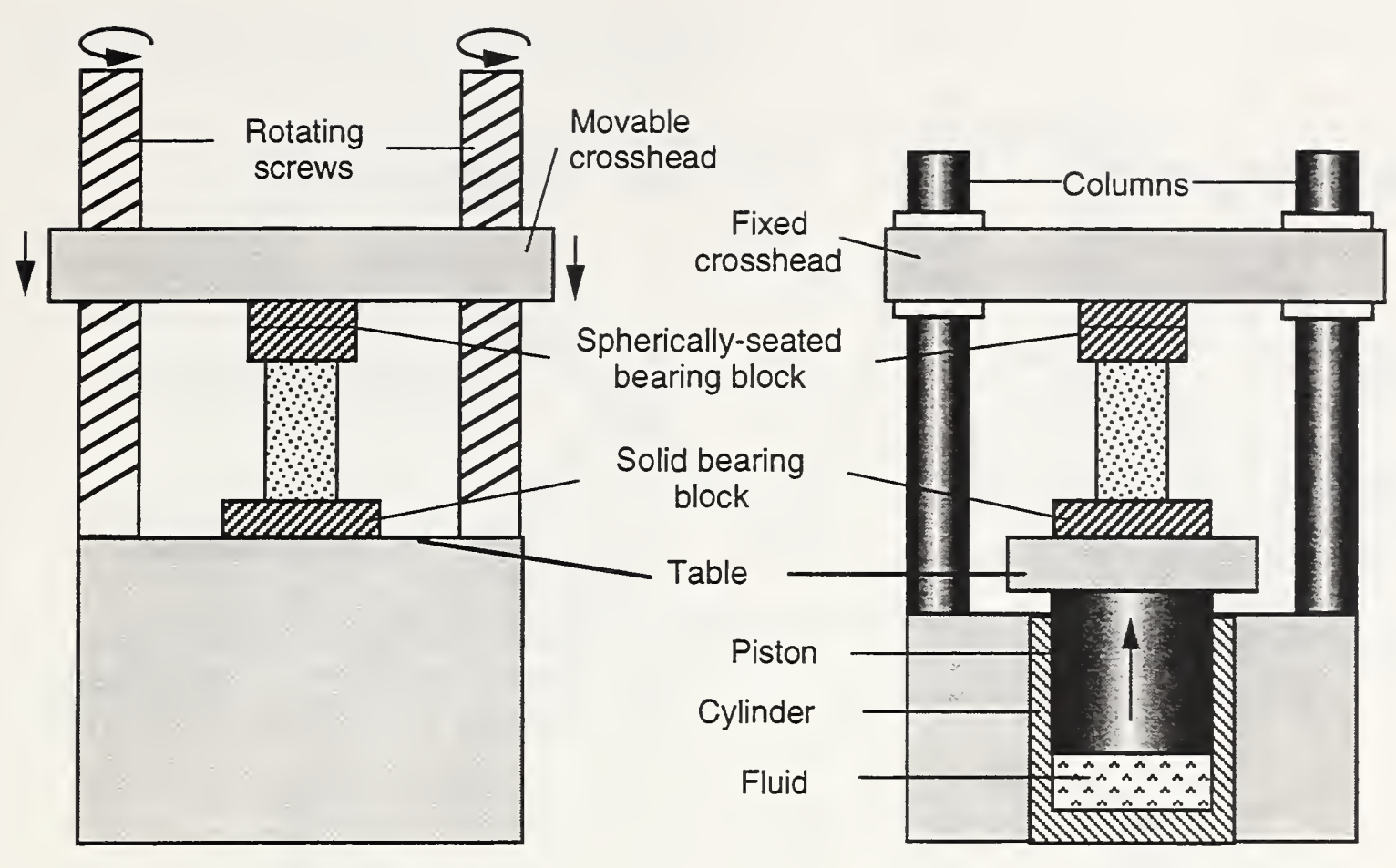

(a) Screw-type

(b) Hydraulically-operated

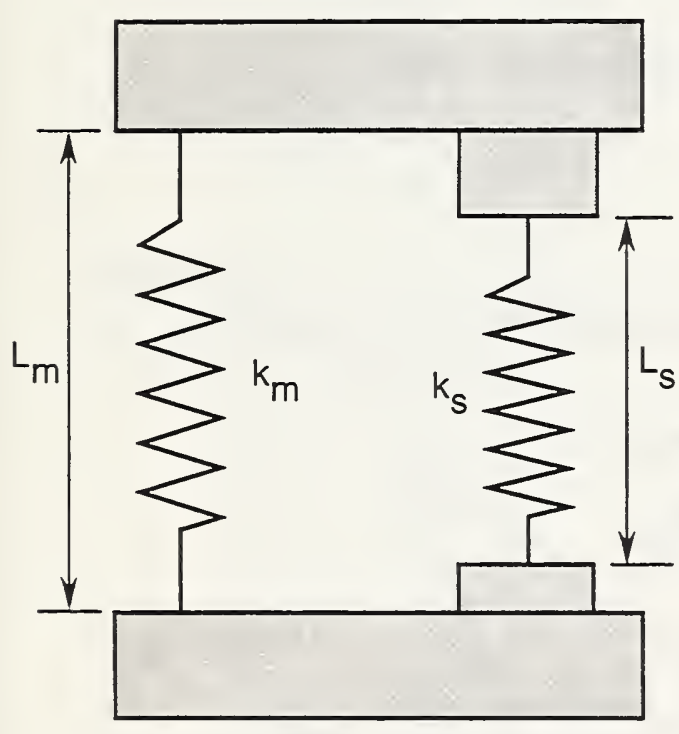

(c) Spring model of testing machine and test specimen

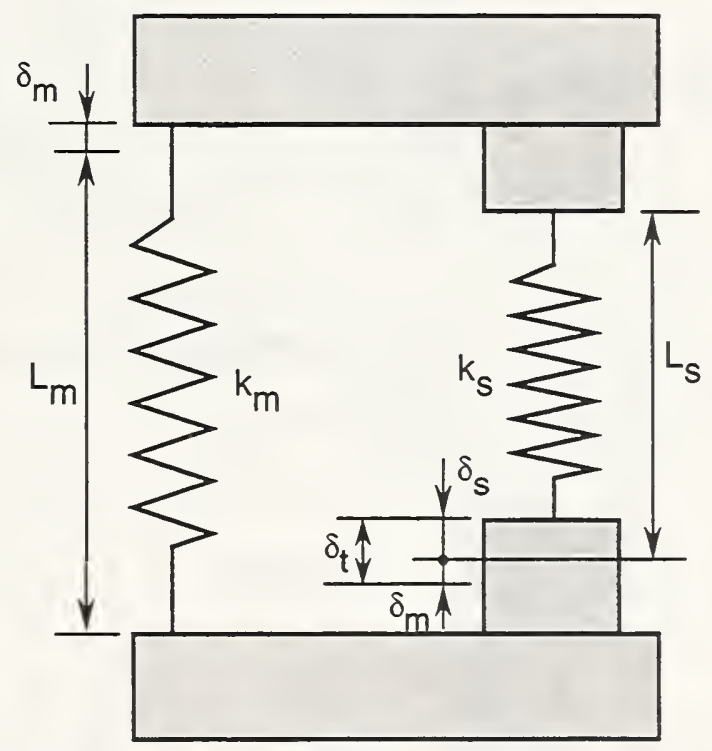

(d) Deformations during test

Figure 1.10 - Schematics of (a) screw-type and (b) hydraulically-operated testing machines; (c) simplified spring model of specimen and testing machine (L'Hermite 1954; Sigvaldason 1966a); and (d) deformations of specimen and testing machine 
(a) "hard" testing machine

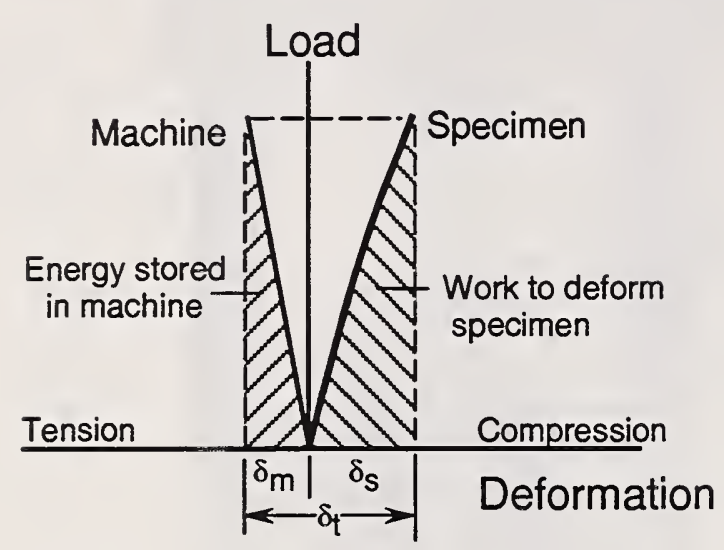

(c) "hard" testing machine

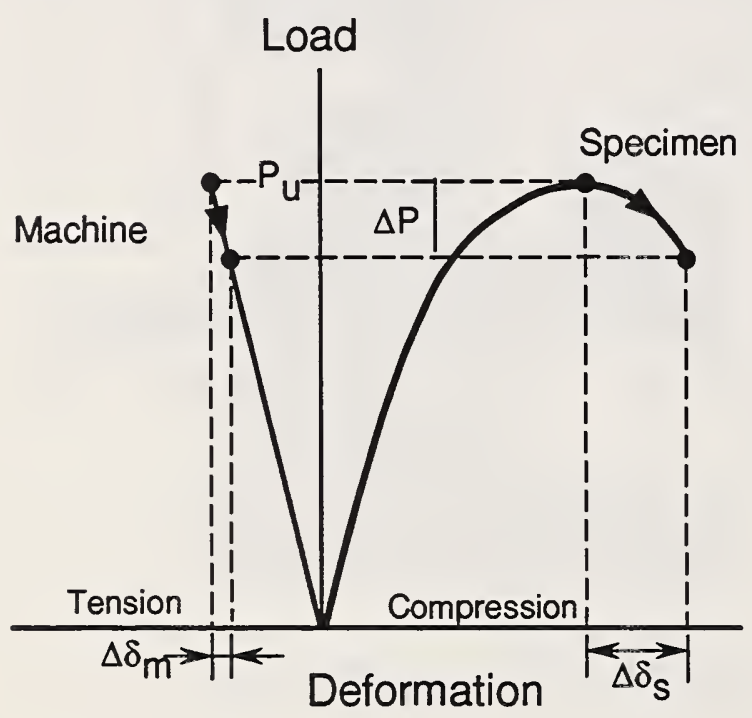

(b) "soft" testing machine

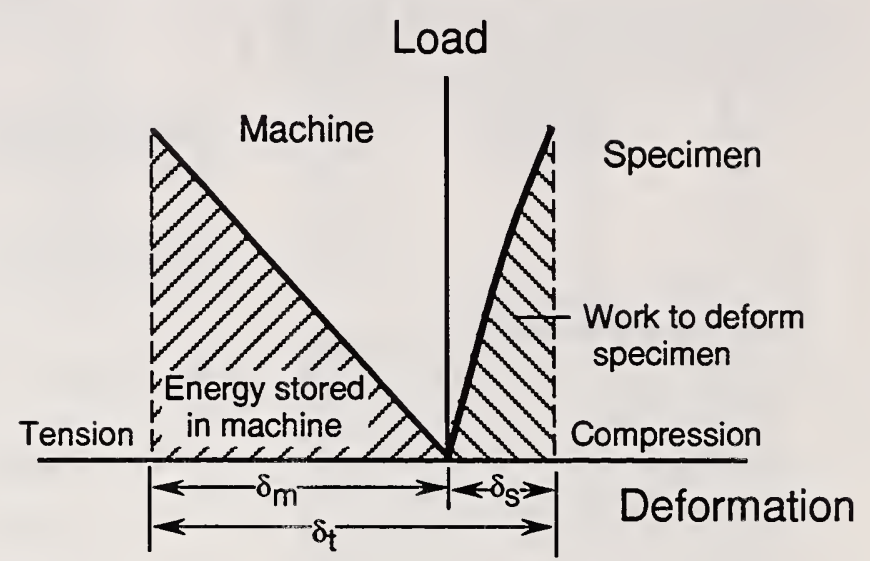

(d) "soft" testing machine

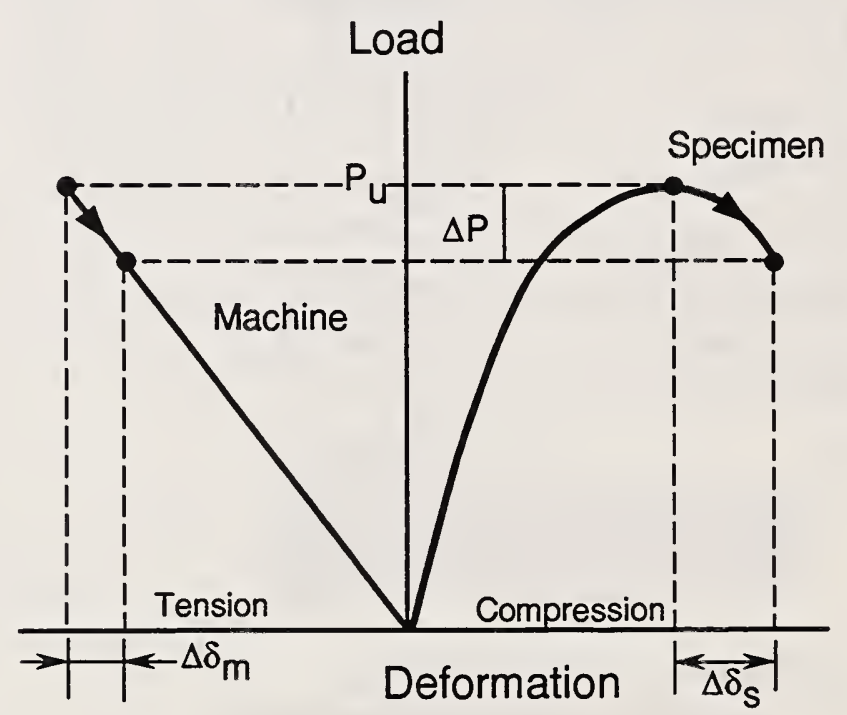

Figure 1.11 - Deformations of specimen and testing machine during loading: (a) using hard machine and (b) using soft machine; deformations beyond ultimate load: (c) using hard machine and (d) using soft machine 
(a) Released energy < Required work

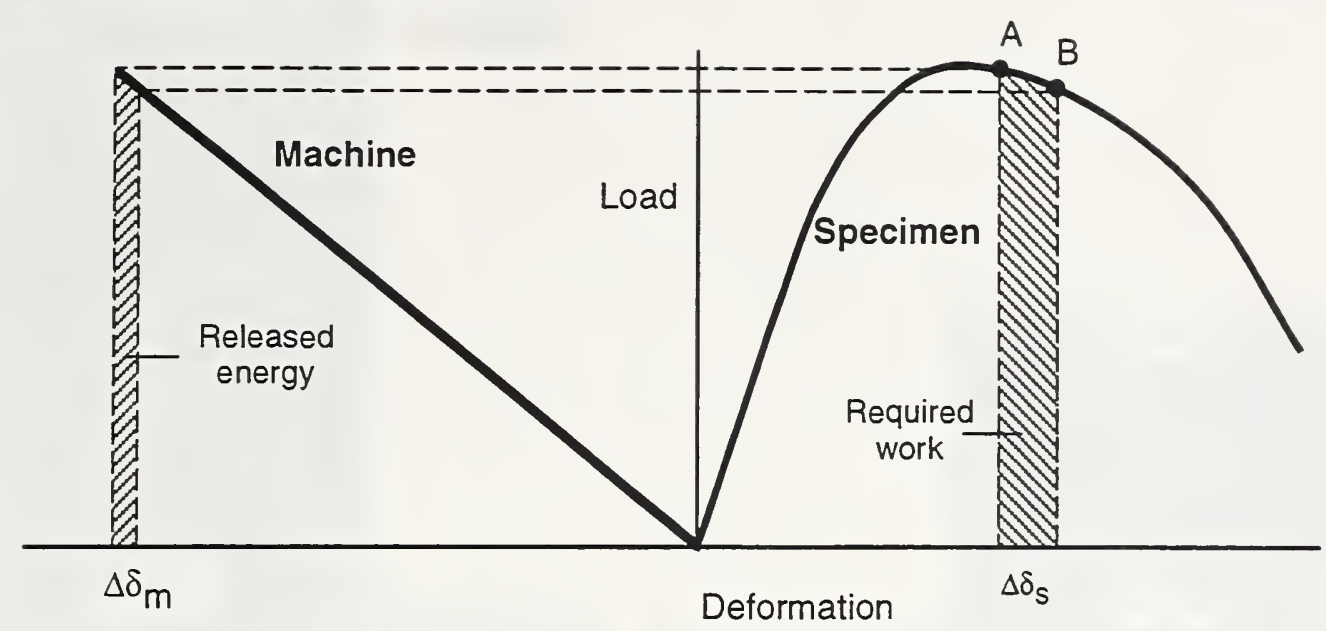

(b) Released energy < Required work

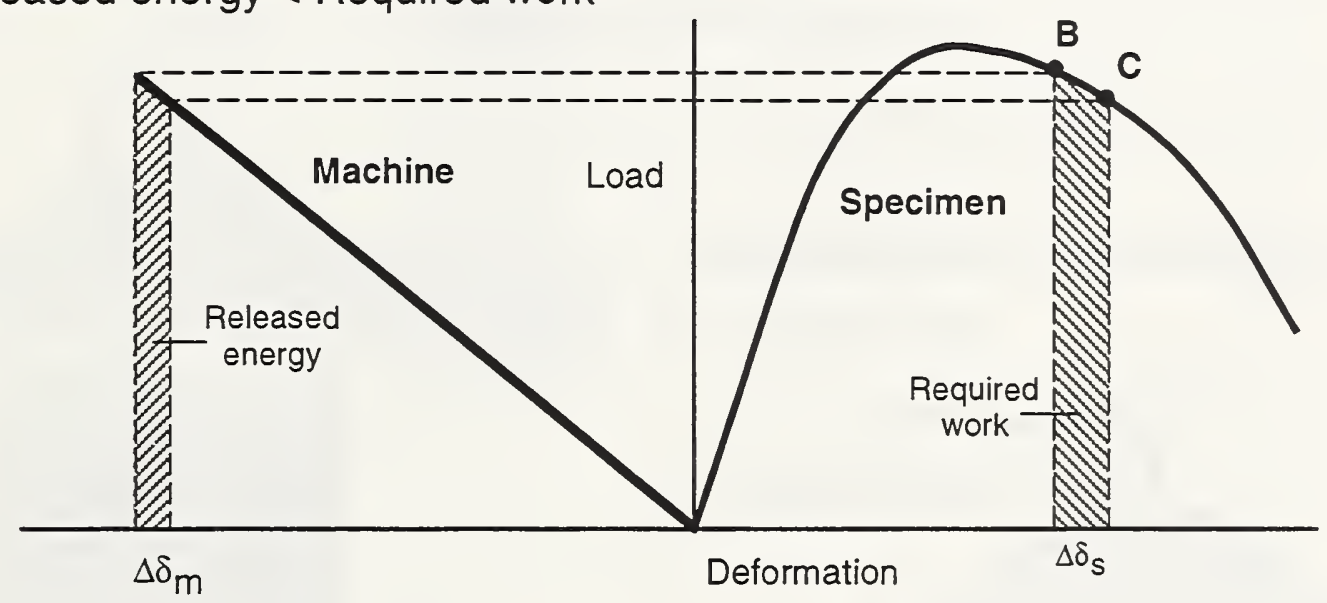

(c) Released energy = Required work; point of instability

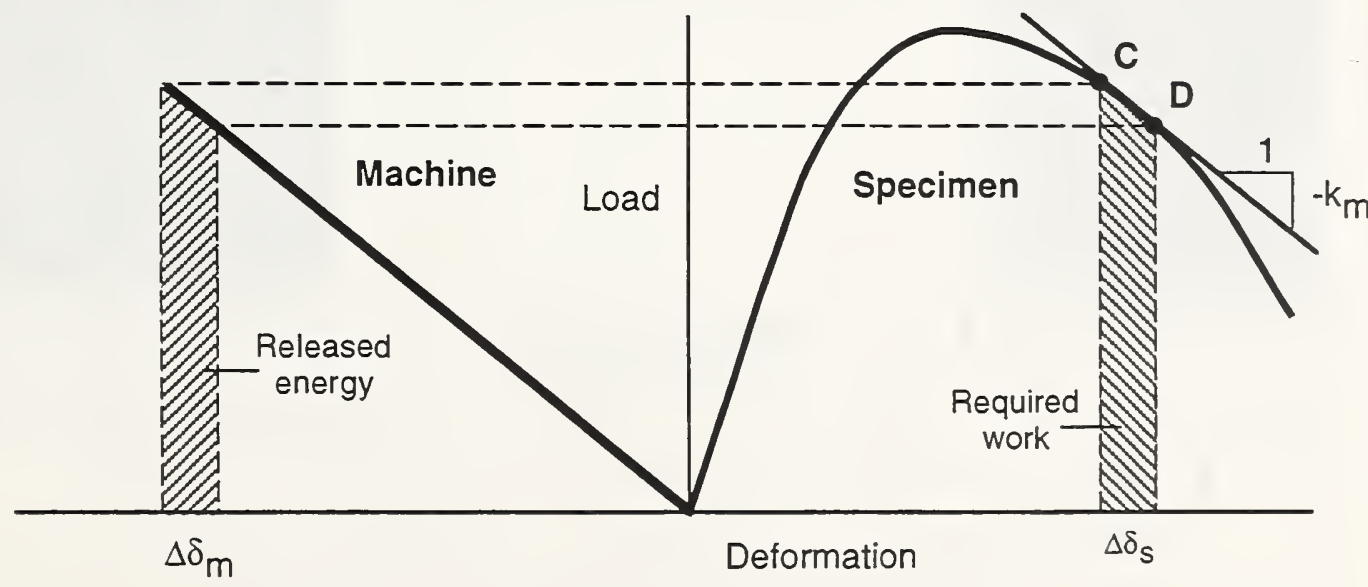

Figure 1.12 - Energy released by testing machine and work required to deform concrete specimens at different points along the descending portion of the load-deformation curve of specimen 
(a) Cast specimens

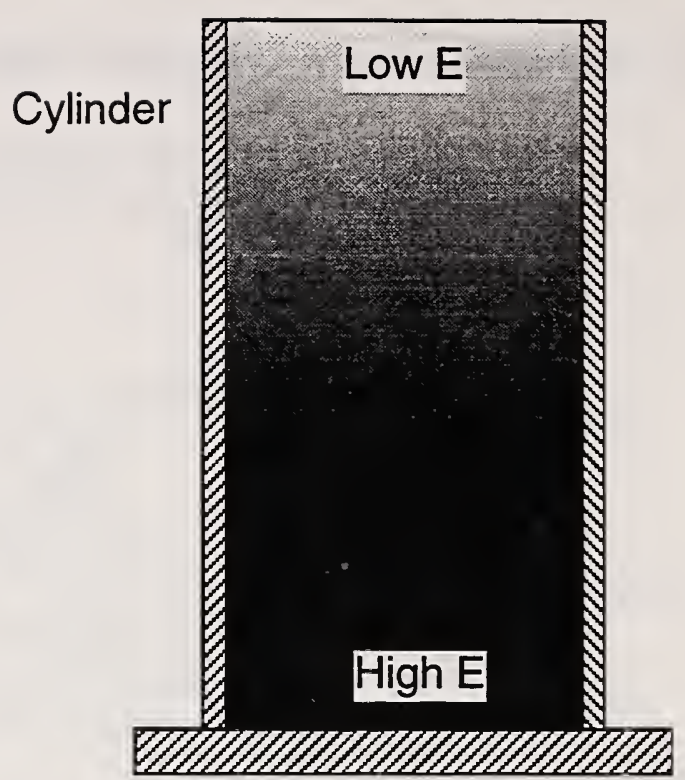

$E=$ Young's Modulus of Elasticity

(b) Specimens subjected to uniform deformation
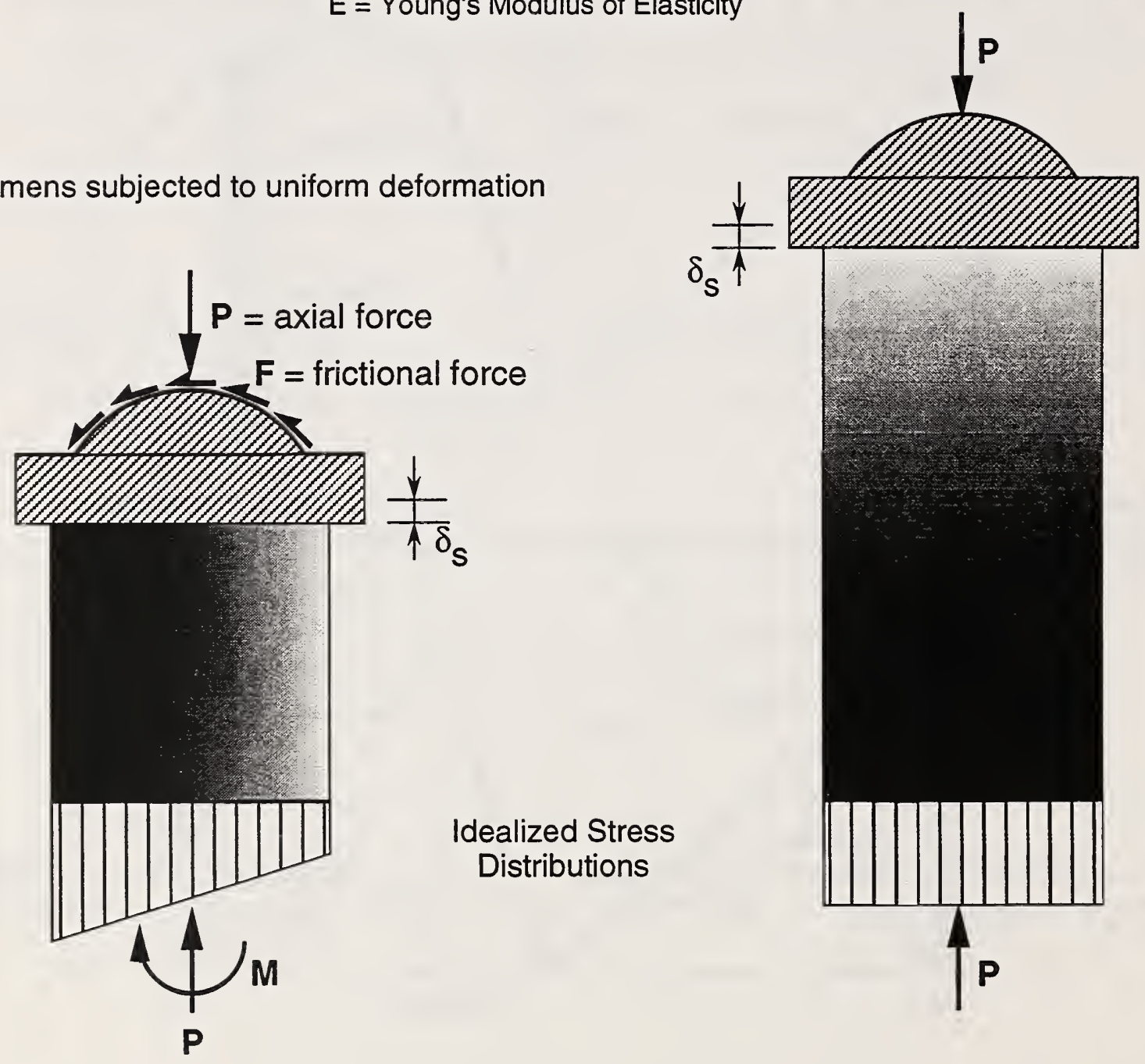

Figure 1.13 - Comparison of cube and cylinder specimens tested in compression 


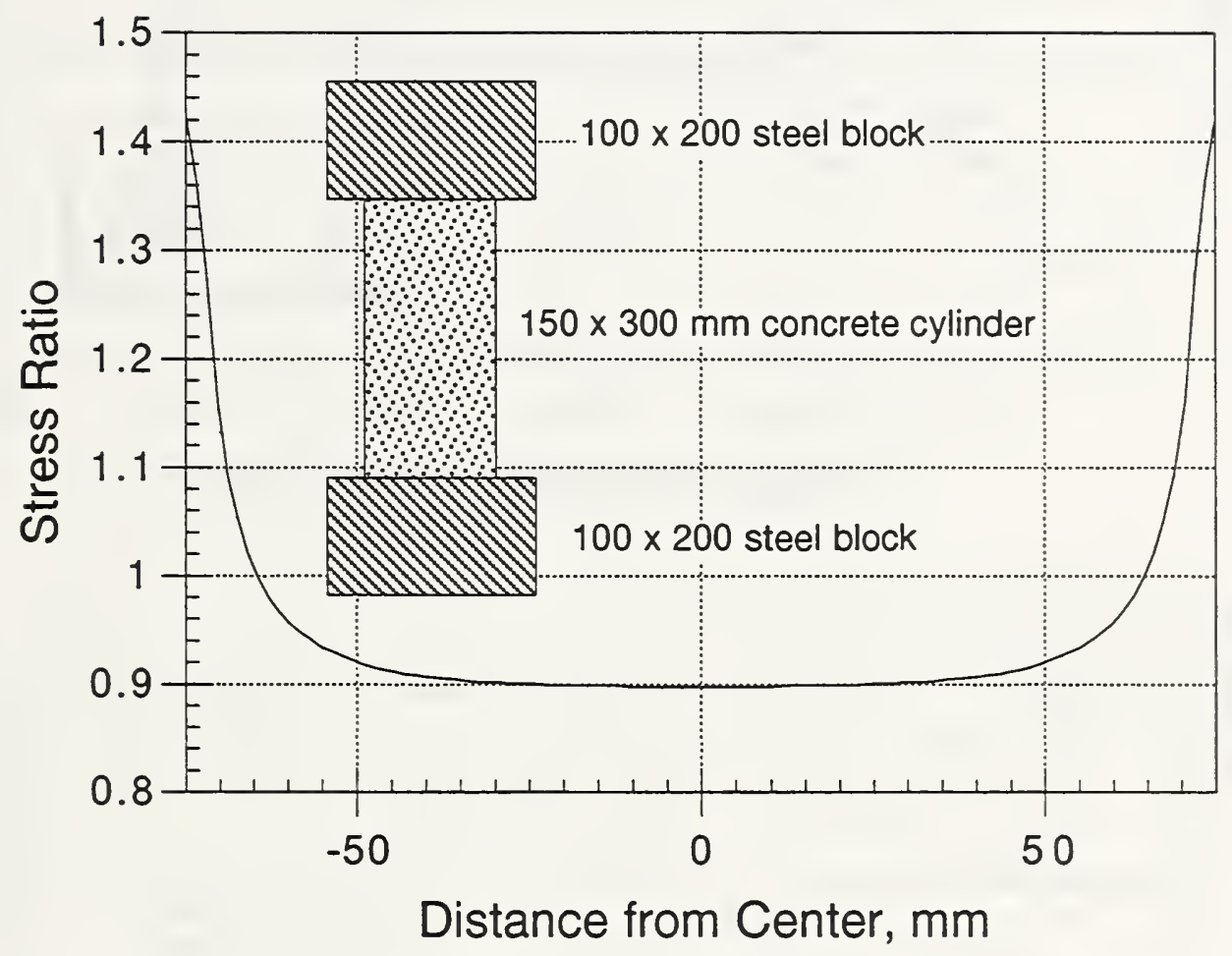

Figure 1.14 - Variation of normal stress at interface between concrete cylinder and steel bearing blocks based on finite-element analysis assuming linear-elastic behavior and a homogeneous specimen 

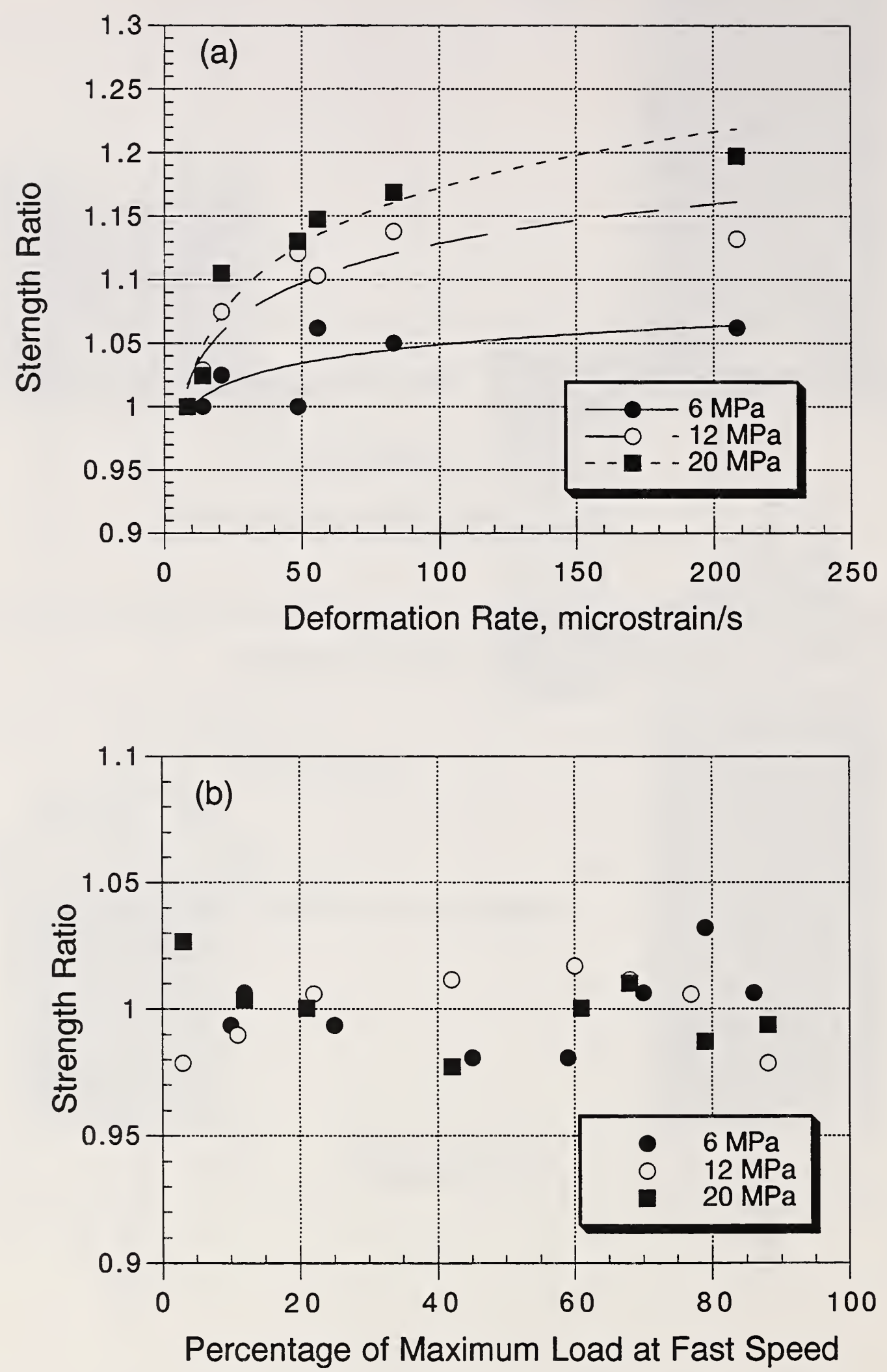

Figure 1.15 - (a) Variation of compressive strength with the deformation rate for three concrete strengths; (b) strength when specimens were loaded at fast rate to indicated portions of ultimate load (data from Abrams 1917) 

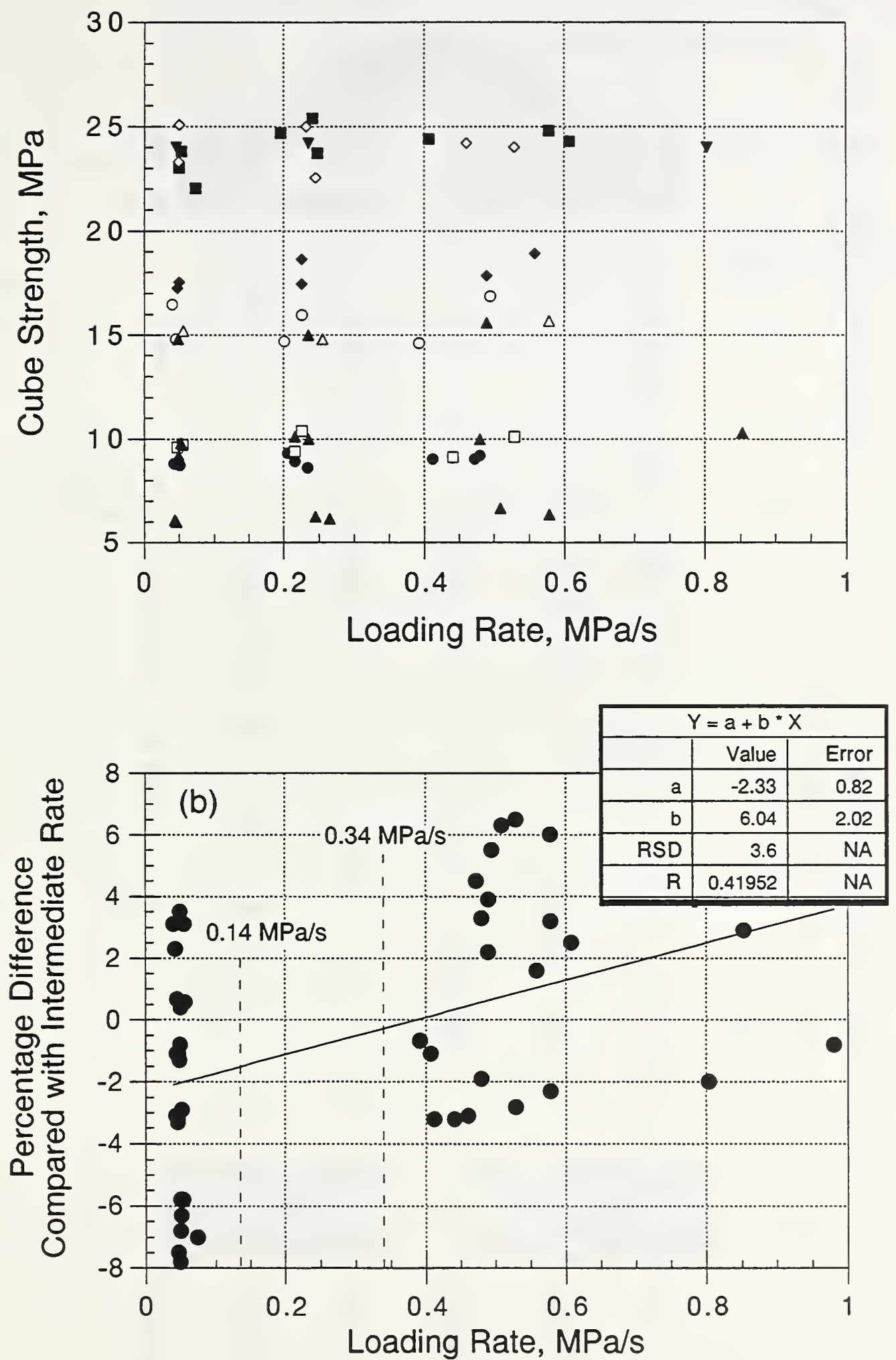

Figure 1.16 - Variation in compressive strength with the stress rate (data from Petkov 1964) 

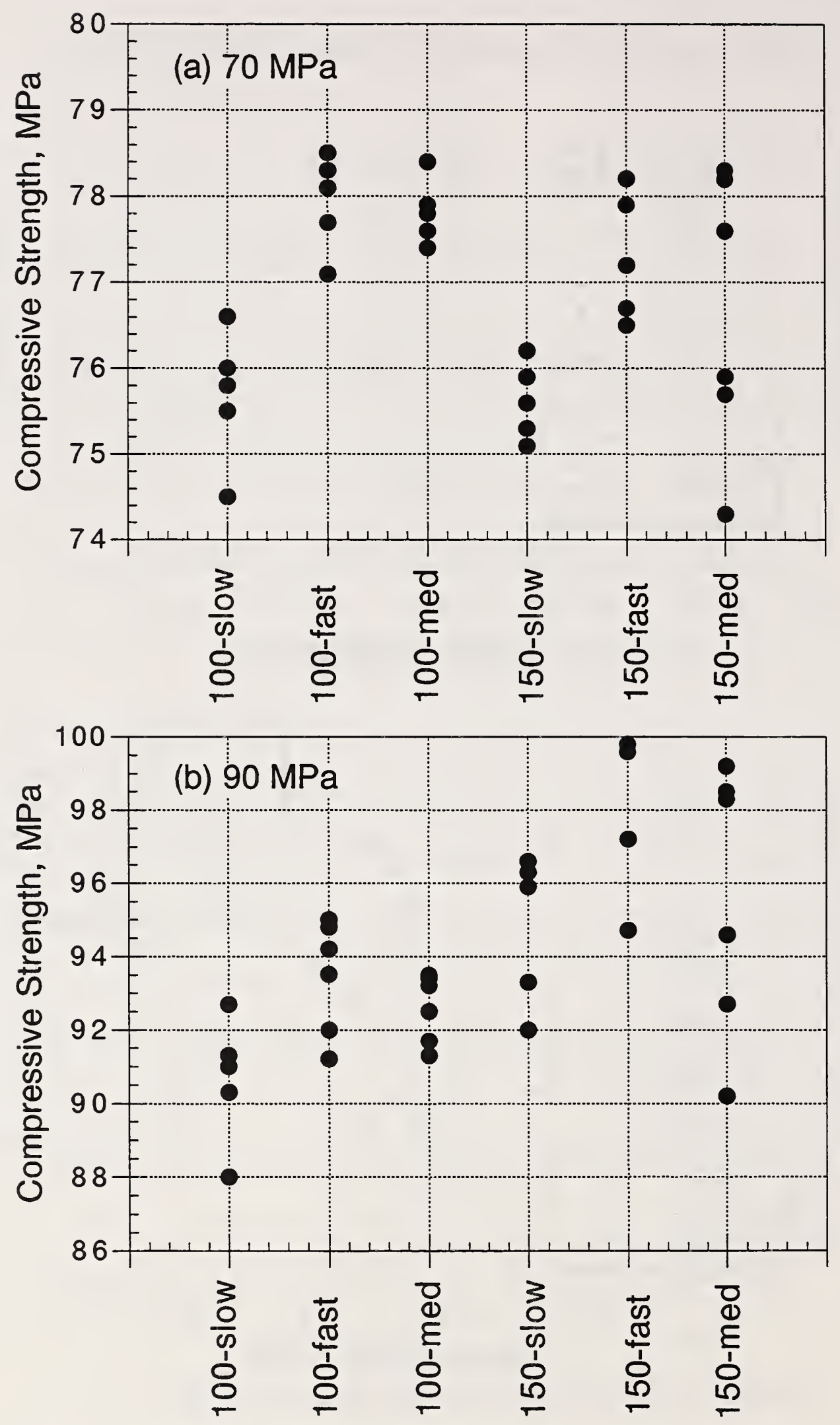

Figure 1.17 - Compressive strength as a function of loading rate and cylinder size (data from Chojnacki and Read 1991) 


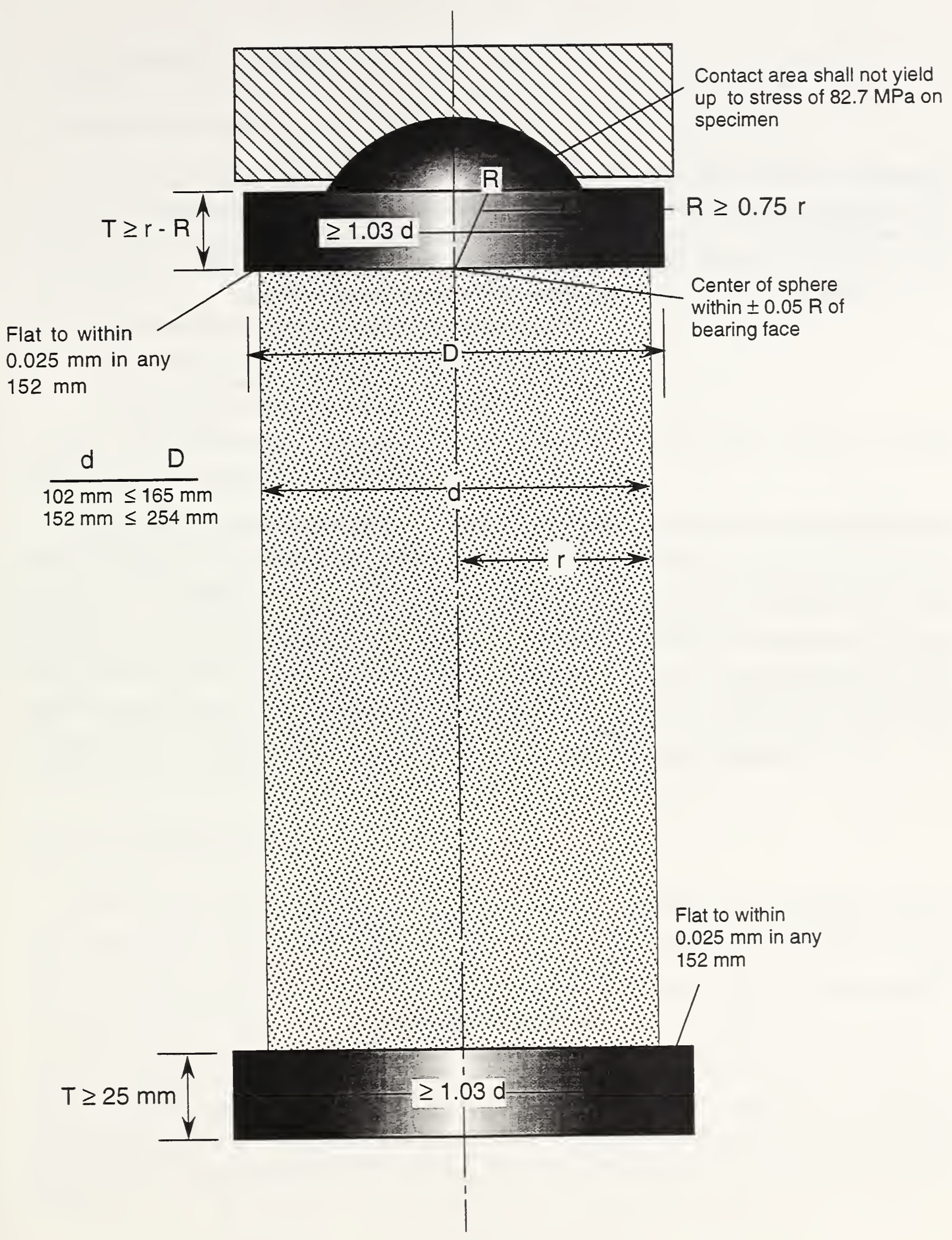

Figure 1.18 - Bearing block requirements in ASTM Test Method C 39-1993a 


\section{EXPERIMENTAL STUDY}

\subsection{Design of Experiment}

The previous chapter has discussed the factors that could affect the measured compressive strength of molded concrete cylinders. It would be a large task to undertake an examination of all the factors that would affect the measured strength of high-strength concrete. The scope of this study was, therefore, limited to examining the effects of key factors and any interactions that may exist among these factors. Based on the review, the following factors were selected for study:

- specimen size (100-mm versus $150-\mathrm{mm}$ diameter)

- end preparation (sulfur mortar versus grinding)

- testing machine (1.33-MN versus 4.45-MN capacity)

- loading rate $(0.14 \mathrm{MPa} / \mathrm{s}$ versus $0.34 \mathrm{MPa} / \mathrm{s})$

To detect whether there were interactions between these factors and strength level, two nominal strength levels were used: 45 and $90 \mathrm{MPa}$.

A full factorial experimental design was used with three replications for each combination of factors. Because it would not have been possible to test $150-\mathrm{mm}$ cylinders of the $90-\mathrm{MPa}$ concrete on the 1.33-MN capacity testing machine, a third mixture with a nominal strength of $65 \mathrm{MPa}$ was substituted. As a result, the strength factor was nested in the factors testing machine and size, and this made subsequent data analysis more complicated. The three replications were tested on different days (except for the 65-MPa cylinders as will be explained). Any differences due to day-to-day effects were accounted for by treating day as a blocking factor. Table 2.1 shows the 32 combinations of factors used. Each combination is identified by the run number. The different runs were tested in random order on different days as shown by the last three columns in Table 2.1.

\subsection{Concrete Mixtures}

Table 2.2 gives the proportions (absolute volume basis) of ingredients in the three mixtures. Physical properties of the ingredients are listed in Table 2.3, and aggregate gradations are given in Tables 2.4 and 2.5. The batch weights per cubic meter are given in Table 2.6. Due to the large number of specimens and the limited capacity of the laboratory mixer, more than one batch was required for each mixture. The batch sizes and the number of batches made for each mixture are listed at the bottom of Table 2.6. For each mixture, the batches were mixed consecutively and placed in a large pan, where they were combined manually with shovels. The time required to fill the mixer, mix the ingredients, and empty the mixer was approximately 10 minutes. Fresh concrete properties are given in Table 2.7. The air content was calculated using the volumetric method (ASTM C 138). Note that the 90-MPa mixture had a significantly higher air content than the other mixtures. 


\subsection{Preparation of Specimens}

The cylindrical specimens were prepared at the laboratory of the National Ready Mixed Concrete Association. Single-use, plastic molds were used. The molds were arranged in regular patterns within two empty curing tanks. The molds were filled in a random order to reduce the possibility of systematic specimen-to-specimen differences that could have occurred if the molds had been filled in a regular order. Following ASTM Practice C 192, the molds were filled in three layers, and each layer was rodded 25 times. After each layer had been rodded, the sides of the molds were struck 10 to 15 times with the tamping rod to close any holes left by the rod and to eliminate large air bubbles. The times required to mold all the specimens were as follows:

- 30 minutes for the 45-MPa mixture,

- 15 minutes for the 65-MPa mixture, and

- 25 minutes for the $90-\mathrm{MPa}$ mixture.

Figure 2.1 shows the arrangement of cylinders in the unfilled curing tanks. The numbers correspond to the run numbers given in Table 2.1. The specimens to be tested on the same day were grouped at random in different portions of the tanks. Cylinders identified with letters $G$ or $S$ were extra specimens in case of problems with the primary specimens. After the top surfaces of the cylinders had been troweled, the curing tanks were filled with water until the tops of the cylinders were submerged. The approximate time from the mixing of the mixtures until the cylinders were covered with water was about one hour for the $45-\mathrm{MPa}$ and $90-\mathrm{MPa}$ mixtures and about two hours for the 65-MPa mixture. The water served two purposes: (1) to provide moisture for curing and (2) to moderate any temperature differences between the $100-\mathrm{mm}$ and $150-\mathrm{mm}$ cylinders during the early stages of hydration. Thermocouples were placed in one cylinder of each size for each mixture, and thermocouples were placed in the water. The thermocouples were read by a datalogger at five minute intervals and the data were transferred to a computer for subsequent plotting. Figure 2.2 shows the recorded temperature histories. The initial temperature drop was due to the addition of water that was colder than wanted because of a heater malfunction. The rise in temperature at about six hours was due to the addition of warm water to raise the bath temperature. The differences between the early-age temperature histories of the two sizes of cylinders were minor. The acceleratory period of hydration for each mixture is shown as the time when the cylinder temperatures rose above the water temperature. Note that the temperature rise of the $90-\mathrm{MPa}$ mixture did not begin until the next day. Apparently, the large dosage of high range water-reducer had a significant retarding effect on the $90-\mathrm{MPa}$ mixture.

The cylinders were kept under water in their molds for two days, then they were stripped and returned to the curing tanks. On the fifth day, the cylinders were removed from the tanks, their surfaces were wiped with cloths, and they were weighed first in air and then submerged in water. The specific gravities of the specimens were calculated from the two weighings. After weighing, the diameters were measured along two perpendicular directions at the midheight, and the cylinders were placed in a moist room for subsequent curing.

On the 19th day, the cylinders were moved to NIST for end preparation and subsequent strength testing. The specimens were stored under water except during the end preparation (capping or grinding) phase, during which time they were kept under moistened burlap while awaiting end 
preparation. Before capping, the heights and longitudinal resonant frequencies were measured. Resonant frequencies were measured by the impact-resonance method (ASTM C 215). For the cylinders with ground ends, heights and resonant frequencies were measured after grinding, which was accomplished by using a surface grinder produced by the Blanchard Machine Co. ${ }^{j}$

To assure uniform sulfur cap thicknesses, the heights of the cylinders were measured before and after each cap was applied. Differences in height represented the nominal cap thickness. If the nominal thickness exceeded $4 \mathrm{~mm}$, the cap was removed and a new one was applied. Before testing, a dial gage and a measuring bridge were use to ensure that the caps were flat to within $0.025 \mathrm{~mm}$ measured across two diameters (see Fig. 2.3).

\subsection{Testing Procedures}

The 4.45-MN testing machine is a servo-controlled, hydraulically-operated machine that allows a constant rate of piston travel during the test. A series of preliminary tests was required to find the rates of piston travel that would result in the low and fast loading rates of $0.14 \mathrm{MPa} / \mathrm{s}$ and $0.34 \mathrm{MPa} / \mathrm{s}$ for the two cylinder sizes. Based on these preliminary tests, the rates shown in Table 2.8 were used to control the testing speed. The rate of piston travel was maintained constant throughout the test, that is, the first half of the test was not done at a faster loading rate as allowed by ASTM C 39. The time histories of the piston position and the compressive load were recorded on a computer.

The 1.33-MN testing machine is a hydraulically-operated machine with a pacer dial to help in manual control of the loading rate. To perform a test, the hydraulic needle valve was opened until the load indicator moved at the same speed as the pacer dial. Once the correct loading rate was achieved, the needle valve was not touched as the ultimate load of each specimen was being approached. To have an indication of the rate of specimen deformation during testing, a displacement transducer was used to measure the change in distance between the top of the piston and the machine crosshead (see Fig. 2.4). The time history of the transducer output was recorded by a computer equipped with a data acquisition board. The load history was recorded by using a pressure transducer connected to the hydraulic weighing system of the testing machine.

Figure 2.5(a) shows an example of the recorded histories of stress versus time and piston position versus time for the 4.45-MN machine. The stress history is represented by the curve with the open circles and the piston position is represented by the curve with the solid circles. Note that the piston position is a linear function of time because that is the method used to control the loading rate. The stress-history is nonlinear at the beginning of the test and when the ultimate load is being reached. Between these two extremes, the stress increases approximately linearly with time. A bestfit line was fitted to the straight-line portion of the stress history, and the value of the slope

${ }^{\mathrm{j} C e r t a i n}$ trade names and company products are mentioned in the text to adequately specify the experimental procedure. In no case does such identification imply recommendation or endorsement by the National Institute of Standards and Technology, nor does it imply that the products are necessarily the best available for the purpose. 
represents the nominal stress rate for the test. The particular case in Fig. 2.5(a) was Run \#31 (day 1) and the stress rate was about $0.14 \mathrm{MPa} / \mathrm{s}$.

Figure 2.5(b) shows an example of the recorded data for a test on the 1.33-MN machine. The stress-history is shown by the curve with open circles, and the relative movement between piston and crosshead is shown by the curve with solid circles. The stress-history and movement-history are both nonlinear at the beginning and the end of the test. A straight-line was fitted to the middle portion of the stress-history to obtain the nominal stress rate for the test. The case in Fig. 2.5(b) is Run \#14 (day 1), and the stress rate was $0.35 \mathrm{MPa} / \mathrm{s}$. Note that as the ultimate load is being reached, there is an increase in the rate of relative movement between the piston and the crosshead. This means that the deformation rate of the specimen increases as the ultimate load is being reached. The significance of this deformation behavior is discussed in Chapter 4.

The original plan was to test replicate specimens of each run at ages of 27, 28, and 29 days. However, preliminary tests at 14 days showed that the cylinders for the $65-\mathrm{MPa}$ mixture were close to the anticipated 28-day strength. There was concern that at 28-days, the $65-\mathrm{MPa}$ cylinders would be too strong to test on the 1.33-MN machine. Therefore, all the 65-MPa cylinders were tested at an age of 20 days. The cylinders scheduled for testing on "day 1" were tested first, followed by the cylinders scheduled for "day 2" and "day 3". Although the 65-MPa cylinders were tested on the same day, to simplify subsequent data analysis, the measured strengths were treated as though they were obtained on three separate days. 
Table 2.1 - Experimental design and testing sequence of replications

\begin{tabular}{|c|c|c|c|c|c|c|c|c|}
\hline \multirow{2}{*}{$\begin{array}{l}\text { Run } \\
\text { Number }\end{array}$} & \multirow{2}{*}{$\begin{array}{c}\text { Nominal } \\
\text { Strength, } \\
\mathrm{MPa}\end{array}$} & \multirow{2}{*}{$\begin{array}{c}\text { Cylinder } \\
\text { Diameter, } \\
\mathrm{mm}\end{array}$} & \multirow{2}{*}{$\begin{array}{c}\text { End } \\
\text { Preparation }\end{array}$} & \multirow{2}{*}{$\begin{array}{c}\text { Testing } \\
\text { Machine, } \\
\text { MN }\end{array}$} & \multirow{2}{*}{$\begin{array}{l}\text { Load } \\
\text { Rate }\end{array}$} & \multicolumn{3}{|c|}{ Test Sequence } \\
\hline & & & & & & Day 1 & Day 2 & Day 3 \\
\hline 1 & 45 & 100 & Sulfur & 1.33 & Slow & 24 & 30 & 13 \\
\hline 2 & 45 & 100 & Sulfur & 1.33 & Fast & 16 & 1 & 28 \\
\hline 3 & 45 & 100 & Sulfur & 4.45 & Slow & 9 & 25 & 27 \\
\hline 4 & 45 & 100 & Sulfur & 4.45 & Fast & 30 & 21 & 9 \\
\hline 5 & 45 & 100 & Grind & 1.33 & Slow & 31 & 32 & 18 \\
\hline 6 & 45 & 100 & Grind & 1.33 & Fast & 21 & 12 & 30 \\
\hline 7 & 45 & 100 & Grind & 4.45 & Slow & 1 & 31 & 4 \\
\hline 8 & 45 & 100 & Grind & 4.45 & Fast & 17 & 19 & 32 \\
\hline 9 & 45 & 150 & Sulfur & 1.33 & Slow & 8 & 24 & 16 \\
\hline 10 & 45 & 150 & Sulfur & 1.33 & Fast & 12 & 14 & 20 \\
\hline 11 & 45 & 150 & Sulfur & 4.45 & Slow & 7 & 13 & 3 \\
\hline 12 & 45 & 150 & Sulfur & 4.45 & Fast & 13 & 17 & 29 \\
\hline 13 & 45 & 150 & Grind & 1.33 & Slow & 18 & 5 & 31 \\
\hline 14 & 45 & 150 & Grind & 1.33 & Fast & 23 & 10 & 6 \\
\hline 15 & 45 & 150 & Grind & 4.45 & Slow & 11 & 4 & 26 \\
\hline 16 & 45 & 150 & Grind & 4.45 & Fast & 28 & 15 & 1 \\
\hline 17 & 90 & 100 & Sulfur & 1.33 & Slow & 2 & 28 & 2 \\
\hline 18 & 90 & 100 & Sulfur & 1.33 & Fast & 15 & 29 & 22 \\
\hline 19 & 90 & 100 & Sulfur & 4.45 & Slow & 20 & 7 & 21 \\
\hline 20 & 90 & 100 & Sulfur & 4.45 & Fast & 10 & 8 & 19 \\
\hline 21 & 90 & 100 & Grind & 1.33 & Slow & 19 & 22 & 23 \\
\hline 22 & 90 & 100 & Grind & 1.33 & Fast & 5 & 3 & 12 \\
\hline 23 & 90 & 100 & Grind & 4.45 & Slow & 27 & 9 & 5 \\
\hline 24 & 90 & 100 & Grind & 4.45 & Fast & 29 & 23 & 25 \\
\hline 25 & 65 & 150 & Sulfur & 1.33 & Slow & 4 & 2 & 11 \\
\hline 26 & 65 & 150 & Sulfur & 1.33 & Fast & 26 & 6 & 17 \\
\hline 27 & 90 & 150 & Sulfur & 4.45 & Slow & 3 & 18 & 24 \\
\hline 28 & 90 & 150 & Sulfur & 4.45 & Fast & 22 & 20 & 10 \\
\hline 29 & 65 & 150 & Grind & 1.33 & Slow & 25 & 26 & 15 \\
\hline 30 & 65 & 150 & Grind & 1.33 & Fast & 32 & 11 & 8 \\
\hline 31 & 90 & 150 & Grind & 4.45 & Slow & 14 & 16 & 7 \\
\hline 32 & 90 & 150 & Grind & 4.45 & Fast & 6 & 27 & 14 \\
\hline
\end{tabular}

- Slow $=0.14 \mathrm{MPa} / \mathrm{s}$

Fast $=0.34 \mathrm{MPa} / \mathrm{s}$ 
Table 2.2 - Mixture proportions, percentage bulk volume basis

\begin{tabular}{|l|c|c|c|}
\hline \multicolumn{1}{|c|}{ Ingredient } & $\begin{array}{c}45 \mathrm{MPa} \\
\text { Mixture }\end{array}$ & $\begin{array}{c}65 \mathrm{MPa} \\
\text { Mixture }\end{array}$ & $\begin{array}{c}90 \mathrm{MPa} \\
\text { Mixture }\end{array}$ \\
\hline Cement, Type I & 10.3 & 14.3 & 16.0 \\
\hline Fly Ash, Type C & 0.0 & 0.0 & 4.0 \\
\hline Silica Fume, Dry-densified & 0.0 & 0.0 & 2.6 \\
\hline Water & 16.2 & 17.1 & 18.3 \\
\hline Fine Aggregate, Natural sand & 34.2 & 29.3 & 26.9 \\
\hline $\begin{array}{l}\text { Coarse Aggregate, Crushed } \\
\text { traprock }\end{array}$ & 37.3 & 37.3 & 30.2 \\
\hline Air, assumed & 2.0 & 2.0 & 2.0 \\
\hline
\end{tabular}

Table 2.3 - Physical properties of materials

\begin{tabular}{|l|c|}
\hline \multicolumn{1}{|c|}{ Property } & Value \\
\hline Fine Aggregate Bulk Specific Gravity (dry) & 2.586 \\
\hline Fine Aggregate Absorption, \% & 1.16 \\
\hline Coarse Aggregate ${ }^{*}$ Bulk Specific Gravity (dry) & 2.90 \\
\hline Coarse Aggregate Absorption, \% & 0.91 \\
\hline Coarse Aggregate Dry-rodded Unit Weight, $\mathrm{kg} / \mathrm{m}^{3}$ & $1719^{* *}$ \\
& $1712^{* * *}$ \\
\hline Cement Bulk Specific Gravity & 3.15 \\
\hline Fly Ash Bulk Specific Gravity & 2.25 \\
\hline Silica Fume Bulk Specific Gravity & 2.25 \\
\hline
\end{tabular}

"Nominal maximum size $=13 \mathrm{~mm}(1 / 2$ in.)

${ }^{* *}$ For $45-\mathrm{MPa}$ and $65-\mathrm{MPa}$ mixtures

${ }^{* * *}$ For $90-\mathrm{MPa}$ mixture 
Table $2.4-$ Coarse aggregate gradations

\begin{tabular}{|c|c|c|}
\hline \multirow{2}{*}{ Sieve Size } & \multicolumn{2}{|c|}{ Percentage Passing by Mass } \\
\cline { 2 - 3 } & 45 and 65 MPa Mixtures & 90 MPa Mixture \\
\hline $19 \mathrm{~mm}$ & $100 \%$ & $100 \%$ \\
\hline $12.5 \mathrm{~mm}$ & $63 \%$ & $100 \%$ \\
\hline $9.5 \mathrm{~mm}$ & $39 \%$ & $50 \%$ \\
\hline $4.75 \mathrm{~mm}$ & $0 \%$ & $0 \%$ \\
\hline
\end{tabular}

Table 2.5 - Fine aggregate gradations

\begin{tabular}{|c|c|c|}
\hline \multirow{2}{*}{ Sieve Size } & \multicolumn{2}{|c|}{ Percentage Passing by Mass } \\
\cline { 2 - 3 } & 45 and 65 MPa Mixtures & 90 MPa Mixture \\
\hline $4.75 \mathrm{~mm}$ & $95.7 \%$ & $96.0 \%$ \\
\hline $2.36 \mathrm{~mm}$ & $78.0 \%$ & $77.8 \%$ \\
\hline $1.18 \mathrm{~mm}$ & $59.0 \%$ & $56.8 \%$ \\
\hline $600 \mu \mathrm{m}$ & $30.7 \%$ & $27.2 \%$ \\
\hline $300 \mu \mathrm{m}$ & $8.9 \%$ & $4.9 \%$ \\
\hline $150 \mu \mathrm{m}$ & $3.0 \%$ & $0.8 \%$ \\
\hline $75 \mu \mathrm{m}$ & $1.4 \%$ & $0.2 \%$ \\
\hline
\end{tabular}


Table 2.6-Batch quantities per cubic meter

\begin{tabular}{|l|c|c|c|}
\hline & $\begin{array}{c}45 \mathrm{MPa} \\
\text { Mixture }\end{array}$ & $\begin{array}{c}65 \mathrm{MPa} \\
\text { Mixture }\end{array}$ & $\begin{array}{c}90 \mathrm{MPa} \\
\text { Mixture }\end{array}$ \\
\hline Cement $(\mathrm{kg})$ & 323 & 451 & 504 \\
\hline Fly Ash $(\mathrm{kg})$ & 0 & 0 & 89 \\
\hline Silica Fume $(\mathrm{kg})$ & 0 & 0 & 59 \\
\hline Coarse Aggregate $(\mathrm{kg})$ & 1093 & 1093 & 885 \\
\hline Fine Aggregate $(\mathrm{kg})$ & 895 & 764 & 704 \\
\hline Water $(\mathrm{kg})$ & 172 & 170 & 183 \\
\hline Water Reducer $(\mathrm{L})$ & 0 & 1.47 & 2.12 \\
\hline HRWR (L) & 0 & 2.65 & 17.01 \\
\hline W/(C+FA+SF) & 0.53 & 0.38 & 0.28 \\
\hline \hline Approximate batch size & $0.09 \mathrm{~m}^{3}$ & $0.06 \mathrm{~m}^{3}$ & $0.09 \mathrm{~m}^{3}$ \\
\hline Number of batches & 3 & 2 & 2 \\
\hline
\end{tabular}

Table 2.7 - Fresh concrete properties

\begin{tabular}{|c|c|c|c|c|}
\hline Mixture & Slump, $\mathrm{mm}$ & Unit Weight, $\mathrm{kg} / \mathrm{m}^{3}$ & Air Content, $\%$ & Temperature, ${ }^{\circ} \mathrm{C}$ \\
\hline $45 \mathrm{MPa}$ & 40 & 2456 & 2.2 & 19.5 \\
\hline $65 \mathrm{MPa}$ & 70 & 2496 & 1.4 & 19.5 \\
\hline $90 \mathrm{MPa}$ & 250 & 2356 & 4.9 & 20 \\
\hline
\end{tabular}

Table 2.8 - Rate of piston travel for 4.45 MN testing machine, $\mathrm{mm} /$ minute

\begin{tabular}{|c|c|c|c|c|}
\hline \multirow{2}{*}{$\begin{array}{c}\text { Cylinder size, } \\
\mathrm{mm}\end{array}$} & \multicolumn{2}{|c|}{$45 \mathrm{MPa}$} & \multicolumn{2}{c|}{$90 \mathrm{MPa}$} \\
\cline { 2 - 5 } & Slow & Fast & Slow & Fast \\
\hline 100 & 0.11 & 0.25 & 0.08 & 0.18 \\
\hline 150 & 0.14 & 0.33 & 0.11 & 0.27 \\
\hline
\end{tabular}




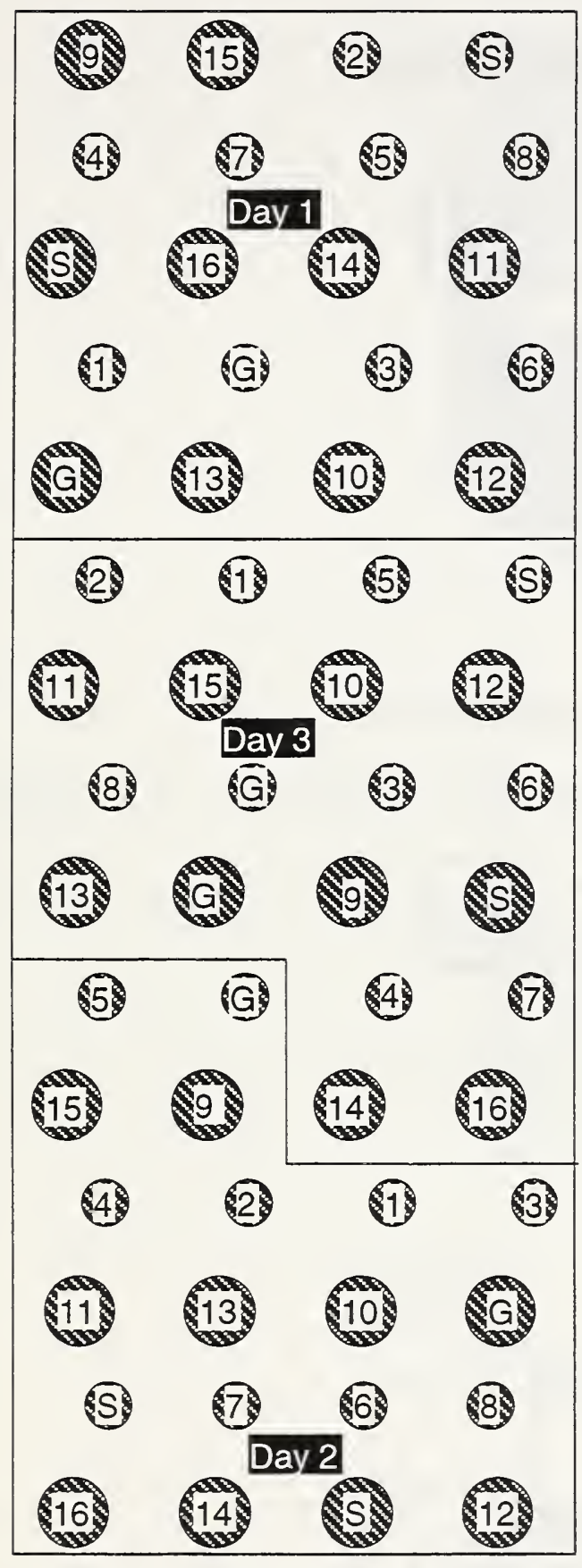

$45 \mathrm{MPa}$

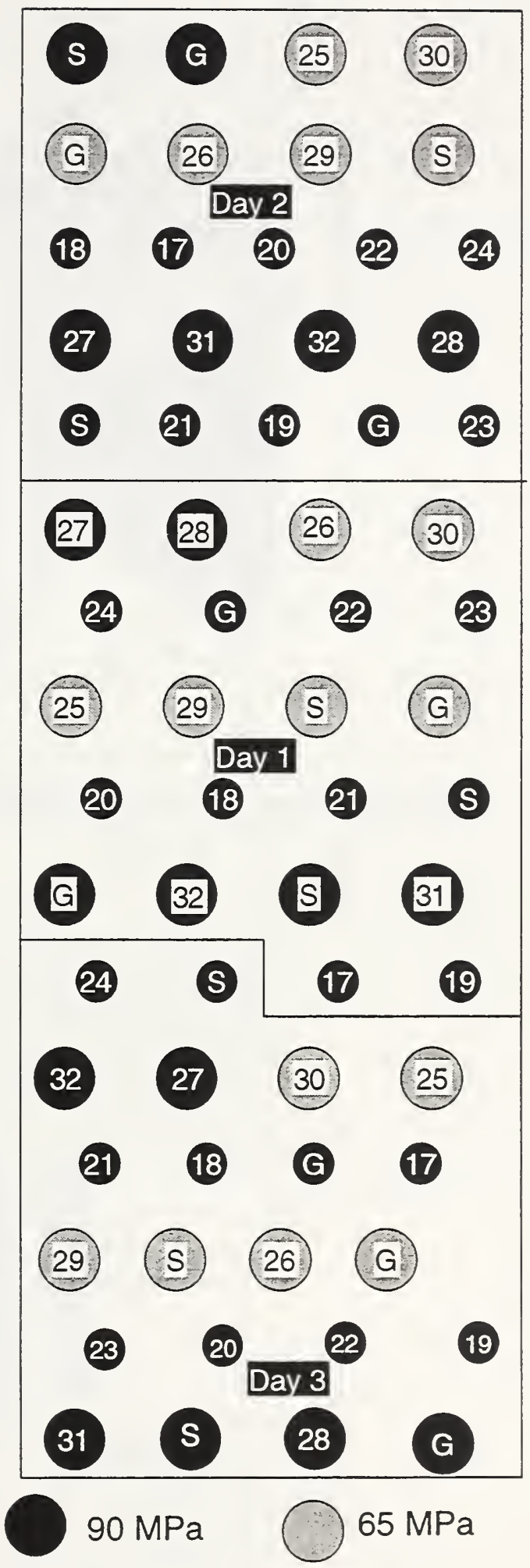

Figure 2.1 - Arrangement of cylinders in curing tanks 

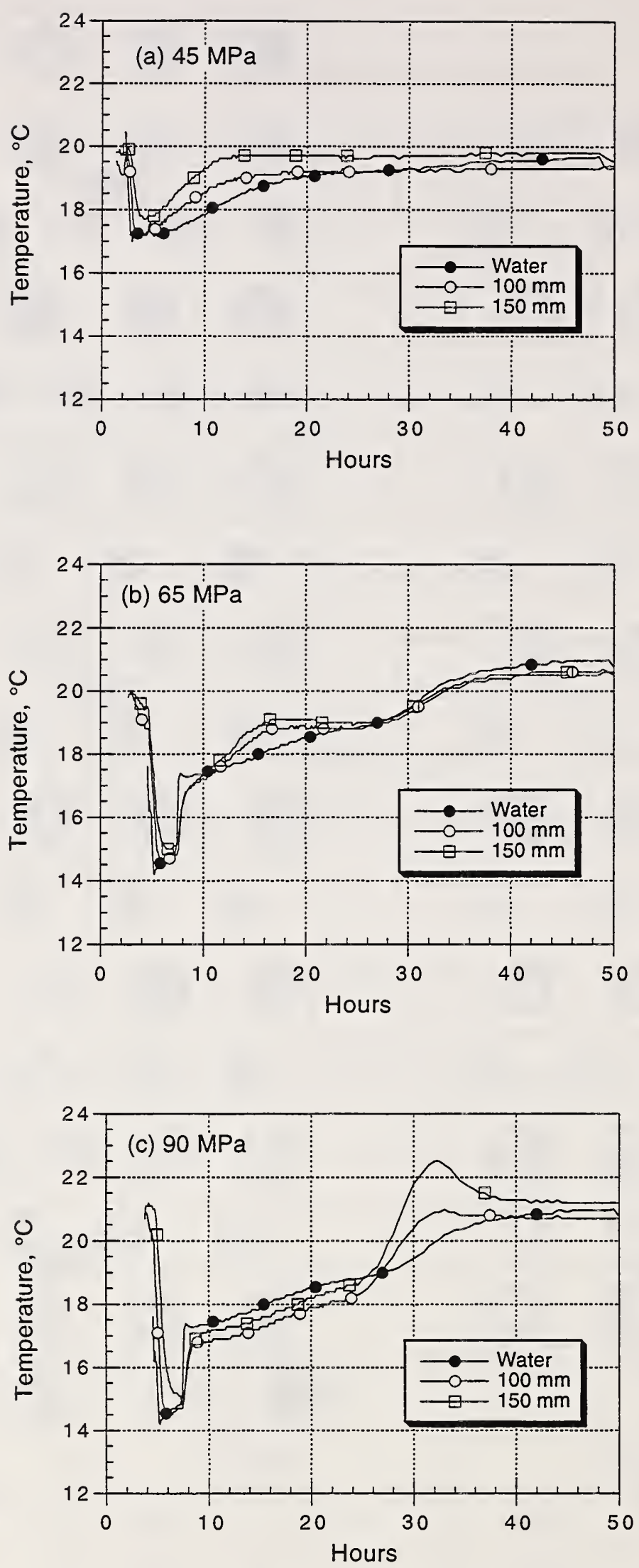

Figure 2.2 - Temperature of cylinders and water in curing tanks during the first 48 hours 


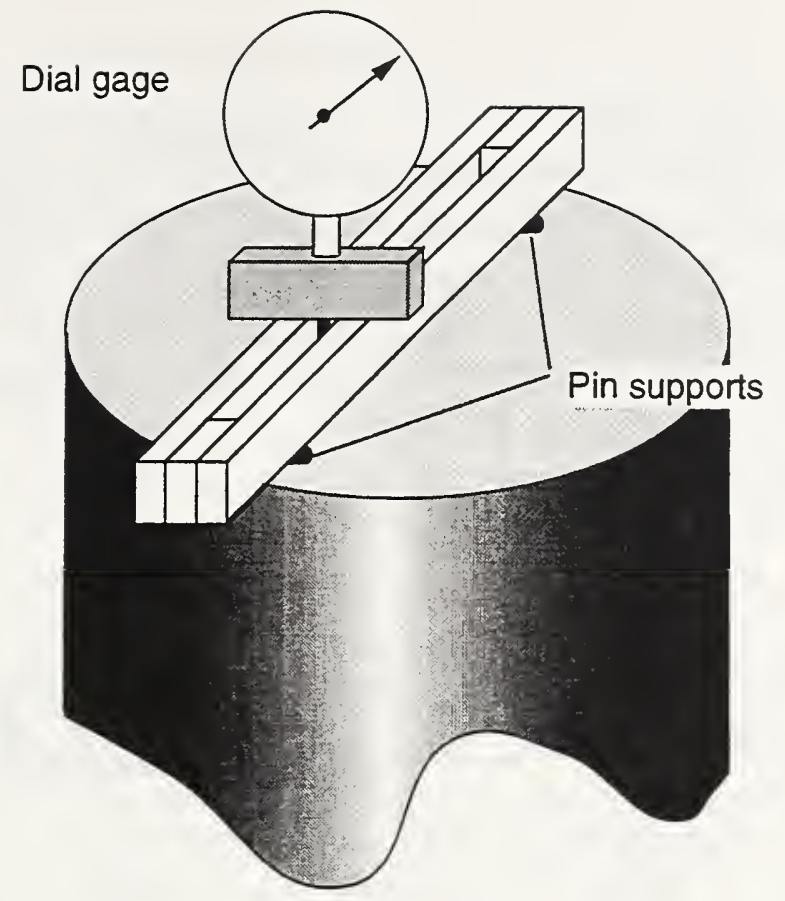

Figure 2.3 - Schematic of bridge assembly and dial gage used to measure flatness

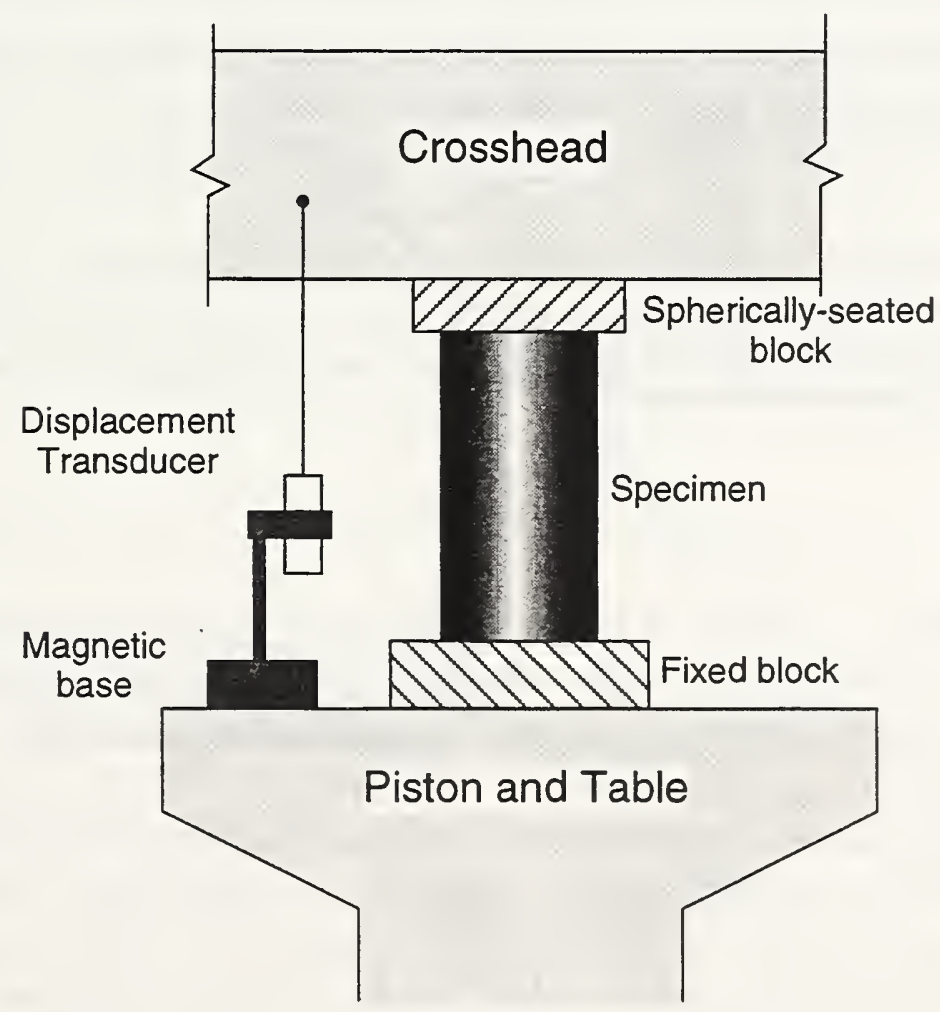

Figure 2.4 - Schematic of arrangement used to measure relative motion between piston and crosshead for 1.33-MN machine 

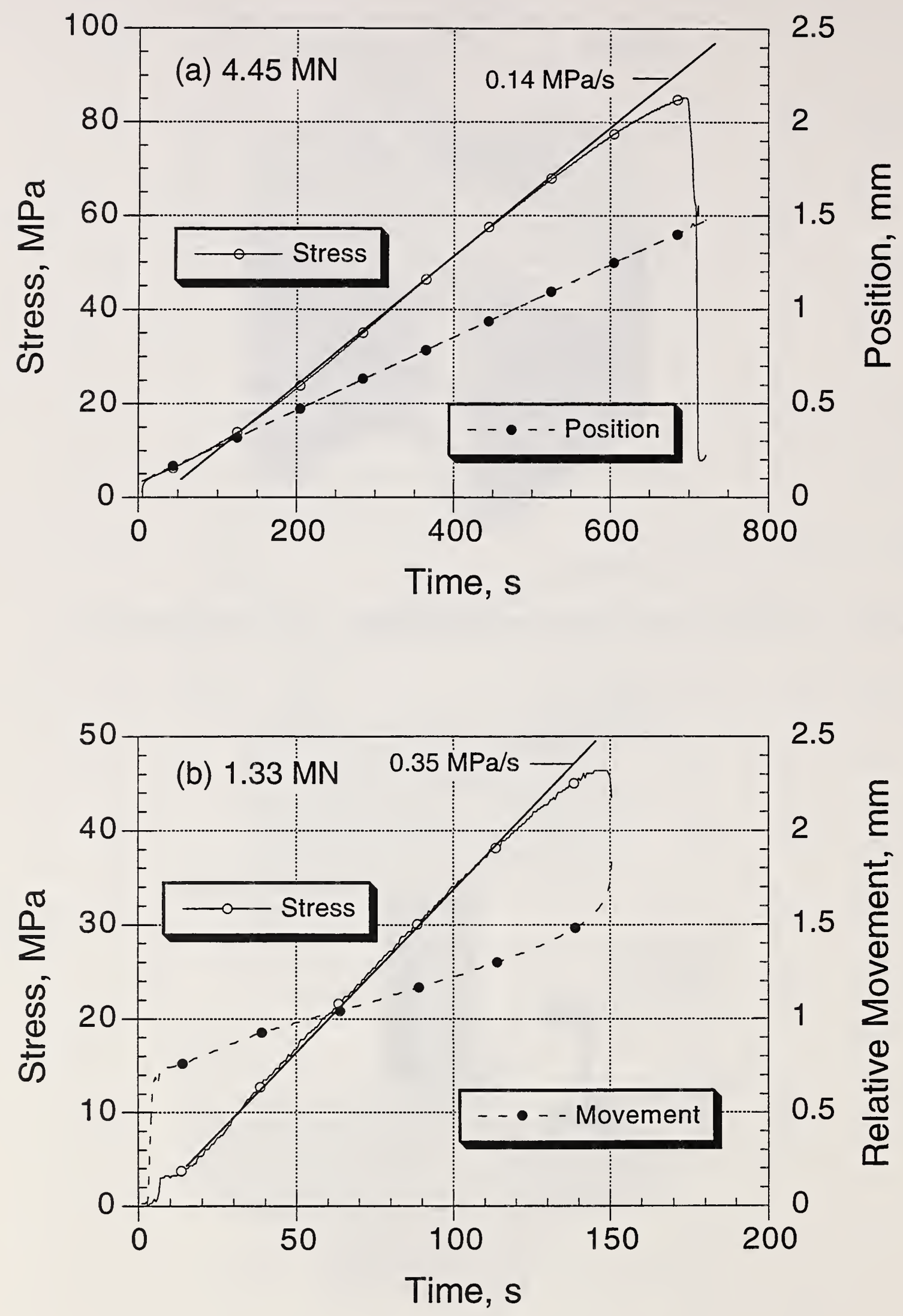

Figure 2.5 - Examples of recorded stress and deformation histories: (a) run \#31, day 1 on 4.45MN machine; (b) run \#14, day 1 on 1.33-MN machine 


\section{RESULTS}

This chapter presents the results of various measurements made on the test cylinders. The strength test results are also presented, but the analysis to find the effects of the testing variables is discussed in the next chapter. Data are presented in a series of tables and graphs, and the reader should refer to Table 2.1 when it is necessary to find the test conditions associated with the run numbers used to identify the data values.

\subsection{Specific Gravity}

Specific gravities were measured for three reasons: (1) to identify specimens with abnormally low densities, which would suggest inadequate consolidation; (2) to examine whether there were systematic differences in density due to cylinder size; and (3) to provide data for computing the dynamic modulus of elasticity from resonance testing. It was found that a cylinder assigned to Run \#22 had a low specific gravity, so it was replaced by a spare cylinder. Table 3.1 lists the specific gravities for all the cylinders used to provide the strength data for this study, and Table 3.2 shows the averages and standard deviations for the different groups. Figures 3.1(a) and 3.1(c) show the individual values plotted as a function of run number. The two cylinder sizes are shown by filled and open circles. To help visualize differences due to cylinder size, Figures 3.1(b) and 3.1(d) are dotplots of the specific gravities for the two sizes. For the 90-MPa mixture, it appears that the 100$\mathrm{mm}$ cylinders were denser than the $150-\mathrm{mm}$ cylinders. For the $45-\mathrm{MPa}$ mixture, the $100-\mathrm{mm}$ cylinders had a higher average specific gravity but it not immediately evident from Fig. 3.1(b) whether the difference is statistically significant. A $t$-test of the means, however, showed that the difference is statistically significant at a significance level less than 0.01 .

Thus, in this study, the specific gravity was affected by the cylinder size, and the effect was greater for the $90-\mathrm{MPa}$ mixture than the 45-MPa mixture. This difference in specific gravity should be kept in mind when the effects of cylinder size on strength are considered in the next chapter.

\subsection{Cap Thickness}

Efforts were made to obtain consistent sulfur cap thicknesses. Measurements of nominal cap thickness were made by using a length comparator, which was composed of a stand whose base had three pins to support the cylinder and a vertical member supported a calibrated dial gage. A metal bar of known length was used to calibrate the dial gage readings. To make a measurement, a cylinder was placed on the stand and the stem of the dial gage was brought into contact with the center of the cylinder. Differences in the length of a cylinder before and after application of a cap were used as a measure of the nominal cap thickness. Table 3.3 shows the nominal top and bottom cap thicknesses for each replication, and Table 3.4 gives the averages and standard deviations for the two cylinder sizes. Figures 2(a) and 2(b) show the nominal thicknesses for each cylinder. On average, the nominal thicknesses of the top caps were about $0.5 \mathrm{~mm}$ greater than those of the bottom caps. This is expected because of the more irregular surface at the top of the cylinders. 
After the cylinders were tested for compressive strength, portions of caps were removed from randomly selected cylinders and their thicknesses were measured with a caliper. Four portions were measured for each cap. Figure 3.2(c) is a plot of the average thickness (based on the four measurements) as a function of the nominal thickness found from the comparator measurements. The best-fit straight lines through the origin show that the measured average thicknesses of the top caps were generally larger than the nominal thicknesses; the opposite was true for the bottom caps. These differences are likely related to differences in roughness and perpendicularity of the top and bottom ends of the cylinders. Mostly, however, the thicknesses based on the comparator readings were within $0.5 \mathrm{~mm}$ of the measured average cap thicknesses. Figure 3.2(d) shows the standard deviation of the four thickness measurements plotted as a function of their average. It is seen that the variability of the top-cap thickness was greater than that of the bottom cap. Again, this can be explained in terms of the more irregular surfaces at the tops of the cylinders.

In summary, a length comparator was used to verify that nominal cap thicknesses were kept below a value of $4 \mathrm{~mm}$. It was found that the top caps were thicker than the bottom caps.

\subsection{Loading Rate}

As explained in section 2.4, a digital record of the stress history of each test was recorded for later analysis. The data were used to create stress versus time plots to identify the portion of the test during which the stress rate was approximately constant. Least-squares regression was used to find the slope of the line that represented the nominal stress rate for the test (refer to Fig. 2.5). These nominal stress rates are listed in Table 3.5 and are plotted in Fig. 3.3(a), where horizontal lines are drawn at the target stress rates of 0.14 and $0.34 \mathrm{MPa} / \mathrm{s}$. It is seen that there is considerable scatter in the nominal stress rates. To examine the variability further, Fig. 3.3(b) shows a dotplot of the nominal stress rates broken down into eight groups according to cylinder size and testing machine. Table 3.6 summarizes the averages and standard deviations for the eight groups. Analysis of variance was used to discern whether there were statistically significant differences among the average rates. It was found that at the slow rate, the $100-\mathrm{mm}$ cylinders on the $1.33-\mathrm{MN}$ machine were loaded at a significantly higher rate than the other three groups. At the fast loading rate, the tests on the 4.45-MN machine were done at significantly lower rates than those on the 1.33-MN machine.

These measured stress histories provide data on the size of the variability in the nominal stress rate that can be expected for tests done according to ASTM C 39. For the 4.45-MN machine, the pooled standard deviation was $0.022 \mathrm{MPa} / \mathrm{s}$, and for the $1.33-\mathrm{MN}$ machine the value was 0.018 $\mathrm{MPa} / \mathrm{s}$. These values may be of use if it is necessary to define a tighter tolerance for loading rate than is currently allowed by ASTM C 39.

\subsection{Wave Speed and Dynamic Modulus of Elasticity}

Although it was not a primary objective of this study, longitudinal resonant frequencies were measured before testing the cylinders. Frequencies were measured using the impact procedure in 
ASTM C 215. A waveform analyzer was used to find the resonant frequency of each cylinder based on the output of the accelerometer mounted on the end of the cylinder. The resonant frequency was used to calculate the longitudinal wave speed as follows:

$$
C_{p}=2 h f
$$

where $\begin{aligned} C_{p} & =\text { longitudinal wave speed, } \mathrm{m} / \mathrm{s}, \\ h & =\text { length of cylinder, } \mathrm{m}, \text { and } \\ f & =\text { resonant frequency, } \mathrm{Hz} .\end{aligned}$

Table 3.7 lists the computed wave speeds.

The resonant frequencies were also used to calculate the dynamic modulus of elasticity by using the following relationship (ASTM C 215):

$$
E_{d}=4 h^{2} f^{2} \gamma
$$

where $E_{d}=$ dynamic modulus of elasticity, $\mathrm{Pa}$, and

$\gamma=$ concrete density, $\mathrm{kg} / \mathrm{m}^{3}$.

The dynamic modulus of elasticity is a measure of stiffness under small strain conditions, and its value will be greater than the usual static modulus of elasticity measured in a compression test according to ASTM C 469 (Philleo 1955). Tests have shown that when static tests are done at low strain levels, the static and the dynamic modulus of elasticity are the same (Bay and Stokoe 1992). Thus the dynamic modulus of elasticity represents the initial tangent modulus of elasticity of concrete (Philleo 1955).

In using Eq. (3.2), it was assumed that the cylinders had the same densities when the resonant frequencies were measured as were found at an age of five days (Table 3.1). The last three columns of Table 3.7 give the calculated values of dynamic modulus of elasticity.

Figure 3.4(a) shows the wave speeds for each cylinder, grouped according to concrete mixture and cylinder size. Table 3.8 summarizes the averages and standard deviations for each group. The standard deviations for each group are very low. Analysis of variance showed that differences in average wave speed due to cylinder size were statistically significant for the $45-\mathrm{MPa}$ and $90-\mathrm{MPa}$ mixtures at significance levels of 0.01 .

Figure 3.4(b) shows the computed values of dynamic modulus of elasticity for each cylinder, grouped according to mixture and cylinder size. The averages and standard deviations for each group are summarized in Table 3.9. Analysis of variance showed that differences in average dynamic modulus due to cylinder size were also statistically significant for the $45-\mathrm{MPa}$ and $90-\mathrm{MPa}$ mixtures at significance levels of 0.01 .

In summary, measurement of longitudinal resonant frequency is a rapid means to assess differences in cylinders molded from the same batch of concrete. When combined with 
measurement of density, the resonant frequency can be used to calculate the dynamic modulus of elasticity. Once the proper instrumentation has been obtained, measurement of dynamic modulus of elasticity is faster and simpler than measurement of the standard static elastic modulus. A similar conclusion was reached by Nilsen and Aitcin, who used the ultrasonic pulse technique instead of the resonant frequency method (Nilsen and Aitcin 1992) to measure the elastic modulus of high-strength concrete.

\subsection{Strength}

Table 3.10 summarizes the compressive strength results. For each run number, the individual test results, the average, standard deviation and coefficient of variation are given. Figure 3.5(a) shows the individual results as a function of the run number. Visual examination of the spread of the replicate results shows that the strengths for the $90-\mathrm{MPa}$ mixture were more variable than for the $45-\mathrm{MPa}$ mixture. Therefore, the coefficient of variation is a better indicator of test dispersion. Figure 3.5(b) shows the coefficient of variation versus run number.

A complete analysis of the strength results is given in the Chapter 4. This section ends with an examination of the relationships between compressive strength and the results of the resonance tests. Figure 3.6(a) shows the longitudinal wave speed as a function of the compressive strength, and Fig. 3.6(b) shows the relationship between dynamic elastic modulus and compressive strength. The significant observation is that the clusters of points for the three different mixtures are not represented by an obvious relationship between elastic modulus and strength. This reinforces the notion that there is not a fundamental relationship between strength and the elastic properties of concrete. It is believed that a reliable relationship to estimate the elastic modulus of a concrete mixture needs to include more factors than compressive strength and density, as is current practice. Factors that account for the volume fractions and properties of the paste and aggregates in the mixture are probably needed. 
Table 3.1 - Specific gravity of cylinders

\begin{tabular}{|c|c|c|c|c|c|}
\hline \multirow{2}{*}{$\begin{array}{c}\text { Run } \\
\text { Number }\end{array}$} & \multirow{2}{*}{$\begin{array}{c}\text { Nominal } \\
\text { Strength, } \\
\mathrm{MPa}\end{array}$} & \multirow{2}{*}{$\begin{array}{c}\text { Nominal } \\
\text { Cylinder } \\
\text { Diameter, } \\
\mathrm{mm}\end{array}$} & \multicolumn{3}{|c|}{ Specific Gravity } \\
\hline & & & Replication 1 & Replication 2 & Replication 3 \\
\hline 1 & 45 & 100 & 2.495 & 2.498 & 2.505 \\
\hline 2 & 45 & 100 & 2.510 & 2.494 & 2.501 \\
\hline 3 & 45 & 100 & 2.493 & 2.488 & 2.491 \\
\hline 4 & 45 & 100 & 2.500 & 2.496 & 2.491 \\
\hline 5 & 45 & 100 & 2.503 & 2.496 & 2.487 \\
\hline 6 & 45 & 100 & 2.490 & 2.495 & 2.489 \\
\hline 7 & 45 & 100 & 2.497 & 2.493 & 2.492 \\
\hline 8 & 45 & 100 & 2.505 & 2.493 & 2.499 \\
\hline 9 & 45 & 150 & 2.488 & 2.490 & 2.494 \\
\hline 10 & 45 & 150 & 2.488 & 2.491 & 2.492 \\
\hline 11 & 45 & 150 & 2.499 & 2.488 & 2.486 \\
\hline 12 & 45 & 150 & 2.490 & 2.492 & 2.486 \\
\hline 13 & 45 & 150 & 2.490 & 2.490 & 2.495 \\
\hline 14 & 45 & 150 & 2.490 & 2.483 & 2.489 \\
\hline 15 & 45 & 150 & 2.489 & 2.492 & 2.498 \\
\hline 16 & 45 & 150 & 2.502 & 2.496 & 2.487 \\
\hline 17 & 90 & 100 & 2.438 & 2.438 & 2.430 \\
\hline 18 & 90 & 100 & 2.433 & 2.439 & 2.439 \\
\hline 19 & 90 & 100 & 2.435 & 2.436 & 2.442 \\
\hline 20 & 90 & 100 & 2.434 & 2.438 & 2.439 \\
\hline 21 & 90 & 100 & 2.431 & 2.435 & 2.443 \\
\hline 22 & 90 & 100 & 2.433 & 2.439 & 2.443 \\
\hline 23 & 90 & 100 & 2.436 & 2.435 & 2.445 \\
\hline 24 & 90 & 100 & 2.441 & 2.433 & 2.442 \\
\hline 25 & 65 & 150 & 2.519 & 2.522 & 2.520 \\
\hline 26 & 65 & 150 & 2.524 & 2.522 & 2.523 \\
\hline 27 & 90 & 150 & 2.424 & 2.424 & 2.425 \\
\hline 28 & 90 & 150 & 2.423 & 2.415 & 2.423 \\
\hline 29 & 65 & 150 & 2.522 & 2.521 & 2.522 \\
\hline 30 & 65 & 150 & 2.524 & 2.522 & 2.522 \\
\hline 31 & 90 & 150 & 2.418 & 2.423 & 2.428 \\
\hline 32 & 90 & 150 & 2.429 & 2.420 & 2.425 \\
\hline
\end{tabular}


Table 3.2 - Summary of specific gravities of cylinders

\begin{tabular}{|c|c|c|c|c|}
\hline $\begin{array}{c}\text { Nominal } \\
\text { Strength, MPa }\end{array}$ & $\begin{array}{c}\text { Nominal Cylinder } \\
\text { Diameter, } \mathrm{mm}\end{array}$ & $\mathrm{n}$ & $\begin{array}{c}\text { Average Specific } \\
\text { Gravity }\end{array}$ & $\begin{array}{c}\text { Standard } \\
\text { Deviation }\end{array}$ \\
\hline 45 & 100 & 24 & 2.496 & 0.006 \\
& 150 & 24 & 2.491 & 0.005 \\
\hline 65 & 150 & 12 & 2.522 & 0.001 \\
\hline 90 & 100 & 24 & 2.437 & 0.004 \\
& 150 & 12 & 2.423 & 0.004 \\
\hline
\end{tabular}

Table 3.3 - Nominal thickness of sulfur caps based on cylinder length measurements

\begin{tabular}{|c|c|c|c|c|c|c|c|c|c|}
\hline \multirow{2}{*}{$\begin{array}{c}\text { Run } \\
\text { Number }\end{array}$} & \multicolumn{3}{|c|}{ Replication 1 } & \multicolumn{3}{c|}{ Replication 2 } & \multicolumn{3}{c|}{ Replication 3 } \\
\cline { 2 - 9 } & $\begin{array}{c}\text { Bottom, } \\
\text { mm }\end{array}$ & $\begin{array}{c}\text { Top, } \\
\text { mm }\end{array}$ & $\begin{array}{c}\text { Sum, } \\
\text { mm }\end{array}$ & $\begin{array}{c}\text { Bottom, } \\
\text { mm }\end{array}$ & $\begin{array}{c}\text { Top, } \\
\text { mm }\end{array}$ & $\begin{array}{c}\text { Sum, } \\
\text { mm }\end{array}$ & $\begin{array}{c}\text { Bottom, } \\
\text { mm }\end{array}$ & $\begin{array}{c}\text { Top, } \\
\text { mm }\end{array}$ & $\begin{array}{c}\text { Sum, } \\
\text { mm }\end{array}$ \\
\hline 1 & 1.7 & 3.1 & 4.8 & 2.9 & 2.9 & 5.8 & 2.5 & 1.7 & 4.2 \\
2 & 1.8 & 2.8 & 4.6 & 1.8 & 2.9 & 4.7 & 2.7 & 2.7 & 5.4 \\
3 & 1.8 & 3.2 & 5.0 & 2.4 & 3.1 & 5.5 & 2.3 & 2.5 & 4.8 \\
4 & 2.6 & 3.2 & 5.8 & 2.3 & 3.1 & 5.4 & 2.8 & 2.6 & 5.4 \\
9 & 2.2 & 2.9 & 5.1 & 2.0 & 2.9 & 4.9 & 2.8 & 3.0 & 5.8 \\
10 & 1.5 & 3.1 & 4.6 & 1.8 & 3.2 & 5.0 & 2.1 & 2.5 & 4.6 \\
11 & 2.8 & 2.6 & 5.4 & 2.3 & 2.5 & 4.8 & 1.8 & 3.0 & 4.8 \\
12 & 2.4 & 2.1 & 4.5 & 1.3 & 2.5 & 3.8 & 2.3 & 3.1 & 5.4 \\
17 & 2.1 & 3.2 & 5.3 & 2.6 & 2.1 & 4.7 & 1.8 & 2.2 & 4.0 \\
18 & 1.9 & 3.4 & 5.3 & 1.7 & 3.6 & 5.3 & 2.4 & 2.5 & 4.9 \\
19 & 2.5 & 2.3 & 4.8 & 2.6 & 2.6 & 5.2 & 2.9 & 2.8 & 5.7 \\
20 & 2.2 & 3.3 & 5.5 & 2.4 & 3.0 & 5.4 & 3.0 & 3.0 & 6.0 \\
25 & 2.6 & 3.4 & 6.0 & 2.7 & 3.6 & 6.3 & 1.9 & 3.0 & 4.9 \\
26 & 1.9 & 3.1 & 5.0 & 2.4 & 3.4 & 5.8 & 1.9 & 2.6 & 4.5 \\
27 & 2.2 & 2.7 & 4.9 & 2.0 & 2.4 & 4.4 & 2.4 & 3.1 & 5.5 \\
28 & 2.6 & 2.5 & 5.1 & 2.4 & 2.3 & 4.7 & 2.6 & 2.7 & 5.3 \\
\hline
\end{tabular}

Table 3.4 - Summary of nominal sulfur cap thicknesses

\begin{tabular}{|l|c|c|c|c|c|c|}
\hline & \multicolumn{3}{|c|}{$100-\mathrm{mm}$ Cylinders } & \multicolumn{3}{c|}{ 150-mm Cylinders } \\
\cline { 2 - 7 } & Bottom & Top & Sum & Bottom & Top & Sum \\
\hline Average, $\mathrm{mm}$ & 2.3 & 2.8 & 5.1 & 2.2 & 2.8 & 5.0 \\
\hline Standard deviation, $\mathrm{mm}$ & 0.4 & 0.5 & 0.5 & 0.4 & 0.4 & 0.6 \\
\hline
\end{tabular}


Table $3.5-$ Nominal stress rate

\begin{tabular}{|c|c|c|c|c|c|c|}
\hline \multirow{2}{*}{$\begin{array}{c}\text { Run } \\
\text { Number }\end{array}$} & \multirow{2}{*}{$\begin{array}{c}\text { Cylinder } \\
\text { Diameter, }\end{array}$} & \multirow{2}{*}{$\begin{array}{c}\text { Testing } \\
\text { Machine }\end{array}$} & Rate & \multicolumn{3}{|c|}{ Stress Rate, MPa/s } \\
\cline { 5 - 7 } & mm & & & $\# 1$ & $\# 2$ & $\# 3$ \\
\hline 1 & 100 & 1.33 & Slow & 0.14 & 0.19 & 0.12 \\
2 & 100 & 1.33 & Fast & 0.39 & 0.32 & 0.35 \\
3 & 100 & 4.45 & Slow & 0.11 & 0.12 & 0.12 \\
4 & 100 & 4.45 & Fast & 0.28 & 0.26 & 0.28 \\
5 & 100 & 1.33 & Slow & 0.16 & 0.17 & 0.16 \\
6 & 100 & 1.33 & Fast & 0.34 & 0.30 & 0.34 \\
7 & 100 & 4.45 & Slow & 0.14 & 0.14 & 0.14 \\
8 & 100 & 4.45 & Fast & 0.32 & 0.34 & 0.33 \\
9 & 150 & 1.33 & Slow & 0.13 & 0.12 & 0.14 \\
10 & 150 & 1.33 & Fast & 0.36 & 0.33 & 0.33 \\
11 & 150 & 4.45 & Slow & 0.12 & 0.11 & 0.13 \\
12 & 150 & 4.45 & Fast & 0.28 & 0.28 & 0.28 \\
13 & 150 & 1.33 & Slow & 0.12 & 0.14 & 0.14 \\
14 & 150 & 1.33 & Fast & 0.34 & 0.34 & 0.31 \\
15 & 150 & 4.45 & Slow & 0.14 & 0.14 & 0.14 \\
16 & 150 & 4.45 & Fast & 0.32 & 0.32 & 0.32 \\
17 & 100 & 1.33 & Slow & 0.14 & 0.14 & 0.19 \\
18 & 100 & 1.33 & Fast & 0.33 & 0.34 & 0.31 \\
19 & 100 & 4.45 & Slow & 0.12 & 0.11 & 0.12 \\
20 & 100 & 4.45 & Fast & 0.29 & 0.29 & 0.27 \\
21 & 100 & 1.33 & Slow & 0.12 & 0.15 & 0.18 \\
22 & 100 & 1.33 & Fast & 0.33 & 0.33 & 0.33 \\
23 & 100 & 4.45 & Slow & 0.14 & 0.13 & 0.14 \\
24 & 100 & 4.45 & Fast & 0.36 & 0.32 & 0.35 \\
25 & 150 & 1.33 & Slow & 0.14 & 0.13 & 0.14 \\
26 & 150 & 1.33 & Fast & 0.35 & 0.33 & 0.31 \\
27 & 150 & 4.45 & Slow & 0.13 & 0.13 & 0.14 \\
28 & 150 & 4.45 & Fast & 0.32 & 0.30 & 0.32 \\
29 & 150 & 1.33 & Slow & 0.15 & 0.14 & 0.13 \\
30 & 150 & 1.33 & Fast & 0.35 & 0.33 & 0.34 \\
31 & 150 & 4.45 & Slow & 0.14 & 0.14 & 0.15 \\
32 & 150 & 4.45 & Fast & 0.33 & 0.31 & 0.34 \\
\hline
\end{tabular}

"Slow $=$ target nominal rate of $0.14 \mathrm{MPa} / \mathrm{s}$

Fast $=$ target nominal rate of $0.34 \mathrm{MPa} / \mathrm{s}$ 
Table 3.6 - Summary of nominal measured stress rate

\begin{tabular}{|c|c|c|c|c|}
\hline $\begin{array}{c}\text { Testing } \\
\text { Machine, MPa }\end{array}$ & $\begin{array}{c}\text { Cylinder } \\
\text { Diameter, } \mathrm{mm}\end{array}$ & Rate & $\begin{array}{l}\text { Average Measured } \\
\text { Stress Rate, } \mathrm{MPa} / \mathrm{s}\end{array}$ & $\begin{array}{c}\text { Standard } \\
\text { Deviation, } \mathrm{MPa} / \mathrm{s}\end{array}$ \\
\hline \multirow{2}{*}{1.33} & 100 & $\begin{array}{c}\text { Slow } \\
\text { Fast }\end{array}$ & $\begin{array}{l}0.155 \\
0.335 \\
\end{array}$ & $\begin{array}{l}0.023 \\
0.022 \\
\end{array}$ \\
\hline & 150 & $\begin{array}{c}\text { Slow } \\
\text { Fast }\end{array}$ & $\begin{array}{l}0.135 \\
0.334 \\
\end{array}$ & $\begin{array}{l}0.008 \\
0.014 \\
\end{array}$ \\
\hline \multirow{2}{*}{4.45} & 100 & $\begin{array}{l}\text { Slow } \\
\text { Fast }\end{array}$ & $\begin{array}{l}0.127 \\
0.305\end{array}$ & $\begin{array}{l}0.011 \\
0.034\end{array}$ \\
\hline & 150 & $\begin{array}{l}\text { Slow } \\
\text { Fast }\end{array}$ & $\begin{array}{l}0.134 \\
0.309\end{array}$ & $\begin{array}{l}0.013 \\
0.020\end{array}$ \\
\hline
\end{tabular}

"Slow $=$ nominal rate of $0.14 \mathrm{MPa} / \mathrm{s}$

Fast $=$ nominal rate of $0.34 \mathrm{MPa} / \mathrm{s}$

$\mathrm{n}=12$ 
Table 3.7 -- Longitudinal wave speed and calculated dynamic modulus of elasticity

\begin{tabular}{|c|c|c|c|c|c|c|}
\hline \multirow{2}{*}{$\begin{array}{c}\text { Run } \\
\text { Number }\end{array}$} & \multicolumn{3}{|c|}{ Longitudinal Wave Speed, $\mathrm{m} / \mathrm{s}$} & \multicolumn{3}{|c|}{ Dynamic Modulus of Elasticity, GPa } \\
\hline & $\# 1$ & $\# 2$ & $\# 3$ & $\# 1$ & \#2 & $\# 3$ \\
\hline 1 & 4173 & 4208 & 4205 & 43.44 & 44.24 & 44.29 \\
\hline 2 & 4219 & 4184 & 4205 & 44.68 & 43.65 & 44.22 \\
\hline 3 & 4186 & 4186 & 4171 & 43.68 & 43.59 & 43.33 \\
\hline 4 & 4199 & 4190 & 4206 & 44.08 & 43.83 & 44.06 \\
\hline 5 & 4203 & 4187 & 4206 & 44.21 & 43.76 & 44.00 \\
\hline 6 & 4176 & 4193 & 4163 & 43.41 & 43.87 & 43.14 \\
\hline 7 & 4197 & 4211 & 4226 & 43.98 & 44.21 & 44.51 \\
\hline 8 & 4214 & 4207 & 4209 & 44.49 & 44.13 & 44.27 \\
\hline 9 & 4173 & 4179 & 4200 & 43.32 & 43.48 & 44.00 \\
\hline 10 & 4181 & 4185 & 4191 & 43.49 & 43.62 & 43.77 \\
\hline 11 & 4178 & 4186 & 4174 & 43.62 & 43.59 & 43.31 \\
\hline 12 & 4164 & 4200 & 4166 & 43.18 & 43.95 & 43.15 \\
\hline 13 & 4166 & 4190 & 4186 & 43.22 & 43.71 & 43.73 \\
\hline 14 & 4172 & 4175 & 4188 & 43.33 & 43.28 & 43.65 \\
\hline 15 & 4187 & 4186 & 4196 & 43.64 & 43.66 & 43.98 \\
\hline 16 & 4213 & 4191 & 4221 & 44.42 & 43.84 & 44.30 \\
\hline 17 & 4411 & 4393 & 4379 & 47.44 & 47.04 & 46.60 \\
\hline 18 & 4362 & 4389 & 4373 & 46.30 & 46.99 & 46.64 \\
\hline 19 & 4369 & 4408 & 4393 & 46.48 & 47.33 & 47.12 \\
\hline 20 & 4385 & 4417 & 4384 & 46.81 & 47.57 & 46.88 \\
\hline 21 & 4373 & 4398 & 4412 & 46.50 & 47.10 & 47.55 \\
\hline 22 & 4364 & 4391 & 4403 & 46.34 & 47.02 & 47.36 \\
\hline 23 & 4379 & 4378 & 4413 & 46.72 & 46.67 & 47.61 \\
\hline 24 & 4388 & 4382 & 4405 & 47.00 & 46.71 & 47.39 \\
\hline 25 & 4409 & 4412 & 4427 & 48.96 & 49.10 & 49.39 \\
\hline 26 & 4432 & 4419 & 4419 & 49.58 & 49.24 & 49.26 \\
\hline 27 & 4360 & 4338 & 4363 & 46.07 & 45.62 & 46.17 \\
\hline 28 & 4333 & 4347 & 4363 & 45.48 & 45.64 & 46.12 \\
\hline 29 & 4411 & 4420 & 4403 & 49.07 & 49.25 & 48.90 \\
\hline 30 & 4414 & 4422 & 4428 & 49.17 & 49.32 & 49.46 \\
\hline 31 & 4329 & 4344 & 4365 & 45.32 & 45.72 & 46.26 \\
\hline 32 & 4353 & 4330 & 4350 & 46.03 & 45.37 & 45.89 \\
\hline
\end{tabular}


Table 3.8 - Summary of wave speed of cylinders

\begin{tabular}{|c|c|c|c|c|}
\hline $\begin{array}{c}\text { Nominal } \\
\text { Strength, MPa }\end{array}$ & $\begin{array}{c}\text { Nominal Cylinder } \\
\text { Diameter, } \mathrm{mm}\end{array}$ & $\mathrm{n}$ & $\begin{array}{c}\text { Average Wave } \\
\text { Speed, } \mathrm{m} / \mathrm{s}\end{array}$ & $\begin{array}{c}\text { Standard } \\
\text { Deviation, } \mathrm{m} / \mathrm{s}\end{array}$ \\
\hline 45 & 100 & 24 & 4197 & 16 \\
& 150 & 24 & 4185 & 14 \\
\hline 65 & 150 & 12 & 4418 & 9 \\
\hline 90 & 100 & 24 & 4390 & 16 \\
& 150 & 12 & 4348 & 13 \\
\hline
\end{tabular}

Table 3.9 - Summary of computed dynamic modulus of elasticity

\begin{tabular}{|c|c|c|c|c|}
\hline $\begin{array}{c}\text { Nominal } \\
\text { Strength, MPa }\end{array}$ & $\begin{array}{c}\text { Nominal Cylinder } \\
\text { Diameter, mm }\end{array}$ & $\mathrm{n}$ & $\begin{array}{c}\text { Average Dynamic } \\
\text { Modulus, GPa }\end{array}$ & $\begin{array}{c}\text { Standard } \\
\text { Deviation, GPa }\end{array}$ \\
\hline 45 & 100 & 24 & 43.96 & 0.40 \\
& 150 & 24 & 43.64 & 0.33 \\
\hline 65 & 150 & 12 & 49.23 & 0.20 \\
\hline 90 & 100 & 24 & 46.97 & 0.40 \\
& 150 & 12 & 45.81 & 0.33 \\
\hline
\end{tabular}


Table 3.10-Compressive strength results

\begin{tabular}{|c|c|c|c|c|c|c|c|c|}
\hline \multirow{2}{*}{$\begin{array}{c}\text { Run } \\
\text { Number }\end{array}$} & \multirow{2}{*}{$\begin{array}{l}\text { Nominal } \\
\text { Strength, } \\
\text { MPa }\end{array}$} & \multirow{2}{*}{$\begin{array}{c}\text { Cylinder } \\
\text { Diameter, } \\
\mathrm{mm}\end{array}$} & \multicolumn{3}{|c|}{ Compressive Strength, MPa } & \multirow{2}{*}{$\begin{array}{c}\text { Average } \\
\text { Strength, } \\
\mathrm{MPa}\end{array}$} & \multirow{2}{*}{$\begin{array}{c}\text { Standard } \\
\text { Deviation, } \\
\mathrm{MPa}\end{array}$} & \multirow{2}{*}{$\begin{array}{c}\text { Coefficient of } \\
\text { Variation, } \\
\%\end{array}$} \\
\hline & & & \# 1 & $\# 2$ & \#3 & & & \\
\hline 1 & 45 & 100 & 45.13 & 45.93 & 46.50 & 45.85 & 0.69 & 1.5 \\
\hline 2 & 45 & 100 & 46.48 & 46.77 & 47.72 & 46.99 & 0.65 & 1.4 \\
\hline 3 & 45 & 100 & 44.75 & 45.25 & 46.87 & 45.62 & 1.11 & 2.4 \\
\hline 4 & 45 & 100 & 45.56 & 44.47 & 46.96 & 45.66 & 1.25 & 2.7 \\
\hline 5 & 45 & 100 & 45.97 & 46.06 & 46.36 & 46.13 & 0.20 & 0.4 \\
\hline 6 & 45 & 100 & 46.75 & 48.97 & 47.99 & 47.90 & 1.11 & 2.3 \\
\hline 7 & 45 & 100 & 43.90 & 45.75 & 44.55 & 44.73 & 0.94 & 2.1 \\
\hline 8 & 45 & 100 & 45.17 & 46.70 & 47.61 & 46.49 & 1.23 & 2.7 \\
\hline 9 & 45 & 150 & 46.17 & 46.01 & 45.04 & 45.74 & 0.61 & 1.3 \\
\hline 10 & 45 & 150 & 46.36 & 47.25 & 46.92 & 46.84 & 0.45 & 1.0 \\
\hline 11 & 45 & 150 & 42.46 & 44.55 & 43.92 & 43.64 & 1.07 & 2.5 \\
\hline 12 & 45 & 150 & 44.69 & 45.02 & 44.55 & 44.75 & 0.24 & 0.5 \\
\hline 13 & 45 & 150 & 46.03 & 46.46 & 46.01 & 46.17 & 0.25 & 0.6 \\
\hline 14 & 45 & 150 & 46.07 & 46.76 & 46.56 & 46.46 & 0.36 & 0.8 \\
\hline 15 & 45 & 150 & 44.28 & 45.35 & 44.67 & 44.77 & 0.54 & 1.2 \\
\hline 16 & 45 & 150 & 46.30 & 45.87 & 45.35 & 45.84 & 0.48 & 1.0 \\
\hline 17 & 90 & 100 & 88.42 & 92.13 & 90.94 & 90.50 & 1.89 & 2.1 \\
\hline 18 & 90 & 100 & 85.67 & 89.98 & 88.55 & 88.07 & 2.20 & 2.5 \\
\hline 19 & 90 & 100 & 85.42 & 86.08 & 81.53 & 84.34 & 2.46 & 2.9 \\
\hline 20 & 90 & 100 & 88.44 & 88.22 & 89.38 & 88.68 & 0.62 & 0.7 \\
\hline 21 & 90 & 100 & 86.96 & 88.28 & 94.64 & 89.96 & 4.11 & 4.6 \\
\hline 22 & 90 & 100 & 92.31 & 92.86 & 96.53 & 93.90 & 2.29 & 2.4 \\
\hline 23 & 90 & 100 & 87.67 & 89.71 & 89.54 & 88.97 & 1.13 & 1.3 \\
\hline 24 & 90 & 100 & 92.56 & 90.86 & 93.09 & 92.17 & 1.17 & 1.3 \\
\hline 25 & 65 & 150 & 67.55 & 67.26 & 67.32 & 67.38 & 0.15 & 0.2 \\
\hline 26 & 65 & 150 & 69.01 & 68.66 & 68.76 & 68.81 & 0.18 & 0.3 \\
\hline 27 & 90 & 150 & 86.34 & 86.20 & 85.89 & 86.14 & 0.23 & 0.3 \\
\hline 28 & 90 & 150 & 84.87 & 83.40 & 90.59 & 86.29 & 3.80 & 4.4 \\
\hline 29 & 65 & 150 & 68.39 & 69.01 & 68.72 & 68.71 & 0.31 & 0.5 \\
\hline 30 & 65 & 150 & 69.13 & 68.96 & 69.39 & 69.16 & 0.22 & 0.3 \\
\hline 31 & 90 & 150 & 85.40 & 89.18 & 89.78 & 88.12 & 2.37 & 2.7 \\
\hline 32 & 90 & 150 & 91.40 & 89.88 & 92.55 & 91.28 & 1.34 & 1.5 \\
\hline
\end{tabular}



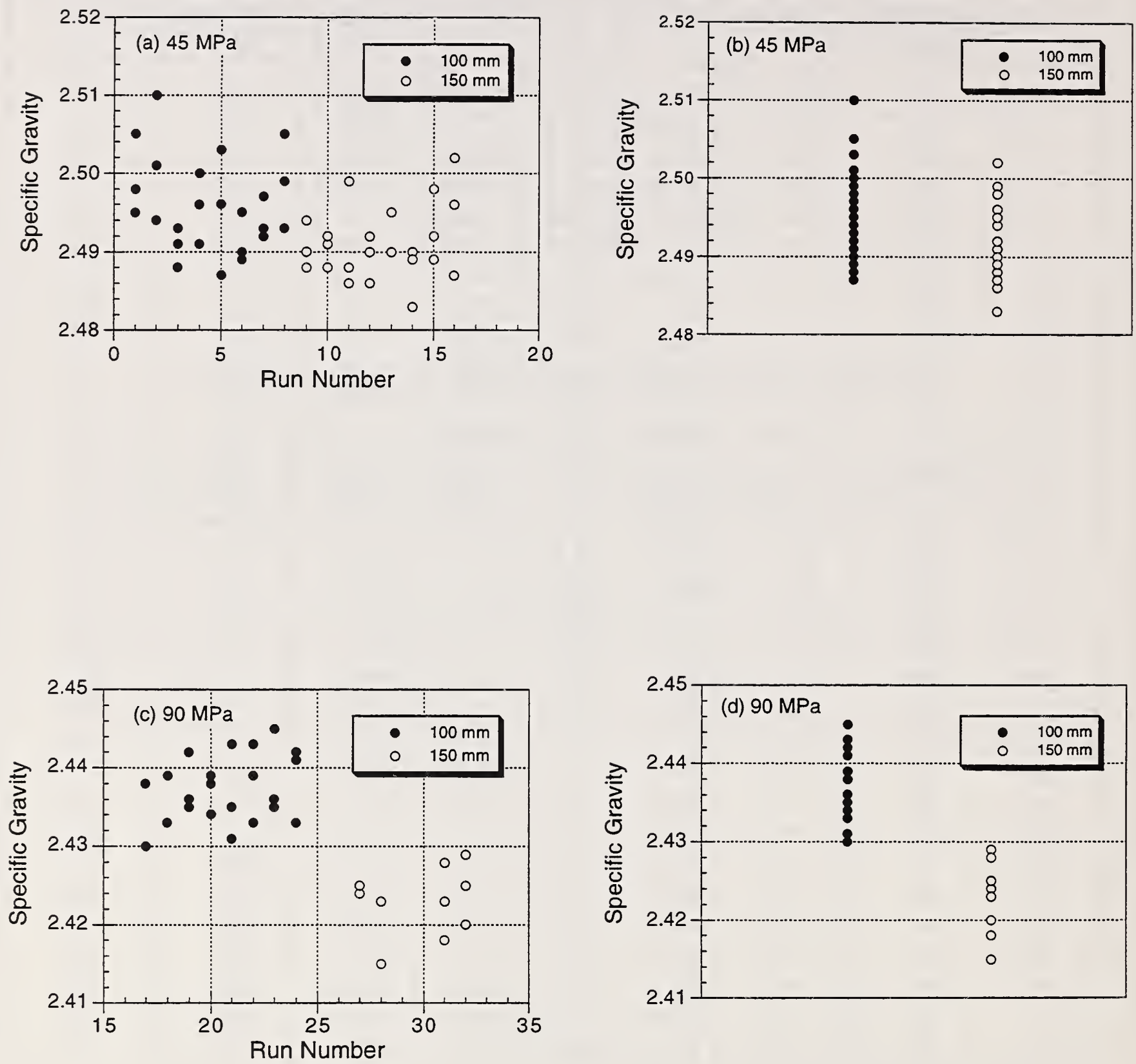

Figure 3.1 - Specific gravity of cylinders: (a) versus run number for 45-MPa mixture; (b) dotplot for 45-MPa mixture; (c) versus run number for 90-MPa mixture; and (d) dotplot for 45-MPa mixture 

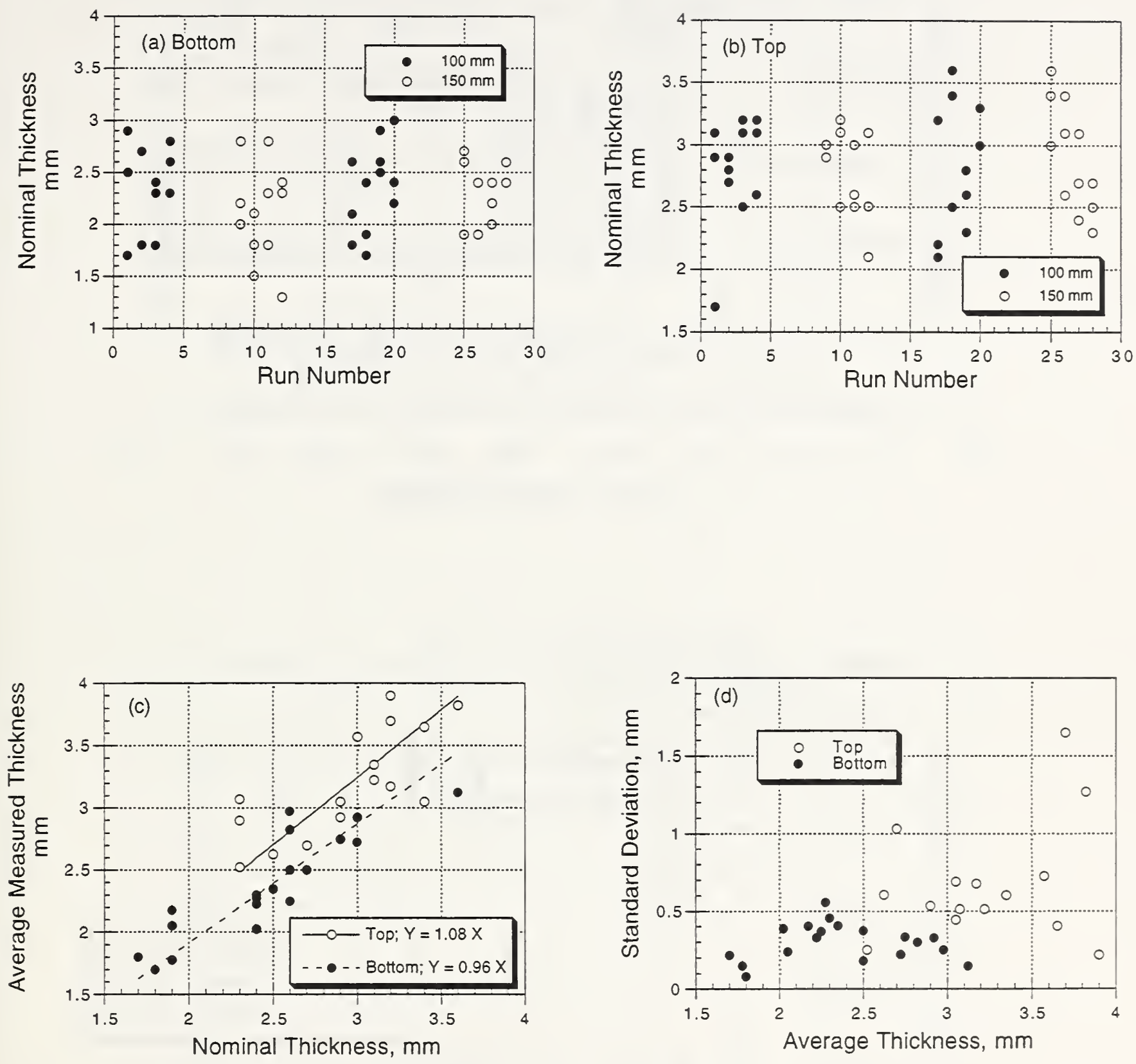

Figure 3.2 - (a) Nominal thickness of top sulfur caps; (b) nominal thickness of bottom sulfur caps; (c) average thickness of four portions of caps versus nominal thickness; and (d) standard deviation of measured portions of caps versus average thickness 

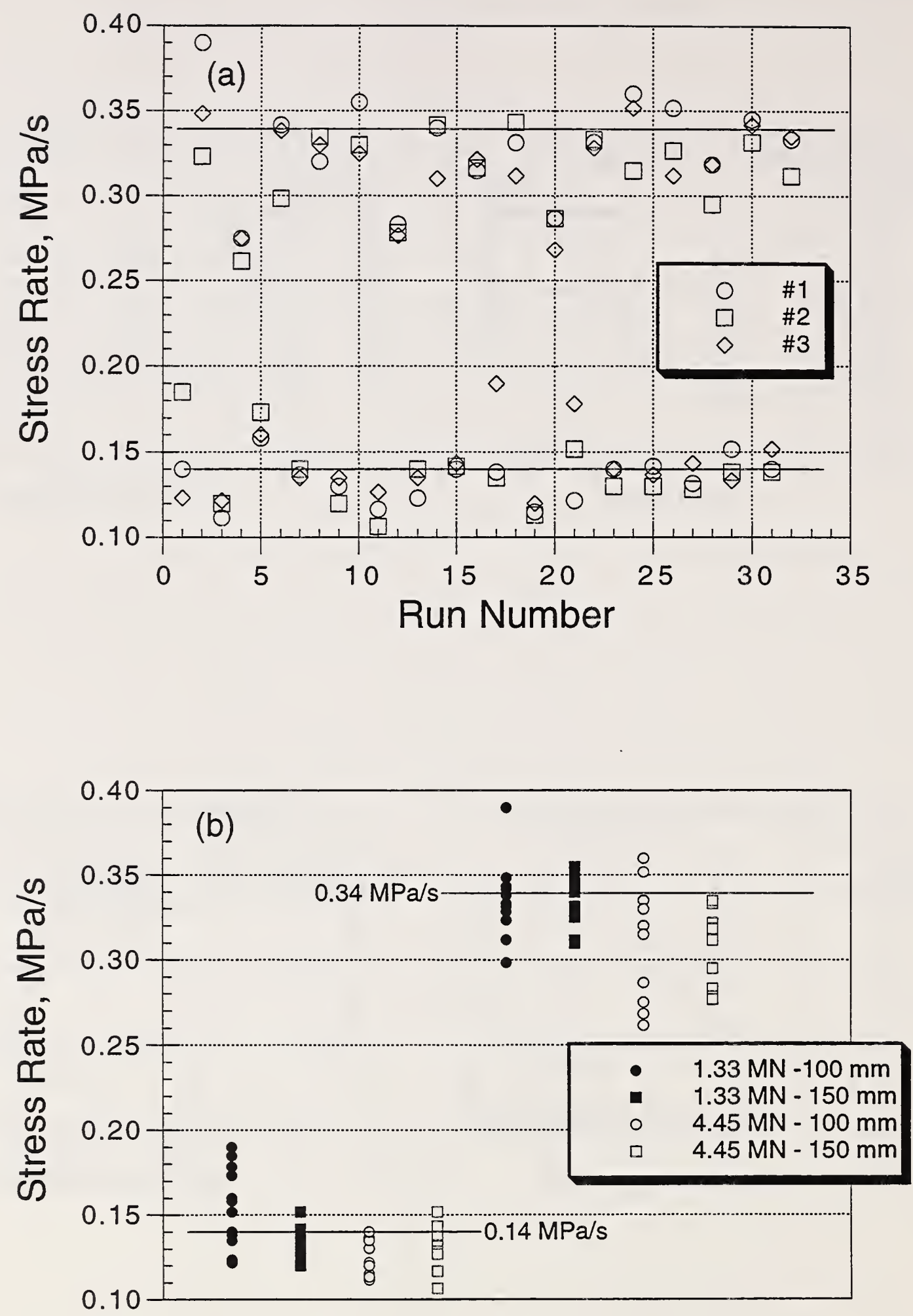

Figure $3.3-$ (a) Nominal stress rate versus run number and (b) dotplot of nominal stress rate 

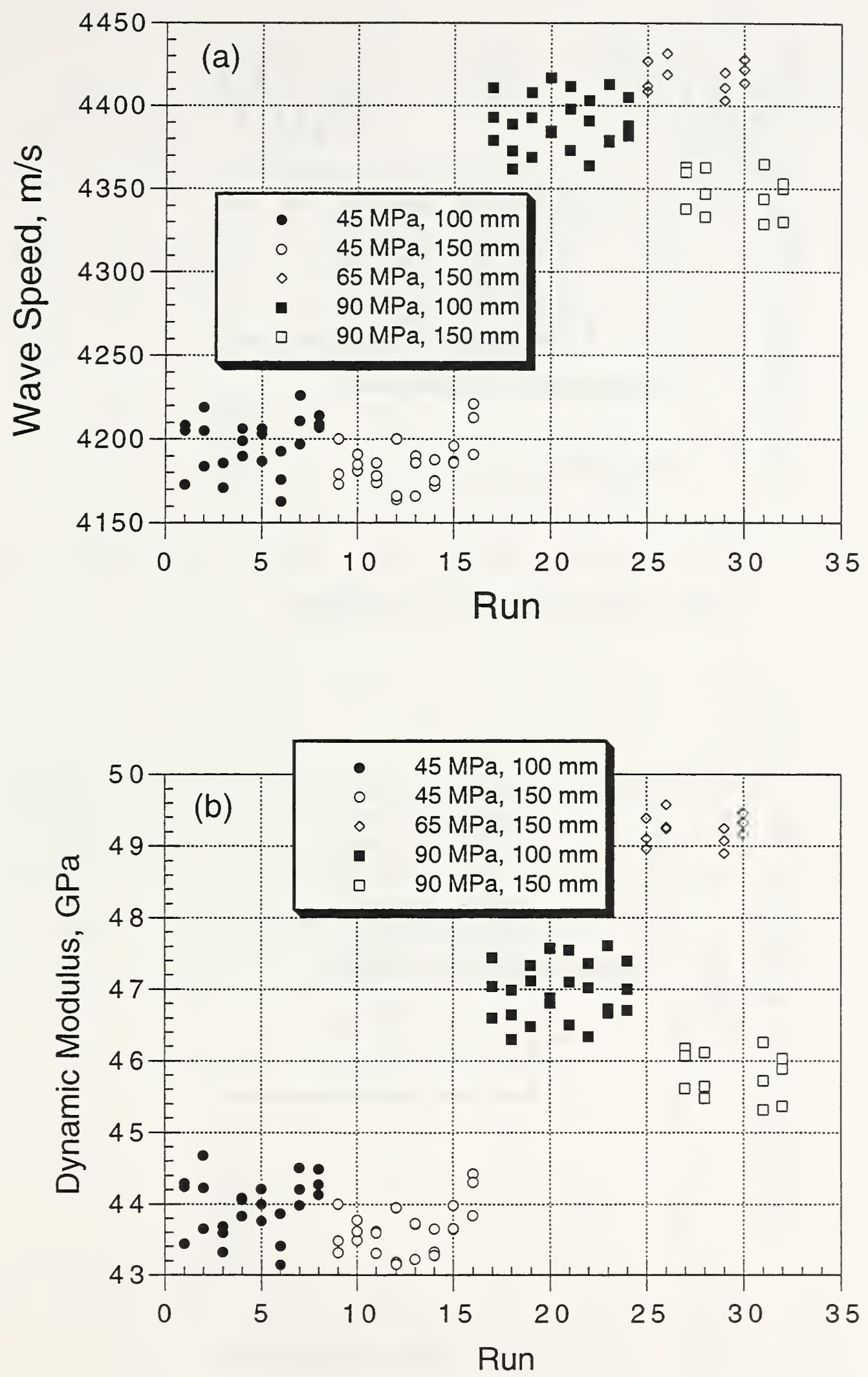

Figure 3.4 - (a) Wave speed, based on longitudinal resonant frequency, versus run number; and (b) computed dynamic modulus of elasticity versus run number 

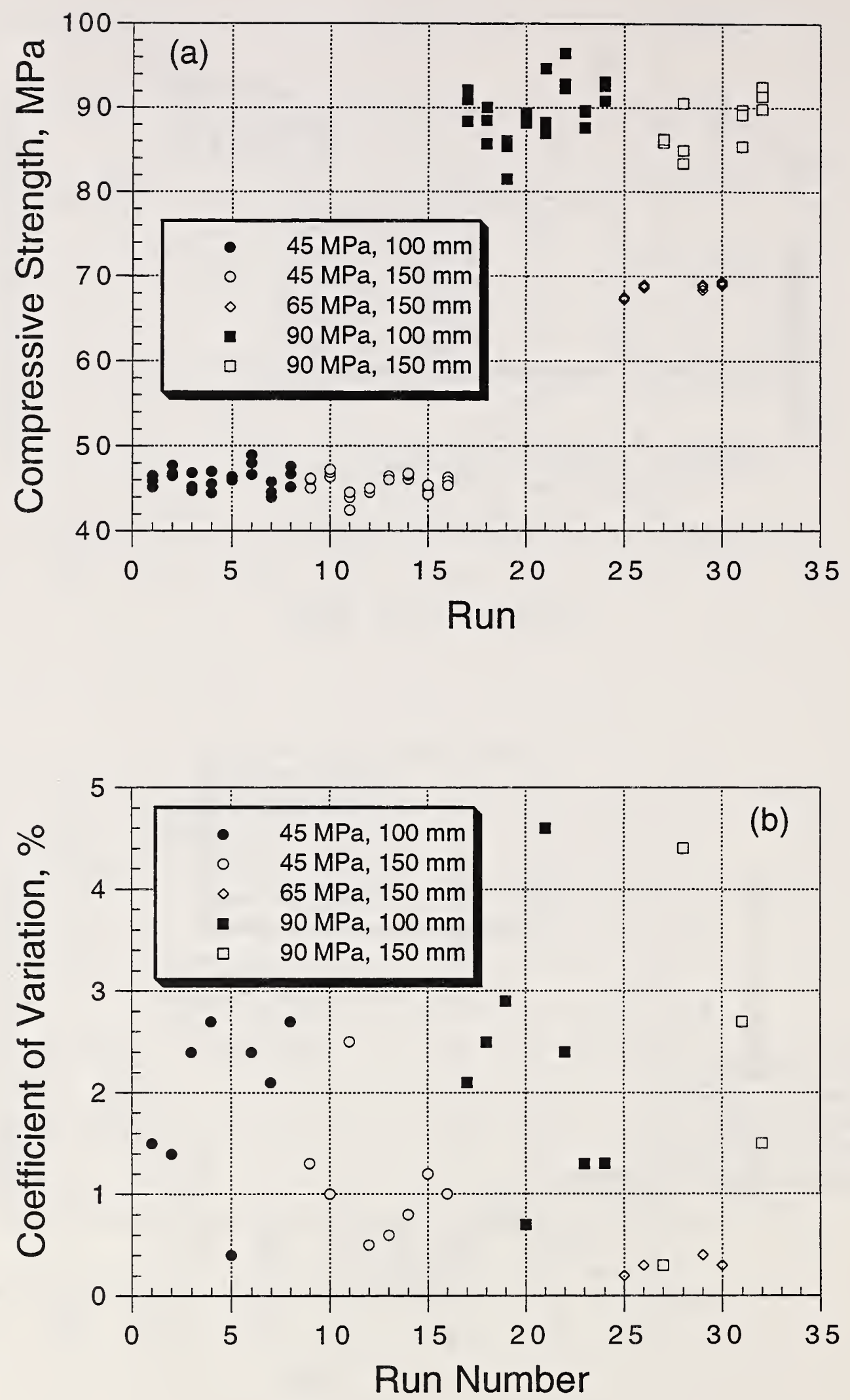

Figure $3.5-$ (a) Compressive strength versus run number, and (b) coefficient of variation versus run number 

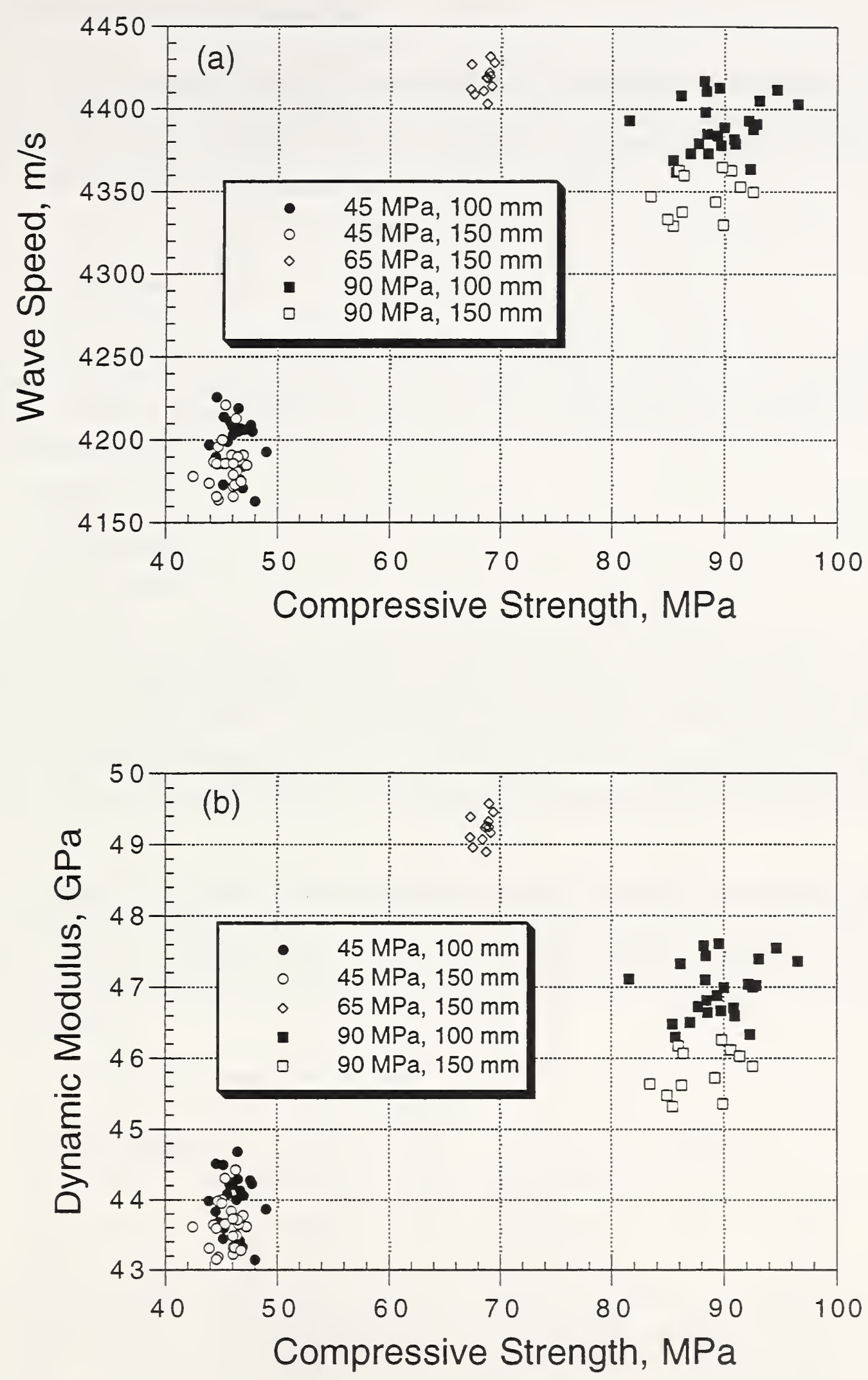

Figure 3.6 - (a) Longitudinal wave speed versus compressive strength, and (b) dynamic modulus of elasticity versus compressive strength 



\section{ANALYSIS OF STRENGTH DATA}

The measured compressive strength data were analyzed statistically to establish which of the factors under study had significant effects on the measured strengths. Recognizing that not all readers might be familiar with these statistical methods, a brief explanation of their general principles is presented before discussing the results of the analyses.

\subsection{Analysis Technique}

As explained in Chapter 2, a full factorial experimental design was used in this study. This type of design is often used in screening studies to detect which of many factors have significant effects on the response variable. In this study the response variable is the measured cylinder compressive strength and the factors are:

- strength level

- cylinder size

- end preparation

- testing machine

- stress rate

In factorial experiments, the factors are typically set at predetermined levels or settings. The most common form of screening experiments employs two settings for each factor, which are termed the low setting and the high setting. A run represents a measurement of the response variable at a particular combination of settings of the factors. The number of runs is established by the type of factorial design. In this study, there were 5 factors and 2 settings per factor, therefore, the number of runs is $2^{5}=32$.

A simple example is presented to illustrate how the results of a factorial experiment are analyzed to establish which factors, including their combinations (interaction), affect the response variable. The example involves two factors, $\mathrm{A}$ and $\mathrm{B}$, with two settings per factor. Thus there are four runs in this full factorial experiment. The following are the settings of the factors in each run and the measured responses:

\begin{tabular}{|c|c|c|c|}
\hline \multirow{2}{*}{ Run Number } & \multicolumn{2}{|c|}{ Settings } & \multirow{2}{*}{ Response } \\
\cline { 2 - 3 } & Factor A & Factor B & \\
\hline 1 & Low (-1) & Low (-1) & 10 \\
\hline 2 & Low (-1) & High (+1) & 7 \\
\hline 3 & High $(+1)$ & Low (-1) & 14 \\
\hline 4 & High $(+1)$ & High $(+1)$ & 12 \\
\hline
\end{tabular}

The results of this experiment can be represented geometrically as shown in Figure 4.1. The origin of the coordinate system is at the center of the square. The coordinates of the corners of the square represent the settings of the factors; a coordinate value of -1 represents the low setting and 
a value of +1 represents the high setting. The measured responses are shown in the circles at the corners of the square. The effect of a factor is the difference between the average response for the runs at the high setting and the average response for the runs at the low setting. In terms of Fig. 4.1, the effect of a factor is the average of the responses on the positive side of the square minus the average of the responses on the negative side. The calculations to determine the effects of factors $\mathrm{A}$ and $\mathrm{B}$ are shown in Fig. 4.1. Besides the effects of the factors, or the main effects, a full factorial experiment also allows determination of the effects due to interactions between factors. An interaction exists when the effect of one factor depends on the setting of another factor. For this simple example, the effect due to the interaction of factors $A$ and $B$ is the difference of the averages along the diagonals of the square. As shown in Fig. 4.1, the interaction effect in this example is 0.5 .

The results of a factorial experiment can also be analyzed using linear regression analysis using a technique known as the general linear model (GLM), in which the settings of the factors and their interactions are the independent variables. Thus the following linear equation could be fitted to the results of this example:

$$
Y=b_{0}+b_{1} x_{1}+b_{2} x_{2}+b_{12} x_{1}^{*} x_{2}
$$

The values of $x_{I}$ and $x_{2}$ represent the settings of the two factors, which are -1 or +1 in this case. The coefficients $\left(b_{0}, b_{1}, b_{2}\right.$, and $\left.b_{12}\right)$ would be found by using ordinary least-squares regression analysis. For this example, the following values would be used as input to the regression analysis:

\begin{tabular}{|c|c|c|c|}
\hline$Y$ & $x_{1}$ & $x_{2}$ & $x_{1} * x_{2}$ \\
\hline 10 & -1 & -1 & +1 \\
7 & -1 & +1 & -1 \\
14 & +1 & -1 & -1 \\
12 & +1 & +1 & +1 \\
\hline
\end{tabular}

For these input values, the regression analysis results in the following equation:

$$
Y=10.75+2.25 x_{1}-1.25 x_{2}+0.25 x_{1} * x_{2}
$$

Comparison with Fig. 4.1 shows that the coefficients $b_{1}$ and $b_{2}$ are one-half of the values of the main effects and the coefficient $b_{12}$ is one-half of the interaction effect. The coefficient $b_{0}$ is the overall, or grand, average of the measured response variable.

This has been a brief explanation of the basic principles used to determine the values of the main effects and interaction effects in a factorial experiment. For further information on the theory of factorial experiments, the reader should refer to textbooks on experimental design (for example, Box, Hunter and Hunter 1978).

The above procedures are to find the values of the effects in a factorial experiment. There is, however, the question of whether the computed effects are statistically significant or are simply due to the inherent variability of the measured responses, that is, the random error. The technique called 
analysis of variance (ANOVA) is one method to establish whether the computed effects (differences between means) are statistically significant. In simple terms, ANOVA finds the likelihood that the observed differences in means could be the result of random variation. Lower likelihood indicates a higher confidence that the differences are due to changes in the levels of the factors rather than random error.

To do an ANOVA, there must be an estimate of the within-test variability, and that is why three replicate tests were used for each run in this study. ANOVA compares the differences between the means of different groups with the variation of the results within each group. If the measure of between-group variability is significantly greater than the measure of within-group variability, it is likely that the differences in the means are real rather than the result of random error. These relative variabilities are expressed by a ratio called the $F$-statistic. A larger $\mathrm{F}$-statistic signifies higher likelihood that the differences between the means are real. In applying this method, the F-statistic computed from the data is compared with tabulated values. If the computed F-statistic exceeds the tabulated values from a F-distribution, one concludes that the group means are not equal. The significance level indicates the level of risk in declaring that the means from the data are not equal when the true means of the populations are equal. Usually, a significance level of 0.05 or 0.01 is used to decide whether differences are statistically significant.

An alternative to ANOVA, for detecting which effects are significant, is to use regression analysis to find the coefficients of the GLM. The regression coefficients are one-half of the values of the effects. The regression analysis also provides an estimate of the standard deviation of the computed values of the effects. From the standard deviation, the confidence intervals for the values of the effects are computed. If a confidence interval includes the value zero, the effect is not statistically significant.

In this study, a computer program that carries out the GLM-technique was used to analyze the strength data. The output of the analysis includes the ANOVA table and the coefficients of the GLM, which are one-half the values of the effects. The following were taken as the high $(+1)$ settings of the factors:

- cylinder size (size): $\quad 150 \mathrm{~mm}$

- end preparation (end): $\quad$ grinding

- testing machine (machine): $4.45 \mathrm{MN}$ capacity

- stress rate (speed): $\quad 0.34 \mathrm{MPa} / \mathrm{s}$

\subsection{Data Transformation}

Before carrying out the analyses to find the effects of the various factors, the strength data were transformed and adjusted. An assumption in ANOVA is that the variance (square of the standard deviation) of the random error is constant. As shown by Fig. 3.5, the within-test standard deviation was greater for the $90-\mathrm{MPa}$ mixture than for the $45-\mathrm{MPa}$ mixture. If the standard deviation is proportional to the mean, that is, if the coefficient of variation is constant, the assumption of constant variance can be satisfied by using the natural logarithms of the data. Hence the individual strength values shown in Table 3.10 were transformed by taking their natural logarithms. These transformed 
values are listed in the third, fourth and fifth columns of Table 4.1. Note that the natural logarithm transformation has a unique property: the standard deviation of the replicate transformed values equals approximately the coefficient of variation of the real values, provided the coefficient of variation is less than about $0.3(30 \%)$.

The response variable in this study is compressive strength, and obviously the strength level of the concrete mixture will have a highly significant effect. In addition, three strength levels were used in this study (as explained in section 2.1). To account for three strength levels and to avoid the possibility that the differences due to strength level would overshadow the effects of other factors, the transformed strengths were adjusted by subtracting the mean (of the transformed values) for each strength level (mixture):

$$
\text { Adjusted Value }=\log _{e} f_{i}-\frac{\sum_{1}^{n} \log _{e} f_{i}}{n}
$$

where $f_{i}=$ individual strength value and

$n=$ number of test results for the mixture.

It can be shown that the adjusted value is equivalent to the natural logarithm of the ratio of the individual strength value to the geometric mean of all the specimens from the particular mixture:

$$
\text { Adjusted Value }=\log _{e}\left(\frac{f_{i}}{\left[\prod_{1}^{n} f_{i}\right]^{\frac{1}{n}}}\right)
$$

The last three columns of Table 4.1 list the adjusted values, and Fig. 4.2 shows these values as a function of the run number. The objective of the subsequent analyses was to establish whether the variability shown in Fig. 4.2 is a result of changes in the settings of the factors under study or simply a result of the inherent error in the measurement of compressive strength. Figure 4.3 shows dotplots of the adjusted values versus the factor settings. Dotplots show the dispersion of the data and whether there may be differences in the means. The dotplots in Fig. 4.3 reveal that there may be differences in the means due to cylinder size, end condition, and testing machine. The analyses discussed in the next section examine whether the observed differences between means are statistically significant. Section 4.4 discusses differences in dispersion.

\subsection{Effects on Means}

\subsubsection{Considering all data}

The adjusted values shown in Table 4.1, and the accompanying settings of the factors, were provided as input to an interactive computer program that carries out the GLM analysis of results of factorial experiments. The factor day was used as a blocking factor to account for any day-to-day 
variability that may have been present. To have degrees of freedom to estimate the value of the random error, all interactions between day and other factors were assumed to be zero. Table 4.2 lists the resulting ANOVA table. The key column is the one labeled Probability, which represents the probability of observing a F-statistic equal to or greater than the computed value due solely to random error. F-statistic values are computed by dividing the mean squares associated with the factors (and interactions) by the error mean square, which is shown in the shaded cell in the fourth column of Table 4.2. The square root of the error mean square is the estimate of the within-test standard deviation of the transformed strengths, that is, the random error, $s_{e}$. Here, the value of the random error, $s_{e}$, of the adjusted strengths is 0.018 . Those effects whose F-statistics have probability levels less than 0.05 are significant, and those effects with probability levels less than 0.01 are highly significant.

The magnitudes of the effects (main effects and interactions) were evaluated by means of regression analysis using the GLM. They could also have been found manually from the differences of the means at the two settings of a factor or interaction of factors. Figure 4.4 shows the residuals of the fitted linear model and the normal probability plot of the residuals. These plots support the underlying assumptions in the GLM, namely, that the errors are normally distributed and have constant variance.

The values of the effects that were found statistically significant from the ANOVA are shown in the second column of Table 4.3. As mentioned, these effects represent the differences between the averages of the adjusted transformed strengths at the high and the low settings of the factor or interaction of factors. Since the differences are between the averages of logarithms of strength values, they are also approximately the fractional differences between the means of the real values. It can be shown that the following approximation is true:

$$
\text { Effect }=\overline{\log _{e}\left(f_{H}\right)}-\overline{\log _{e}\left(f_{L}\right)} \approx \frac{\overline{f_{H}}-\overline{f_{L}}}{\overline{f_{L}}}
$$

where the overline indicates an average value, and the subscripts $H$ and $L$ correspond to the high and low settings. Thus the values of the effects shown in Table 4.3 are approximately the differences in average strengths at the high and low settings divided by the average at the low setting, that is, they are approximately relative strength differences. This is a good approximation up to relative strength differences of \pm 0.10 .

An effect is the difference between two means, therefore, the standard deviation of the computed value of the effect is

$$
s_{\text {effect }}=s_{e} \sqrt{\frac{1}{n_{H}}+\frac{1}{n_{L}}}
$$

The approximate $95 \%$ confidence limits for an effect would be the computed value plus and minus an uncertainty equal to $2 \cdot s_{\text {effect. }}$. For the values in Table 4.3 , the value of $n_{H}=n_{L}=48$, and it can be shown that the uncertainty in the effects equals $0.408 \cdot s_{e}=0.007$. The confidence limits for the effects are shown in the fourth and fifth columns of Table 4.3. The confidence limits do not include 
the value zero, which confirms that these effects are statistically significant as indicated by the ANOVA.

The results in Table 4.3 are interpreted as follows:

- Overall, the $150-\mathrm{mm}$ cylinders had about $1.3 \%$ lower strength than the $100-\mathrm{mm}$ cylinders.

- Overall, the ground cylinders had about $2.1 \%$ greater strength than the cylinders with sulfur caps.

- Overall, the 4.45-MN testing machine resulted in about 2.3\% lower strength than the 1.33 $\mathrm{MN}$ testing machine.

- Overall, the faster loading rate resulted in $2.2 \%$ higher strength than the slower rate.

- There are significant interaction effects.

The ANOVA results in Table 4.2 show a statistically significant strength*end interaction effect, which means that the effect of the end condition depends on the level of strength. In Table 4.3, however, there are four separate values of the strength*end interaction effect. A single interaction effect is not appropriate here because of the nesting ${ }^{k}$ of strength within the factors machine and size. Instead, the interaction is computed separately for each combination of machine and size. The uncertainty of these effects is larger than that of the non-nested effects because fewer measurements are used in each of the four estimates. Using Eq. (4.5) and that $n_{H}=n_{L}=12$ implies that the uncertainty in these effects is $0.816 \cdot s_{e}=0.015$.

Table 4.3 also shows a significant effect due to the interaction of size*end*machine ${ }^{*}$ speed. As a result, the effect of end condition is affected by the settings of all the other factors. To obtain an understanding of how the difference between the strength of ground cylinders and capped cylinders is affected by the other factors, it is necessary to analyze the 16 groups involving different combinations of the factors strength, machine, size, and speed. Each combination includes three replicate tests with sulfur caps and three with ground ends. Table 4.4 shows the effects of end condition for each combination of the settings. The effects are simply the differences between the means of the adjusted strengths of cylinders with sulfur caps and those with ground ends. For $s_{e}=$ 0.018 , as computed from all the data, the uncertainty in the effect for each group is 0.029 , which is $\sqrt{ } 16=4$ times the uncertainty used to compute the effects shown in Table 4.3. The larger uncertainty is due to the smaller number (3) of individual test results used to compute the means in each group. The last two columns in Table 4.4 list the approximate $95 \%$ confidence limits for the effect of end condition for the different groups. Those effects with a confidence interval that includes zero are not statistically significant. The confidence intervals for each group are plotted in Fig. 4.5. The effects have been arranged in decreasing value, and the effects for the slow rate are shown with the filled circles. In general, Fig. 4.5 shows that grinding results in statistically significant higher strengths for the $90-\mathrm{MPa}$ mixture.

${ }^{k}$ Recall that the 65-MPa mixture was used because the $150-\mathrm{mm}$ cylinders of the 90-MPa mixture could not be tested on the $1.33-\mathrm{MN}$ testing machine. In the experimental design, the $65-\mathrm{MPa}$ mixture was substituted for the 90-MPa mixture when the settings of size and machine were $150 \mathrm{~mm}$ and 1.33 MN, respectively. Thus, in this experiment, the level of the factor strength depends on the settings of the factors machine and size. In statistical terms, the factor strength is nested within the factors machine and size. 
In summary, while the overall effect of grinding was a $2.1 \%$ increase in strength compared with using sulfur caps, it is affected by the other factors in this study. The increase was more pronounced in the tests of the $90-\mathrm{MPa}$ concrete. The highest strength increase due to grinding was more than $6 \%$, and it occurred in the $100-\mathrm{mm}, 90-\mathrm{MPa}$ cylinders tested at the fast rate on the $1.33-\mathrm{MN}$ machine.

Tables 4.2 and 4.3 show that there is also a significant interaction effect of size ${ }^{*}$ end*machine*speed. As a result the effects of size, machine, and speed are dependent on the particular settings of the other factors. By using a similar approach to that used for the effect of end condition, the effects of size, machine and speed were found for the various combinations of the other factors. Here, there are eight combinations of settings to consider. The results of the calculations are shown in Table 4.5. The standard deviation for the effects is $s_{e} \sqrt{2} / \sqrt{ } 6=0.010$ because the effects are based on the differences between averages of six replications. The uncertainty is \pm 0.021 . The effects and their confidence intervals are shown in Fig. 4.6, where the effects have been arranged in order of decreasing value. The following summarizes the effects of the factors:

- The overall effect of size is $1.3 \%$ lower strength for the $150-\mathrm{mm}$ cylinders, but a difference as high as $3.7 \%$ occurred for ground cylinders tested at the fast rate on the $1.33-\mathrm{MN}$ machine.

- The overall effect of stress rate (speed) is a $2.2 \%$ increase in strength at the faster rate, but the difference was as high as $4 \%$ for $100-\mathrm{mm}$ ground cylinders tested on the $1.33-\mathrm{MN}$ machine. The effect of stress rate was generally more pronounced for tests using $100-\mathrm{mm}$ cylinders and for tests on the 4.45-MN machine.

- Overall, tests on the $4.45-\mathrm{MN}$ testing machine resulted in $2.3 \%$ lower strength, but the reduction was as much as $4 \%$ for the capped, $150-\mathrm{mm}$ cylinders tested at the fast rate. It appears that the capped cylinders were affected more than the ground cylinders.

In summary, the analysis of all the data showed that the factors chosen for this experiment had statistically significant effects on the measured cylinder strength. There were, however, significant interaction effects. As a result, the effect of any factor depended on the settings of the other factors. Overall, effects of the factors resulted in strength differences less than $3 \%$, but due to interaction effects differences as high as $6 \%$ were observed for particular settings of the factors.

\subsubsection{Sub-analyses of 100-mm cylinders and 4.45-MN machine}

To avoid the problem of nesting of the strength factor within the factors machine and size, two sub-analyses were carried out. These separate analyses considered only the tests of $100-\mathrm{mm}$ cylinders and only the tests on the 4.45-MN machine, both of which do not involve the $65-\mathrm{MPa}$ concrete.

First, the analysis of the $100-\mathrm{mm}$ cylinder data is considered. Figure 4.7 shows dotplots of the adjusted strengths versus the factor settings. Table 4.6 shows the ANOVA table, and the significant effects are noted. As before, the GLM was used to evaluate the effects. Fig. 4.8 shows the residuals of the GLM as a function of the predicted values, and it also shows the normal probability plot of 
the residuals. The assumption of normally distributed residuals with constant variance is justified. The estimated value of the random error for this subset is 0.019 (square root of the mean square for error in Table 4.5), which is practically identical to the value of 0.018 from the previous analysis of all the data.

Table 4.7 summarizes the values of the statistically significant effects for the $100-\mathrm{mm}$ cylinder data. Each effect is based on the differences between means computed from 24 individual results, and it can be shown that the uncertainty of the effects is 0.011 . Note the similarity in the values of the main effects due to end condition, stress rate (speed), and testing machine compared to the values in Table 4, 3 which are based on all the data. The ANOVA table, however, shows that there are significant effects due to interactions among the factors. Thus the effects of end condition, stress rate (speed), and testing machine depend on the setting of the other factors (including strength). To examine this further, the effects of each of these three factors were computed for combinations of factor settings. There are eight combinations of the settings to consider for each factor. The effect of a factor is the difference between the means of the three replicate tests at the high and low settings of that factor. The standard deviation of the effect is $s_{e} \sqrt{ } 2 / \sqrt{ } 3 \approx 0.016$, and the uncertainty is taken as twice this value, or about 0.032 .

Table 4.8 shows the effects of end conditions, stress rate (speed), and testing machine for the various combinations of factor settings. Those effects whose confidence intervals do not include zero are identified are statistically significant. Figure 4.9 shows the confidence intervals for the computed effects, which are arranged in descending order.

The following summarizes the results of this analysis of the subset composed of only the 100mm cylinder strengths:

- Overall, grinding results in $2.2 \%$ greater strength compared with using sulfur caps. Figure 4.9(a), however, shows that the effects are more pronounced with the 90-MPa concrete, and a difference of over $6 \%$ was obtained for tests on the $1.33-\mathrm{MN}$ machine at the high stress rate.

- Overall, the higher stress rate results in $2.5 \%$ greater strength than the lower rate. However, Figure 4.9 (b) shows that the effect can be as high as $5 \%$.

- Overall, the 4.45-MN testing machine resulted in $2.3 \%$ lower strength compared with the 1.33-MN machine. Examination of Fig. 4.9(c) shows that the 45-MPa cylinders were more prone to a machine effect. The exception is for the capped, $90-\mathrm{MPa}$ cylinders tested at the slow rate, where the 4.45 -machine resulted in $7 \%$ lower strength. This large difference is, in part, a result of the (possibly outlying) low strength for the test on the 4.45-MN machine in Run 19, day 3 (see Tables 3.10 or 4.1).

The other sub-analysis considered only the results obtained with the $4.45-\mathrm{N}$ testing machine. Figure 4.10 shows dotplots of the adjusted strength versus the factor settings. Table 4.9 shows the results of the ANOVA analysis. The estimated value of the random error is 0.020 , slightly larger than the values in the previous analyses. Figure 4.11 shows the residuals, from fitting the GLM, versus the predicted values. The normal probability plot shows that the residuals satisfy the normality assumption. Table 4.10 shows the values of statistically significant effects. The uncertainty for these effects is 0.012 . Compared with the analysis of the $100-\mathrm{mm}$ cylinder subset, 
the analysis of the data from only the $4.45-\mathrm{MN}$ machine resulted in fewer statistically significant effects. The only significant interaction effect was end ${ }^{*}$ strength, which is consistent with the previous analyses. Thus the effect of end condition is the sum of the main effect plus and minus the interaction effect. For the $90-\mathrm{MPa}$ cylinders, the effect of grinding compared with sulfur caps is $0.027+0.015=0.042$. The uncertainty is $\sqrt{ } 2 \cdot 0.012=0.017$ because the effect is the sum of the main effect plus the interaction effect. The $95 \%$ confidence interval for the effect of grinding for the 90-MPa cylinders is 0.025 to 0.059 . For the $45-\mathrm{MPa}$ cylinders, the effect of grinding is $0.027-0.015$ $=0.012$, and the $95 \%$ confidence interval is -0.005 to 0.029 . Since this confidence interval includes zero, the effect of grinding is not statistically significant for the 45-MPa cylinders.

\subsubsection{Summary of results}

The general linear model technique was used to find the effects of the chosen factors on the measured cylinder compressive strength. It was found that cylinder size, end conditions, testing machine and stress rate all had statistically significant effects. On average, the magnitudes of the effects were small. There were, however, significant interactions among the factors. As a result, there were large strength differences for particular combinations of the factor settings.

There was a significant interaction effect between strength level and end conditions. Due to this interaction, grinding resulted in greater strength increases in the $90-\mathrm{MPa}$ cylinders compared with the lower-strength cylinders. Strength increases above $5 \%$ were observed in some tests with the 90 $\mathrm{MPa}$ concrete. A strength difference of this amount is important, and it shows that the sulfur mortar used in this study is not appropriate for testing very high-strength concrete.

Overall, the $100-\mathrm{mm}$ cylinders had $1.3 \%$ greater strength than the $150-\mathrm{mm}$ cylinders. Due to interactions, however, the differences were as high as $4 \%$ for a particular combination of the factor settings. The size effect seemed to be more pronounced at the faster stress rate.

On average, the faster loading rate produced $2.2 \%$ higher strength, but the increase varied with the specific testing conditions. Tests with $100-\mathrm{mm}$ cylinders and on the $4.45-\mathrm{MN}$ machine appeared to be more sensitive to stress rate. In general, the strength increase agreed with the results obtained by Chojnacki and Read (1991).

On average, tests on the 1.33-MN, manually-operated testing machine resulted in $2.3 \%$ greater strength compared with tests on the 4.45-M,N servo-controlled machine. Due to interaction effects, the difference was as high as $4 \%$ for particular factor settings. This result was unexpected. A possible explanation for this effect is provided by Fig. 2.5, which shows the time-history of the relative motion between the piston and the crosshead. This relative motion corresponds to the approximate deformation of the cylinder. It is seen that in the 1.33-MN machine, the rate of specimen deformation increases as the ultimate load is being reached. It is well known that strength of concrete increases with strain rate. Thus the apparently higher strength recorded on the 1.33-MN machine could be attributed to the higher strain rate before ultimate load. 


\subsubsection{Supplementary tests}

After the above tests had been completed, the spherically-seated blocks of both testing machine were measured for documentation purposes. Figure 4.12 shows the approximate dimensions of the two blocks. Comparison with Fig. 1.18 shows that the block for the 1.33-MN machine deviates from the requirements of ASTM C 39 in two respects. The center of the sphere does not fall on the bearing surface. This is due to many re-facings over the lifetime of the machine. This deviation is probably not of practical significance, since the head acts as a fixed block during the test. In addition, the diameter of the bearing face exceeds the allowable diameter for testing $100-\mathrm{mm}$ cylinders. It is not known whether this deviation is important.

During measurement of the block dimensions, the bearing surface was inspected with a flat edge and a feeler gage. The bearing surface of the block on the 4.45-MN machine was found to exceed the $0.025-\mathrm{mm}$ flatness requirement of ASTM C 39. The bearing block surface was measured on a precision coordinate-measuring machine to obtain an accurate assessment of the surface profile. Figure 4.13(a) shows the measurement points along two diameters. Figures 4.13(b) and 4.13(c) show the surface profiles along the two diameters. The central $100-\mathrm{mm}$ of the head exceeds the ASTM C 39 flatness requirement by almost a factor of 10. It is believed that the damage occurred during machine calibration due to the use of an inadequate spacer plate between the load cell and the bearing block. This condition raised the question whether the lower strengths obtained on the 4.45MN machine were caused by the defective bearing block. A new block was obtained, and Fig. 4.14 shows the surface profiles obtained from the coordinate measurement system. It is seen that the bearing surface has a slight inclination, and the perimeter is at a higher elevation than the rest of the surface.

A comparative study was carried to examine whether the defective head would result in lower measured strengths. The experimental plan involved testing $100-\mathrm{mm}$ and $150-\mathrm{mm}$ cylinders on the 4.45-MN machine using the defective and flat bearing block. Eight replicate tests were done for each of the four conditions. All cylinders were tested with ground ends. The cylinders were fabricated at the National Ready Mixed Concrete Association laboratory. The concrete mixture proportions were similar to the $90-\mathrm{MPa}$ mixture used in the main series of tests. The cement, however, came from a different source. Two batches were mixed and combined in a pan using shovels. The cylinders were molded using two layers, each of which was consolidated with an internal vibrator. For the $100-\mathrm{mm}$ cylinders, a $16-\mathrm{mm}$ diameter rod was fastened to the vibrator for insertion into the concrete. The sides of the cylinders were tapped with a $16-\mathrm{mm}$ rod after vibration of each layer. The cylinders were stored under water for six days, when they were removed from their molds, weighed in air and under water, and stored in a moist room. They were moved to NIST on the 28th day and stored under water except when their ends were being ground. On the 35th day, the compressive strength was measured. The $4.45-\mathrm{MN}$ machine was operated at a constant rate of piston travel: $0.13 \mathrm{~mm} / \mathrm{m}$ for the $100-\mathrm{mm}$ cylinders and $0.19 \mathrm{~mm} / \mathrm{m}$ for the $150-\mathrm{mm}$ cylinders. A list of random numbers was used to assign the type of head to be used for each cylinder, and the cylinders (identified by a number) were tested in a random order.

The measured specific gravities, nominal stress rates and compressive strengths are listed in Table 4.11. The average nominal stress rate for the $100-\mathrm{mm}$ cylinders was $0.20 \mathrm{MPa} / \mathrm{s}$, and it was 
$0.22 \mathrm{MPa} / \mathrm{s}$ for the $150-\mathrm{mm}$ cylinders. Figures 4.15 (a) and 4.15 (b) are dotplots of the specific gravities and compressive strengths, respectively, grouped according to cylinder size and type of head. The letter " $F$ " indicates specimens tested with the flat head, and the letter "D" indicates specimens tested with the damaged, or dished, head. The first analysis was to detect whether there were any statistically significant differences among the specific gravities of the cylinders in the four groups. Table 4.12 shows the means and standard deviations for each group. Table 4.13 shows the results of the ANOVA to test whether there were any significant differences among means. It was found that there were no significant differences in the mean specific gravities of the cylinders assigned to the four groups. Note that the average specific gravity for the $100-\mathrm{mm}$ cylinders was 2.378 and for the 150 -mm cylinders it was 2.375 . Thus, in contrast to the results in the main series of tests, the $100-\mathrm{mm}$ cylinders were not denser than the $150-\mathrm{mm}$ cylinders.

Two of the strength results were identified as possible outliers by the computer program, and these are identified with a "?" in Fig. 4.15(b). Table 4.14 shows the group means based on all the data and based on the data without the potential outliers. The ANOVA, to establish whether there were differences in the mean strengths of the four groups, was done with and without these potential outliers. Table 4.15 shows the ANOVA results for the analysis of all the data. The estimate of the within-group standard deviation is $1.91 \mathrm{MPa}$. Surprisingly, there were no statistically significant differences in the mean strength due to either specimen diameter or type of bearing block. The mean strength of all the $100-\mathrm{mm}$ cylinders was $67.34 \mathrm{MPa}$ compared with $67.87 \mathrm{MPa}$ for the $150-\mathrm{mm}$ cylinders. For the $100-\mathrm{mm}$ cylinders, the mean strength for the tests with the dished head was $1.4 \%$ lower than for the tests with the flat head, and this difference was only $0.6 \%$ for the $150-\mathrm{mm}$ cylinders. Both differences, however, were not statistically significant. Note that the within-group coefficient of variation tended to be higher for the $100-\mathrm{mm}$ cylinders $(3.4 \%)$ than for the $150-\mathrm{mm}$ cylinders $(2 \%)^{1}$.

Table 4.16 shows the results of the ANOVA with the two potential outliers removed. The estimate of the within-group standard deviation is $1.70 \mathrm{MPa}$. Again, the analysis showed no statistically significant differences in means due to cylinder size or type of head. The overall mean strength of the $100-\mathrm{mm}$ cylinders was $67.02 \mathrm{MPa}$ compared with $68.03 \mathrm{MPa}$ for the $150-\mathrm{mm}$ cylinders. For the $100-\mathrm{mm}$ cylinders, the mean strength for the tests with the dished head was $0.5 \%$ lower than for the tests with the flat head, and this difference was only $0.1 \%$ for the $150-\mathrm{mm}$ cylinders.

In summary, these supplemental tests showed that the defective bearing block resulted in only small decreases in the measured strength, which were not statistically significant. These decreases were not large enough to explain the $2.3 \%$ lower strength obtained with the $4.45-\mathrm{MN}$ testing machine in the main series of tests. Thus it is believed that the previous explanation (higher strain rate in the 1.33-MN machine as the ultimate load was being reached) is still plausible. These tests also showed that the strengths of the $100-\mathrm{mm}$ cylinders tended to be lower than those of the $150-\mathrm{mm}$ cylinders. These differences, however, were not statistically significant, which can, perhaps, be explained by the fact that the specific gravities were not different for the two cylinder sizes.

'Bartlett's test for homogeneity of variance (Snedecor and Cochran 1967) indicated that there were no statistically significant $(\alpha=0.05)$ differences among the variabilities of the four groups. 


\subsection{Effects on Dispersion}

An analysis was also done to determine whether the experimental factors affected the dispersion of the test results. As mentioned, the standard deviation of the logarithms of the strength values is approximately equal to the coefficient of variation $(c v)$ of the actual strength values. Table 4.17 shows the standard deviation of the natural logarithms of the strength values presented in Table 3.10. Note that the standard deviations in Table 4.17 are similar numerically to the coefficients of variation shown in Table 3.10 .

The general linear model was used to analyze the effects of the experimental factors on the dispersion of the data. To better satisfy the assumptions of normality and constant variance that are fundamental to the application of the general linear model, the measure of dispersion was taken as the natural logarithm of the standard deviation of the transformed data. This is approximately the same as using the natural logarithms of the $c v$ of the strength values. Thus the measure of dispersion is as follows:

$$
\begin{aligned}
\text { Measure of Dispersion } & =\log _{e}\left(s_{\log f}\right) \\
& =\log _{e}(c v)
\end{aligned}
$$

where $s_{\log f}$ is the standard deviation of the transformed strengths for each run. The last column in Table 4.17 shows the measures of dispersion used in the general linear model. The average value of this last column is -4.4094 . The sum of the logarithms of a series of numbers equals the logarithm of the product of the numbers, and division of a logarithm by $n$ equals the logarithm of the $n t h$ root of the number. Therefore, the average value of the logarithms equals the logarithm of the geometric mean of the $c v$ :

$$
\text { Average }=\frac{\sum \log _{e}(c v)}{n}=\log _{e}\left(\prod c v\right)^{\frac{1}{n}}
$$

The exponential of -4.4094 (that is, $e^{-4.4094}$ ) equals 0.012 , which represents the overall geometric mean $c v$ of the strength values.

Figure 4.16 shows dotplots of the measures of dispersion versus the settings of the factors. The most obvious anomalies are the low values associated with the tests of $65-\mathrm{MPa}$ concrete (run numbers $25,26,29$ and 30). These cylinders were all tested on one day, so there is no day-to-day variation as is present in the results of the other runs. In addition, these tests involved loads that were about $90 \%$ of the capacity of the $1.33-\mathrm{MN}$ machine, and there were some unusual plots of piston-crosshead distance versus time. Thus some testing conditions for the 65-MPa cylinders may have been abnormal.

In using the general linear model to establish whether the factors had statistically significant effects on the dispersion, it was assumed that all interactions involving three or more factors were 
not significant ${ }^{\mathrm{m}}$. If all interaction terms were included, there would be no degrees of freedom to evaluate the error, and it would not be possible to use ANOVA to discern which effects were significant. Table 4.18 shows the results of the ANOVA when only two-factor interactions are included in the analysis. As for the analysis of means, the factor strength was nested in the factors machine and size. The estimate of the error is 0.771 .

The ANOVA table shows that cylinder diameter appears as the only factor having a statistically significant effect on the dispersion of the test results. The size of the effect of a factor on the dispersion is computed in the same way as the effect on the mean, that is, by subtracting the mean at the high setting of the factor from the mean of the low setting.

$$
\text { Effect on Dispersion }=\frac{\sum \log _{e}(c v)_{H}}{n_{H}}-\frac{\sum \log _{e}(c v)_{L}}{n_{L}}
$$

However, the subtraction in Eq. (4.8) is equivalent to the logarithm of the ratio of the geometric mean $c v$ at the high setting to the geometric mean $c v$ at the low setting:

$$
\text { Effect on Dispersion }=\log _{e}\left(\frac{\left(\Pi c v_{H}\right)^{\frac{1}{n_{H}}}}{\left(\Pi c v_{L}\right)^{\frac{1}{n_{L}}}}\right)
$$

Thus the exponential of the effect value is the ratio of the geometric mean $c v$ at the high setting to the geometric mean $c v$ at the low setting. The effect of cylinder size on dispersion was found to equal -0.809 . Since the effect is based on the difference between averages, each calculated from 16 values, the standard error is $0.771 / \sqrt{ } 8=0.273$. The confidence interval for the effect of cylinder size is $-0.809 \pm 2 \cdot 0.273$, or -1.355 to -0.263 . Taking exponentials of these values, the estimate of the ratio of the geometric mean $c v(150-\mathrm{mm}$ cylinders to $100-\mathrm{mm}$ cylinders $)$ is $e^{-0.809}=0.45$, with a confidence interval of $e^{-1.355}=0.26$ to $e^{-0.263}=0.77$. The geometric mean $c v$ for the $150-\mathrm{mm}$ cylinders is 0.008 and for the $100-\mathrm{mm}$ cylinders it is 0.018 .

To examine further the effect of cylinder size on dispersion, Fig. 4.17(a) presents a graphical representation of the geometric mean $c v$ for different combinations of strength*diameter*machine. The values shown in the spheres at the corners of the cube are the geometric mean coefficients of variation computed from four cases (two end conditions and two loading speeds). The effect due to cylinder diameter is the difference between the $\log _{e}$ of the geometric mean of the values on the $150-\mathrm{mm}$ face of the cube and the $\log _{e}$ of the geometric mean of the values on the $100-\mathrm{mm}$ face. It is seen that the geometric mean $c v$ for the cases involving $65-\mathrm{MPa}$ concrete is considerably smaller than the other values on the $150-\mathrm{mm}$ face of the cube. This factor could explain why there is a difference in the dispersion for the two cylinder sizes. To examine this further, an analysis was

${ }^{\mathrm{m}}$ The suitability of this assumption was verified by another analytical technique which considered all interactions and evaluated the significance of the effects by means of a normal probability plot. The normal probability plot was able to identify those effects which were large enough to be considered statistically significant. 
performed using only the tests on the 4.45-MN testing machine, which do not involve the $65-\mathrm{MPa}$ concrete. Again, only two-factor interactions were considered in the GLM analysis. The results of the ANOVA for this subset are shown in Table 4.19, and it is seen that there are no statistically significant effects on the dispersion.

To complete the analysis of the dispersion, the results for only the $100-\mathrm{mm}$ cylinders were considered. The results of the ANOVA are shown in Table 4.20, and it is seen that the only statistically significant effect was due to the machine* strength interaction. Figure 4.17(b) shows the 100-mm face of the cube in Fig. 4.17(a), which helps to explain the meaning of the interaction effect. It is seen that for the 45-MPa cylinders, the geometric mean $c v$ was higher on the 4.45-MN machine than on the 1.33-MN machine. On the other hand, for the $90-\mathrm{MPa}$ cylinders, the geometric mean $c v$ was greater on the $1.33-\mathrm{MN}$ machine. The cause of this interaction effect is not known. Perhaps, the higher dispersion for the 45-MPa cylinders on the 4.45-MN machine can be attributed to the inherent measurement precision when the machine is operated at a low fraction of its capacity $(<10 \%$ of capacity in these tests).

In summary, the general linear model technique was used to analyze effects on the dispersion of the data. When all data were considered, there was a significant effect due to cylinder size. Closer examination of the data, however, showed that this finding can be attributed to the abnormally low dispersion recorded for the $150-\mathrm{mm}$ cylinders made with the 65-MPa concrete. There were some indications that these tests may have involved abnormal conditions because the test loads were close to the capacity of the $1.33-\mathrm{MN}$ machine. The subset that included only the tests on the 4.45-MN machine showed no effects on dispersion. The tests of the $100-\mathrm{mm}$ cylinders showed an interaction effect due to machine*strength.

\subsection{Summary}

This chapter has presented the results of the statistical analyses to establish the effects of the design factors on the means and dispersion of the measured compressive strength. The technique known as the general linear model was used to calculate the effects, and ANOVA was used to establish whether the effects were statistically significant. To satisfy the assumptions in the GLM analysis, the strength data were transformed by taking their natural logarithms. The transformed values were further adjusted by subtracting the mean for each strength level. For the analysis of effects on dispersion, the natural logarithms of the standard deviation of the transformed strength values were used. These are approximately the same as the logarithms of the coefficient of variation of the actual strengths.

The analysis of the effects on the means showed that cylinder size, end condition, stress rate, and testing machine had statistically significant effects on the results. However, there were significant interaction effects, so that the effect of each factor depended on the particular settings of the other factors. In some cases, differences more than $5 \%$ were observed due to a change in the setting of a single factor. 
The analysis of the effects on the dispersion showed an effect due to cylinder size. However, closer examination of the data showed that this conclusion may be attributed to the abnormally low dispersion associated with the tests of the $150-\mathrm{mm}$ cylinders of the $65-\mathrm{MPa}$ concrete. Thus this study failed to demonstrate conclusively whether size affects the dispersion of cylinder strengths. 
Table 4.1 - Transformed and adjusted strength values for data analysis

\begin{tabular}{|c|c|c|c|c|r|r|r|}
\hline \multirow{2}{*}{$\begin{array}{c}\text { Run } \\
\text { Number }\end{array}$} & \multirow{2}{*}{$\begin{array}{c}\text { Nominal } \\
\text { Strength, } \\
\text { MPA }\end{array}$} & \multicolumn{2}{|c|}{ Transformed Strength } & \multicolumn{2}{|c|}{ Adjusted Transformed Strength } \\
\cline { 3 - 8 } & Ln(\#1) & Ln(\#2) & Ln(\#3) & \multicolumn{1}{|c|}{$\# 1$} & \multicolumn{1}{|c|}{$\# 2$} & \multicolumn{1}{c|}{$\# 3$} \\
\hline 1 & 45 & 3.8095 & 3.8271 & 3.8395 & -0.0155 & 0.0021 & 0.0144 \\
2 & 45 & 3.8390 & 3.8452 & 3.8654 & 0.0140 & 0.0202 & 0.0403 \\
3 & 45 & 3.8011 & 3.8122 & 3.8474 & -0.0240 & -0.0128 & 0.0223 \\
4 & 45 & 3.8190 & 3.7948 & 3.8493 & -0.0060 & -0.0302 & 0.0242 \\
5 & 45 & 3.8280 & 3.8299 & 3.8364 & 0.0029 & 0.0049 & 0.0114 \\
6 & 45 & 3.8448 & 3.8912 & 3.8710 & 0.0198 & 0.0662 & 0.0459 \\
7 & 45 & 3.7819 & 3.8232 & 3.7966 & -0.0431 & -0.0019 & -0.0284 \\
8 & 45 & 3.8104 & 3.8437 & 3.8630 & -0.0146 & 0.0187 & 0.0380 \\
9 & 45 & 3.8323 & 3.8289 & 3.8076 & 0.0073 & 0.0038 & -0.0175 \\
10 & 45 & 3.8364 & 3.8555 & 3.8484 & 0.0114 & 0.0304 & 0.0234 \\
11 & 45 & 3.7486 & 3.7966 & 3.7824 & -0.0765 & -0.0284 & -0.0427 \\
12 & 45 & 3.7997 & 3.8071 & 3.7966 & -0.0253 & -0.0179 & -0.0284 \\
13 & 45 & 3.8293 & 3.8386 & 3.8289 & 0.0042 & 0.0135 & 0.0038 \\
14 & 45 & 3.8302 & 3.8450 & 3.8407 & 0.0051 & 0.0200 & 0.0157 \\
15 & 45 & 3.7905 & 3.8144 & 3.7993 & -0.0345 & -0.0106 & -0.0257 \\
16 & 45 & 3.8351 & 3.8258 & 3.8144 & 0.0101 & 0.0008 & -0.0106 \\
17 & 90 & 4.4821 & 4.5232 & 4.5102 & -0.0063 & 0.0348 & 0.0218 \\
18 & 90 & 4.4505 & 4.4996 & 4.4836 & -0.0379 & 0.0112 & -0.0048 \\
19 & 90 & 4.4476 & 4.4553 & 4.4010 & -0.0408 & -0.0331 & -0.0874 \\
20 & 90 & 4.4823 & 4.4798 & 4.4929 & -0.0061 & -0.0085 & 0.0045 \\
21 & 90 & 4.4654 & 4.4805 & 4.5501 & -0.0229 & -0.0079 & 0.0617 \\
22 & 90 & 4.5252 & 4.5311 & 4.5699 & 0.0368 & 0.0427 & 0.0815 \\
23 & 90 & 4.4736 & 4.4966 & 4.4947 & -0.0148 & 0.0082 & 0.0063 \\
24 & 90 & 4.5279 & 4.5093 & 4.5336 & 0.0395 & 0.0209 & 0.0452 \\
25 & 65 & 4.2129 & 4.2086 & 4.2095 & -0.0141 & -0.0184 & -0.0175 \\
26 & 65 & 4.2343 & 4.2292 & 4.2306 & 0.0073 & 0.0022 & 0.0036 \\
27 & 90 & 4.4583 & 4.4567 & 4.4531 & -0.0301 & -0.0317 & -0.0353 \\
28 & 90 & 4.4411 & 4.4236 & 4.5063 & -0.0473 & -0.0647 & 0.0180 \\
29 & 65 & 4.2252 & 4.2343 & 4.2300 & -0.0017 & 0.0073 & 0.0031 \\
30 & 65 & 4.2360 & 4.2335 & 4.2397 & 0.0090 & 0.0066 & 0.0128 \\
31 & 90 & 4.4473 & 4.4907 & 4.4974 & -0.0410 & 0.0023 & 0.0090 \\
32 & 90 & 4.5152 & 4.4985 & 4.5277 & 0.0269 & 0.0101 & 0.0394 \\
\hline
\end{tabular}

Average transformed strengths: for 45-MPa mixture $=3.8250 ; 65-\mathrm{MPa}=4.2270 ; 90-\mathrm{MPa}=4.4884$ 
Table 4.2 - ANOVA table for effects on the means (all data)

\begin{tabular}{|c|c|c|c|c|c|}
\hline Source & $\mathrm{df}$ & $\begin{array}{l}\text { Sums of } \\
\text { Squares } \\
\end{array}$ & $\begin{array}{c}\text { Mean } \\
\text { Square }\end{array}$ & F-statistic & Probability \\
\hline Day & 2 & 0.005003 & 0.002501 & 7.725 & $0.0010 \dagger \uparrow$ \\
\hline Size & 1 & 0.004093 & 0.004093 & 12.639 & $0.0007 \dagger \dagger$ \\
\hline End & 1 & 0.010112 & 0.010112 & 31.227 & $\leq 0.0001 \dagger i$ \\
\hline Size*End & 1 & 0.000033 & 0.000033 & 0.102 & 0.7501 \\
\hline Machine & 1 & 0.012991 & 0.012991 & 40.117 & $\leq 0.0001 \dagger i$ \\
\hline Size*Machine & 1 & 0.000000 & 0.000000 & 0.001 & 0.9745 \\
\hline End*Machine & 1 & 0.001146 & 0.001146 & 3.539 & 0.0647 \\
\hline Size*End*Machine & 1 & 0.000856 & 0.000856 & 2.642 & 0.1092 \\
\hline Speed & 1 & 0.011260 & 0.011260 & 34.772 & $\leq 0.0001 \dagger \dagger$ \\
\hline Size*Speed & 1 & 0.000334 & 0.000334 & 1.030 & 0.3141 \\
\hline End*Speed & 1 & 0.001070 & 0.001070 & 3.305 & 0.0739 \\
\hline Size*End*Speed & 1 & 0.001038 & 0.001038 & 3.206 & 0.0783 \\
\hline Machine*Speed & 1 & 0.000516 & 0.000516 & 1.594 & 0.2114 \\
\hline Size*Machine* Speed & 1 & 0.000035 & 0.000035 & 0.109 & 0.7428 \\
\hline End*Machine*Speed & 1 & 0.000001 & 0.000001 & 0.004 & 0.9491 \\
\hline Size*End*Mach*Speed & 1 & 0.001487 & 0.001487 & 4.592 & $0.0361 \uparrow$ \\
\hline Strength & 4 & 0.001500 & 0.000375 & 1.158 & 0.3380 \\
\hline End*Strength & 4 & 0.004230 & 0.001057 & 3.266 & $0.0171 \uparrow$ \\
\hline Speed*Strength & 4 & 0.001667 & 0.000417 & 1.287 & 0.2849 \\
\hline End*Speed*Strength & 4 & 0.002778 & 0.000695 & 2.145 & 0.0858 \\
\hline Error & 62 & 0.020077 & 0.000324 & & \\
\hline Total & 95 & 0.080227 & & & \\
\hline
\end{tabular}

$\dagger \dagger=$ highly significant

$\dagger=$ significant 
Table 4.3 - Summary of significant effects on the means (all 32 runs)

\begin{tabular}{|c|c|c|c|c|}
\hline Factor & Effect & $\begin{array}{c}\text { Uncertainty } \\
\pm 2 \cdot S_{\text {effect }}\end{array}$ & $\begin{array}{c}\text { Lower } \\
\text { Limit }\end{array}$ & $\begin{array}{c}\text { Upper } \\
\text { Limit }\end{array}$ \\
\hline Size & -0.013 & \pm 0.007 & -0.020 & -0.006 \\
\hline End & 0.021 & \pm 0.007 & 0.013 & 0.028 \\
\hline Machine & -0.023 & \pm 0.007 & -0.030 & -0.016 \\
\hline Speed & 0.022 & \pm 0.007 & 0.014 & 0.029 \\
\hline End*Strength广 & 0.008 & \pm 0.015 & -0.007 & 0.023 \\
$100 \mathrm{~mm}-1.33 \mathrm{MN}$ & 0.023 & \pm 0.015 & 0.008 & 0.038 \\
$100 \mathrm{~mm}-4.45 \mathrm{MN}$ & 0.006 & \pm 0.015 & -0.009 & 0.021 \\
$150 \mathrm{~mm}-1.33 \mathrm{MN}$ & 0.007 & \pm 0.015 & -0.008 & 0.022 \\
\hline $150 \mathrm{~mm}-4.45 \mathrm{MN}$ & 0.008 & \pm 0.007 & 0.001 & 0.015 \\
\hline Size*End*Machine*Speed & & &
\end{tabular}

$\uparrow$ Cannot be summarized as a single effect due to nesting of strength within size and machine. Therefore, four values are given for combinations of size and machine (the first number listed is the cylinder diameter and the second number is the testing machine capacity). 
Table 4.4 - Effect of end condition for different settings of other four factors (all 32 runs)

\begin{tabular}{|c|c|c|c|c|}
\hline $\begin{array}{c}\text { Factor Settings } \\
\text { (see legend) }\end{array}$ & End Effect & $\begin{array}{c}\text { Uncertainty, } \\
\pm 2 \cdot S_{\text {effec }}\end{array}$ & Lower Limit & Upper Limit \\
\hline $45-100-1.33-\mathrm{Sl}$ & 0.006 & \pm 0.029 & -0.023 & 0.035 \\
\hline $45-100-1.33-\mathrm{F}$ & 0.019 & \pm 0.029 & -0.010 & 0.048 \\
\hline $45-100-4.45-\mathrm{Sl}$ & -0.020 & \pm 0.029 & -0.049 & 0.009 \\
\hline $45-100-4.45-\mathrm{F}$ & 0.018 & \pm 0.029 & -0.011 & 0.047 \\
\hline $45-150-1.33-\mathrm{Sl}$ & 0.009 & \pm 0.029 & -0.020 & 0.038 \\
\hline $45-150-1.33-\mathrm{F}$ & -0.008 & \pm 0.029 & -0.037 & 0.021 \\
\hline $45-150-4.45-\mathrm{Sl}$ & 0.026 & \pm 0.029 & -0.003 & 0.055 \\
\hline $45-150-4.45-\mathrm{F}$ & 0.024 & \pm 0.029 & -0.005 & 0.053 \\
\hline $65-150-1.33-\mathrm{Sl}$ & 0.020 & \pm 0.029 & -0.009 & 0.049 \\
\hline $65-150-1.33-\mathrm{F}$ & 0.005 & \pm 0.029 & -0.024 & 0.034 \\
\hline $90-100-1.33-\mathrm{Sl}$ & -0.006 & \pm 0.029 & -0.035 & 0.023 \\
\hline $90-100-1.33-\mathrm{F}$ & $0.064 \dagger$ & \pm 0.029 & 0.035 & 0.093 \\
\hline $90-100-4.45-\mathrm{Sl}$ & $0.054 \dagger$ & \pm 0.029 & 0.025 & 0.083 \\
\hline $90-100-4.45-\mathrm{F}$ & $0.039 \dagger$ & \pm 0.029 & 0.010 & 0.068 \\
\hline $90-150-4.45-\mathrm{Sl}$ & 0.022 & \pm 0.029 & -0.007 & 0.051 \\
\hline $90-150-4.45-\mathrm{F}$ & $0.057 \dagger$ & \pm 0.029 & 0.028 & 0.086 \\
\hline
\end{tabular}

$\dagger$ significant $(\alpha \leq 0.05)$

Legend: $\quad 45=45-\mathrm{MPa}$ mixture

$90=90-\mathrm{MPa}$ mixture $\quad 65=65-\mathrm{MPa}$ mixture

$100=100-\mathrm{mm}$ cylinder

$150=150-\mathrm{mm}$ cylinder

$1.33=1.33-\mathrm{MN}$ machine

$4.45=4.45-\mathrm{MN}$ machine

$\mathrm{Sl}=0.14 \mathrm{MPa} / \mathrm{s}$

$\mathrm{F}=0.34 \mathrm{MPa} / \mathrm{s}$ 
Table 4.5 - Effects of diameter (size), stress rate, and testing machine for different settings of other factors (all 32 runs)

\begin{tabular}{|c|c|c|c|c|}
\hline Factor Settings & & & & \\
\hline \multirow{2}{*}{ End*Machine*Speed } & \multicolumn{4}{|c|}{ Effect of size $(150 \mathrm{~mm}-100 \mathrm{~mm})$} \\
\hline & Effect & Uncertainty, $\pm 2 \cdot s_{\text {effect }}$ & Lower Limit & Upper Limit \\
\hline $\begin{array}{l}\text { G-1.33-F } \\
\text { S-1.33.F } \\
\text { G-4.45-F } \\
\text { S-4.45-F } \\
\text { G-1.33-S1 } \\
\text { S-1.33-S1 } \\
\text { G-4.45-Sl } \\
\text { S-4.45-Sl }\end{array}$ & $\begin{array}{l}-0.037 \dagger \\
0.006 \\
-0.012 \\
-0.024 \uparrow \\
-0.003 \\
-0.018 \\
-0.005 \\
-0.012 \\
\end{array}$ & $\begin{array}{l} \pm 0.021 \\
\pm 0.021 \\
\pm 0.021 \\
\pm 0.021 \\
\pm 0.021 \\
\pm 0.021 \\
\pm 0.021 \\
\pm 0.021\end{array}$ & $\begin{array}{l}-0.058 \\
-0.015 \\
-0.033 \\
-0.045 \\
-0.024 \\
-0.039 \\
-0.026 \\
-0.033 \\
\end{array}$ & $\begin{array}{r}-0.016 \\
0.027 \\
0.009 \\
-0.003 \\
0.018 \\
0.003 \\
0.016 \\
0.009 \\
\end{array}$ \\
\hline \multirow{2}{*}{ Size*End*Machine } & \multicolumn{4}{|c|}{ Effect of stress rate (Fast - Slow) } \\
\hline & Effect & Uncertainty, $\pm 2 \cdot s_{\text {effect }}$ & Lower Limit & Upper Limit \\
\hline $\begin{array}{l}100-\mathrm{G}-1.33 \\
150-\mathrm{G}-1.33 \\
100-\mathrm{S}-1.33 \\
150-\mathrm{S}-1.33 \\
100-\mathrm{G}-4.45 \\
150-\mathrm{G}-4.45 \\
100-\mathrm{S}-4.45 \\
150-\mathrm{S}-4.45\end{array}$ & $\begin{array}{c}0.040 \uparrow \\
0.007 \\
-0.001 \\
0.023 \dagger \\
0.037 \dagger \\
0.030 \uparrow \\
0.026 \dagger \\
0.013\end{array}$ & $\begin{array}{l} \pm 0.021 \\
\pm 0.021 \\
\pm 0.021 \\
\pm 0.021 \\
\pm 0.021 \\
\pm 0.021 \\
\pm 0.021 \\
\pm 0.021\end{array}$ & $\begin{array}{r}0.019 \\
-0.014 \\
-0.022 \\
0.002 \\
0.016 \\
0.009 \\
0.005 \\
-0.008 \\
\end{array}$ & $\begin{array}{l}0.061 \\
0.028 \\
0.020 \\
0.044 \\
0.058 \\
0.051 \\
0.047 \\
0.034 \\
\end{array}$ \\
\hline \multirow{2}{*}{ Size*End*Speed } & \multicolumn{4}{|c|}{ Effect of testing machine (4.45 MN $-1.33 \mathrm{MN})$} \\
\hline & Effect & Uncertainty, $\pm 2 \cdot s_{\text {effect }}$ & Lower Limit & Upper Limit \\
\hline $\begin{array}{c}100-\mathrm{G}-\mathrm{F} \\
150-\mathrm{G}-\mathrm{F} \\
100-\mathrm{S}-\mathrm{F} \\
150-\mathrm{S}-\mathrm{F} \\
100-\mathrm{G}-\mathrm{Sl} \\
150-\mathrm{G}-\mathrm{Sl} \\
100-\mathrm{S}-\mathrm{Sl} \\
150-\mathrm{S}-\mathrm{Sl}\end{array}$ & $\begin{array}{l}-0.024 \uparrow \\
0.001 \\
-0.011 \\
-0.041 \uparrow \\
-0.021 \uparrow \\
-0.022 \uparrow \\
-0.038 \uparrow \\
-0.031 \uparrow\end{array}$ & $\begin{array}{l} \pm 0.021 \\
\pm 0.021 \\
\pm 0.021 \\
\pm 0.021 \\
\pm 0.021 \\
\pm 0.021 \\
\pm 0.021 \\
\pm 0.021\end{array}$ & $\begin{array}{l}-0.045 \\
-0.020 \\
-0.032 \\
-0.062 \\
-0.042 \\
-0.043 \\
-0.059 \\
-0.052\end{array}$ & $\begin{array}{r}-0.003 \\
0.022 \\
0.010 \\
-0.020 \\
0.000 \\
-0.001 \\
-0.017 \\
-0.010\end{array}$ \\
\hline
\end{tabular}

$\dagger$ significant $(\alpha \leq 0.05)$

Legend: $1.33=1.33-\mathrm{MN}$ machine

$$
\begin{aligned}
& \mathrm{F}=0.34 \mathrm{MPa} / \mathrm{s} \\
& \mathrm{G}=\text { ground ends } \\
& 100=100-\mathrm{mm} \text { cylinder }
\end{aligned}
$$

$4.45=4.45-\mathrm{MN}$ machine

$\mathrm{Sl}=0.14 \mathrm{MPa} / \mathrm{s}$

$\mathrm{S}=$ sulfur caps

$150=150-\mathrm{mm}$ cylinder 
Table 4.6 ANOVA table for effects on the means (100-mm cylinders only)

\begin{tabular}{|c|c|c|c|c|c|}
\hline Source & df & $\begin{array}{l}\text { Sums of } \\
\text { Squares }\end{array}$ & $\begin{array}{c}\text { Mean } \\
\text { Squares }\end{array}$ & F-statistic & Probability \\
\hline Day & 2 & 0.005500 & 0.002750 & 7.324 & $0.0026 \dagger \dagger$ \\
\hline End & 1 & 0.005651 & 0.005651 & 15.050 & $0.0005 \uparrow \dagger$ \\
\hline Machine & 1 & 0.006561 & 0.006561 & 17.474 & $0.0002 \uparrow \uparrow$ \\
\hline End*Machine & 1 & 0.000011 & 0.000011 & 0.0282 & 0.8678 \\
\hline Speed & 1 & 0.007735 & 0.007735 & 20.599 & $\leq 0.0001 \uparrow \uparrow$ \\
\hline End*Speed & 1 & 0.002108 & 0.002108 & 5.614 & $0.0244 \dagger$ \\
\hline Machine*Speed & 1 & 0.000411 & 0.000411 & 1.093 & 0.3041 \\
\hline End*Machine*Speed & 1 & 0.000700 & 0.000700 & 1.863 & 0.1824 \\
\hline Strength & 1 & 0.000012 & 0.000012 & 0.032 & 0.8597 \\
\hline End*Strength & 1 & 0.002986 & 0.002986 & 7.952 & $0.0084 \uparrow \dagger$ \\
\hline Machine*Strength & 1 & 0.000001 & 0.000001 & 0.003 & 0.9567 \\
\hline End*Machine* Strength & 1 & 0.000712 & 0.000712 & 1.895 & 0.1788 \\
\hline Speed*Strength & 1 & 0.000000 & 0.000000 & 0.000 & 0.9910 \\
\hline End*Speed*Strength & 1 & 0.000005 & 0.000005 & 0.012 & 0.9131 \\
\hline Machine*Speed*Strength & 1 & 0.001606 & 0.001606 & 4.276 & $0.0474 \uparrow$ \\
\hline End*Machine*Speed ${ }^{*}$ Strength & 1 & 0.002286 & 0.002286 & 6.087 & $0.0195 \dagger$ \\
\hline Error & 30 & 0.011265 & 0.000376 & & \\
\hline Total & 47 & 0.047549 & & & \\
\hline
\end{tabular}

$\dagger \dagger=$ highly significant

$\dagger=$ significant 
Table 4.7 - Summary of effects on the means (100-mm cylinders only)

\begin{tabular}{|c|c|c|c|c|}
\hline Factor & Effect & $\begin{array}{c}\text { Uncertainty, } \\
\pm 2 \cdot S_{\text {effect }}\end{array}$ & $\begin{array}{c}\text { Lower } \\
\text { Limit }\end{array}$ & $\begin{array}{c}\text { Upper } \\
\text { Limit }\end{array}$ \\
\hline End & 0.022 & \pm 0.011 & 0.011 & 0.033 \\
\hline Machine & -0.023 & \pm 0.011 & -0.034 & -0.012 \\
\hline Speed & 0.025 & \pm 0.011 & 0.014 & 0.036 \\
\hline End*Strength & 0.016 & \pm 0.011 & 0.005 & 0.027 \\
\hline End*Speed & 0.013 & \pm 0.011 & 0.002 & 0.024 \\
\hline Speed*Strength*Machine & 0.012 & \pm 0.011 & 0.001 & 0.023 \\
\hline End*Speed*Strength*Machine & -0.014 & \pm 0.011 & -0.025 & -0.003 \\
\hline
\end{tabular}


Table 4.8 - Effects of end condition, stress rate, and testing machine for different settings of the factors (100-mm cylinders only)

\begin{tabular}{|c|c|c|c|c|}
\hline Factor Settings & & & & \\
\hline \multirow{2}{*}{ Machine*Speed*Strength } & \multicolumn{4}{|c|}{ Effect of end condition (G-S) } \\
\hline & Effect & Uncertainty, $\pm 2 \cdot s_{\text {effect }}$ & Lower Limit & Upper Limit \\
\hline $\begin{array}{l}1.33-\mathrm{F}-45 \\
4.45-\mathrm{F}-45 \\
1.33-\mathrm{Sl}-45 \\
4.45-\mathrm{Sl}-45 \\
1.33-\mathrm{F}-90 \\
4.45-\mathrm{F}-90 \\
1.33-\mathrm{Sl}-90 \\
4.45-\mathrm{Sl}-90\end{array}$ & $\begin{array}{l}0.019 \\
0.018 \\
0.006 \\
-0.020 \\
0.064 \uparrow \\
0.039 \uparrow \\
-0.007 \\
0.054 \uparrow \\
\end{array}$ & $\begin{array}{l} \pm 0.032 \\
\pm 0.032 \\
\pm 0.032 \\
\pm 0.032 \\
\pm 0.032 \\
\pm 0.032 \\
\pm 0.032 \\
\pm 0.032\end{array}$ & $\begin{array}{r}-0.013 \\
-0.014 \\
-0.026 \\
-0.052 \\
0.032 \\
0.007 \\
-0.039 \\
0.022 \\
\end{array}$ & $\begin{array}{l}0.051 \\
0.050 \\
0.038 \\
0.012 \\
0.096 \\
0.071 \\
0.025 \\
0.086\end{array}$ \\
\hline \multirow{2}{*}{ End*Machine*Strength } & \multicolumn{4}{|c|}{ Effect of stress rate $(\mathrm{F}-\mathrm{Sl})$} \\
\hline & Effect & Uncertainty, $\pm 2 \cdot s_{\text {effect }}$ & Lower Limit & Upper Limit \\
\hline $\begin{array}{l}\text { G-1.33-45 } \\
\text { S-1.33-45 } \\
\text { G-4.45-45 } \\
\text { S-4.45-45 } \\
\text { G-1.33-90 } \\
\text { S-1.33-90 } \\
\text { G-4.45-90 } \\
\text { S-4.45-90 }\end{array}$ & $\begin{array}{l}0.038 \dagger \\
0.025 \\
0.038 \dagger \\
0.001 \\
0.043 \dagger \\
-0.027 \\
0.035 \dagger \\
0.051 \dagger \\
\end{array}$ & $\begin{array}{l} \pm 0.032 \\
\pm 0.032 \\
\pm 0.032 \\
\pm 0.032 \\
\pm 0.032 \\
\pm 0.032 \\
\pm 0.032 \\
\pm 0.032\end{array}$ & $\begin{array}{r}0.006 \\
-0.007 \\
0.006 \\
-0.031 \\
0.011 \\
-0.059 \\
0.003 \\
0.019 \\
\end{array}$ & $\begin{array}{l}0.070 \\
0.057 \\
0.070 \\
0.033 \\
0.075 \\
0.005 \\
0.067 \\
0.083 \\
\end{array}$ \\
\hline \multirow{2}{*}{ End*Speed*Strength } & \multicolumn{4}{|c|}{ Effect of testing machine (4.45-MN - 1.33-MN) } \\
\hline & Effect & Uncertainty, $\pm 2 \cdot s_{\text {effect }}$ & Lower Limit & Upper Limit \\
\hline $\begin{array}{c}\text { G-F-45 } \\
\text { S-F-45 } \\
\text { G-Sl-45 } \\
\text { S-Sl-45 } \\
\text { G-F-90 } \\
\text { S-F-90 } \\
\text { G-Sl-90 } \\
\text { S-Sl-90 }\end{array}$ & $\begin{array}{l}-0.030 \\
-0.029 \\
-0.031 \\
-0.005 \\
-0.019 \\
0.007 \\
-0.010 \\
-0.071\end{array}$ & $\begin{array}{l} \pm 0.032 \\
\pm 0.032 \\
\pm 0.032 \\
\pm 0.032 \\
\pm 0.032 \\
\pm 0.032 \\
\pm 0.032 \\
\pm 0.032\end{array}$ & $\begin{array}{l}-0.062 \\
-0.061 \\
-0.063 \\
-0.037 \\
-0.051 \\
-0.025 \\
-0.042 \\
-0.103\end{array}$ & $\begin{array}{r}0.002 \\
0.003 \\
0.001 \\
0.027 \\
0.013 \\
0.039 \\
0.022 \\
-0.039\end{array}$ \\
\hline
\end{tabular}

$\dagger$ significant $(\alpha \leq 0.05)$

Legend: $1.33=1.33-\mathrm{MN}$ machine

$$
\begin{aligned}
& \mathrm{F}=0.34 \mathrm{MPa} / \mathrm{s} \\
& \mathrm{G}=\text { ground ends } \\
& 45=45-\mathrm{MPa} \text { mixture }
\end{aligned}
$$

$4.45=4.45-\mathrm{MN}$ machine

$\mathrm{Sl}=0.14 \mathrm{MPa} / \mathrm{s}$

$\mathrm{S}=$ sulfur caps

$90=90-\mathrm{MPa}$ mixture 
Table 4.9 - ANOVA table for effects on the means (4.45-MN machine only)

\begin{tabular}{|c|c|c|c|c|c|}
\hline Source & $\mathrm{df}$ & $\begin{array}{c}\text { Sums of } \\
\text { Squares }\end{array}$ & $\begin{array}{c}\text { Mean } \\
\text { Square }\end{array}$ & F-statistic & Probability \\
\hline Day & 2 & 0.002378 & 0.001189 & 2.843 & 0.0740 \\
\hline Size & 1 & 0.002010 & 0.002010 & 4.805 & $0.0363 \dagger$ \\
\hline End & 1 & 0.009033 & 0.009033 & 21.598 & $\leq 0.0001 \dagger \dagger$ \\
\hline Size*End & 1 & 0.000276 & 0.000276 & 0.660 & 0.4230 \\
\hline Speed & 1 & 0.008299 & 0.008299 & 19.844 & $0.0001 \dagger \dagger$ \\
\hline Size*Speed & 1 & 0.000293 & 0.000293 & 0.700 & 0.4094 \\
\hline End*Speed & 1 & 0.000573 & 0.000573 & 1.371 & 0.2508 \\
\hline Size*End*Speed & 1 & 0.000020 & 0.000020 & 0.048 & 0.8279 \\
\hline Strength & 1 & 0.000389 & 0.000389 & 0.931 & 0.3423 \\
\hline Size*Strength & 1 & 0.000490 & 0.000490 & 1.171 & 0.2879 \\
\hline End*Strength & 1 & 0.002856 & 0.002856 & 6.829 & $0.0139 \dagger$ \\
\hline Size*End*Strength & 1 & 0.000777 & 0.000777 & 1.859 & 0.1829 \\
\hline Speed*Strength & 1 & 0.000217 & 0.000217 & 0.519 & 0.4767 \\
\hline Size*Speed*Strength & 1 & 0.000653 & 0.000653 & 1.561 & 0.2212 \\
\hline End*Speed*Strength & 1 & 0.000053 & 0.000053 & 0.127 & 0.7245 \\
\hline Size*End*Speed*Strength & 1 & 0.001475 & 0.001475 & 3.526 & 0.0702 \\
\hline Error & 30 & 0.012547 & 0.000418 & & \\
\hline Total & 47 & 0.042339 & & & \\
\hline
\end{tabular}

$\dagger \dagger=$ highly significant

$\dagger=$ significant 
Table 4.10 - Summary of effects on the means (4.45-MN machine only)

\begin{tabular}{|c|c|c|c|c|}
\hline Factor & Effect & $\begin{array}{c}\text { Uncertainty } \\
\pm 2 \cdot S_{\text {effect }}\end{array}$ & Lower Limit & Upper Limit \\
\hline Size & -0.013 & \pm 0.012 & -0.025 & -0.001 \\
\hline End & 0.027 & \pm 0.012 & 0.015 & 0.039 \\
\hline Speed & 0.026 & \pm 0.012 & 0.014 & 0.038 \\
\hline End * Strength & 0.015 & \pm 0.012 & 0.003 & 0.027 \\
\hline
\end{tabular}

Table 4.11 - Summary of supplementary tests to investigate effect of damaged sphericallyseated block of 4.45-MN machine

\begin{tabular}{|c|c|c|c|c|c|c|}
\hline $\begin{array}{c}\text { Diameter, } \\
\mathrm{mm}\end{array}$ & ID \# & $\begin{array}{l}\text { Head } \\
\text { Type }^{\dagger}\end{array}$ & $\begin{array}{c}\text { Test } \\
\text { Sequence }\end{array}$ & $\begin{array}{l}\text { Specific } \\
\text { Gravity }\end{array}$ & $\begin{array}{c}\text { Stress Rate, } \\
\mathrm{MPa} / \mathrm{s}\end{array}$ & $\begin{array}{c}\text { Strength, } \\
\mathrm{MPa}\end{array}$ \\
\hline 100 & 6 & $\mathrm{~F}$ & 32 & 2.358 & 0.207 & 64.48 \\
\hline 100 & 4 & $\mathrm{~F}$ & 29 & 2.395 & 0.192 & 64.81 \\
\hline 100 & 3 & $\mathrm{~F}$ & 13 & 2.364 & 0.205 & 66.95 \\
\hline 100 & 7 & $\mathrm{~F}$ & 20 & 2.370 & 0.205 & 68.21 \\
\hline 100 & 11 & $\mathrm{~F}$ & 24 & 2.387 & 0.182 & 68.21 \\
\hline 100 & 14 & $\mathrm{~F}$ & 5 & 2.376 & 0.207 & 68.22 \\
\hline 100 & 5 & $\mathrm{~F}$ & 8 & 2.384 & 0.205 & 69.53 \\
\hline 100 & 2 & $\mathrm{~F}$ & 3 & 2.403 & 0.217 & 72.12 \\
\hline 100 & 1 & D & 28 & 2.350 & 0.200 & 63.16 \\
\hline 100 & 8 & D & 4 & 2.379 & 0.199 & 64.31 \\
\hline 100 & 10 & D & 14 & 2.375 & 0.203 & 66.51 \\
\hline 100 & 13 & D & 25 & 2.373 & 0.204 & 66.51 \\
\hline 100 & 16 & D & 22 & 2.381 & 0.201 & 68.38 \\
\hline 100 & 15 & D & 21 & 2.379 & 0.203 & 68.49 \\
\hline 100 & 9 & D & 11 & 2.402 & 0.197 & 68.76 \\
\hline 100 & 12 & D & 19 & 2.371 & 0.202 & 68.87 \\
\hline 150 & 7 & $\mathrm{~F}$ & 12 & 2.365 & 0.224 & 65.90 \\
\hline 150 & 12 & $\mathrm{~F}$ & 2 & 2.354 & 0.213 & 66.14 \\
\hline 150 & 1 & $\mathrm{~F}$ & 1 & 2.379 & 0.232 & 67.29 \\
\hline 150 & 3 & $\mathrm{~F}$ & 10 & 2.390 & 0.230 & 68.22 \\
\hline 150 & 8 & $\mathrm{~F}$ & 27 & 2.391 & 0.214 & 68.25 \\
\hline 150 & 9 & $\mathrm{~F}$ & 26 & 2.383 & 0.188 & 68.66 \\
\hline 150 & 11 & $\mathrm{~F}$ & 30 & 2.389 & 0.230 & 69.94 \\
\hline 150 & 16 & $\mathrm{~F}$ & 23 & 2.361 & 0.220 & 70.20 \\
\hline 150 & 4 & D & 15 & 2.366 & 0.218 & 65.21 \\
\hline 150 & 2 & $\mathrm{D}$ & 6 & 2.380 & 0.225 & 66.89 \\
\hline 150 & 15 & $\mathrm{D}$ & 7 & 2.378 & 0.233 & 67.56 \\
\hline 150 & 10 & D & 16 & 2.378 & 0.205 & 67.83 \\
\hline 150 & 6 & D & 9 & 2.366 & 0.218 & 67.83 \\
\hline 150 & 13 & D & 31 & 2.370 & 0.211 & 68.13 \\
\hline 150 & 5 & $\mathrm{D}$ & 17 & 2.384 & 0.190 & 68.59 \\
\hline 150 & 14 & $\mathrm{D}$ & 18 & 2.364 & 0.228 & 68.98 \\
\hline
\end{tabular}

$\dagger F=$ flat; $D=$ dished 
Table 4.12 - Summary of specific gravities of cylinders assigned to different groups in the supplementary tests

\begin{tabular}{|c|c|c|c|}
\hline Diameter, $\mathrm{mm}$ & Head Type & Average & Standard Deviation \\
\hline 100 & Flat & 2.380 & 0.015 \\
\hline 100 & Damaged & 2.376 & 0.014 \\
\hline 150 & Flat & 2.377 & 0.015 \\
\hline 150 & Damaged & 2.373 & 0.008 \\
\hline
\end{tabular}

Table 4.13 - ANOVA table for the mean specific gravities

\begin{tabular}{|c|c|c|c|c|c|}
\hline Source & $\mathrm{df}$ & $\begin{array}{c}\text { Sums of } \\
\text { Squares }\end{array}$ & $\begin{array}{c}\text { Mean } \\
\text { Square }\end{array}$ & F-statistic & Probability \\
\hline Diameter & 1 & 0.000075 & 0.000075 & 0.421 & 0.522 \\
\hline Head type & 1 & 0.000088 & 0.000088 & 0.493 & 0.488 \\
\hline Diameter*Head & 1 & 0.000000 & 0.000000 & 0.000 & 0.990 \\
\hline Error & 28 & 0.004987 & 0.000178 & & \\
\hline Total & 31 & 0.005150 & \multicolumn{3}{|l}{} \\
\hline
\end{tabular}

Table 4.14 - Summary of compressive strength for cylinders in different groups for the supplementary tests ( 8 replications per group)

\begin{tabular}{|c|c|c|c|}
\hline Diameter, mm & Head Type & Average, MPa & $\begin{array}{c}\text { Standard } \\
\text { Deviation, MPa }\end{array}$ \\
\hline 100 & Flat & $\begin{array}{l}67.81 \\
67.20 \dagger\end{array}$ & $\begin{array}{c}2.48 \\
1.90 \dagger\end{array}$ \\
\hline 100 & Damaged & 66.87 & 2.17 \\
\hline 150 & Flat & 68.07 & 1.58 \\
\hline 150 & Damaged & 67.63 & 1.16 \\
& & $67.97 \dagger$ & $0.68 \dagger$ \\
\hline
\end{tabular}

†Outlier removed, $\mathrm{n}=7$ 
Table 4.15 - ANOVA table for differences in mean strengths in supplementary tests (all data)

\begin{tabular}{|c|c|c|c|c|c|}
\hline Source & $\mathrm{df}$ & $\begin{array}{c}\text { Sums of } \\
\text { Squares }\end{array}$ & $\begin{array}{c}\text { Mean } \\
\text { Square }\end{array}$ & F-statistic & Probability \\
\hline Diameter & 1 & 2.07615 & 2.07615 & 0.565 & 0.459 \\
\hline Head type & 1 & 3.85017 & 3.85017 & 1.047 & 0.315 \\
\hline Diameter*Head & 1 & 0.49048 & 0.49048 & 0.133 & 0.718 \\
\hline Error & 28 & 102.944 & 3.67657 & & \\
\hline Total & 31 & 109.361 & \multicolumn{5}{|l}{} \\
\hline
\end{tabular}

Table 4.16 - ANOVA table for differences in mean strengths in supplementary tests (outliers removed)

\begin{tabular}{|c|c|c|c|c|c|}
\hline Source & $\mathrm{df}$ & $\begin{array}{c}\text { Sums of } \\
\text { Squares }\end{array}$ & $\begin{array}{c}\text { Mean } \\
\text { Square }\end{array}$ & F-statistic & Probability \\
\hline Diameter & 1 & 7.31636 & 7.31636 & 2.534 & 0.124 \\
\hline Head type & 1 & 0.58496 & 0.58496 & 0.203 & 0.656 \\
\hline Diameter*Head & 1 & 0.09556 & 0.09556 & 0.033 & 0.857 \\
\hline Error & 26 & 75.0649 & 2.88711 & & \\
\hline Total & 29 & 83.0618 & & \\
\hline
\end{tabular}


Table 4.17 - Natural logarithms of the strength values (Table 3.10), standard deviation of logarithms, and the natural logarithm of the standard deviation

\begin{tabular}{|c|c|c|c|c|c|}
\hline Run & $\begin{array}{c}\text { Replication } \\
\# 1\end{array}$ & $\begin{array}{c}\text { Replication } \\
\# 2\end{array}$ & $\begin{array}{c}\text { Replication } \\
\# 3\end{array}$ & $\begin{array}{c}\text { Standard } \\
\text { Deviation } \uparrow, \mathrm{s}\end{array}$ & $\ln (s)$ \\
\hline 1 & 3.8095 & 3.8271 & 3.8395 & 0.0150 & -4.1978 \\
\hline 2 & 3.8390 & 3.8452 & 3.8654 & 0.0138 & -4.2859 \\
\hline 3 & 3.8011 & 3.8122 & 3.8474 & 0.0242 & -3.7229 \\
\hline 4 & 3.8190 & 3.7948 & 3.8493 & 0.0273 & -3.6010 \\
\hline 5 & 3.8280 & 3.8299 & 3.8364 & 0.0044 & -5.4211 \\
\hline 6 & 3.8448 & 3.8912 & 3.8710 & 0.0233 & -3.7610 \\
\hline 7 & 3.7819 & 3.8232 & 3.7966 & 0.0209 & -3.8670 \\
\hline 8 & 3.8104 & 3.8437 & 3.8630 & 0.0266 & -3.6263 \\
\hline 9 & 3.8323 & 3.8289 & 3.8076 & 0.0134 & -4.3112 \\
\hline 10 & 3.8364 & 3.8555 & 3.8484 & 0.0096 & -4.6443 \\
\hline 11 & 3.7486 & 3.7966 & 3.7824 & 0.0247 & -3.7018 \\
\hline 12 & 3.7997 & 3.8071 & 3.7966 & 0.0054 & -5.2238 \\
\hline 13 & 3.8293 & 3.8386 & 3.8289 & 0.0055 & -5.2033 \\
\hline 14 & 3.8302 & 3.8450 & 3.8407 & 0.0077 & -4.8728 \\
\hline 15 & 3.7905 & 3.8144 & 3.7993 & 0.0121 & -4.4164 \\
\hline 16 & 3.8351 & 3.8258 & 3.8144 & 0.0104 & -4.5676 \\
\hline 17 & 4.4821 & 4.5232 & 4.5102 & 0.0210 & -3.8628 \\
\hline 18 & 4.4505 & 4.4996 & 4.4836 & 0.0250 & -3.6877 \\
\hline 19 & 4.4476 & 4.4553 & 4.4010 & 0.0294 & -3.5273 \\
\hline 20 & 4.4823 & 4.4798 & 4.4929 & 0.0069 & -4.9711 \\
\hline 21 & 4.4654 & 4.4805 & 4.5501 & 0.0451 & -3.0979 \\
\hline 22 & 4.5252 & 4.5311 & 4.5699 & 0.0243 & -3.7183 \\
\hline 23 & 4.4736 & 4.4966 & 4.4947 & 0.0128 & -4.3608 \\
\hline 24 & 4.5279 & 4.5093 & 4.5336 & 0.0127 & -4.3680 \\
\hline 25 & 4.2129 & 4.2086 & 4.2095 & 0.0023 & -6.0876 \\
\hline 26 & 4.2343 & 4.2292 & 4.2306 & 0.0026 & -5.9451 \\
\hline 27 & 4.4583 & 4.4567 & 4.4531 & 0.0027 & -5.9240 \\
\hline 28 & 4.4411 & 4.4236 & 4.5063 & 0.0436 & -3.1330 \\
\hline 29 & 4.2252 & 4.2343 & 4.2300 & 0.0045 & -5.4002 \\
\hline 30 & 4.2360 & 4.2335 & 4.2397 & 0.0031 & -5.7666 \\
\hline 31 & 4.4473 & 4.4907 & 4.4974 & 0.0271 & -3.6064 \\
\hline 32 & 4.5152 & 4.4985 & 4.5277 & 0.0147 & -4.2207 \\
\hline
\end{tabular}

$\dagger$ The standard deviation of the logarithms is approximately equal to the coefficient of variation of the original strength values (Table 3.10) 
Table 4.18 - ANOVA table for analysis of effects on dispersion (all data)

\begin{tabular}{|c|c|c|c|c|c|}
\hline Source & df & $\begin{array}{c}\text { Sums of } \\
\text { Squares }\end{array}$ & $\begin{array}{c}\text { Mean } \\
\text { Square }\end{array}$ & F-statistic & Probability \\
\hline Diameter & 1 & 5.23900 & 5.23900 & 8.8093 & $0.0158 \dagger$ \\
\hline End & 1 & 0.009553 & 0.009553 & 0.01606 & 0.9019 \\
\hline Diameter*End & 1 & 0.051256 & 0.051256 & 0.08619 & 0.7757 \\
\hline Machine & 1 & 1.72306 & 1.72306 & 2.8973 & 0.1229 \\
\hline Diameter*Machine & 1 & 1.73413 & 1.73413 & 2.9159 & 0.1219 \\
\hline End*Machine & 1 & 0.030659 & 0.030659 & 0.05155 & 0.8255 \\
\hline Speed & 1 & 0.003107 & 0.003107 & 0.00522 & 0.9440 \\
\hline Diameter*Speed & 1 & 0.001781 & 0.001781 & 0.00299 & 0.9576 \\
\hline End*Speed & 1 & 0.012336 & 0.012336 & 0.02074 & 0.8887 \\
\hline Machine*Speed & 1 & 0.068923 & 0.068923 & 0.11589 & 0.7413 \\
\hline Strength & 4 & 4.38940 & 1.09735 & 1.8452 & 0.2045 \\
\hline End*Strength & 4 & 0.957781 & 0.239445 & 0.40262 & 0.8024 \\
\hline Speed*Strength & 4 & 2.77867 & 0.694667 & 1.1681 & 0.3866 \\
\hline Error & 9 & 5.35241 & 0.594713 & & \\
\hline Total & 31 & 22.3521 & & & \\
\hline
\end{tabular}

$\dagger$ Significant 
Table 4.19 - ANOVA table for analysis of effects on dispersion (4.45 MN machine only)

\begin{tabular}{|c|c|c|c|c|c|}
\hline Source & $\mathrm{df}$ & $\begin{array}{c}\text { Sums of } \\
\text { Squares }\end{array}$ & $\begin{array}{c}\text { Mean } \\
\text { Square }\end{array}$ & F-statistic & Probability \\
\hline Diameter & 1 & 0.472416 & 0.472416 & 0.39418 & 0.5577 \\
\hline End & 1 & 0.037220 & 0.037220 & 0.03106 & 0.8670 \\
\hline Diameter*End & 1 & 0.154311 & 0.154311 & 0.12876 & 0.7344 \\
\hline Speed & 1 & 0.021382 & 0.021382 & 0.01784 & 0.8990 \\
\hline Diameter*Speed & 1 & 0.158384 & 0.158384 & 0.13215 & 0.7311 \\
\hline End*Speed & 1 & 0.014346 & 0.014346 & 0.01197 & 0.9171 \\
\hline Strength & 1 & 0.119803 & 0.119803 & 0.09996 & 0.7646 \\
\hline Diameter*Strength & 1 & 0.737666 & 0.737666 & 0.61550 & 0.4682 \\
\hline End*Strength & 1 & 0.094142 & 0.094142 & 0.07855 & 0.7905 \\
\hline Speed*Strength & 1 & 0.259157 & 0.259157 & 0.21624 & 0.6615 \\
\hline Error & 5 & 5.99242 & 1.19848 & & \\
\hline Total & 15 & 8.06124 & & & \\
\hline
\end{tabular}


Table 4.20 - ANOVA table for analysis of effects on dispersion (100-mm cylinders only)

\begin{tabular}{|c|c|c|l|l|l|}
\hline Source & df & $\begin{array}{c}\text { Sums of } \\
\text { Squares }\end{array}$ & $\begin{array}{c}\text { Mean } \\
\text { Square }\end{array}$ & F-statistic & Probability \\
\hline End & 1 & 0.008276 & 0.008276 & 0.03476 & 0.8594 \\
\hline Machine & 1 & 0.000009 & 0.000009 & 0.00004 & 0.9954 \\
\hline End*Machine & 1 & 0.011865 & 0.011865 & 0.04983 & 0.8322 \\
\hline Speed & 1 & 0.000092 & 0.000092 & 0.00039 & 0.9851 \\
\hline End*Speed & 1 & 0.393160 & 0.393160 & 1.6511 & 0.2551 \\
\hline Machine*Speed & 1 & 0.306667 & 0.306667 & 1.2878 & 0.3079 \\
\hline Strength & 1 & 0.049406 & 0.049406 & 0.20748 & 0.6678 \\
\hline End*Strength & 1 & 0.117598 & 0.117598 & 0.49385 & 0.5136 \\
\hline Machine*Strength & 1 & 2.03711 & 2.03711 & 8.5549 & $0.0328 \uparrow$ \\
\hline Speed*Strength & 1 & 0.917237 & 0.917237 & 3.8519 & 0.1069 \\
\hline Error & 5 & 1.19062 & 0.238124 & & \\
\hline Total & 15 & 5.03204 & & & \\
\hline
\end{tabular}

$广$ Significant 


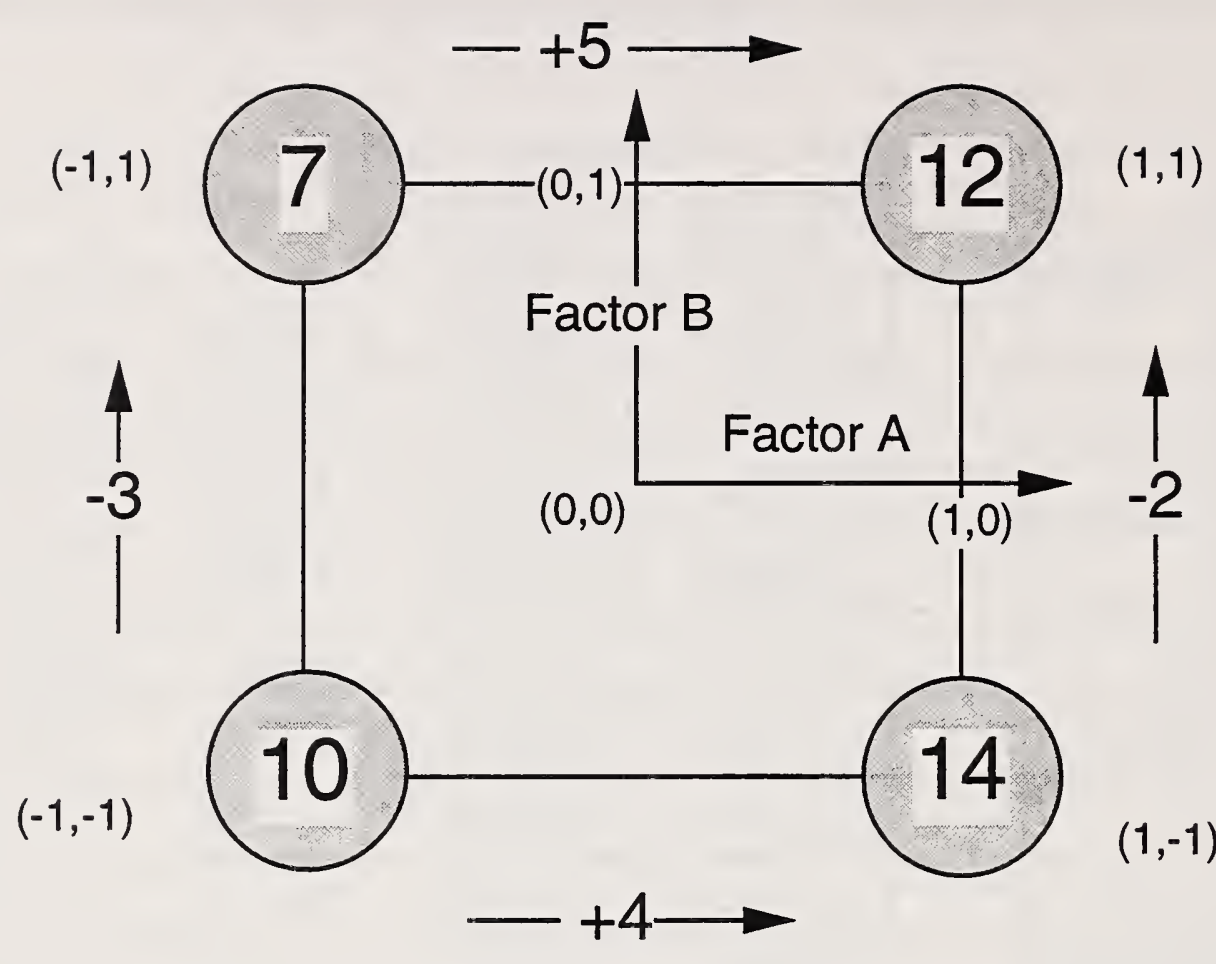

Effect of factor $A:\left(\frac{14+12}{2}\right)-\left(\frac{10+7}{2}\right)=a=4.5$

Effect of factor $B:\left(\frac{7+12}{2}\right)-\left(\frac{10+14}{2}\right)=b=-2.5$

A-B Interaction: $\quad\left(\frac{10+12}{2}\right)-\left(\frac{7+14}{2}\right)=a b=0.5$

Linear Model:

$$
Y=\bar{Y}+1 / 2 a(-1,1)+1 / 2 b(-1,1)+1 / 2 a b(-1,1)
$$

Figure 4.1 - Example to illustrate computation of the effects due to changes in the settings of the factors in a factorial experiment 


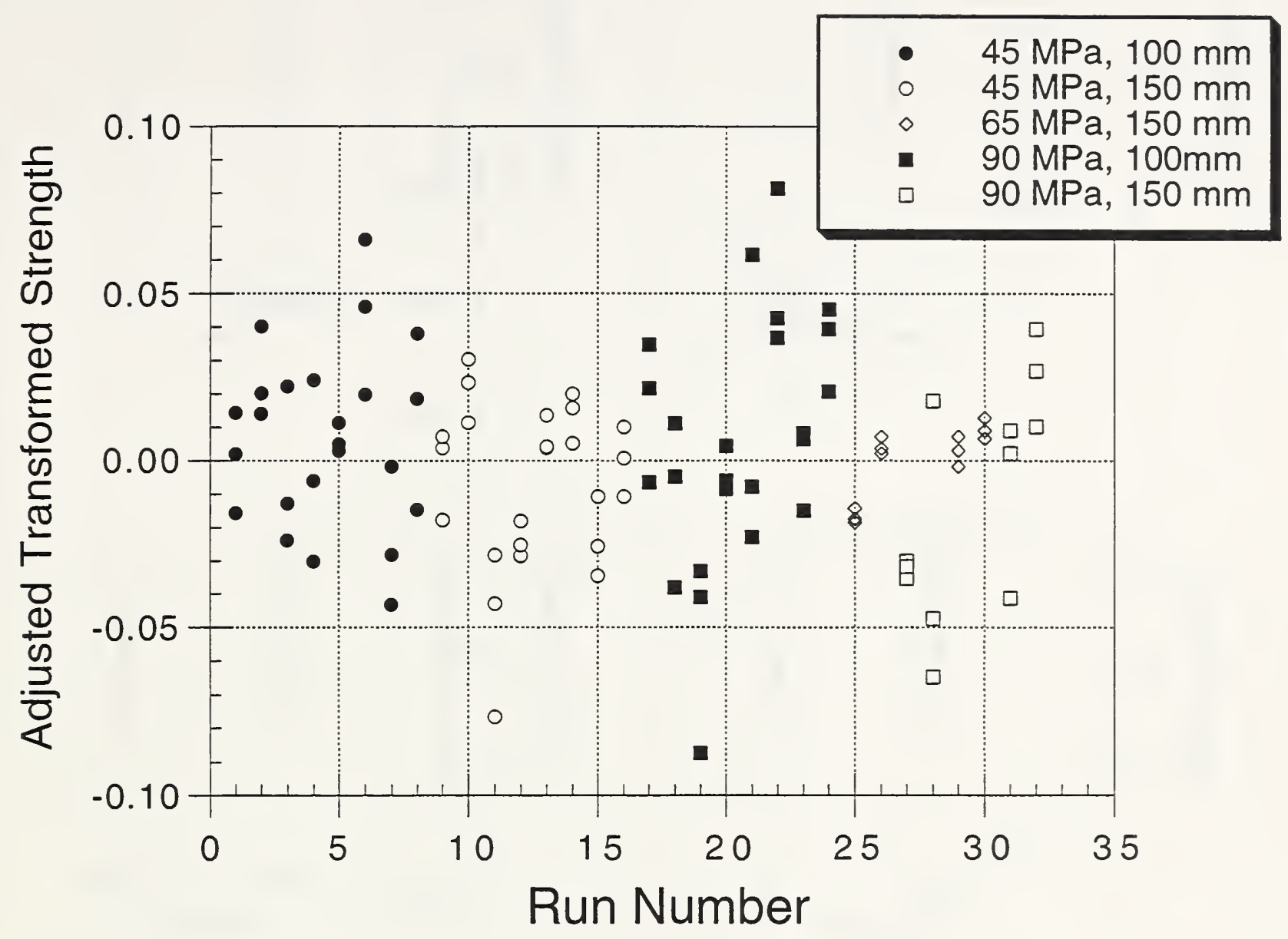

Figure 4.2 - Adjusted transformed strength versus run number 

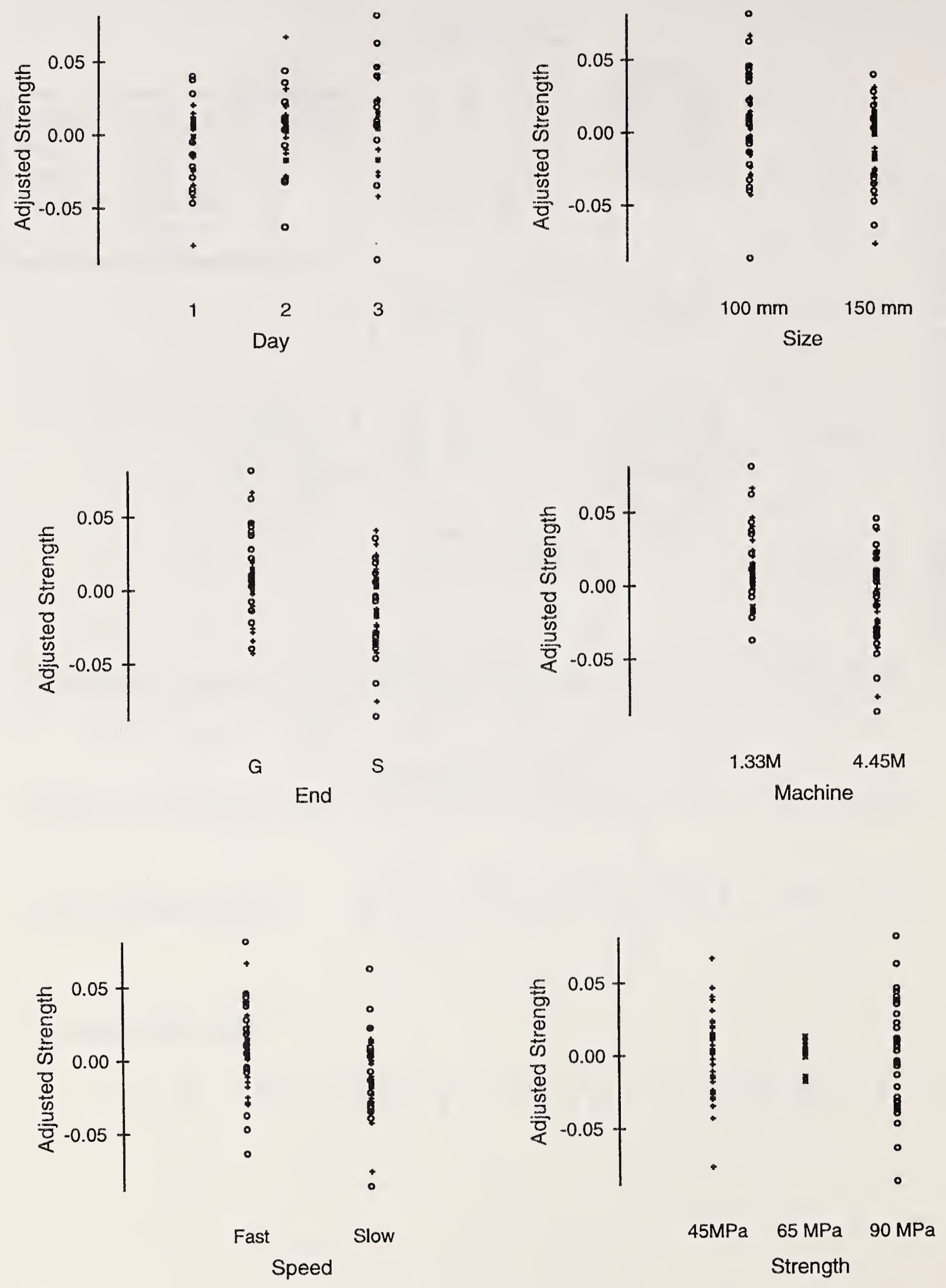

Figure 4.3 - Dotplots of adjusted transformed strength values versus the settings of the factors used in this study 

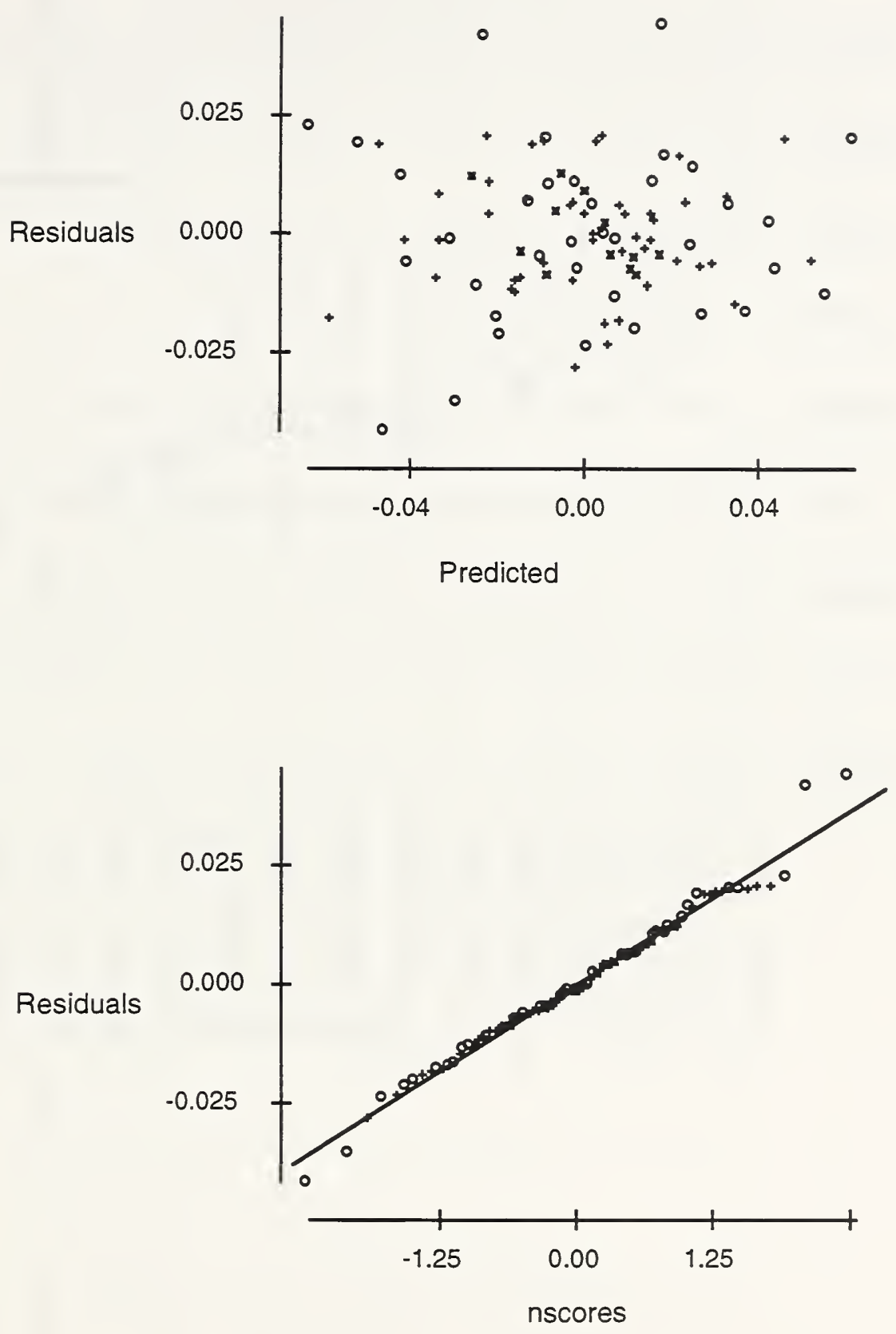

Figure 4.4 - Plots of residuals for regression analysis using the general linear model for all 32 runs: (top) residuals versus predicted values and (bottom) normal probability plot of residuals 


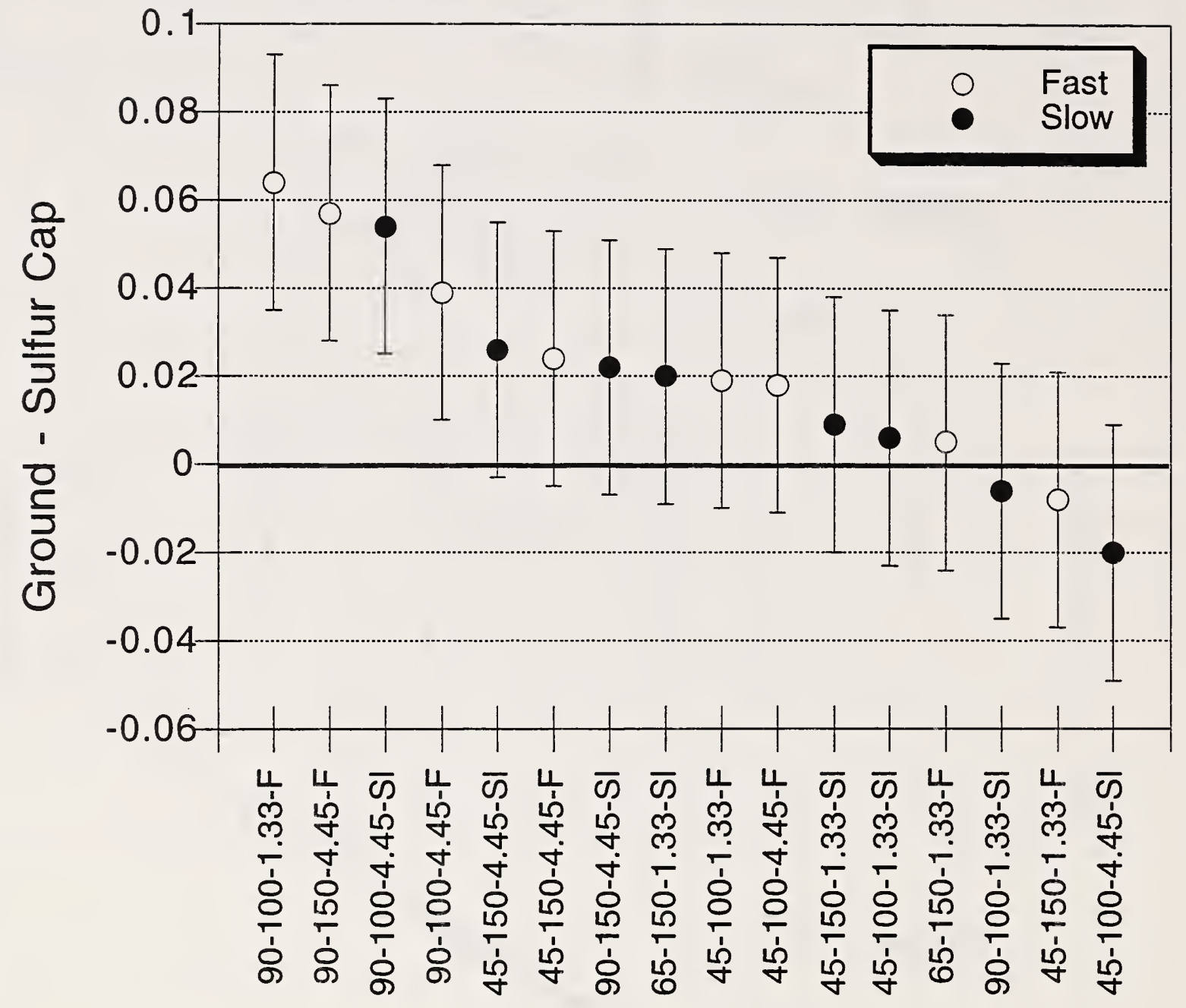

Figure 4.5 - Approximate 95\% confidence intervals for the effect of end condition (grinding sulfur caps) for the different strength ${ }^{*}$ size ${ }^{*}$ machine ${ }^{*}$ speed combinations (all 32 runs) 

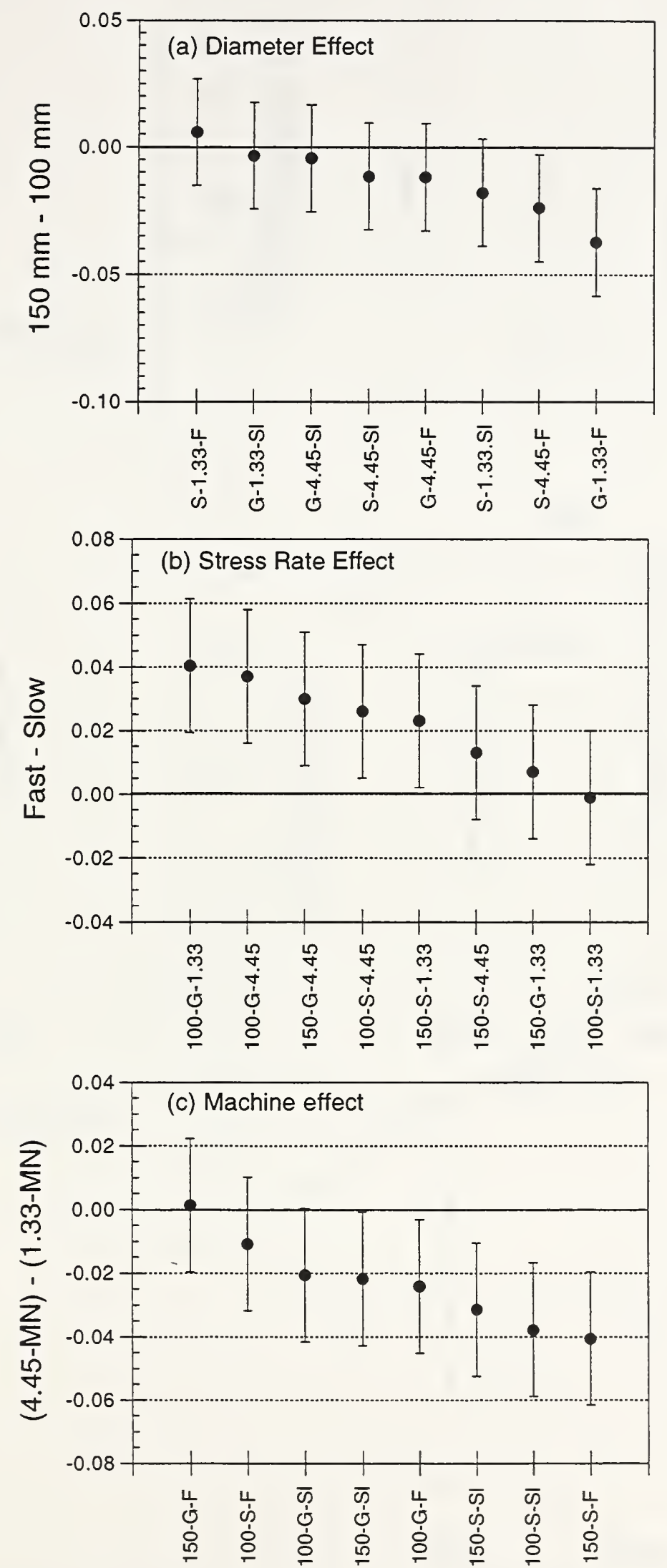

Figure 4.6- Confidence intervals for the effects of diameter, stress rate (speed), and machine for different settings of other factors (all 32 runs) 

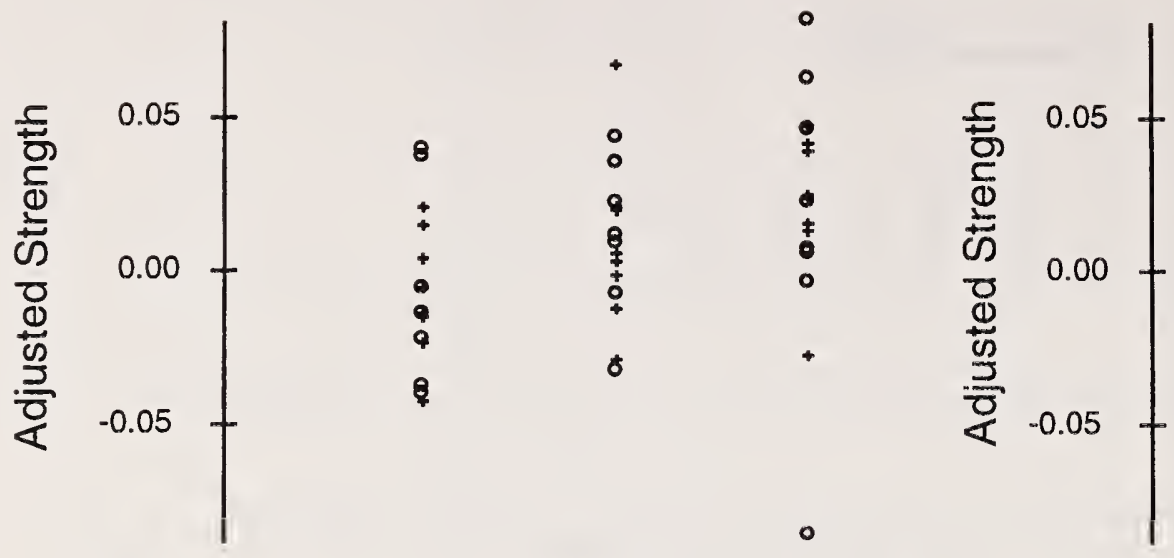

1

2

3

G

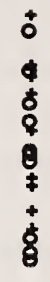

Day
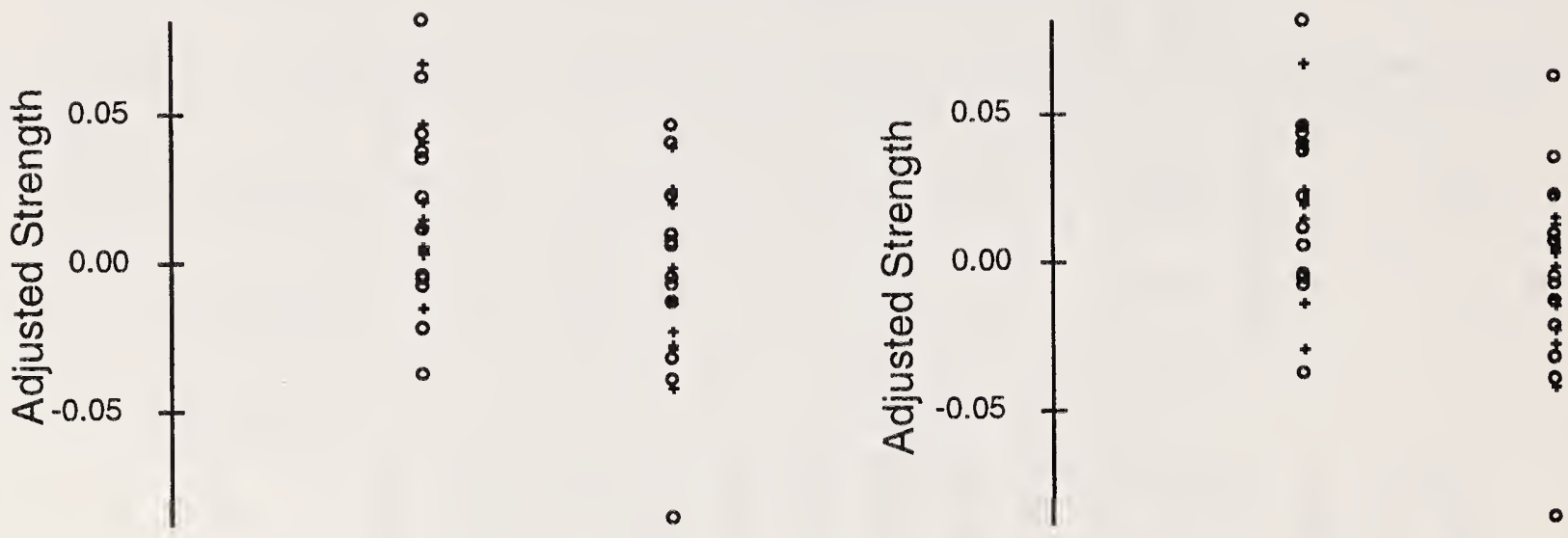

$1.33 \mathrm{M}$

4.45M

Fast

End

Machine
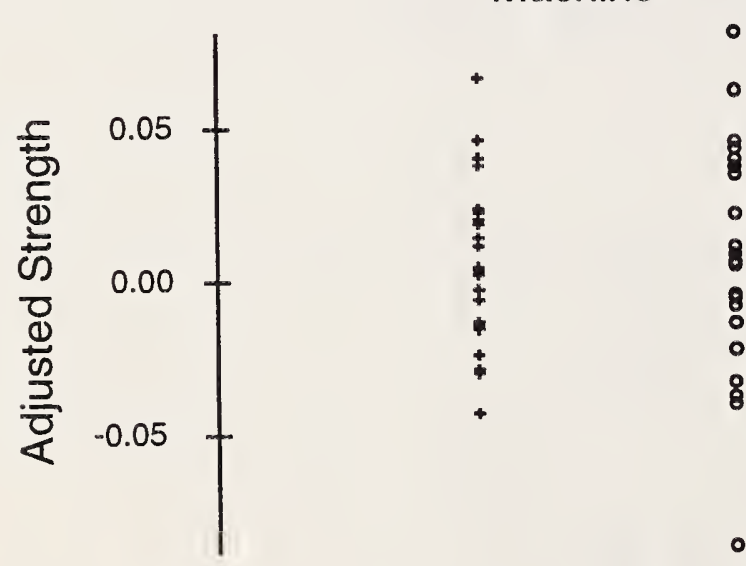

Speed

Slow

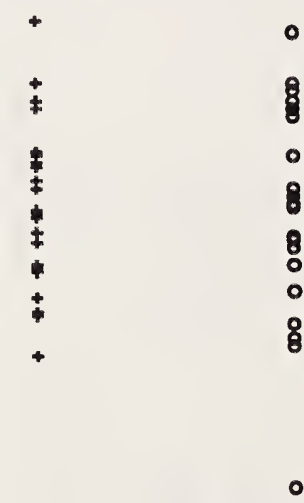

$45 \mathrm{MPa} \quad 90 \mathrm{MPa}$
Strength

Figure 4.7 - Dotplots of adjusted transformed strength values of only the $100-\mathrm{mm}$ cylinders grouped according to the settings of the factors 

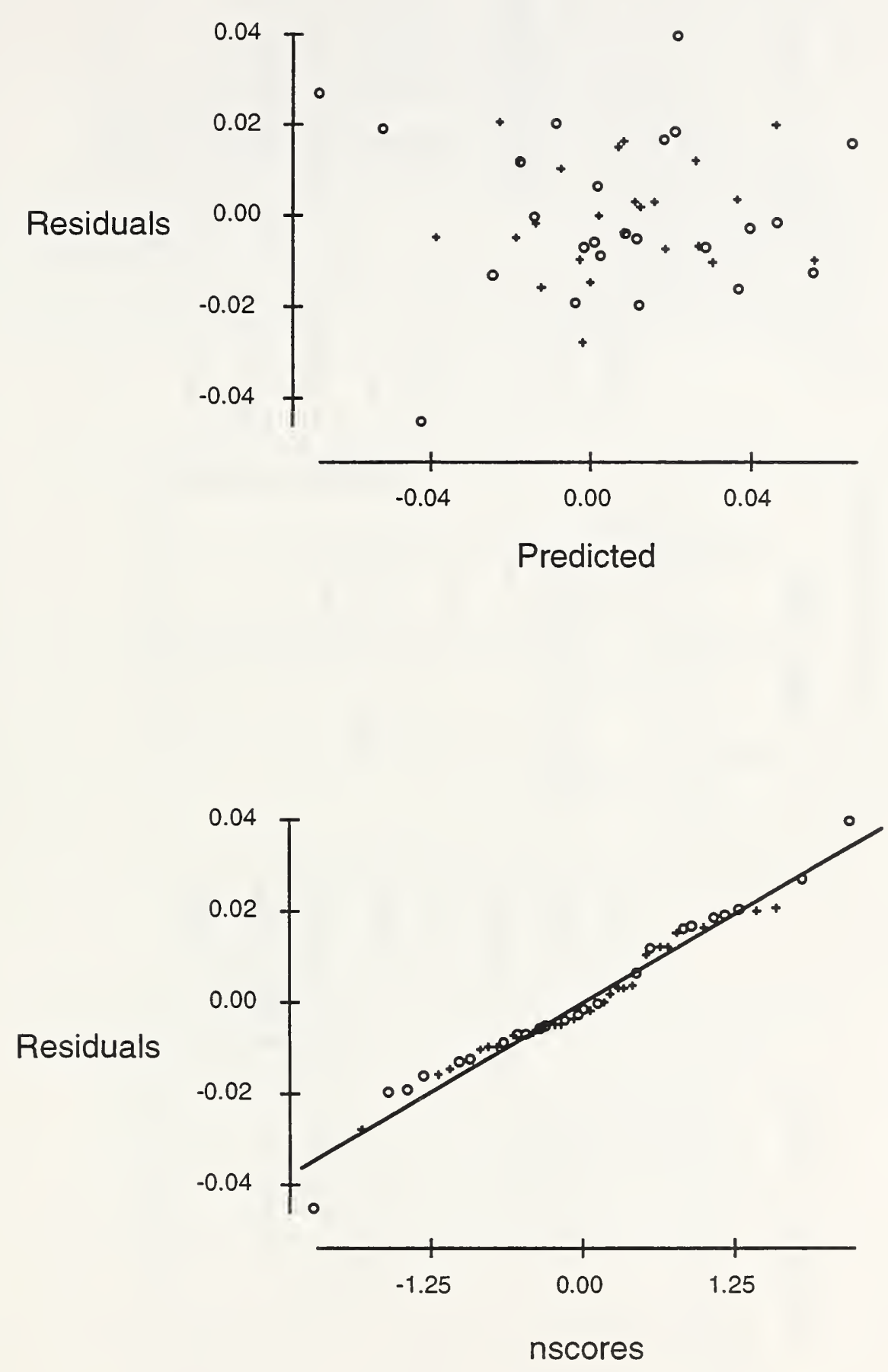

Figure 4.8 - Plots of residuals for regression analysis using the general linear model for results with 100-mm cylinders: (top) residuals versus predicted values and (bottom) normal probability plot of residuals 

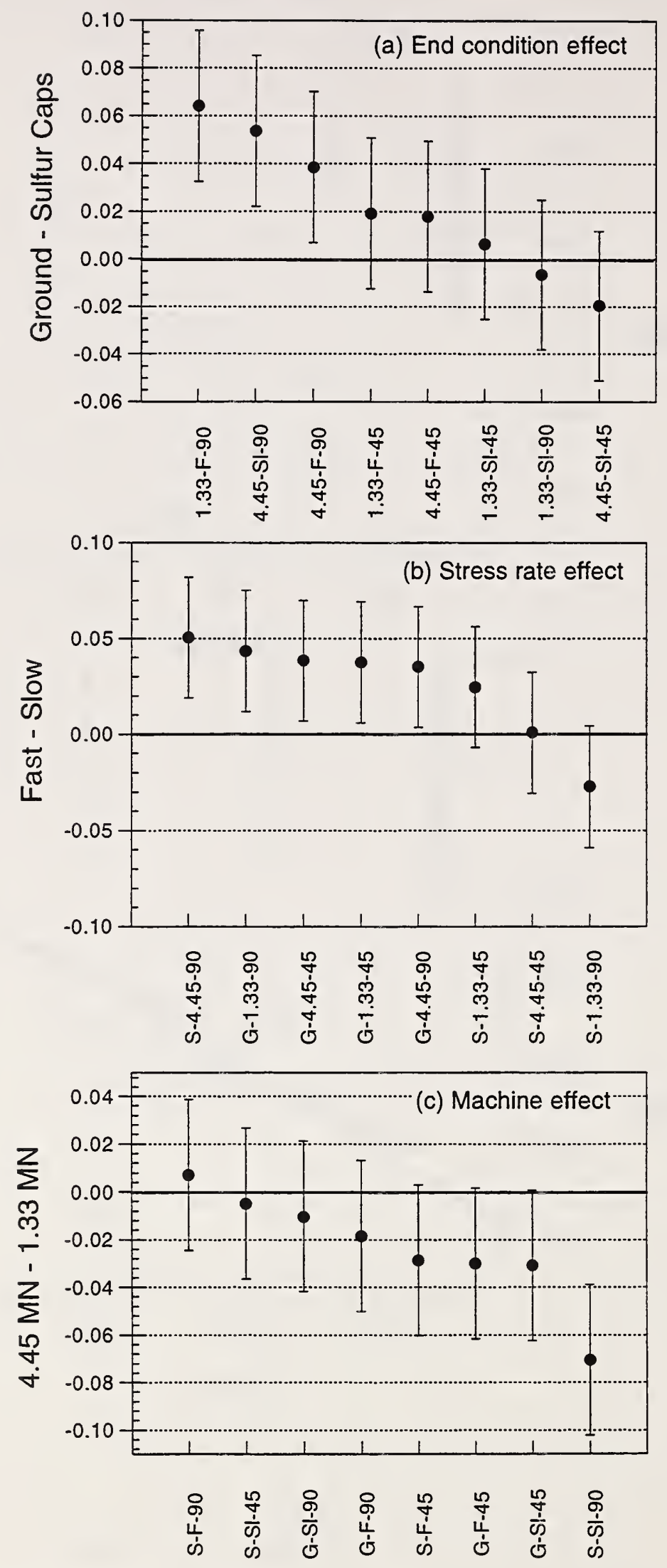

Figure 4.9- Confidence intervals for the effects of end condition, stress rate, and testing machine for different settings of other factors (100-mm cylinders only) 

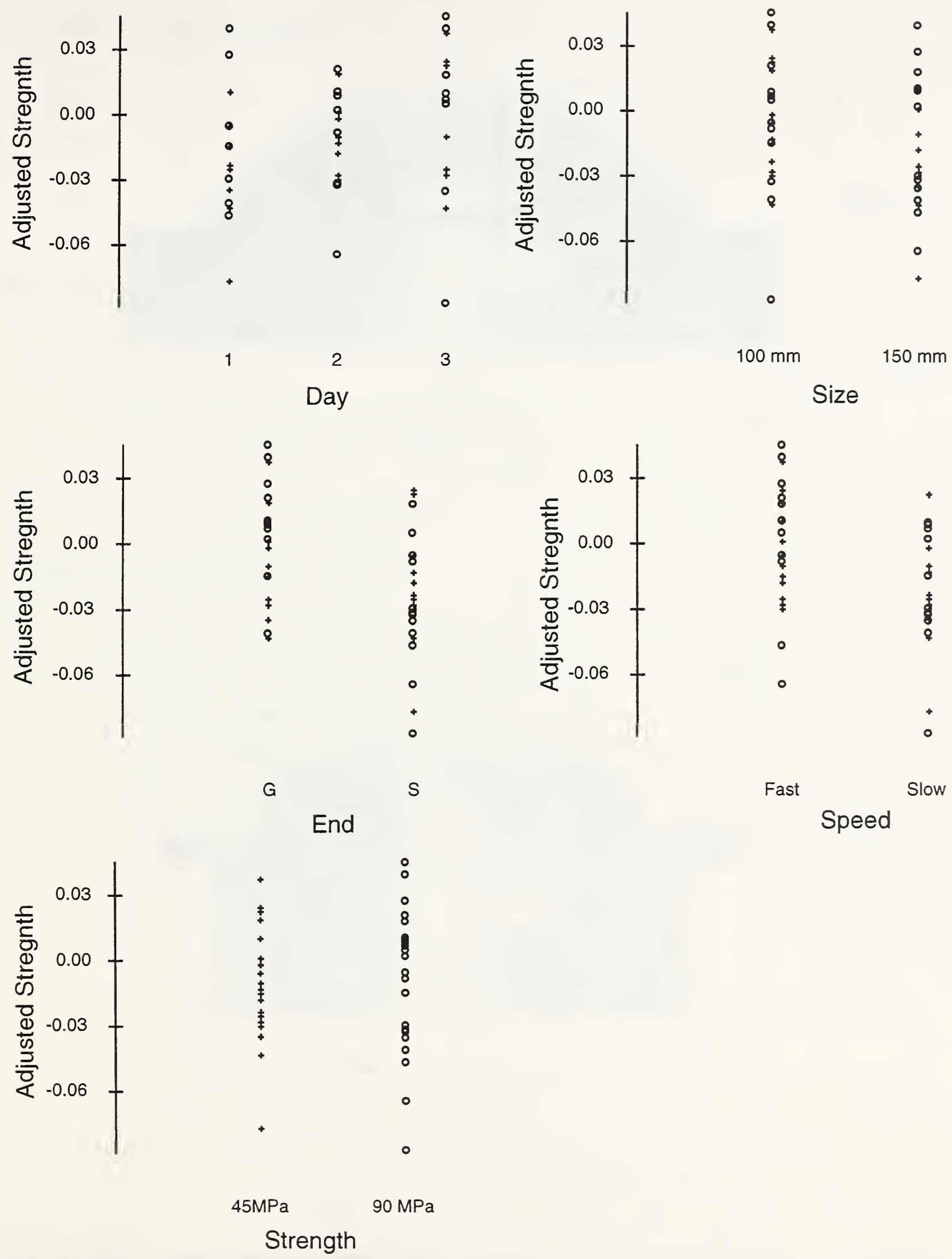

Figure 4.10 - Dotplots of adjusted transformed strength values of tests on the 4-45-MN machine grouped according to the settings of the factors 

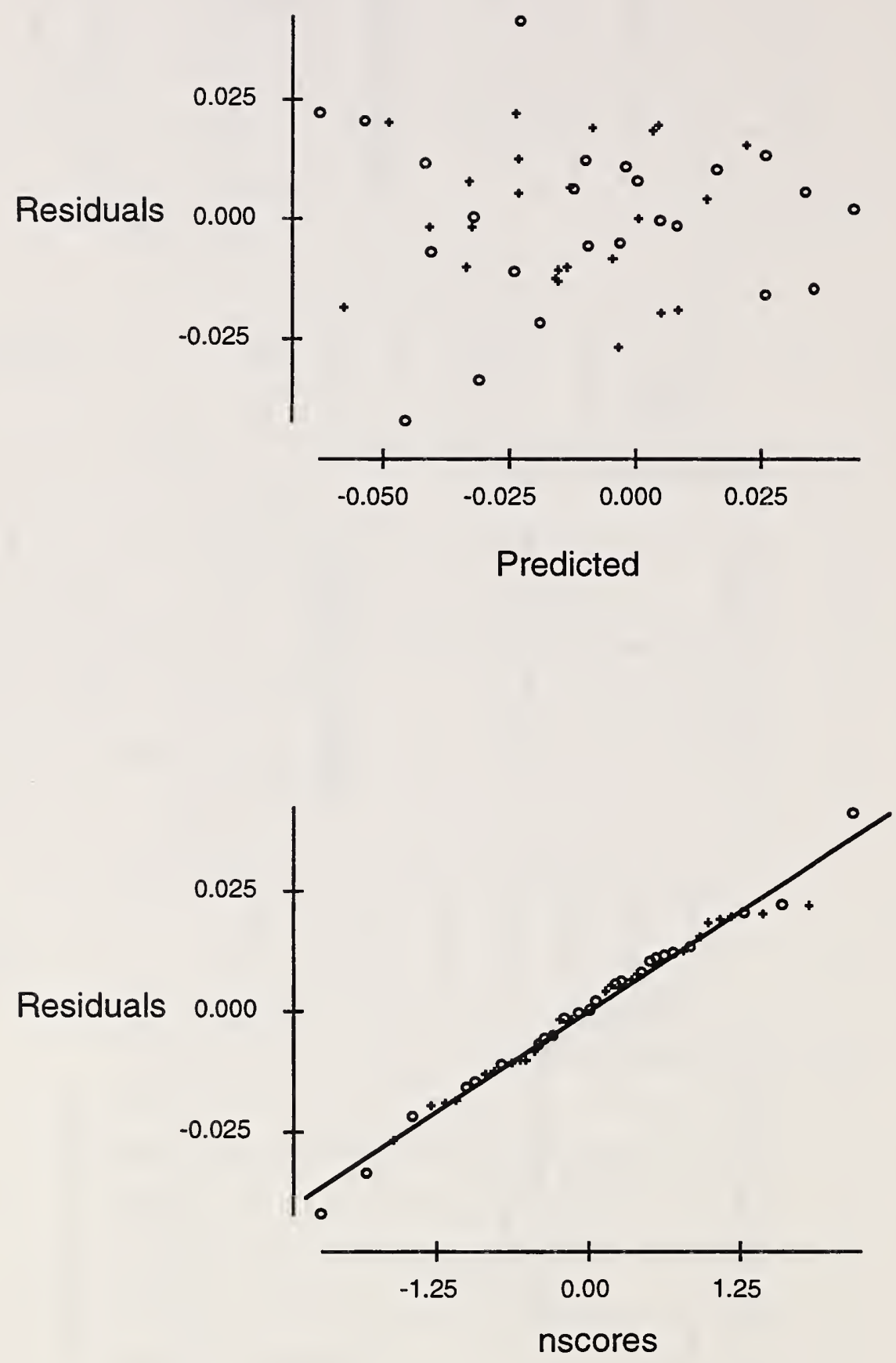

Figure 4.11 - Plots of residuals for regression analysis using the general linear model for results of tests on the 4.45-MN machine: (top) residuals versus predicted values and (bottom) normal probability plot of residuals 


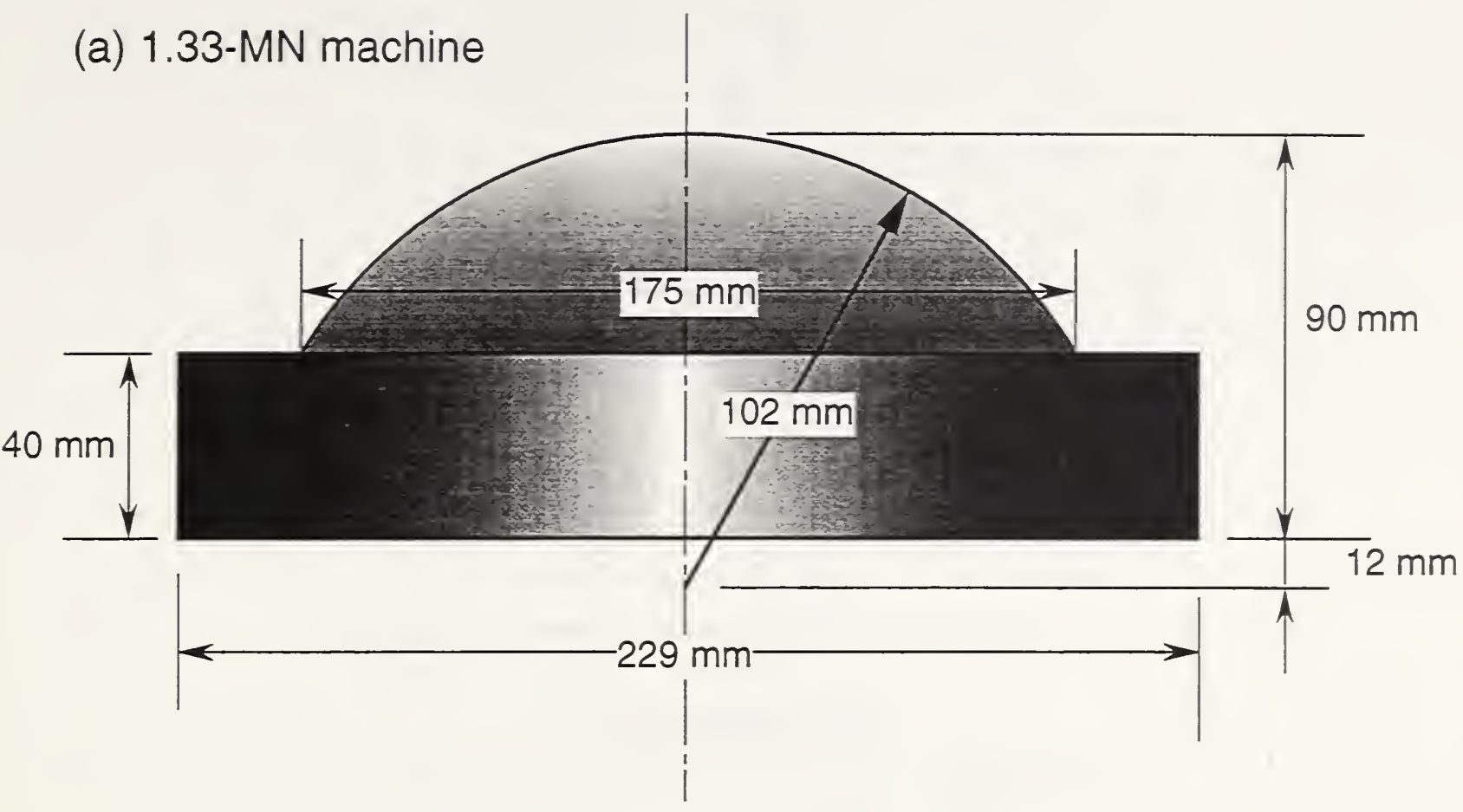

(b) 4.45-MN machine

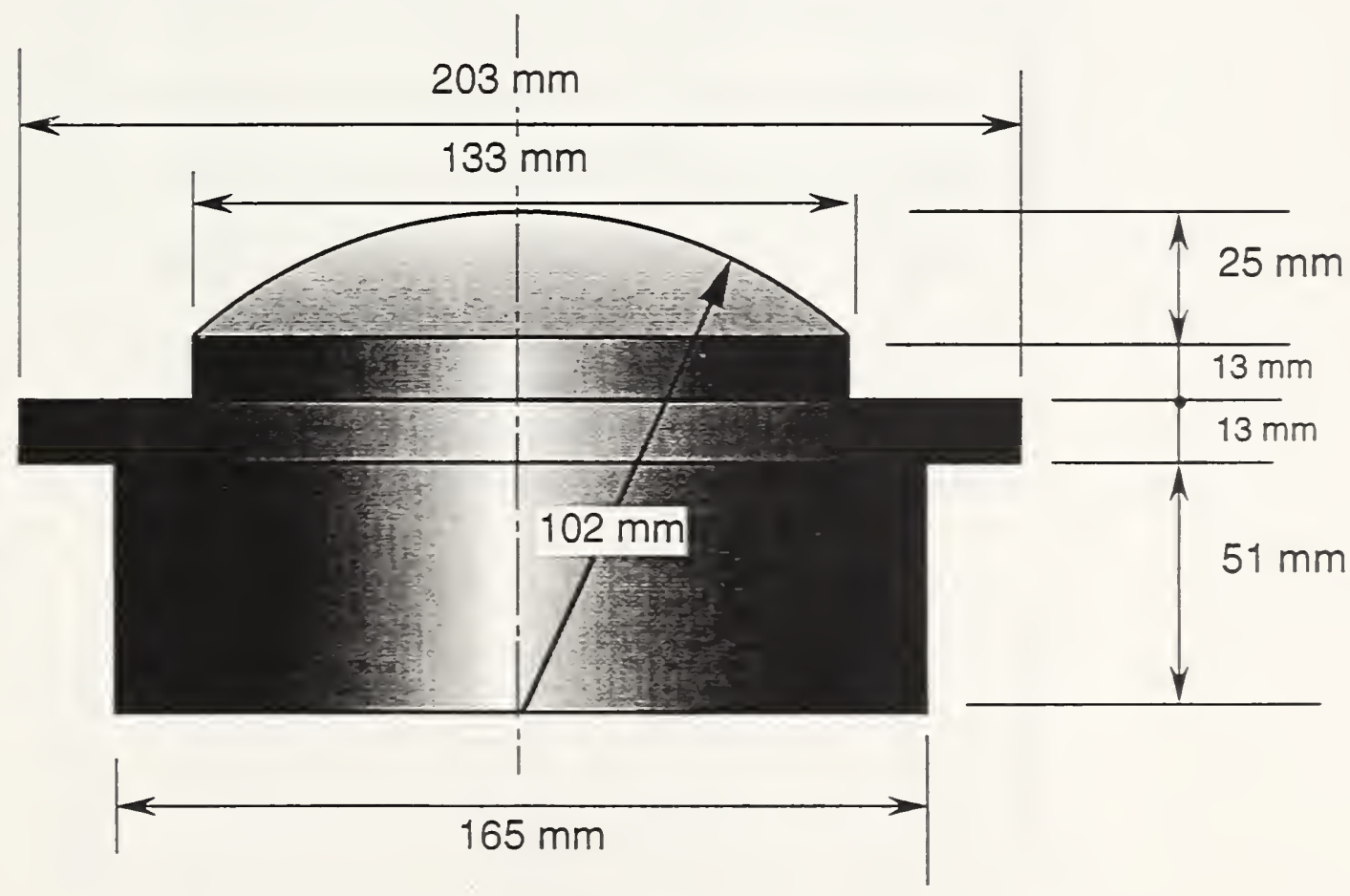

Figure 4.12 - Approximate dimensions of the spherically-seated bearing blocks of the testing machines used in this study 

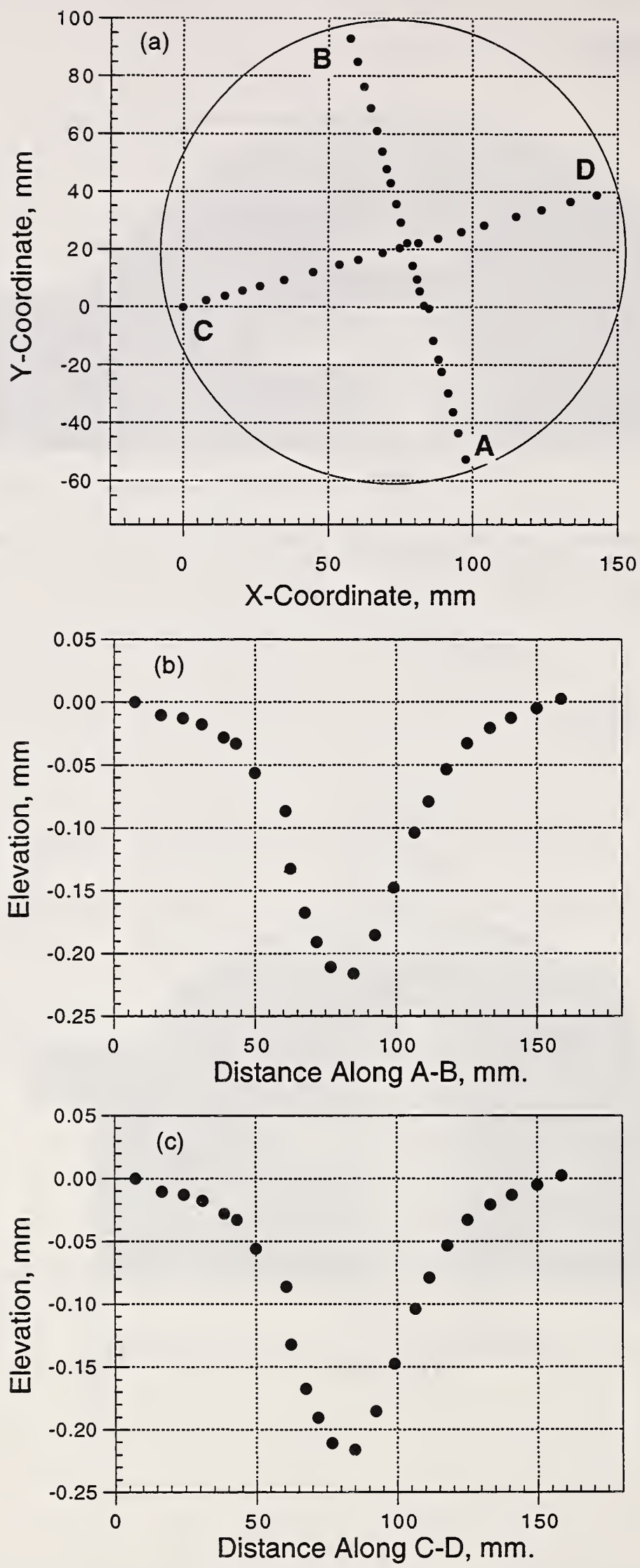

Figure 4.13 - (a) Locations of measurement points on defective bearing block; (b) surface profile along diameter A-B; (c) surface profile along diameter C-D 

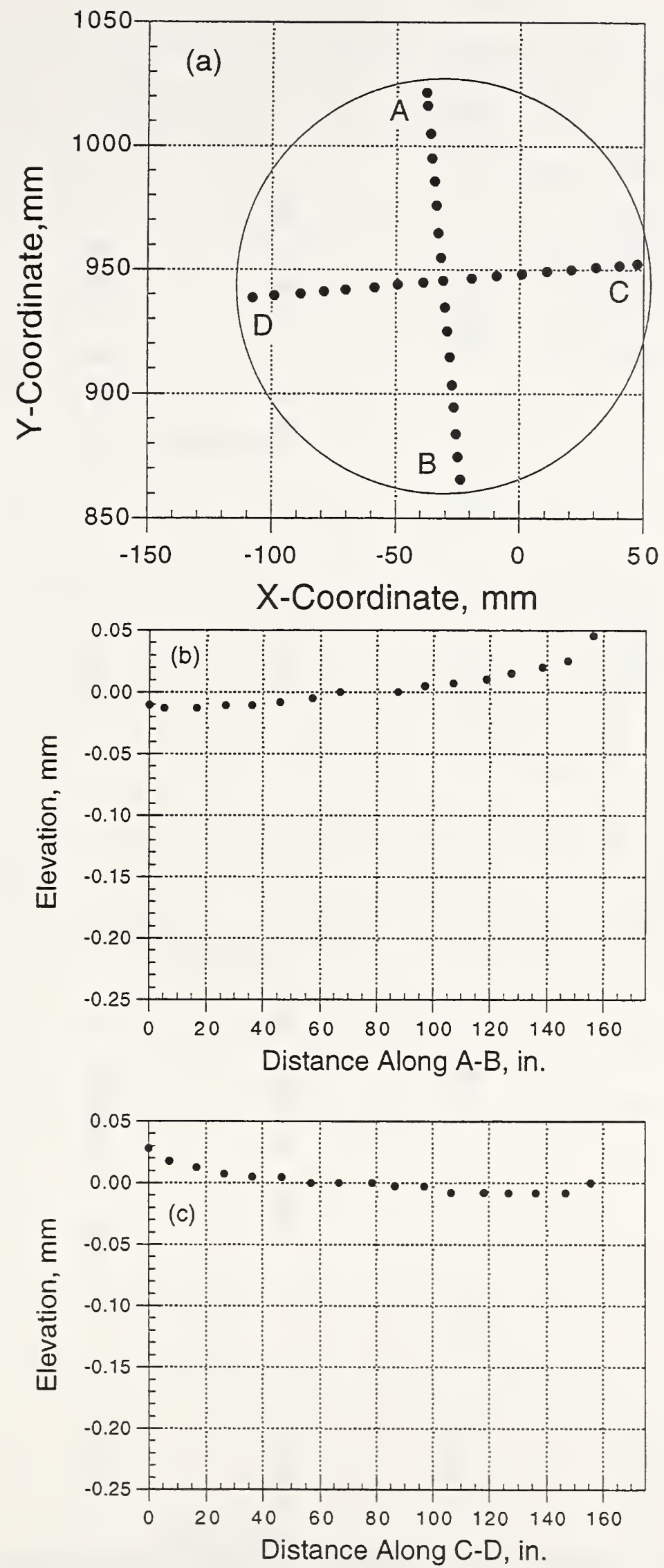

Figure 4.14 - (a) Locations of measurement points on flat bearing block; (b) surface profile along diameter A-B; (c) surface profile along diameter C-D 

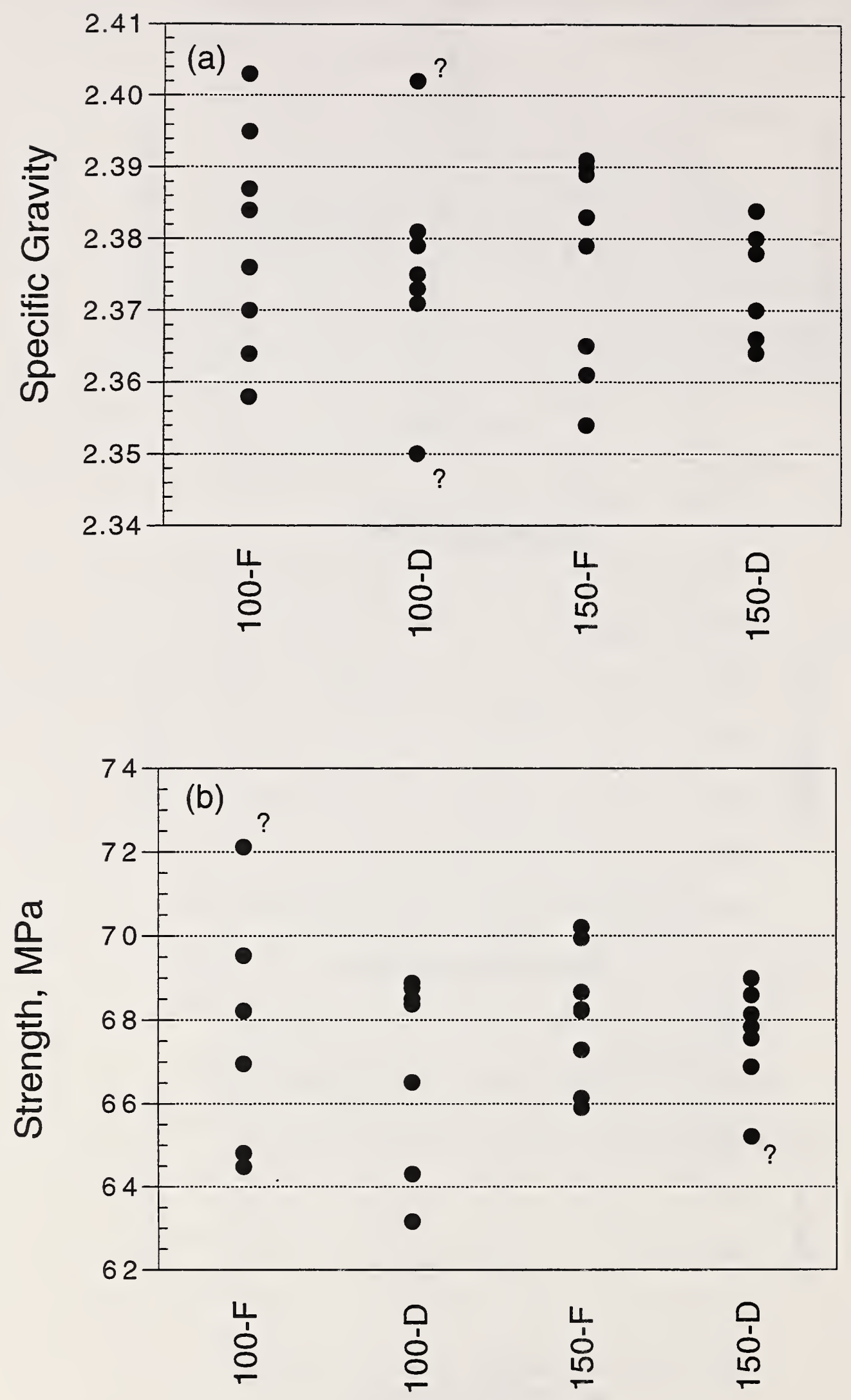

Figure 4.15 - Dotplots of (a) specific gravity and (b) compressive strength from supplementary tests grouped according to cylinder size and type of bearing block $(F=$ flat and $D$ $=$ dished) 

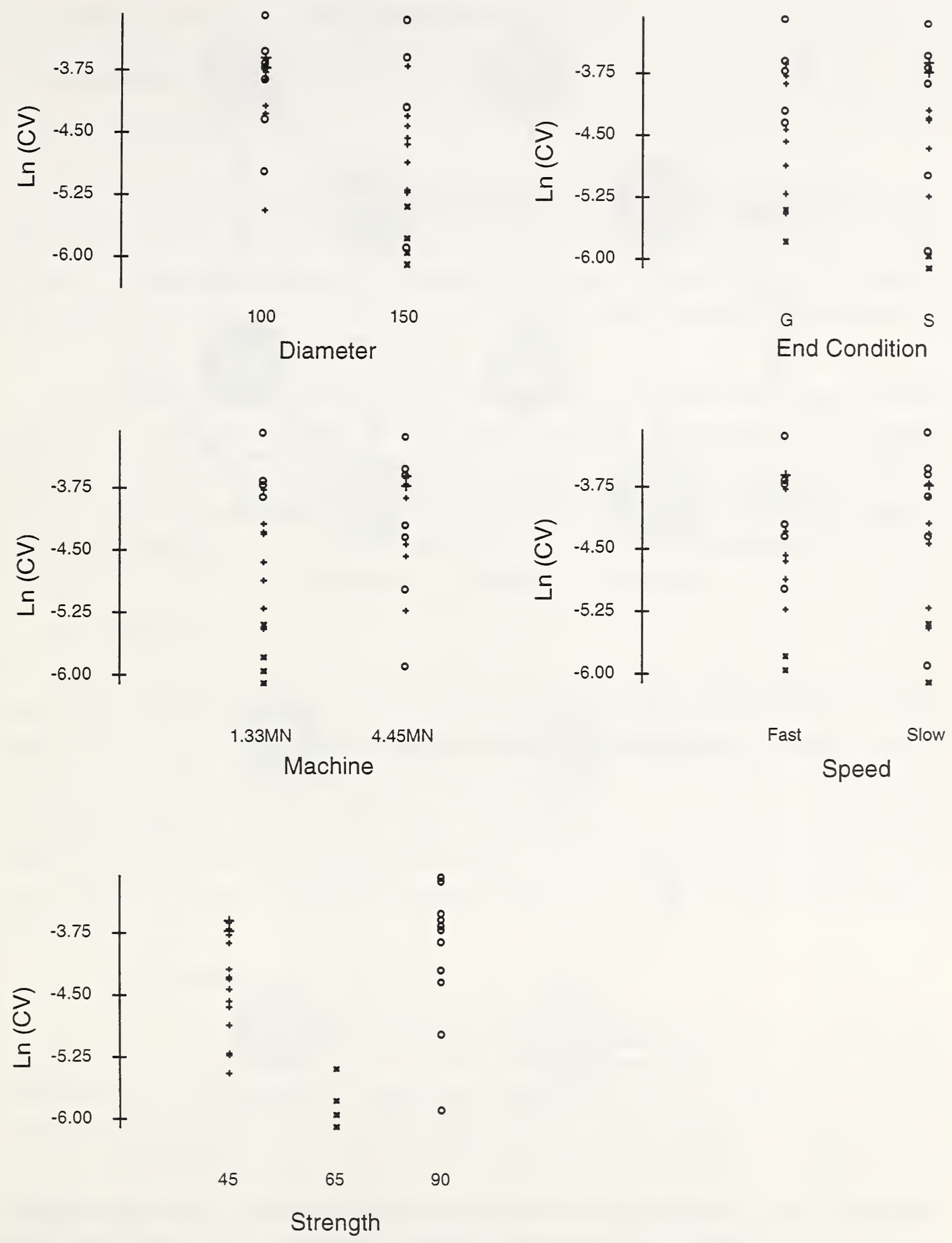

Figure 4.16 - Dotplots of logarithm of coefficient of variation versus settings of factors in main experiment 


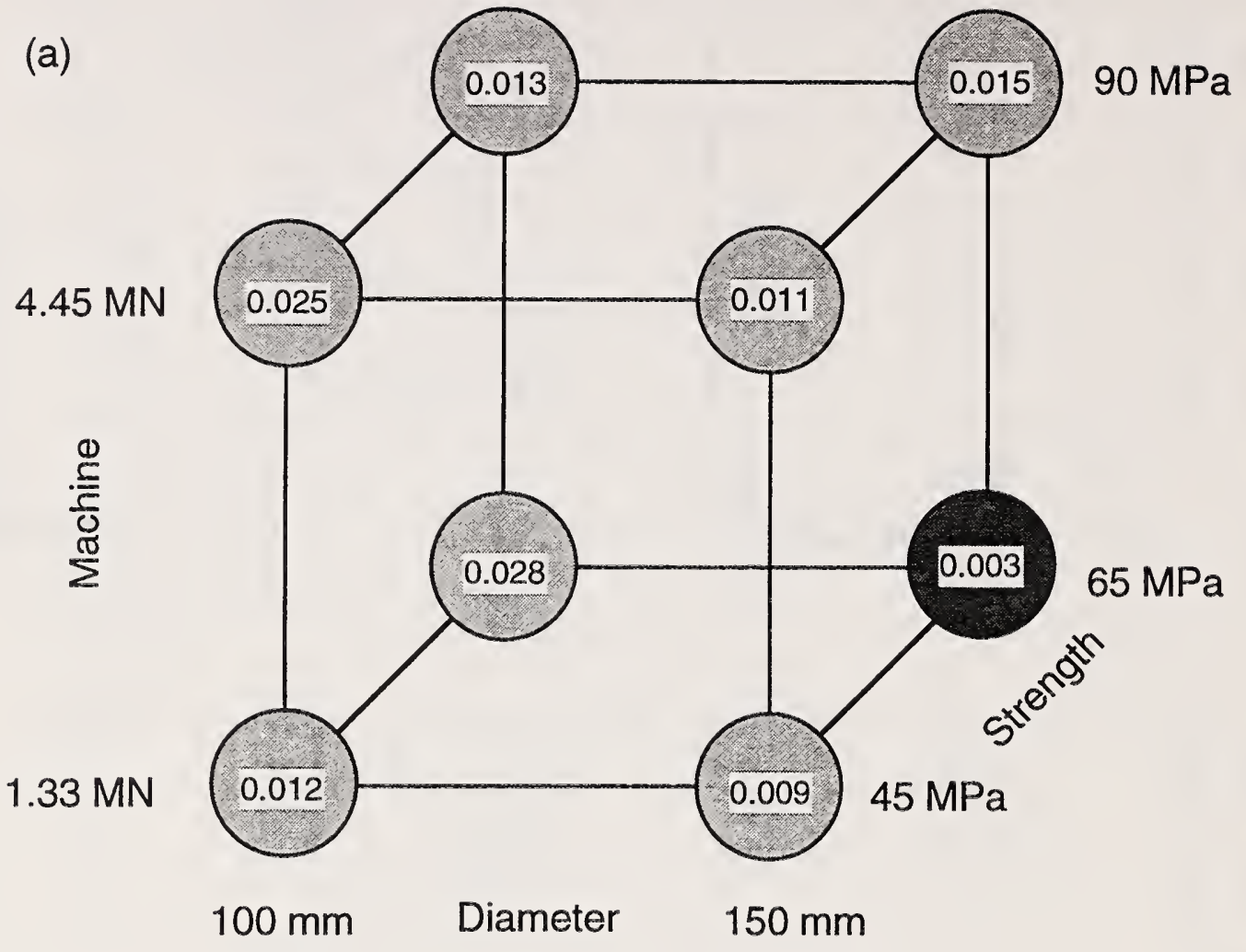

(b)

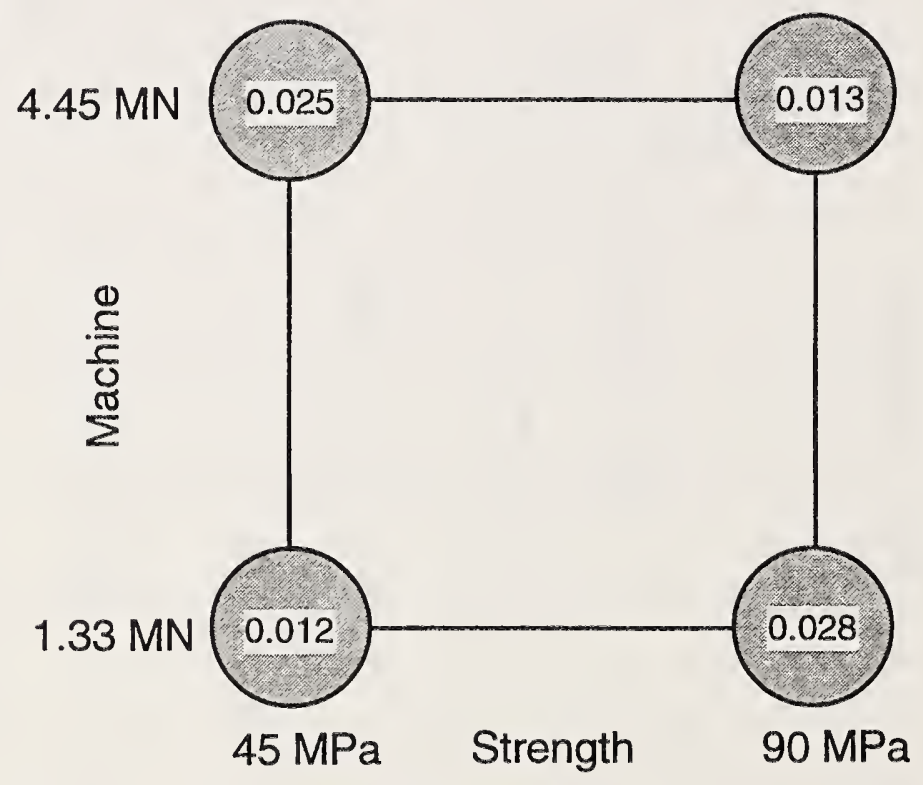

Figure 4.17 - (a) Geometric means of coefficients of variation for (diameter*strength*machine)combinations; (b) geometric means of coefficients of variation for $100-\mathrm{mm}$ cylinders for (machine* strength)-combinations 


\section{CONCLUSIONS AND RECOMMENDATIONS}

\subsection{Conclusions}

\subsubsection{Cylinder size}

Based on the literature review presented in Chapter 1, it was expected that the strength of 100$\mathrm{mm}$ cylinders would be greater than the strength of 150 -mm cylinders. This was the result obtained from the factorial experiment. The average difference in strength, however, was only $1.3 \%$ compared with the expected value of $4 \%$ discussed in Chapter 1 . However, there were significant interactions between size and other factors. As a result, differences as high as $4 \%$ were observed for particular settings of the other factors studied.

Measurements of specific gravity showed that the $100-\mathrm{mm}$ cylinders in the main study were denser than the $150-\mathrm{mm}$ cylinders, and this could explain the greater strength of the smaller cylinders. For the supplementary tests, which were done to examine the effects of a defective bearing block on the 4.45-MN machine, there were no differences in the specific gravities of the two cylinder sizes, and there were also no differences in strength. The similarity of the specific gravities in the supplementary tests may have resulted from the use of vibration instead of rodding to consolidate the concrete.

\subsubsection{End condition}

Based on the literature review, it was expected that the magnitudes of the differences between the strengths of the capped and ground cylinders would depend on the concrete strength level. Test results confirmed this expectation. On average, the strength of the ground cylinders was $2.1 \%$ greater than the strength of the capped cylinders. However, there was a significant effect due to the interaction of strength and end condition. As a result, the effect of grinding was generally not statistically significant for the $45-\mathrm{MPa}$ cylinders. On the other hand, grinding resulted in about $6 \%$ higher strengths in some tests with $90-\mathrm{MPa}$ concrete. The nominal cap thicknesses in this study were less than $4 \mathrm{~mm}$, and it is expected that greater differences could have occurred if the caps had been thicker.

\subsubsection{Testing machine}

On average, tests on the stiff, $4.45-\mathrm{MN}$, servo-controlled machine resulted in $2.3 \%$ lower strength than tests on the less stiff, 1.33-MN, manually-operated machine. There were also significant interaction effects among machine and other factors, so that the difference was as much as $4 \%$ under certain conditions. The lower strength with the $4.45-\mathrm{MN}$ machine was unexpected, and it is believed that the difference is due to the actual strain rate of the specimen as the ultimate load is reached. The 4.45-MN machine was operated so that the rate of piston travel remained constant throughout the tests. For the $1.33-\mathrm{MN}$ machine, the rate of change in the distance between the crosshead and the piston increased as the ultimate load was approached. Thus specimens in the 1.33$\mathrm{MN}$ were subjected to higher strain rates before ultimate. The ultimate strength in the compression test is governed by the attainment of a critical state of microcracking. It is possible that the 
interaction between the faster strain rate on the 1.33-MN machine and the rate of microcrack growth allowed a specimen to support a greater load before the critical state of microcracking was reached. These results refute the notion that a less stiff testing machine results in a lower measured compressive strength.

Supplementary tests were done to determine whether the defective surface of the sphericallyseated bearing block on the 4.45-MN machine could have accounted for the lower strengths. Comparative tests with $67-\mathrm{MPa}$ concrete showed no statistically significant effect due to the bearing block for ground cylinders $(100$ and $150 \mathrm{~mm})$. Therefore, it is concluded that the lower strengths recorded on the 4.45-MN machine were not a result of the defective bearing block.

\subsubsection{Loading rate}

The strength of concrete increases with strain rate. Generally, it is believed that an order of magnitude change in the strain rate is needed to observe significant strength increases. Consequently, it has been accepted that the stress range of 0.14 to $0.34 \mathrm{MPa} / \mathrm{s}$ specified in ASTM C 39 is sufficiently narrow to not affect strength. Based on the literature review it was expected that tests at the extremes of the permissible range could result in measurable differences. This expectation was confirmed in this study. On average, the faster rate produced about $2.2 \%$ greater strength, which is general agreement with previous work reported in section 1.2.4. However, due to interactions among testing machine and other factors, the difference was as high as $4 \%$ for some factor settings.

Analysis of the actual nominal stress rates attained during the tests showed a standard deviation of about $0.02 \mathrm{MPa} / \mathrm{s}$.

\subsubsection{Superposition of effects}

The above summaries indicate that, taken individually, the average effects of the factors may not be of practical significance. It must be realized, however, the effects are additive, as suggested by the general linear model, and there are significant interaction effects. As a result, the range of the measured strengths for the different factor settings is of practical significance. A review of the range of the predicted adjusted strength values shown in Figs. 4.4, 4.7, and 4.9 shows that strength differences as high as $10 \%$ could be expected for extreme settings of the factors. To reduce both within- and between-laboratory variability, efforts should be taken to provide closer control of those factors that have statistically significant effects on measured cylinder strength.

\subsubsection{Effects on dispersion}

An analysis of the within-test dispersion using all the data from the main experiment showed a significant effect due to cylinder size. The geometric mean coefficient of variation of the $150-\mathrm{mm}$ cylinders was about $45 \%$ of that of the 100 -mm cylinders. It was concluded that this result was primarily due to the abnormally low dispersion of the strengths of the $65-\mathrm{MPa}, 150-\mathrm{mm}$ cylinders. When only the tests on the 4.45-MN machine were considered, the geometric mean coefficient of variation of the $150-\mathrm{mm}$ cylinders was about $70 \%$ of that of the $100-\mathrm{mm}$ cylinders. This difference, 
however, was not statistically significant. The results of the tests involving only the $100-\mathrm{mm}$ cylinders showed a significant strength*machine interaction.

In the supplementary tests, the dispersion of the 150 -mm cylinder strengths was about $60 \%$ of that of the $100-\mathrm{mm}$ cylinders, but the difference was not statistically different.

\subsection{Recommendations}

\subsubsection{Modifications to ASTM standards}

The portions of ASTM C 39 dealing with the allowable loading rate during the latter part of the compression test should be modified in two ways. First, the allowable range of the stress rate should be reduced. It is recommended that the loading rate be specified as $0.25 \pm 0.05 \mathrm{MPa} / \mathrm{s}$. This narrower range should not be difficult to achieve and it should reduce some testing variability. The second change concerns the use of a screw-type testing machine. The current requirement is that the moving head shall travel at a rate of approximately $1.3 \mathrm{~mm} / \mathrm{m}$ when the machine is running idle. Such a requirement can result in vastly different stress rates depending on machine and specimen stiffnesses. The existing wording should be changed to the following:

For screw-type testing machines, the rate of crosshead movement shall produce a stress rate of $0.25 \pm 0.05 \mathrm{MPa} / \mathrm{s}$ during the portion of the loading cycle up to $70 \%$ of the expected ultimate load.

The $70 \%$ limit represents approximately the point at which the stress-strain curve begins to deviate significantly from linear behavior.

There are insufficient data to formulate a requirement for the properties and the allowable maximum thickness of capping materials for testing high-strength concrete cylinders. Therefore, a performance requirement should be added to Practice C 617, such as the following:

For concrete strength over $50 \mathrm{MPa}$, the capping method shall have been shown to result in an average strength that is not lower than the average strength obtained by grinding the ends of the cylinders. A proprietary capping material shall be labeled with the maximum strength of concrete for which it can be used and the maximum cap thickness.

An appendix could be added to explain how to plan a comparative testing program and analyze the data to show compliance with this requirement. This is similar to the approach used in the recentlyadopted ASTM C 1231 to qualify unbonded pad-caps (see also the Annex of AASHTO T 22). This requirement may place economic burdens on the manufacturers of capping materials, but it will protect the supplier of high-strength concrete against the use of inappropriate capping materials. Reuse of sulfur mortar for capping high-strength concrete should be prohibited until data are provided which show that such a practice will not reduce measured strengths. 
There is no justification for excluding the routine use of $100-\mathrm{mm}$ cylinders for concrete mixtures, provided the maximum size of aggregate is less than a specified value ${ }^{\mathrm{n}}$. The small difference between the strength of 100 - and $150-\mathrm{mm}$ cylinders is not expected to have a significant impact on the in-place performance of the concrete. The project specifications, however, should state specifically the specimen size that is to be used to evaluate the acceptability of the concrete. This would avoid any disputes arising due to the use of different specimen sizes by the different parties involved in the project. Data from this study appear to support the notion that the within-test variability of $100-\mathrm{mm}$ cylinders is greater than that of $150-\mathrm{mm}$ cylinders. However, due to the limited sample sizes in this study, the difference in dispersion was not statistically significant. Nevertheless, it appears that three or four replicate tests of $100-\mathrm{mm}$ cylinders may be required to obtain a mean strength value with the same precision as by using two $150-\mathrm{mm}$ cylinders.

ASTM C 192 (Practice for Making and Curing Concrete Test Specimens in the Laboratory) states that molds should be removed from specimens $24 \pm 8 \mathrm{~h}$ after casting. A similar requirement is given in ASTM C 31 for specimens made in the field and subjected to standard curing. The provisions in these two standards should be revised to allow for the possibility of concrete mixtures that have retarded setting times, either because of the addition of a set retarder or a high dosage of high range water-reducer. Such mixtures may not reach sufficient strength within $24 \mathrm{~h}$ to withstand damage during form removal. In this study, for example, the cylinders from 90-MPa mixture could not be removed from their molds until $48 \mathrm{~h}$ after casting.

\subsubsection{Research topics}

Despite over 75 years of testing on the effect of capping materials, there is still an incomplete understanding of the required mechanical properties to ensure measured cylinder strengths that are comparable to cylinders with ground ends. It is necessary to learn how the presence of capping material affects the stress distribution at the bearing block interface. Logic suggests that matching the elastic properties between capping material and concrete may be more important than matching the strength. The development of the finite-element method and the availability of powerful computers provide the opportunity for new approaches to study the cylinder compression test (Ottosen 1984, Bakht, et al. 1989). Systematic, finite-element method studies should be done to gain an understanding of the effect of capping materials on the stress distribution in the cylinder. Such studies should include the effects of irregular concrete surfaces and cap thickness. Experiments can be planned to verify the analytical predictions. If the elastic properties of the capping material are the most important factors, test methods must to developed to measure these properties. It is likely that resonant frequency tests will prove to be efficient means for such measurements. A problem that must be surmounted is preparing specimens of capping material that represent the material when used as a thin cap. Perhaps, thin plate specimens will be superior to the currently-used cubes and prisms, which are prone to the incorporation of macroscopic flaws that are not representative of those in caps.

nIn this study, the maximum size of aggregate was $1 / 5$ to $1 / 8$ of the cylinder diameter. The current limit of $1 / 3$ of the diameter specified in ASTM C 31 and C 192 may need to be verified for high-strength cylinders. 
Another area of study should be the consolidation procedure for cylinders of different sizes to assure specimens of similar density. This study has provided evidence that some observed differences due to cylinder size may be due to differences in specific gravity. Experiments should be designed to investigate this hypothesis further by using different consolidation methods. The permissible maximum aggregate size for $100-\mathrm{mm}$ cylinders of high-strength concrete should also be investigated to assure that the limits in current standards are appropriate.

The influence of testing machine characteristics on the measured cylinder strength is also not completely understood. Many conclusions derived from studies on the effects of machine characteristics on measured cube strength are not applicable to cylinders because of the fundamental differences between these two test specimens. Additional studies are needed to understand the performance of different types of testing machines during the compression test. This is especially important now that servo-controlled machines are finding their way into commercial testing laboratories. This study shows that a stiff, servo-controlled testing machine may result in lower strength than a more flexible, manually-operated machine. These findings need to be verified by additional independent studies. The importance of lateral machine stiffness on the performance of the cylinder test also needs to be understood. If machine stiffness is an important parameter, methods are needed to verify the adequacy of existing machines for testing concrete of different strength levels.

The final recommendation concerns the planning of experimental programs to evaluate the effects of different factors on measured compressive strength. Very often, testing programs are planned with too many factors and too few tests, without consideration of potential interactions that can confound the results and make it impossible to draw firm conclusions. This study has demonstrated the application of common experimental design techniques to investigate the effects of fixed factors. There are other types of designs besides the factorial design used here, each bestsuited for answering a specific question. Those who design test programs should consult with an expert in experimental design to ensure that the desired information can be gained from the planned tests. 


\section{ACKNOWLEDGMENTS}

Gratitude is expressed to Mr. Richard D. Gaynor, Executive Vice President of the National Ready Mixed Concrete Association (NRMCA), for his assistance in planning this work and in providing the materials and facilities to fabricate the specimens. Mr. Gary Mullings, Laboratory Supervisor at the NRMCA, is thanked for providing his expertise in fabricating test specimens, making physical measurements, and careful capping of cylinders. Mr. Solomon Ben-Barka, Laboratory Technician at NRMCA, is thanked for his contributions to all aspects of sample preparation and for doing all fresh concrete tests.

Gratitude is also expressed to personnel in the Structures Division at NIST. Mr. James Little is thanked for his careful grinding of the cylinders and his assistance in instrument calibration. Mr. Frank Rankin is acknowledged for his assistance in fabricating the devices to measure cylinder lengths and flatness of the ends of the cylinders. Mr. Max Peltz is thanked for his assistance in handling the test specimens, which helped making the large number of tests per day. Mr. Curtis Spring, of the Cement and Concrete Reference Laboratory, is thanked for his help in performing testing machine calibrations and measuring the spherically-seated bearing blocks.

The authors acknowledge Mr. Thomas J. Pasko, Jr., Director of the Office of Advanced Research at the Turner-Fairbank Highway Research Center, Federal Highway Administration, for providing supplemental funding to enable the completion of this report and for providing a technical review of the report. Mr. Louis Colucci is thanked for his efforts as the contracting officers technical representative for the project. 


\section{REFERENCES}

Abrams, D. A., 1917, "Effect of Rate of Application of Load on the Compressive Strength of Concrete," ASTM Proceedings, V. 17, Part II, pp. 364-374.

Adams, O. V., 1927, "Alumina Cement Caps Successful on Hardened Concrete Specimens," Engineering News-Record, V. 98, January 27, pg. 153.

ACI Committee 363, 1992, "State of the Art Report on High-Strength Concrete," ACI 363R-92, Manual of Concrete Practice Part 1 - 1993, American Concrete Institute, Detroit, 55 pp.

Annual Book of ASTM Standards, 1993, V. 04.02:

C 31 Practice for Making and Curing Concrete Test Specimens in the Field (AASHTO T 23)

C 39 Test Method for Compressive Strength of Cylindrical Concrete Specimens (AASHTO T 22)

C 138 Test Method for Unit Weight, Yield, and Air Content (Gravimetric) of Concrete (AASHTO T 121)

C 192 Practice for Making and Curing Concrete Test Specimens in the Laboratory (AASHTO T 126)

C 215 Test Method for Fundamental Transverse, Longitudinal, and Torsional Frequencies of Concrete Specimens

C 469 Test Method for Static Modulus of Elasticity and Poisson's Ratio of Concrete in Compression

C 617 Practice for Capping Cylindrical Concrete Specimens (AASHTO T 231)

C 873 Test Method for Compressive Strength of Concrete Cylinders Cast in Place in Cylindrical Molds

C 1231 Practice for Use of Unbonded Caps in Determination of Compressive Strength of Hardened Concrete Cylinders (Annex of AASHTO T 22)

Baalbaki, W., Baalbaki, M, Benmokrane, B, and Aitcin, P. C., 1992, "Influence of Specimen Size on Compressive Strength and Elastic Modulus of High-Performance Concrete," Cement, Concrete, and Aggregates (ASTM), V. 14, No. 2, Winter, pp. 113-117.

Bakht, B., Jaeger, L. G., and Mufti, A. A, 1989, "Elastic Modulus of Concrete from Compression Tests," ACI Materials Journal, V. 86, No.3, May-June, pp. 220-224.

Barnard, P.R., 1964, "Researches Into the Complete Stress-Strain Curve for Concrete," Magazine of Concrete Research, V. 16, No. 49, December, pp. 203-210.

Bay, J. A. and Stokoe, K. H., II, 1992, "Field and Laboratory Determination of Elastic Properties of PCC Using Seismic Techniques," Paper No. 920749, Annual Meeting of the Transportation Research Board, January 12-16, 34 pp.

Bažant, Z. and Panula, L, 1978, "Statistical Stability Effects in Concrete Failure," Journal of the Engineering Mechanics Division (ASCE), V. 104, No. EM5, October, pp. 1196-1211.

Bažant, Z. P. and B. H. Oh, 1982, "Strain-Rate Effect in Rapid Triaxial Loading of Concrete," Journal of the Engineering Mechanics Division (ASCE), V. 108, No. EM5, October, pp. 764782.

Bernhardt, C. J., 1964a, "A Study of the Influence of Deviations in the Planeness of the Bearing Surfaces of Concrete Test Specimens," Proceedings RILEM Symposium on the Experimental Research of Field Testing of Concrete, Trondheim, Norway, October 5-7, 1964, pg. 160-166 Boulay, C. and de Larrard, F., 1993, "The Sand-Box," Concrete International, V. 15, No. 4, April, pp. 63-66. 
Box, G. E. P., Hunter, W. G., and Hunter, J. S., 1978, Statistics for Experimenters, John Wiley \& Sons.

Carette, C. G., Malhotra, V. M., 1984, "In Situ Tests: Variability and Strength Prediction of Concrete at Early Ages," In-Situ/Non-Destructive Testing of Concrete, pp 123-125.

Carrasquillo, P. M., Carrasquillo, R. L., 1986, "Guidelines for Use of High Strength Concrete in Texas Highways," Center for Transportation Research Report 367-1F, The University of Texas at Austin, August, $227 \mathrm{pp}$.

Carrasquillo, P. M. and Carrasquillo, R. L., 1988b, "Effect of Using Unbonded Capping Systems on the Compressive Strength of Concrete Cylinders," ACI Materials Journal, V. 85, No. 3, MayJune, pp. 141-147.

Carrasquillo, P. M. and Carrasquillo, R. L., 1988, "Evaluation of the Use of Current Practice in the Production of High-Strength Concrete," ACI Materials Journal, V. 85, No. 1, January-February, pp. 49-54.

Chojnacki, B., Read, P., 1991, "Compressive Strength Test Procedures for Testing High Strength Concrete: Final Report," available NTIS, Springfield, VA (MIC-91-01018/WBT)

Cole, C. D., 1964, "The Accuracy of Compressive Testing Machines and Other Factors Which Affect the Accuracy of Concrete Strength Tests," Proceedings RILEM Symposium on the Experimental Research of Field Testing of Concrete, Trondheim, Norway, October 5-7, 1964, pg. 309-326.

Cole, D.G., 1967, "Some Mechanical Aspects of Compression Testing Machines," Magazine of Concrete Research, V. 19, No. 61, December, pp. 247-251.

Collins, H. G., 1941, "Sulfur Mixtures for Capping," ACI Journal, (Proceedings V. 37), V. 12, No. 6, June, pp. 693-696.

Cook, J. E., 1989, "10,000 psi Concrete," Concrete International, V. 11, No. 10, October, pp 67-75. Date, C. G., Schnormeier, R. H., 1984, "Day to Day Comparison of High Strength Concrete," Concrete International, V. 6, No. 8, August, pp 24-28.

Entroy, H.C., 1964, "The Effect of Some Variation in the Crushing Procedure on the Indicated Cube Compressive Strength," Proceedings RILEM Symposium on the Experimental Research of Field Testing of Concrete, Trondheim, Norway, October 5-7, 1964, pg. 284-308

Foote, P., 1970, "A Proving Device for Concrete Cube Testing Machines," Cement and Concrete Association (London), Report TRA 443, July, 8 pp.

Forstie, D. A., Schnormeier, R. H., 1981, "Implementation of 4 by 8 Inch Concrete Cylinders in Arizona," Concrete International, V. 3, No. 7, July, pp 42-45.

Freeman, P. J., 1928, "Capping Device for Concrete Cylinders," Engineering News-Record, V. 101, November 22, pg. 777.

Freeman, P. J., 1930, "Method of Capping Concrete Cylinders Using Sulfur Compound," ASTM Proceedings, V. 30, pp. 518-520.

French, C. W. and Mokhtarzadeh, A., 1993, "High-Strength Concrete: Effects of Materials, Curing and Test Procedures on Short-Term Compressive Strength," PCI Journal, V. 38, No. 3, May/June, pp. 76-87.

Glucklich, J. and Cohen, L. J., 1967, "Size as a Factor in the Brittle-Ductile Transition and the Strength of Some Materials," International Journal of Fracture Mechanics, V. 3, No. 4, December, pp. 278-288.

Glucklich, J. and Cohen, L. J., 1968, "Strain-Energy and Size Effects in a Brittle Material," Materials Research and Standards (ASTM), V. 8, No. 10, October, pp. 17-22. 
Gonnerman, H. F., 1924, "Effect of End Condition of Cylinder in Compression Tests of Concrete," ASTM Proceedings, V. 24, Part II, pp. 1036-1065.

Gonnerman, H. F., 1925, "Effect of Size and Shape of Test Specimen on Compressive Strength of Concrete," ASTM Proceedings, V. 25, pp. 237-255.

Gopalan, M. K., Haque, M. N., 1990, "Fly Ash in High Strength Concrete," in ACI SP-121, Utilization of High Strength Concrete - Second International Symposium, W.T. Hester, Editor, American Concrete Institute, Detroit.

Hester, W. T., 1980, "Field Testing of High-Strength Concretes: A Critical Review of the State-ofthe-Art," Concrete International, V. 2, No. 12, December, pp. 27-38.

Hinde, P. B., 1964, "Testing Machine Stiffness Problem," The Engineer, V. 217, No. 5657, June 26, pp. 1124-1127.

Hudson, J. A., Crouch, S. L., and Fairhurst, C., 1972, "Soft, Stiff and Servo-Controlled Testing Machines: A Review with Reference to Rock Failure," Engineering Geology, V. 6, No. 3, pp. 155-189.

Janak, K. J., 1985, "Comparative Compressive Strength of $4 \times 8$ in. Versus $6 \times 12$ in. Concrete Cylinders Along With the Investigation of Concrete Compressive Strength at 56 Days," Materials and Tests Division, Report 3-I-4-116, Texas State Dept. of Highways and Public Transportation, March, 36. pp.

Jones, P. G. and Richart, F. E., 1936, "The Effect of Testing Speed on Strength and Elastic Properties of Concrete," ASTM Proceedings, V. 36, Part II, pp. 380-391.

Kaplan, S. A., 1980, "Factors Affecting the Relationship Between Rate of Loading and Measured Compressive Strength of Concrete," Magazine of Concrete Research, V. 32, No. 111, June, pp. 79-88.

Lessard, M., Chaallal, O., and Aitcin, P. C., 1993, "Testing High-Strength Concrete Compressive Strength," ACI Materials Journal, V. 90, No. 4, July-August, pp. 303-308.

L'Hermite, R., 1954, "Present-Day Ideas on Concrete Technology: Third Part, The Failure of Concrete," RILEM Bulletin, No. 18, June, pp. 27-39.

Masters, F. M., Jr., and Loewer, A. C., Jr., 1952, "The Effects of Capping Materials on the Apparent Strength of Concrete Specimens," Concrete, V. 60, No. 11, November, pp. 30-36.

Malhotra, V.M., 1976, "Are 4 x 8 Inch Concrete Cylinders as Good as 6 x 12 Inch Cylinders for Quality Control of Concrete," ACI Journal, Proceedings, V. 73, No. 1, January, pp. 33-36.

Malhotra, V. M., Carette, C. G., 1980, "Comparison of Pullout Strength of Concrete with Compressive Strength of Cylinders and Cores, Pulse Velocity, and Rebound Number," $A C I$ Journal, Proceedings, V. 77, No. 3, May-June, pp 161-170.

McGuire, D. D., 1930, "Testing Concrete Cylinders Using Confined Sand Cushion," ASTM Proceedings, V. 30, pp. 515-517.

Mindess, S. and Bentur, A., 1984, "The Effect of the Longitudinal Stiffness of the Testing Machine on the Strength of Hardened Cement Paste," Materials and Structures, V. 17, No. 98, MarchApril, pp. 149-155.

Neville, A. M., 1966, "A General Relation for Strength of Concrete Specimens of Different Shapes and Sizes," ACI Journal, Proceedings, V. 63, No. 10, October, pp. 1095-1109.

Neville, A. M., 1973, Properties of Concrete, 2nd Ed., Halstead Press, New York.

Newman, K. and Lachance, L, 1964, "The Testing of Brittle Materials Under Uniform Uniaxial Compressive Stress," ASTM Proceedings, V. 64, pp. 1044-1067. 
Newman, K. and Sigvaldason, O. T., 1965, "Testing Machine and Specimen Characteristics and Their Effect on the Mode of Deformation, Failure, and Strength of Materials," Proceedings Institution of Mechanical Engineers, Part 3A, September, pp. 399-410.

Newman, K. and Spooner, D. C., 1969, "Towards a Standard for Compression Testing Machines," Concrete, No. 83, pp. 220-226.

Nilsen, U. and Aitcin, P. C., 1992, "Static Modulus of Elasticity of High-Strength Concrete from Pulse Velocity Tests," Cement, Concrete, and Aggregates (ASTM), V. 14, No. 1, Summer, pp. 64-66.

Ottosen, N. S., 1984, "Evaluation of Concrete Cylinder Tests Using Finite Elements," 1984, Journal of the Engineering Mechanics Division (ASCE), V. 110, No. EM3, March, pp. 465-481.

Ozyildirim, C., 1985, "Neoprene Pads for Capping Concrete Cylinders," Cement, Concrete, and Aggregates (ASTM), V. 7, No. 1, Summer, pp. 25-28.

Perkins, G. B., 1986, "Correlation of Compressive Strength for Internally Vibrated Versus Rodded Cylinders (4"x8" and 6"x12")," Materials and Tests Division, Report 3-I-5-127, Texas State Dept. of Highways and Public Transportation, October, $17 \mathrm{pp}$.

Peterman, M. B., Carrasquillo, R. L., 1986, Production of High Strength Concrete, Noyes Publications, pp 259-266.

Petkov, V., 1964, "The Effect of Loading Speed on the Results Obtained For Strength by Testing Trial Cubes in Compression," Proceedings RILEM Symposium on the Experimental Research of Field Testing of Concrete, Trondheim, Norway, October 5-7, 1964, pg. 189-198.

Philleo, R. E., 1955, "Comparison of Results of Three Methods for Determining Young's Modulus of Elasticity of Concrete," ACI Journal, V. 26, No. 5, (Proceedings V. 51), January, pp. 461469.

Pistelli, M. F. and Willems, T., 1993, "Evaluation of Cylinder Size and Capping Method in Compression Testing of Concrete," Cement, Concrete, and Aggregates (ASTM), V. 15, No. 1, Summer, pp. 59-69.

Powell, J. A., 1966, Personal communication to R. D. Gaynor.

Purrington, W. F. and McCormick, J., 1926, "A Simple Device to Obviate Capping of Concrete Specimens," ASTM Proceedings, V. 26, Part II, pp. 488-492.

Price, W. H., 1951, "Factors Influencing Concrete Strength, ACI Journal, V. 22, No. 6, (Proceedings V. 47), February, pp. 417-432.

Richardson, D. N., 1990, "Effects of Testing Variables on the Comparison of Neoprene Pad and Sulfur Mortar-Capped Concrete Test Cylinders," ACI Materials Journal, V. No. , SeptemberOctober, pp. 489-495.

Richardson, D. N., 1991, "Review of Variables that Influence Measured Concrete Compressive Strength," Journal of Materials in Civil Engineering (ASCE), V. 3, No. 2, May, pp. 95-112.

Salamon, M. D. G., 1970, "Stability, Instability and Design of Pillar Workings," International Journal of Rock Mechanics and Mining Sciences, V. 7, No. 6, November, pp. 613-631.

Saucier, K. L., 1972, "Effect of Method of Preparation of Ends of Concrete Cylinders for Testing," Miscellaneous Paper C-72-12, U.S. Army Engineer Waterways Experiment Station, Vicksburg, MS, April, 51 pp.

Schuyler, M, 1913, "Spherical Bearings," ASTM Proceedings, V. 13, pp. 1004-1018.

Shah, S. P., Gokoz, U, and Ansari, F., 1981, "An Experimental Technique for Obtaining Complete Stress-Strain Curves for High Strength Concrete, Cement, Concrete, and Aggregates (ASTM), V. 3, No. 1, Summer, pp. 21-27. 
Sigvaldason, O. T., 1966a, "The Influence of the Testing Machine on the Compressive Strength of Concrete," Proceedings Symposium on Concrete Quality, 10-12 November 1964, Cement and Concrete Association (London), pp. 162-171.

Sigvaldason, O. T., 1966b, "The Influence of Testing Machine Characteristics Upon the Cube and Cylinder Strength of Concrete," Magazine of Concrete Research, V. 18, No. 57, December, pp. 197-206.

Sigvaldason, O.T., 1966c, "Spherical Seating Behavior," The Engineer, V. 221, No. 5757, May, pp. 793-796.

Simons, B. P., 1990, Personal communication to N. J. Carino.

Snedecor, G. W. and Cochran, W. G., 1967, Statistical Methods, 6th Ed., Iowa State University Press, pp. 296-298.

Timms, A. G., 1939, "Sulphur for Capping Test Cylinders?" ACI Journal, V. 10, No. 5, (Proceedings V. 39), April, pp. 420-421.

Troxell, G. E., 1941, "The Effect of Capping Methods and End Conditions Before Capping Upon Compressive Strength of Concrete Test Cylinders," ASTM Proceedings, V. 41, pp. 1039-1052 (including discussions by Vidal, Murray, and Durelli).

Tucker, J., Jr., 1927, "A Study of the Compressive Strength Dispersion of Materials with Applications," Proceedings, Franklin Institute, V. 204, No. 6, December, pp. 751-781.

Tucker, J., Jr., 1941, "Statistical Theory of the Effect of Dimensions and Method of Loading Upon the Modulus of Rupture of Beams," ASTM Proceedings, V. 41, pp. 1072-1094.

Tucker, J., Jr., 1945, "Effect of Dimensions of Specimens Upon Precision of Strength Data," ASTM Proceedings, V. 45, pp. 952-960.

Turner, P. W. and Barnard, P. R., 1962, "Stiff Constant Strain Rate Testing Machine," The Engineer, V. 214 , No. 5557 , July 27 , pp. 146-148.

Vutukuri, V. S., Lama, R. D., and Saluja, S. S., 1974, Handbook on Mechanical Properties of Rocks, Appendix, "Stiff Testing Machines", Trans Tech Publications, pp. 253-267.

Wang, P. T., Shah, S. P. and Naaman, A. E., 1978, "Stress-Strain Curves of Normal and Lightweight Concrete in Compression," ACI Journal, V. 75, No. 11, November, pp. 603-611.

Werner, G., 1958, "The Effect of Capping Material on the Compressive Strength of Concrete Cylinders," ASTM Proceedings, V. 58, pp. 1166-1186 (including Discussion by S. Helms).

Whitney, C. S., 1943, Discussion of "The Plasticity Ration of Concrete and Its Effect on the Ultimate Strength of Beams," by V. P. Jensen, ACI Journal Proceedings, V. 39 (supplement), November, pp. 584-2 to 584-6.

Wright, P. J. F., 1957, "Compression Testing Machines for Concrete," The Engineer, V. 203, No. 5283, April 26, pp. 639-641. 

